\title{
The fast-running flies (Diptera, Hybotidae, Tachydromiinae) of Singapore and adjacent regions
}

Grootaert P. \& Shamshev I.V. 2012. The fast-running flies (Diptera, Hybotidae, Tachydromiinae) of Singapore and adjacent regions. European Journal of Taxonomy 5: 1-162. http://dx.doi.org/10.5852/ejt.2012.5

\section{PATRICK GROOTAERT ${ }^{1} \&$ IGOR V. SHAMSHEV ${ }^{2}$}

${ }^{1}$ Department of Entomology, Royal Belgian Institute of Natural Sciences, rue Vautier 29, B-1000, Brussels, Belgium. E-mail: Patrick.Grootaert@naturalsciences.be (corresponding author)

${ }^{2}$ All-Russian Institute of Plant Protection, shosse Podbel'skogo 3, 188620, St.Petersburg - Pushkin, Russia. Present address: Royal Belgian Institute of Natural Sciences, Brussels.

E-mail:shamshev@mail.ru

\begin{abstract}
This is the first comprehensive introduction to the flies of the subfamily Tachydromiinae (Hybotidae) of Singapore. The monograph summarizes all publications on the Tachydromiinae of Singapore and includes new data resulting from mass-trapping surveys made in Singapore during the last six years. A few samples from Malaysia (Johor province, Pulau Tioman and Langkawi) have been also included in this study. In Singapore the Tachydromiinae are the most diverse group of Empidoidea (except Dolichopodidae) and currently comprise 85 species belonging to the following nine genera: Platypalpus (1), Tachydromia (1), Chersodromia (6), Pontodromia (1), Drapetis (5), Elaphropeza (60), Crossopalpus (1), Nanodromia (3) and Stilpon (7). All species are diagnosed and illustrated. The following 28 species are described as new for science: Chersodromia bulohensis sp. nov. (Singapore), $C$. glandula sp. nov. (Singapore, Malaysia), C. malaysiana sp. nov. (Singapore, Malaysia), C. pasir sp. nov. (Malaysia), C. sylvicola sp. nov. (Singapore), C. tiomanensis sp. nov. (Malaysia), Crossopalpus temasek sp. nov. (Singapore), Drapetis bakau sp. nov. (Singapore, Malaysia), D. hutan sp. nov. (Singapore), D. laut sp. nov. (Singapore, Malaysia), D. mandai sp. nov. (Singapore), D. pantai sp. nov. (Singapore, Malaysia), Elaphropeza chanae sp. nov. (Singapore), E. collini sp. nov. (Singapore), E. gohae sp. nov. (Singapore), E. kranjiensis sp. nov. (Singapore), E. lowi sp. nov. (Singapore), E. semakau sp. nov. (Singapore), E. shufenae sp. nov. (Singapore), Nanodromia hutan sp. nov. (Singapore), N. spinulosa sp. nov. (Singapore), Platypalpus singaporensis sp. nov. (Singapore), Pontodromia pantai sp. nov. (Singapore), Stilpon arcuatum sp. nov. (Singapore), S. neesoonensis sp. nov. (Singapore), S. nigripennis sp. nov. (Singapore), S. singaporensis sp. nov. (Singapore), S. weilingae sp. nov. (Singapore). A redescription is given for Crossopalpus exul (Osten-Sacken, 1882) (Taiwan). Males of Elaphropeza feminata Shamshev \& Grootaert, 2007 and E. modesta Shamshev \& Grootaert, 2007 as well as females of Elaphropeza ubinensis Shamshev \& Grootaert, 2007 and Nanodromia narmkroi Grootaert \& Shamshev, 2003 are described for the first time. Keys to genera and species, which are generally applicable to the whole of Southeast Asia, are compiled. An analysis of the species ecological preferenda is presented.
\end{abstract}

Key words. Diptera, Hybotidae, revision, new species, Oriental Region. 


\section{TABLE OF CONTENTS}

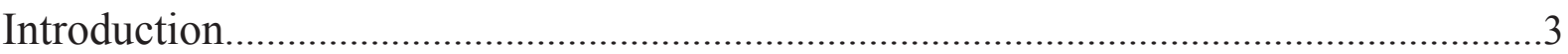

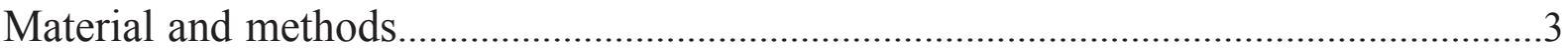

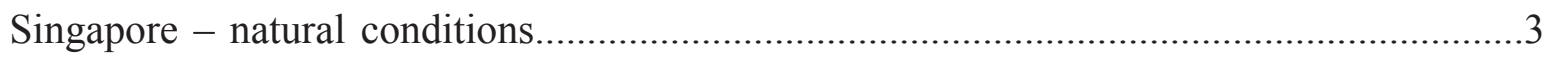

Collecting methods, specimen preservation and preparation.............................................4

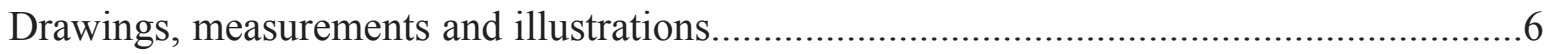

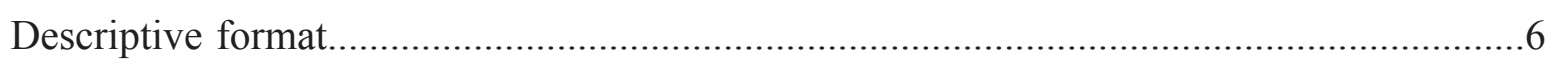

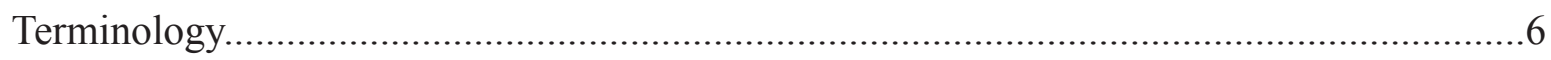

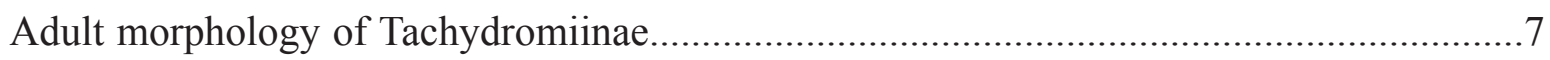

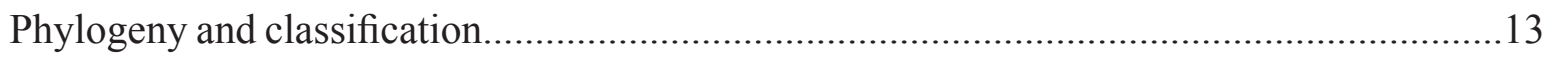

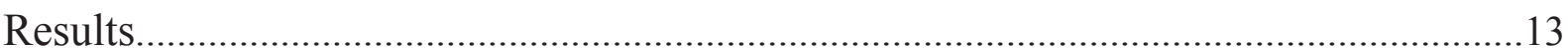

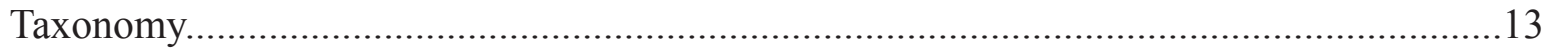

Key to the genera of Tachydromiinae from the Oriental Region..................................................13

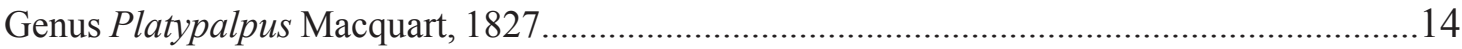

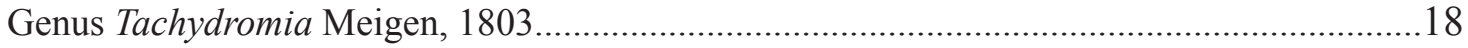

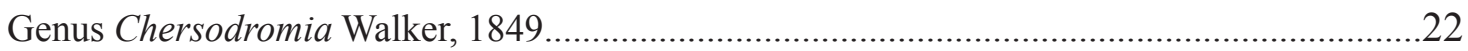

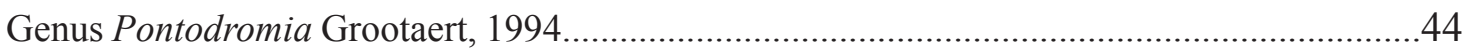

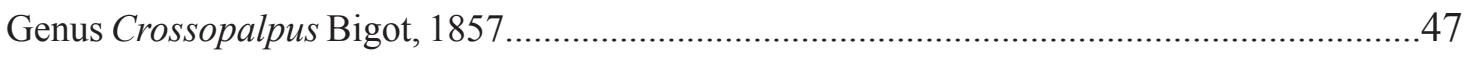

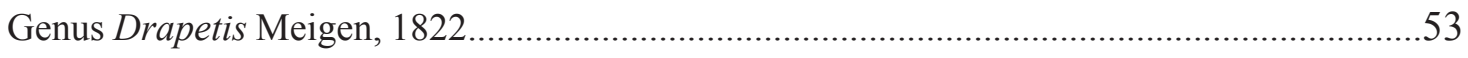

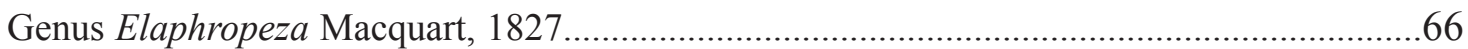

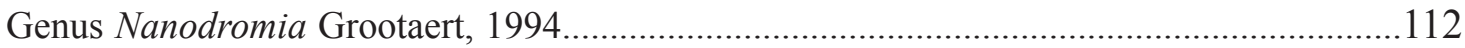

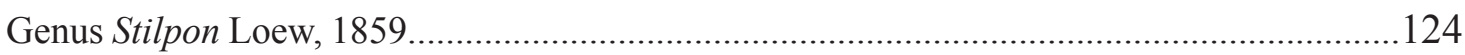

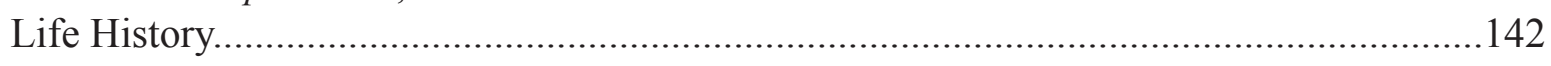

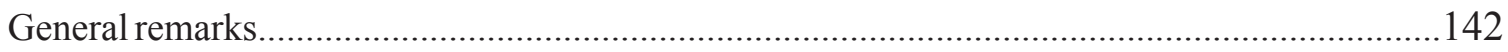

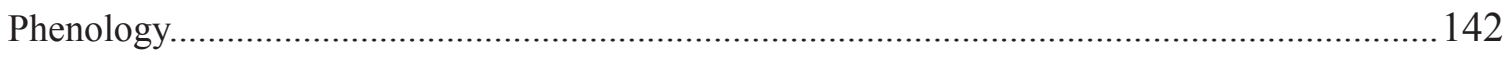

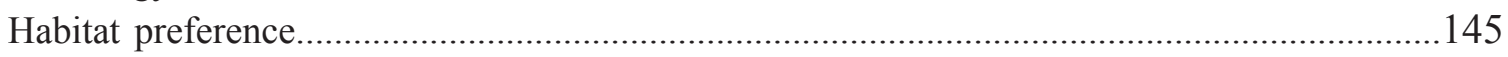

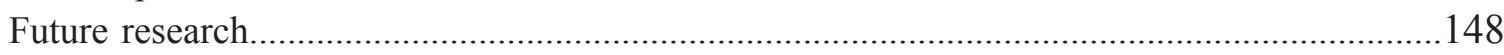

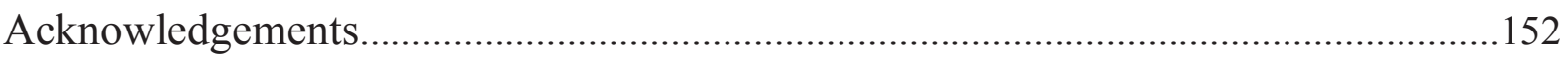

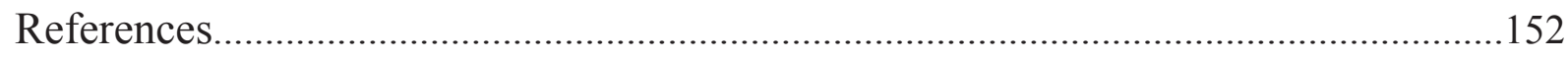

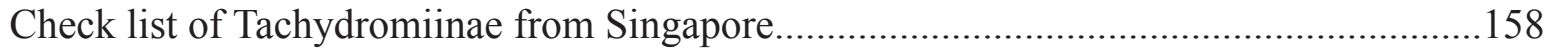

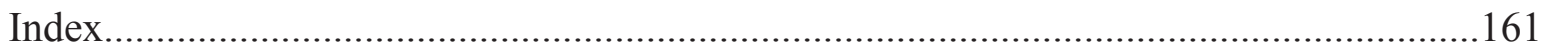




\section{INTRODUCTION}

The Tachydromiinae is a very diverse subfamily in the family Hybotidae comprising quite small (1.0 to $5.0 \mathrm{~mm}$ ) predatory flies that are generally seen running on leaves of vegetation but also occur under many other conditions including tree-trunks, stones, sandy biotopes, etc.

The name of the subfamily reflects the behaviour of tachydromiines. These flies rather run than fly around (except species of the genus Symballophthalmus Becker). Tachydromiines run (Greek 'dromein') around quite fast (Greek 'tachy', speed) on substrates and jump upon prey, including small insects or mites, holding them with their raptorial fore and mid legs and pierce the prey with their strong proboscis (cf. robber flies).

The Tachydromiinae are worldwide in distribution and rich in species. Currently the subfamily includes about 1200 species (Yang et al. 2007). Largest number of Tachydromiinae species (about 500) is known from the Palaearctic where this group of empidoids has been most extensively investigated. The results of these studies have been summarized in several monographs (Collin 1961; Chvála 1975, 1989; Grootaert \& Chvála 1992). In other regions the subfamily has been very inadequately studied and still many species are awaiting description, especially from tropical and subtropical areas.

Southeast Asia and especially its border with South China is probably the cradle of many ancient groups with a mixture of tropical and temperate groups originating from the Palaearctic Region (Grootaert 2009). Currently, about 250 species of Tachydromiinae are recorded from the Oriental Region.

The fauna of Singapore is tropical and although the island is small and densely urbanised it has a very rich Tachydromiinae fauna. Remaining groups of Hybotidae are poorly represented in Singapore and they include Syndyas Loew, Syneches Walker and Hybos Meigen, which mostly remain unidentified (Grootaert \& Yang 2009). The only genus of Empididae known from Singapore is Empis (Coptophlebia) and five species have been recorded (Daugeron \& Grootaert 2005).

In the present study we give a survey of all the Tachydromiinae recorded so far from Singapore. Nine genera are currently known and a total of 85 species. Keys are presented to identify the genera and the species. Each genus is treated in view of the known distribution in the Oriental Region. Here we present a complete inventory of the Tachydromiinae fauna on a restricted geographical area rather than getting lost in a megadiverse fauna such as in Malaysia with the risk of never achieving an overview and little insight.

No comprehensive works on the subfamily Tachydromiinae (and Hybotidae on the whole) are available for the Oriental Region. For this reason a general introduction to morphology and life history of tachydromiines are provided, in the hope that our monograph will stimulate students in the study of these fascinating flies.

\section{MATERial AND METHODS}

\section{Singapore - natural conditions}

Singapore is a small island republic situated at the southern tip of the Malaysian Peninsula with the huge island of Sumatra at its western side and numerous smaller Indonesian islands at the southern and eastern borders (Fig. 1). Singapore lies 137 kilometres north of the Equator in the middle of the Oriental Region and is expected to have a similar fauna like the very diverse fauna of the Malaysian Peninsula. Singapore consists of the main island of Singapore and about 60 small adjacent islands. It has a land area of about $710 \mathrm{~km}^{2}$ with a population of almost 5 million people. Although the southern coast is densely urbanised, 
the central forested hills of the Central Catchment are rather well conserved. The Central Catchment is a hilly area covered with various types of mainly rain forest and with large water reservoirs. Bukit Timah has the highest elevation at $163 \mathrm{~m}$ and is covered by primary rain forest. Singapore is one of the few cities in the world that has a primary rain forest in the middle of the city. The northern coast has still some unique mangrove forests that proved to host a unique and very diverse empidoid fauna.

The microclimate of Singapore is different from the adjacent Malay Peninsula. It is monsoonal but the highest rainfall is in January followed by a drier spell in February. The north of Malaysia has a rainy season from May to September, while the southern part of the Malaysian Peninsula has a rainy season opposite to it from October until March.

The mornings are usually dry in Singapore, but from noon onwards there are often short, but heavy showers resulting in high humidity persisting throughout the year. Straddling the Equator and being an island, the daily temperatures in Singapore are quite uniform throughout the year, with a maximum around $32^{\circ} \mathrm{C}$ during the day and a minimum of $24^{\circ} \mathrm{C}$ at night.

\section{Collecting methods, specimen preservation and preparation}

The present revision is based on 833 samples and 2,114 specimens of Tachydromiinae, of which 731 samples and 1,891 specimens from Singapore were examined.

Material was partly collected by sweep net (5-13 October 2000, 4-13 December 2002, 19 November-11 December 2003, March 2005-February 2006, May 2009) and partly with Malaise traps. A major sampling

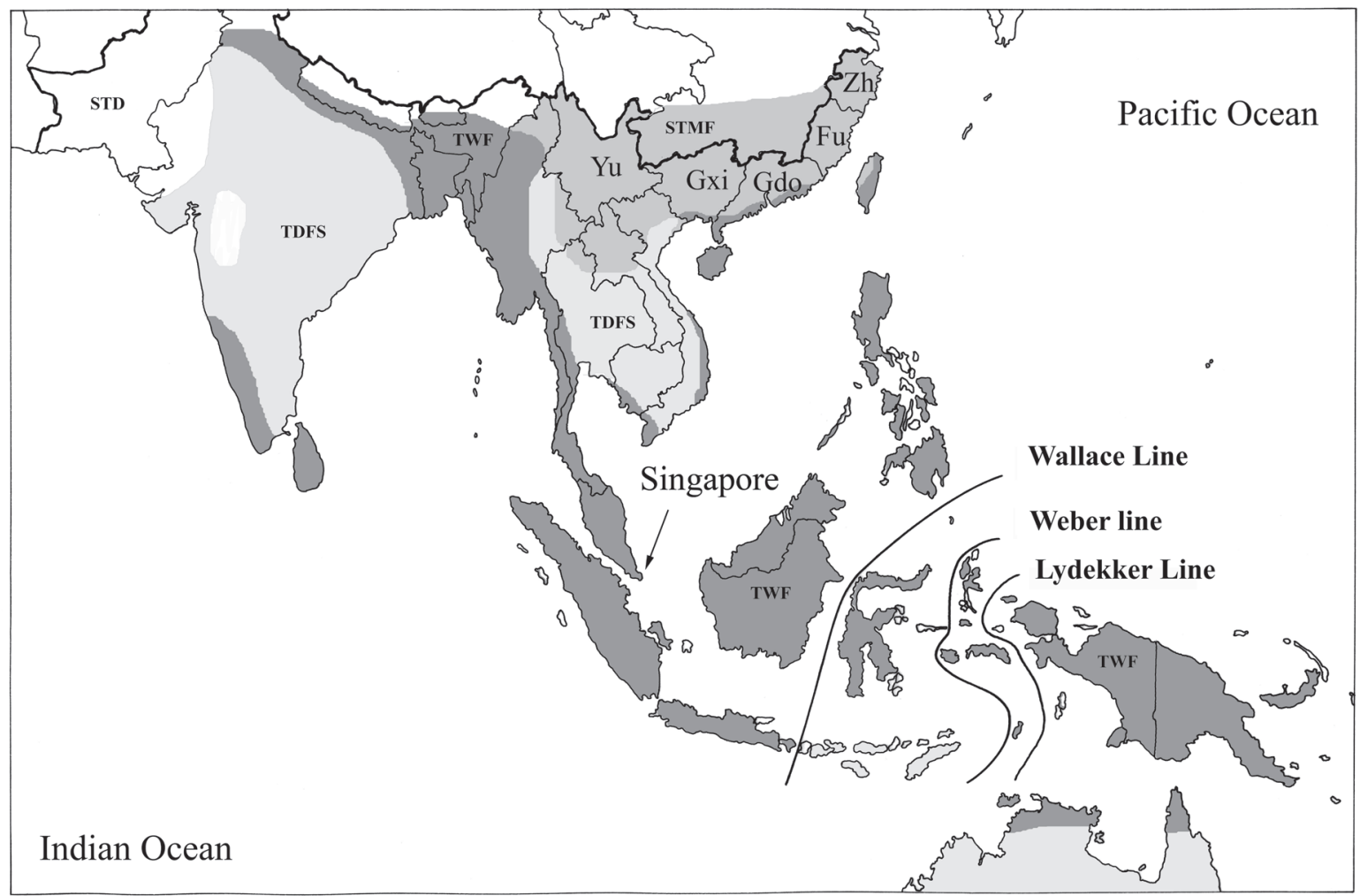

Fig. 1. Singapore in the Oriental Region (after Grootaert, 2009). STMF = subtropical mixed forest; STD $=$ subtropical desert and semidesert; TDFS $=$ tropical dry forest and savannah; $\mathbf{T W F}=$ tropical wet forest. The Weber line is considered to form the southeast boundary of the Oriental Region. 
effort was done from 1 March 2005 to 28 February 2006 when eight Malaise traps were operated during a whole year at the following sites in Singapore: Bukit Timah (1'20'53.70" N, 10346'38.25”'E), primary rain forest, but secondary rain forest at place of sampling, 1 trap), Sime forest ( 2 traps in rain forest along small streams: Mal $1\left(1^{\circ} 21^{\prime} 18.72^{\prime}{ }^{\prime} \mathrm{N}, 103^{\circ} 48^{\prime} 39.76^{\prime \prime} \mathrm{E}\right)$ across a narrow stream that filled with water only after rainfall; Mal $2\left(1^{\circ} 21^{\prime} 16.76^{\prime \prime} \mathrm{N}, 103^{\circ} 48^{\prime} 19.12^{\prime \prime} \mathrm{E}\right)$ in a broader, more swampy part of a broad stream that was continuously wet), Central Catchment Area (Nee Soon, entrance Upper Peirce Reservoir Park, swamp forest (Fig. 239); 3 traps: Mal 1 (1 $\left.{ }^{\circ} 22^{\prime} 55.61^{\prime \prime} \mathrm{N}, 103^{\circ} 48^{\prime} 56.92^{\prime \prime} \mathrm{E}\right)$ on the border of a small permanent stream; Mal $2\left(1^{\circ} 23^{\prime} 09.44^{\prime \prime} \mathrm{N}, 103^{\circ} 48^{\prime} 39.96^{\prime \prime} \mathrm{E}\right)$ across a small permanent stream; Mal 3 $\left(1^{\circ} 23^{\prime} 07.83^{\prime \prime N}, 103^{\circ} 48^{\prime} 39.48^{\prime \prime} \mathrm{E}\right)$ in drier area of the swamp forest), Sungei Buloh Wetland Reserve (2 traps in mangrove; Fig. 241): Mal $1\left(1^{\circ} 26^{\prime} 49.01^{\prime \prime} \mathrm{N}, 103^{\circ} 43^{\prime} 47.95^{\prime \prime} \mathrm{E}\right)$ with only base flooded at high tide; Mal $2\left(1^{\circ} 26^{\prime} 49.96^{\prime \prime} \mathrm{N}, 103^{\circ} 49^{\prime} 46.37^{\prime \prime} \mathrm{E}\right)$ with water raising up to one meter at high tide). Malaise traps were emptied almost weekly (7-10 days). Moreover three more Malaise traps were operated temporarily (6 weeks) on the island Pulau Ubin (mangrove at Chek Jawa; Fig. 240). An additional year of Malaise trap sampling was done by the late Mr. K.L. Yeo at Nee Soon (2 traps: Mal 2, Mal 3) and Sungei Buloh (2 traps Mal 1, Mal 2) for the period of 28 February 2006 until 9 March 2007. In contrast to earlier studies (Shamshev \& Grootaert 2007; Zhang et al. 2007, 2008) the samples collected by Mr. K.L. Yeo are included here. A third major sampling effort took place during the SMIP project (Singapore Mangrove Insect Project) sponsored by NParks. In 2009, eleven mangrove sites (Fig. 2) were sampled during one month (5 May-12 June 2009) with at least two Malaise traps per site, however there were five

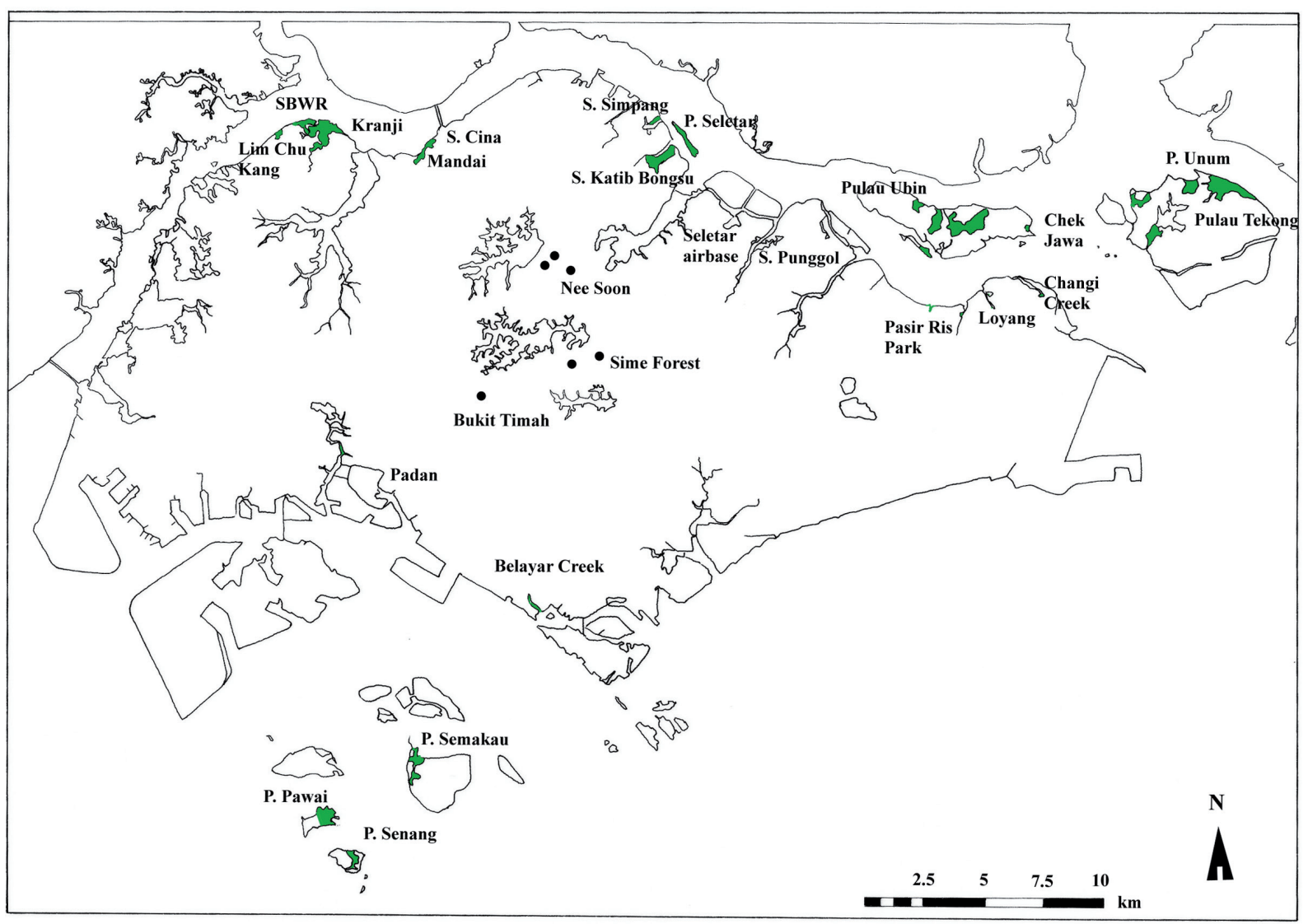

Fig. 2. Extent of the mangroves in Singapore (in green). During the SMIP project in 2009 Malaise traps sampled at Lim Chu Kang, Sungei Buloh Wetland Reserve, Kranji Nature Trail, Sungei Cina, Pulau Seletar, Pasir Ris, Changi Creek, Pulau Ubin (Chek Jawa), Belayar Creek and Pulau Semakau. Nee Soon, Sime forest and Bukit Timah are terrestrial reference sites (map made with help of NParks staff). 
Malaise traps on Pulau Semakau and three at Lim Chu Kang. This resulted in 104 samples that contained 484 Tachydromiinae. Site descriptions of SMIP will be published separately. It should be noted that the earlier samples from Sungei Buloh are in fact from the adjacent reserve Kranji Nature trail. The Malaise traps operated from 2005-2007 at Sungei Buloh and at Kranji in 2009 were from the same site.

Under the heading 'Material examined' we mention all material that was not recorded in our previous revisions.

All holotypes are stored in alcohol in the collections of the Raffles Museum for Biodiversity Research, Singapore (ZRC: Zoological Reference Collection), most paratypes are kept at the Royal Belgian Institute of Natural Sciences, Brussels (RBINS). For each record a register number is given (register number in Database linked to collection data such as locality, date, collector, habitat). The locality of the holotype is considered here as the type locality. In addition, each species sample is given an inventory number (e.g. Si200), which indicates where the specimens can be found in the wet collection.

To facilitate observations, the terminalia were macerated in hot $85 \%$ lactic acid (or sometimes first in $\mathrm{KOH}$ for a short period and then in lactic acid) and immersed in glycerine (Cumming 1992).

\section{Drawings, measurements and illustrations}

To make illustrations, macerated details of specimens were mounted temporarily in glycerine on depression slides, using a small amount of gel to anchor the specimen. Drawings were made with a camera lucida attached to a compound microscope. Before being inked on tracing paper, line drawings were checked for accuracy under a dissecting microscope.

The right and left side of the male terminalia are based on the unrotated position viewed posteriorly, so that in the illustrations the right surstylus appears on the readers left side and vice versa. All male terminalia are figured in their unrotated position.

The length of a wing was measured from the extreme base in a straight line along the costal margin to a line perpendicular to the tip of the wing. The costal index of the wing is based on distances measured directly from tip to tip of the first four veins where they join the costa. The first section is measured from the humeral crossvein rather than the wing base for purposes of accuracy.

Only a few habitus illustrations are given in this work. We want to refer to internet sites where plenty habitus photos of most genera may be found. In the near future most mangrove species of empididoids will be illustrated for Singapore.

\section{Descriptive format}

For previously described species, reference to the original description and short diagnosis are provided. Newly described species are characterized in detail. General list of the species known from Singapore is given at the end of the paper rather than under each subsequent genus.

\section{Terminology}

Terms used for adult structures primarily follow those recently summarised by Cumming \& Wood (2009). Homologies for the male and female terminalia follow Cumming \& Cooper (1992) and Sinclair (2000). The term bristle is used for differentiated large setae on the head, mesonotum, and legs bearing a particular name or for one of a series with a particular name, e.g., notopleural bristle, dorsocentral bristle, anteroventral bristle. 


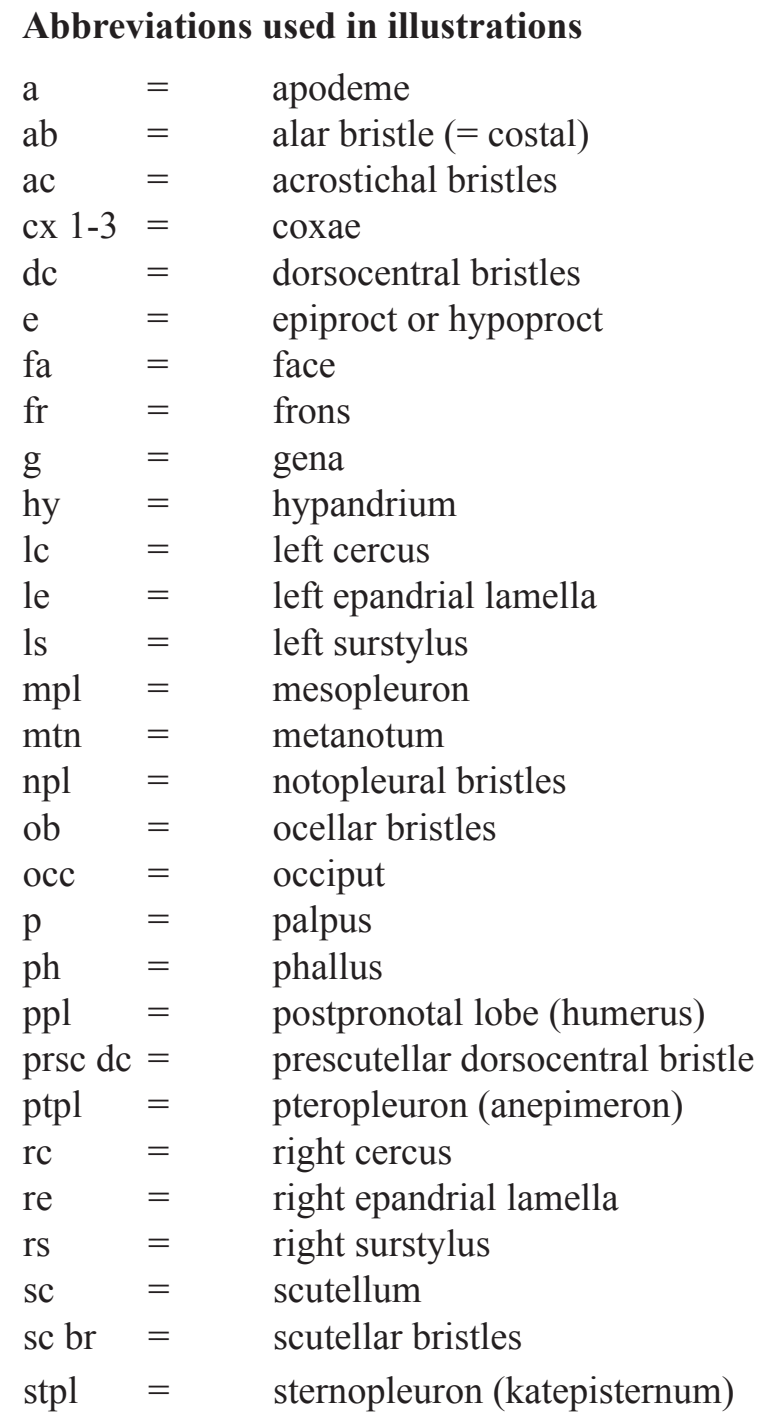

\section{Adult morphology of Tachydromiinae}

HEAD. (Figs 3-4) Black to yellow in ground colour. Eyes usually dichoptic in both sexes, separated by more or less broad frons and with subequally small ommatidia, rarely holoptic or closely approximated; bare or with dense ommatrichia. Face flat, level with eyes, very narrow, sometimes linear or wide; clypeus distinct, membranous laterally. Gena not extended or, sometimes distinctly extended below eye. Ocellar tubercle very prominent, with 1-2 pairs of bristles but posterior pair often minute. Antenna (Figs 19-26). Scape greatly reduced, bare; pedicel cup-shaped; postpedicel varying in shape but usually more or less conical. Stylus usually apical but sometimes subapical or dorsal; usually with long slender apical mechanoreceptor. Proboscis rather short, strong, directed downwards but often slightly recurved; lacinia absent (fused to labial paraphyses); pseudotracheae absent; maxillary palpus very distinct, onesegmented, connected with special sclerite (palpifer), projecting obliquely, short, usually elongate-ovate, often with distinct subapical seta.

THORAX. (Figs 5-6) Rather short and robust or distinctly elongated, slightly convex dorsally; varying considerably in ground-colour (from yellow to black) and degree of tomentosity, sometimes with distinct colour pattern, often shining. Prosternum separate between fore coxae or fused to proepisternum forming precoxal bridge; proepisternum bare or with scattered setae. Postpronotal lobe undifferentiated or differentiated, varying from large and elongate (e.g. Tachydromia and Tachypeza) to small 
(some Platypalpus); postpronotal bristle usually prominent but sometimes absent. Mesopleuron [= anepisternum] bare, rarely setose. Laterotergite bare. Metaepimeron sometimes enlarged. Postalar callus partially differentiated. Mesonotal vestiture varying, but usually with 1-3 distinct notopleurals, 1 postalar and 2-4 scutellars; acrostichals and dorsocentrals usually differentiated by gap but sometimes undifferentiated or acrostichals absent.

LEGS. Sometimes all pairs quite slender and hardly modified but usually quite robust with fore or mid legs specialised for catching and holding prey. Coxae and trochanters unmodified. Fore and mid femora usually thickened in different degrees. Fore tibia often spindle-shaped; mid tibia often slightly curved and with apical spur-like projection. Tarsomeres and hind legs usually slender, unmodified. Setation
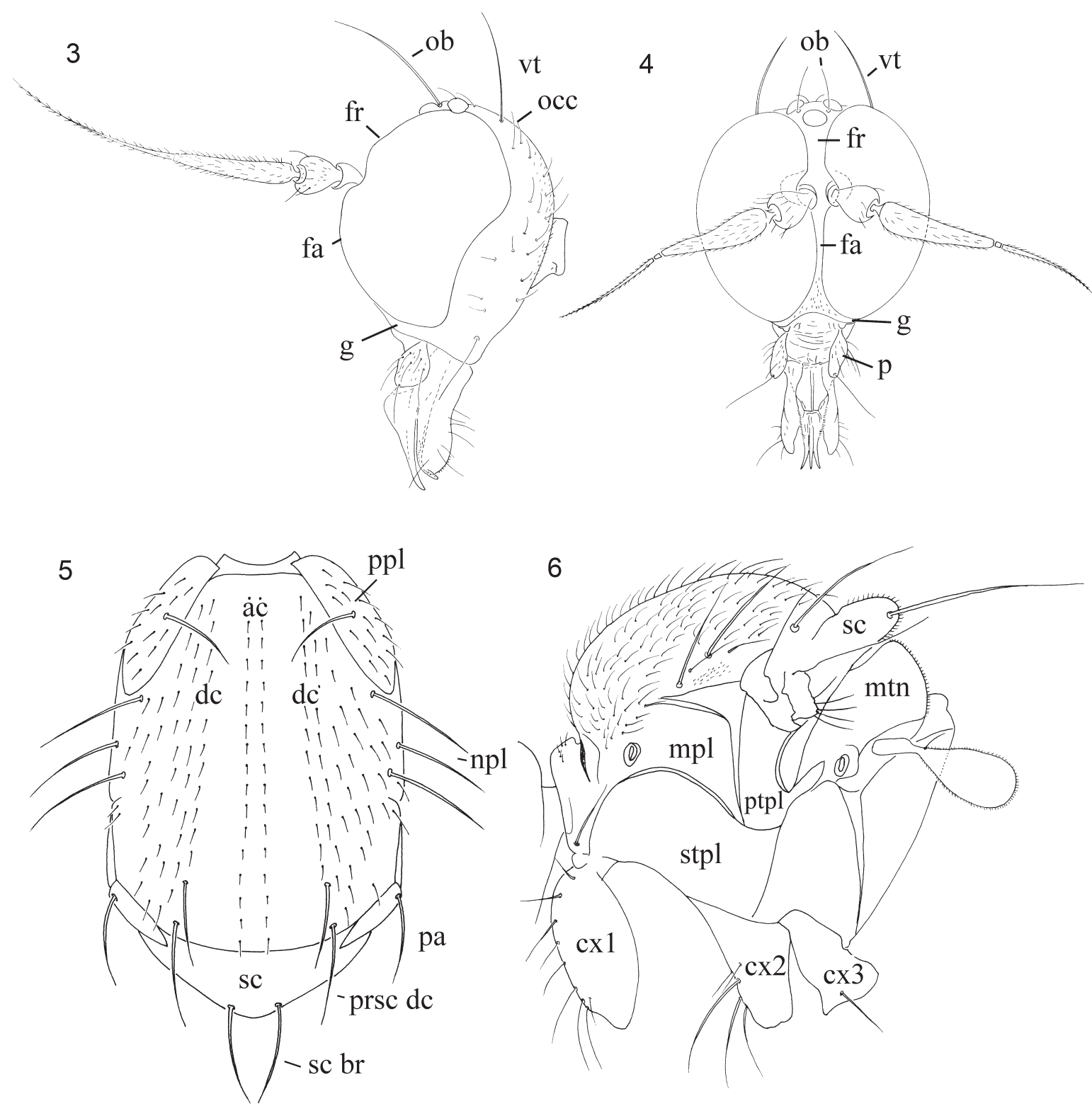

Figs 3-6. Elaphropeza biuncinata (Melander, 1928). 3. head, §, lateral view. 4. head, §, frontal view. 5. Platypalpus sp. scutum dorsal view. 6. E. biuncinata thorax, lateral view. 
generally greatly reduced but often strongly modified (especially on mid femur and tibia). Fore tibia with gland near base. Fore tibial anteroapical comb present or absent. Hind tibial posteroapical comb present.

WING. (Figs 10-18) Usually normally developed (no cases of brachyptery known from the Oriental Region but see Grootaert \& Shamshev (2008) for a review of this phenomenon among empidoids) or sometimes narrow, with axillary lobe wide to greatly reduced; more or less infuscate, hyaline or with distinct pattern. Microtrichia uniform. Costal bristle usually present. Pterostigma absent. Costa distinct or rarely (Symballophthalmus, not Oriental) practically circumambient, only weakened posteriorly; ending at vein $\mathrm{M}_{1+2}$; bearing unmodified setae. Subcosta very indistinct, incomplete, attached close to vein $\mathrm{R}_{1}$, ending just short of costa. Vein $\mathrm{R}_{1}$ (Fig. 10) meeting costa at or before middle of wing, rarely very short; usually uniformly thickened. Vein Rs originating distant from humeral crossvein, nearly halfway along $R_{1}$. Vein $R_{2+3}$ (Fig. 10) complete or incomplete. Vein $R_{4+5}$ unbranched (Fig. 10). Vein $\mathrm{M}$ unforked $\left(\mathrm{M}_{2}\right.$ lost). Discal cell absent (dm-cu crossvein lost). Cell cup present or absent, if present then shorter than apical portion of $\mathrm{A}_{1}$. Vein $\mathrm{CuA}_{2}$ present or absent, if present straight. Cells br (upper basal cell) and bm (lower basal cell) varying in length. Anal vein present or absent; if present varying in degree of sclerotisation, complete, reaching wing margin even as fold or incomplete. Crossvein bm-cu transverse or oblique.

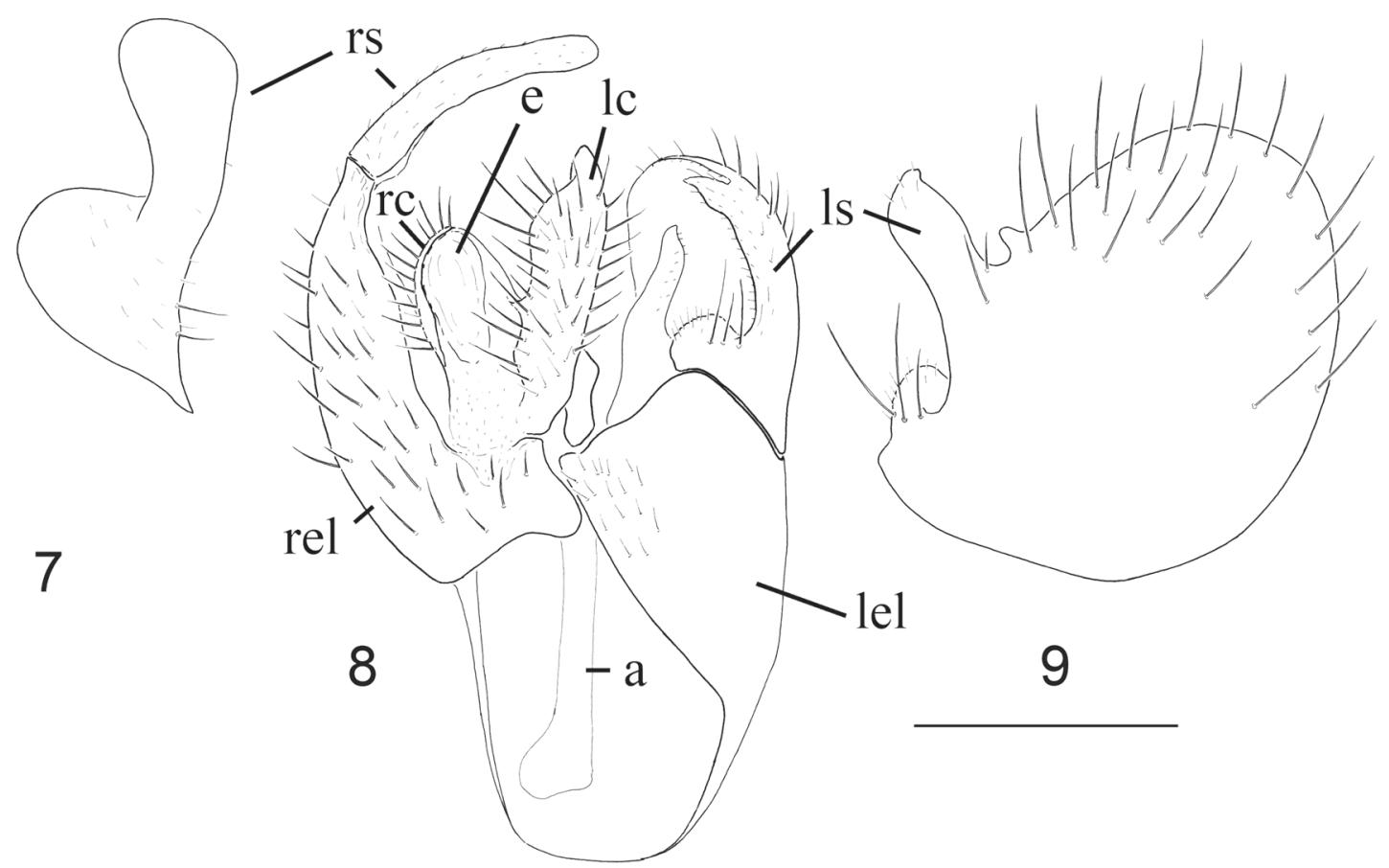

Figs 7-9. Elaphropeza biuncinata (Melander, 1928). 7. right surstylus. 8. epandrium with cerci. 9. left surstylus. a: ejaculatory apodeme; $\mathrm{e}=$ epiproct; lel = left epandrial lamella; $1 \mathrm{c}=$ left cercus; $\mathrm{rc}=$ right cercus; $r s=$ right surstylus. Scale bar $=0.1 \mathrm{~mm}$. 


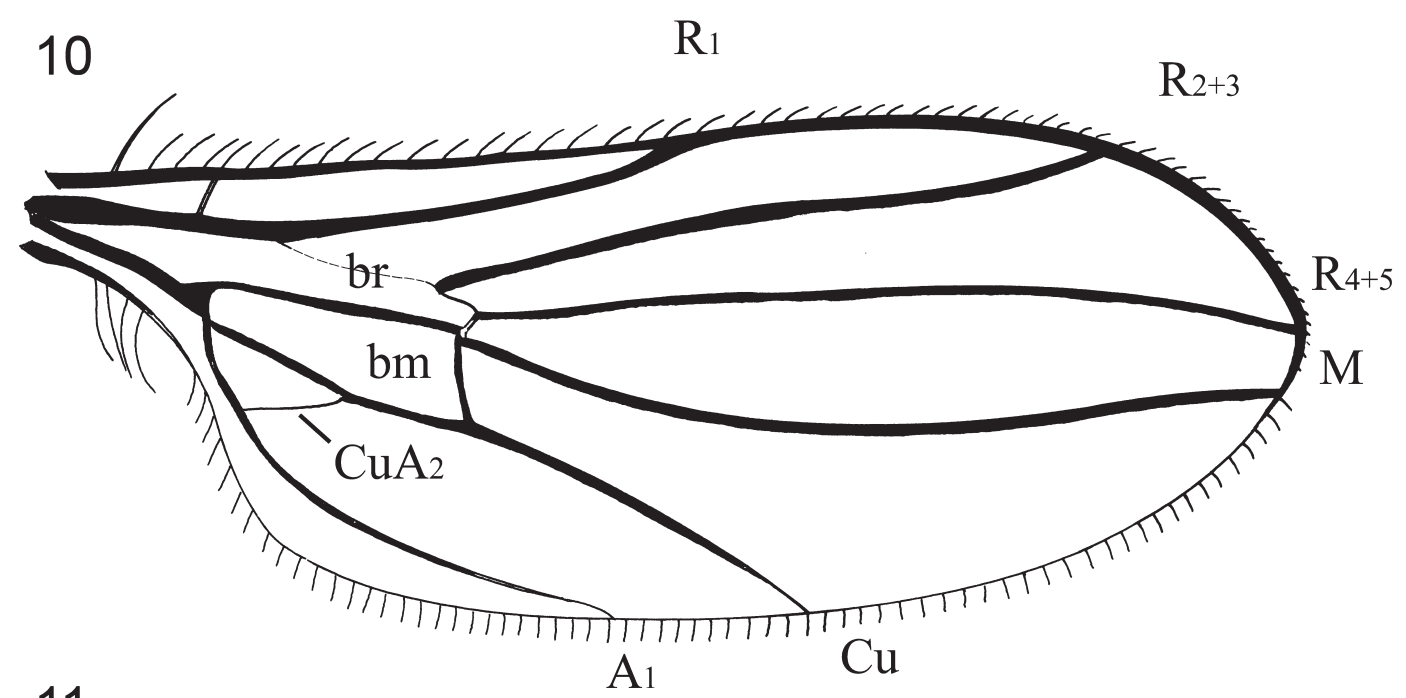

11

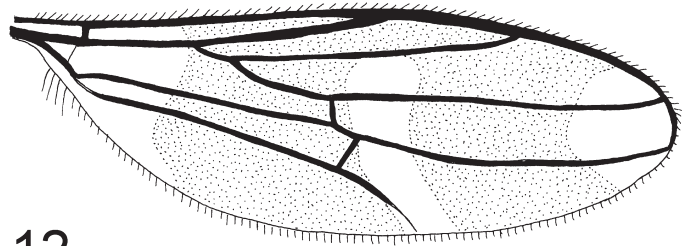

\section{5}
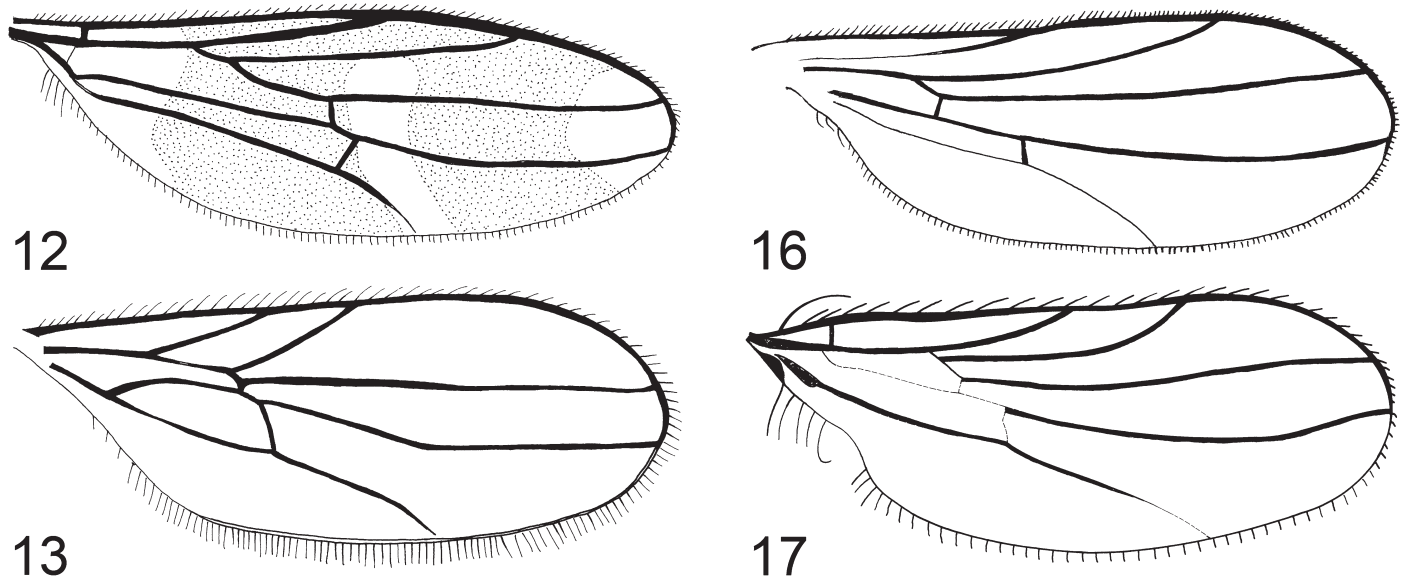

16
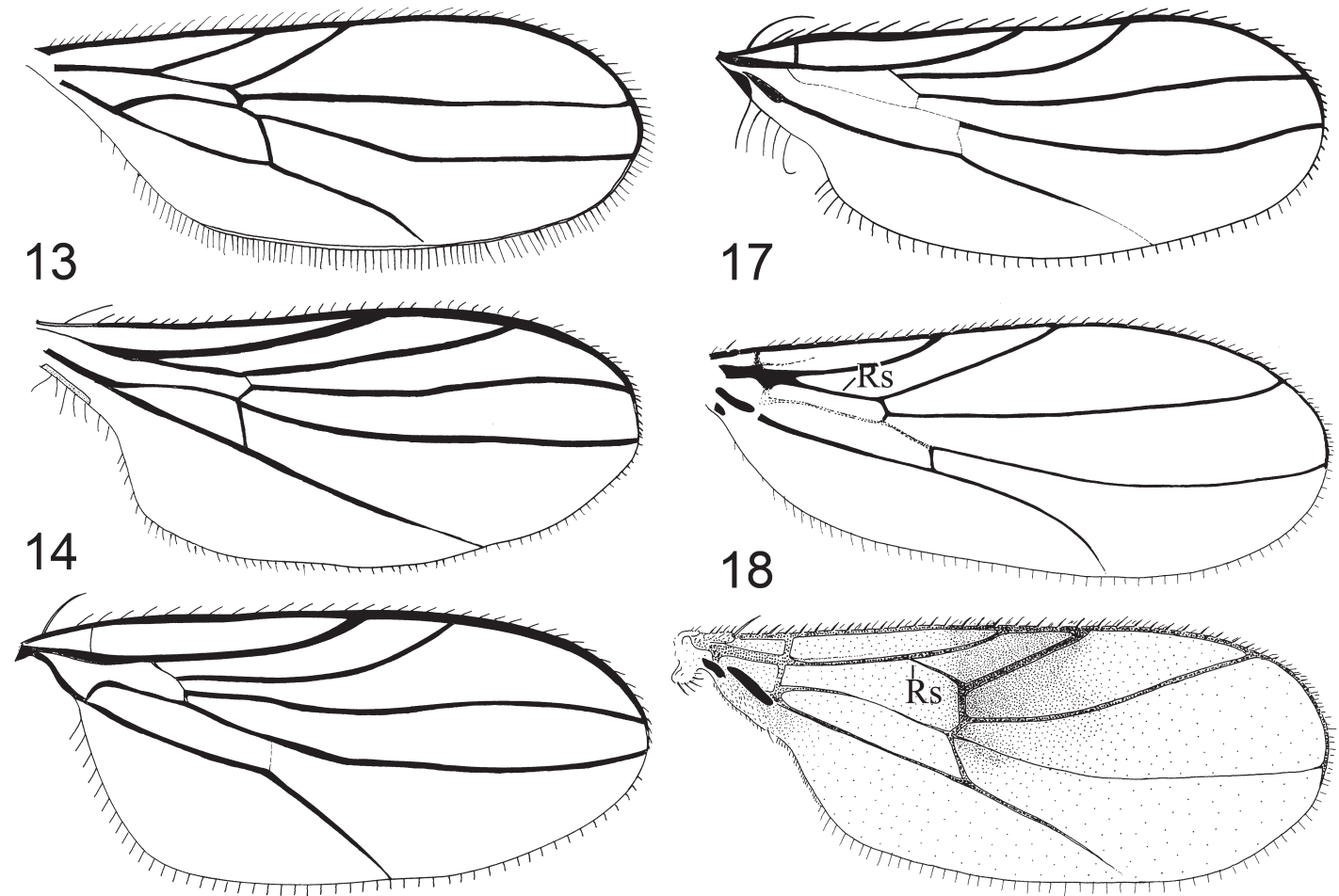

Figs 10-18. Wings of Tachydromiinae. 10. Platypalpus singaporensis sp. nov. 11. Tachydromia luang Shamshev \& Grootaert, 2005. 12. Chersodromia sylvicola sp. nov. 13. Chersodromia glandula sp. nov. 14. Drapetis laut sp. nov. 15. Elaphropeza biuncinata (Melander, 1928). 16. Crossopalpus temasek sp. nov. 17. Stilpon laawae Shamshev \& Grootaert, 2004. 18. Nanodromia narmjeud Grootaert \& Shamshev, 2003. 
19

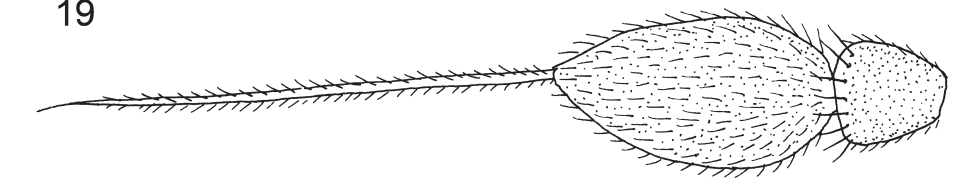

20

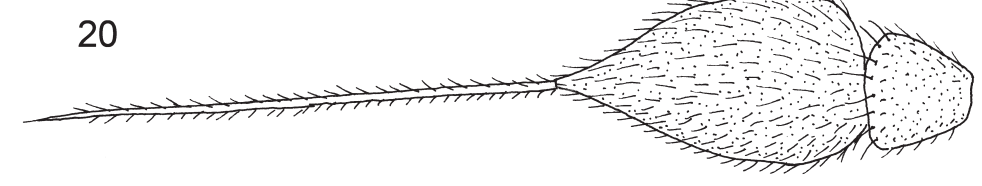

21

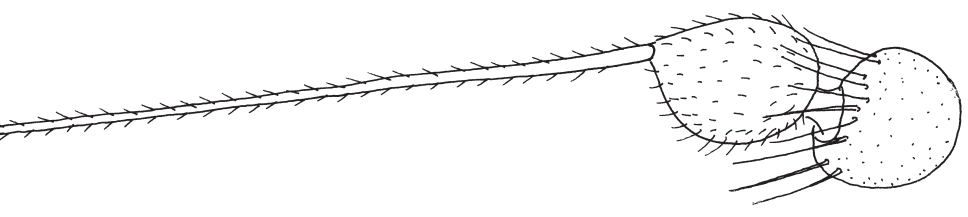

22

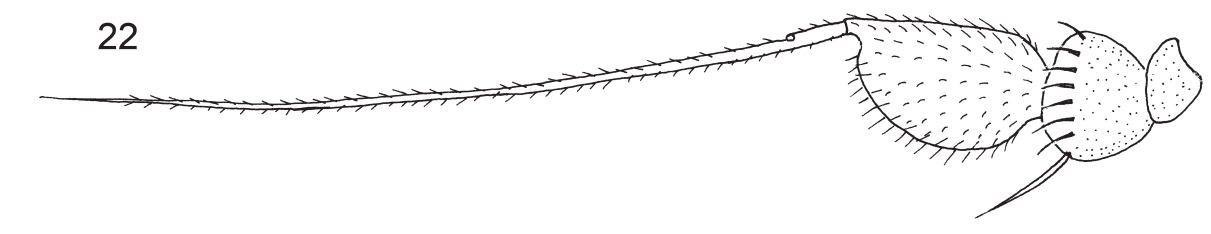

23

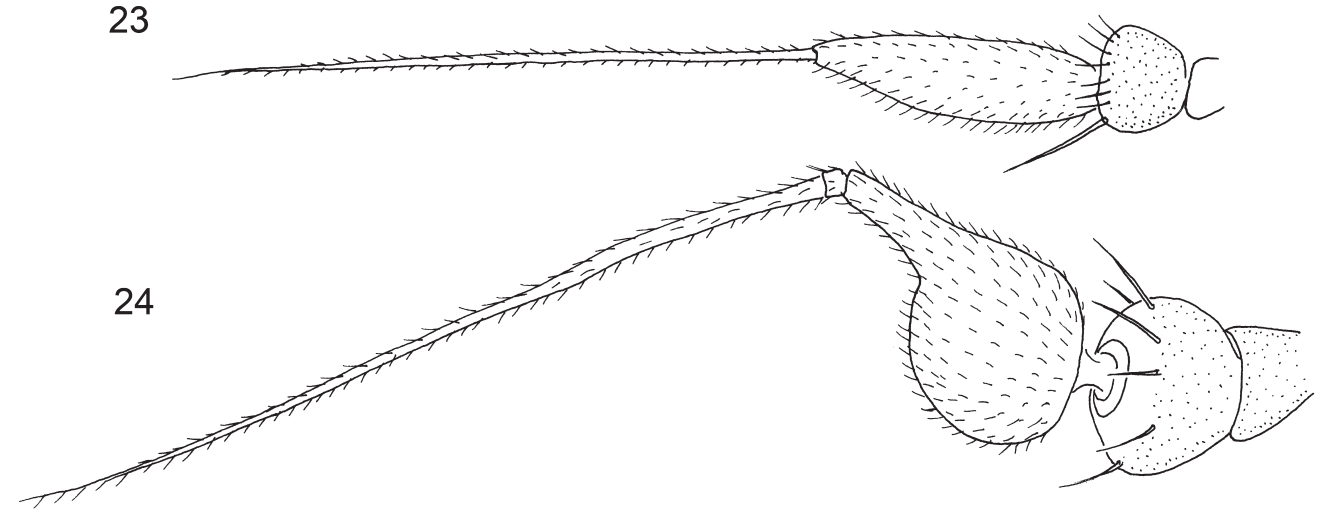

25

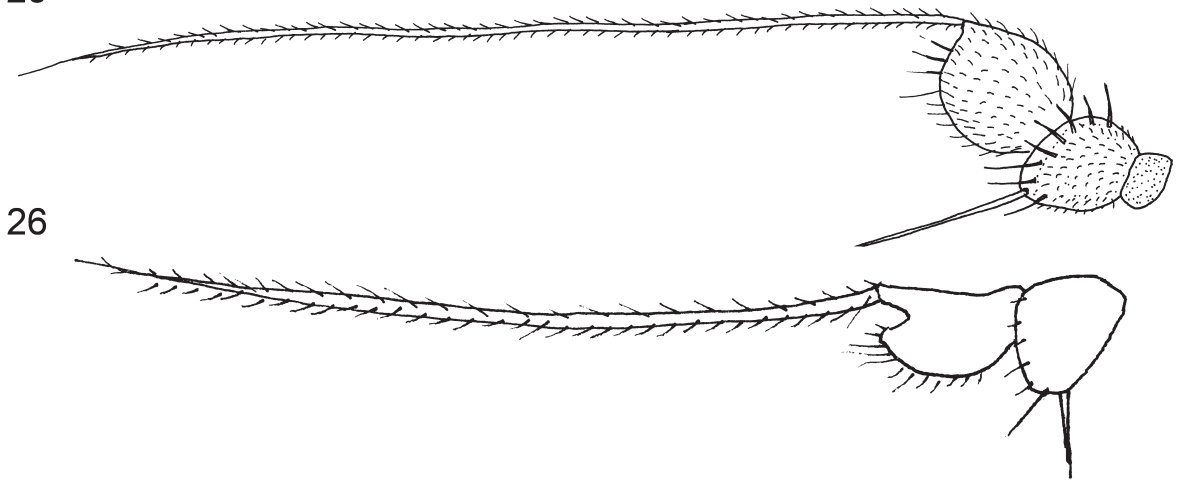

Figs 19-26. Antennae of Tachydromiinae. 19. Platypalpus singaporensis sp. nov. 20. Platypalpus hualuang Grootaert \& Shamshev, 2006. 21. Tachydromia luang Shamshev \& Grootaert, 2005. 22. Drapetis mandai sp. nov. 23. Drapetis hutan sp. nov. 24. Chersodromia singaporensis Shamshev \& Grootaert, 2005. 25. Crossopalpus temasek sp. nov. 26. Stilpon singaporensis sp. nov. 
AвDomen. Male abdomen more or less conical. In species of tribes Symballophthalmini and Tachydromiini segments 1-6 usually fully sclerotised and lacking modifications, tergites of subequal width (except tergite 1); no gland-like intersegmental structures. In Drapetini abdominal segments 1-6 varying considerably in ground-colour, shape, degree of sclerotisation and setation; segment 1 usually very narrow, tergites 2-3 of subequal width but tergite 4 often stronger sclerotised and enlarged, correlated with very narrow tergite 5; tergal vestiture sometimes modified and tergites 4-5 (sometimes 3-5) bearing squamiform setae; gland-like intersegmental structures often present between tergites 4 and 5 or between tergites 3 , 4 and 5. Sternites usually unmodified, weakly sclerotised, covered with scattered unmodified setulae. Pregenital segments unrotated. Segment 7 usually with unmodified structure and vestiture. Segment 8 often modified, with tergite slender or more or less notched posteriorly and stronger sclerotised and with tendency to fusion with sternite, usually with greatly reduced setation, symmetrical. Female abdomen telescopic, with all segments more or less exposed, sometimes appearing blunt-ended; segments 1-7 usually with unmodified structure and vestiture, sometimes with same modifications as in male. Seven pairs of spiracles present in segments 1-7.

Male terminalia. Asymmetrical, rotated between $45-90^{\circ}$ to the right with most components of left side often reduced in size (Figs 7-9). Epandrium undivided or completely divided; left epandrial lamella usually smaller than right epandrial lamella and sometimes fused to hypandrium (e.g. Stilpon Loew, 1859); right epandrial lamella relatively large, positioned ventrally or on left, sometimes with additional lobes; surstylus absent or, if present, positioned apically, hardly differentiated from epandrium or sometimes fully articulated with epandrium; left surstylus often divided into separate components. Hypandrium large, usually subrectangular and more or less flat, bearing few setae or bare. Gonocoxal apodeme confined to anterior margin of hypandrium. Postgonites present, associated with apex of hypandrium; right postgonite fused to apex of right hypandrial prolongation. Phallus firmly attached to distal part of hypandrium, usually straight and very short, with simple apex, sometimes greatly lengthened and curiously coiled (e.g. some Elaphropeza and Stilpon). Ejaculatory apodeme not fused to phallus base, rod-shaped. Single ventral apodeme usually present, long, slender, articulated to phallus, rarely absent (Stilpon). Subepandrial membrane completely sclerotised. Cerci, including subepandrial sclerite, sometimes fused together basally and closely approximated with margin of right epandrial lamella, or completely fused forming single lobe (e.g. some Elaphropeza), or more or less separated; usually fleshy, thinly sclerotised and clothed in fine short setae but sometimes greatly modified and bearing spine-like setae.

Female terminalia. Sclerites of segment 8 usually separated by pleural membrane but sometimes fused anteriorly; sternite 8 entire, or with apex hinged and partly or completely separated from base. Tergite 9 absent; sternite 9 reduced to small internal sclerite. Tergite 10 present, separated from sternite 10; or sometimes absent and then sternite 10 positioned below proctiger; undivided or more or less divided medially. Cercus slightly sclerotised, varying in shape from long, slender to short, ovate; clothed in fine short setulae. Single, unpigmented, membranous spermatheca present; spermathecal receptacle tubular or sac-like.

Sexual dimorphism. The degree of the sexual dimorphism varies depending on the genus. Within the tribe Tachydromiini differences between males and females usually are very slight or absent in species of Platypalpus. However, in Tachydromia or Tachypeza males often possess special modifications (colour pattern, spines, tubercles, etc.) on fore or mid legs. Within the tribe Drapetini the sexual dimorphic characters can also involve (beside setation of legs) modifications of some abdominal segments and presence of gland-like abdominal structures (e.g. Stilpon). 


\section{Phylogeny and classification}

Recently, Sinclair \& Cumming (2006) revised the higher classification of Empidoidea that is followed in our paper. The Tachydromiinae is one of five subfamilies (together with Trichininae, Ocydromiinae, Oedaleinae and Hybotinae), which are currently included in the family Hybotidae. Chvála (1975) provided a historical review of the systematic position of Tachydromiinae, and this will not be repeated here.

The subfamily Tachydromiinae is clearly monophyletic and this group is generally characterized by the apomorphic loss of vein $\mathrm{M}_{2}$ and cell $\mathrm{dm}$ (due to the loss of dm-cu crossvein). Additionally, tachydromiines have no wing pterostigma and pseudotracheae as well as they possess some distinctive features of the male terminalia including simple apex of the phallus and the ejaculatory apodeme not fused to phallus base (Sinclair \& Cumming 2006). Also, nucleotide data indicated robust support for the Tachydromiinae (Moulton \& Wiegmann 2007). Chvála (1975) presented a cladogram of the phylogenetic relationships within the subfamily Tachydromiinae and his pattern is generally accepted.

The subfamily is currently divided into three tribes, namely Symballophthalmini, Tachydromiini and Drapetini (Chvála 1975; Sinclair \& Cumming 2006). The tribe Symballophthalmini includes the single genus Symballophthalmus (absent in the Oriental Region), which is the most plesiomorphic group among recent representatives of Tachydromiinae. The Drapetini are very diverse and comprise 19 genera, nine of which are known from the Oriental Region. Seven genera of this tribe (Chersodromia Walker, Crossopalpus Bigot, Drapetis Meigen, Elaphropeza Macquart, Nanodromia Grootaert, Pontodromia Grootaert and Stilpon Loew) have been found from Singapore. Finally, the tribe Tachydromiini includes eight genera and is represented in the Oriental Region by Platypalpus, Tachydromia and Tachypeza (absent in Singapore).

The subfamily Tachydromiinae is one of the most abundantly represented groups of Empidoidea found in both Tertiary and Mesozoic ambers. For further data concerning extinct taxa of tachydromiines we refer to papers of Grimaldi \& Cumming (1999) and Solórzano Kraemer et al. (2005).

\section{Results}

\section{Taxonomy}

\section{Key to the genera of Tachydromiinae from the Oriental Region}

1. Postpronotal lobe differentiated (Fig. 5). Eyes bare. Scutum usually distinctly longer than broad.......2

- Postpronotal lobe undifferentiated. Eyes with tiny ommatrichia. Scutum not or scarcely longer than broad.

2. Vein $A_{1}$ present (Fig. 10), even if sometimes faint. Mid femur thickened and armed with rows of spinelike setae ventrally Platypalpus Macquart, 1827

- Vein $\mathrm{A}_{1}$ absent. Mid femur more or less slender and usually with weak setae ventrally..................

3. Vein $\mathrm{CuA}_{2}$ present

Tachypeza Meigen, 1830

- Vein $\mathrm{CuA}_{2}$ absent Tachydromia Meigen, 1803

4. Cells br and bm subequal in length at apex (Figs 12-13, 18; if in doubt, then eyes widely separated on face and hind tibia bristly).

- Cell br much shorter than cell bm at apex...............................................................

5. Scutellum with 3-4 pairs of bristles. Vein $\mathrm{A}_{1}$ present..............................egagrapha Melander, 1928

- Scutellum with 1-2 pairs of bristles. Vein $A_{1}$ absent. 
6. Legs with hind tibia bristly. Eyes usually widely separated on face and frons

Chersodromia Walker, 1849

- Legs with hind tibia lacking bristles. Eyes contiguous on face and widely separated on frons

.Nanodromia Grootaert, 1994

7. Antenna with arista-like stylus dorsoapical (Fig. 26; postpedicel with dorsoapical extension). Abdominal tergites without squamiform setae, tergites 3-5 usually of subequal width.....

- Antenna with arista-like stylus apical or subapical (postpedicel without dorsoapical extension). Some abdominal tergites often with squamiform setae laterally; if squamiform setae absent, then gena distinctly developed below eye or tergite 4 enlarged.

8. Scutum with subequally short dorsocentrals. Rs originating at most halfway along $R_{1}$, longer than crossvein bm-cu.

Stilpon Loew, 1859

- Scutum with pair of long presutural dorsocentrals. Rs originating far beyond halfway along $\mathrm{R}_{1}$, nearly as long as crossvein bm-cu.

Pontodromia Grootaert, 1994

9. Gena distinctly developed below eye. Pedicel usually with very long ventral seta. Rs usually shorter than crossvein bm-cu....

Crossopalpus Bigot, 1857

- Gena scarcely extended below eye. Pedicel usually with circlet of subequally short setae. Rs usually longer, at least as long as crossvein bm-cu.

10. Occiput convex. Postpedicel conical to lanceolate. Hind tibia usually with long anterodorsal bristles. Body often with yellowish markings.

Elaphropeza Macquart, 1827

- Occiput somewhat flattened (head closely set upon thorax). Postpedicel oval. Hind tibia without long anterodorsal bristles. Body dark brown to black.

11. Abdominal tergites with squamiform setae.

Drapetis Meigen, 1822

- Abdominal tergites without squamiform setae...... Sinodrapetis Yang, Gaimari \& Grootaert, 2004

Tribe Tachydromiini

The tribe Tachydromiini is defined by the following apomorphies: presence of a precoxal bridge and a weakened $\mathrm{A}_{1}$ (Sinclair \& Cumming, 2006). The tribe includes 8 genera worldwide but only two of them (Platypalpus Macquart and Tachydromia Meigen) are currently found in Singapore.

\section{Genus Platypalpus Macquart, 1827}

Coryneta Meigen, 1800: 27. Type-species: Musca cursitans Fabricius, 1775, by subsequent designation of Engel (1939: 43). Suppressed by I.C.Z.N. 1963: 339 (Opinion 678).

Platypalpus Macquart, 1827: 92. Type-species: Musca cursitans Fabricius, 1775, by subsequent designation of Westwood (1840: 132).

Phoroxypha Rondani, 1856: 146. Type-species: Tachydromia longicornis Meigen, 1822, by original designation.

Cleptodromia Corti, 1907: 101 (as subgenus of Tachydromia). Type-species: Tachydromia (Cleptodromia) longimana Corti, 1907 by monotypy.

Brevios Brunetti, 1913: 22. Type-species: B. longicornis Brunetti, 1913 by original designation (not in Yang et al. 2007).

Howlettia Brunetti, 1913: 23. Type-species: H. flavipes Brunetti, 1913 by monotypy. (not in Yang et al. 2007).

Tachydromia, authors, not Meigen, 1803, misidentifications. 


\section{Recognition}

Recognised by the following combination of characters: eyes separated in both sexes, bare; postpronotal lobe well differentiated; scutum usually distinctly longer than broad; mid leg raptorial, mid femur thickened and armed with rows of spine-like setae ventrally, mid tibia usually with more or less prominent apical spur; wing with veins $\mathrm{A}_{1}$ and $\mathrm{CuA}_{2}$ present (cell cup present).

\section{Diagnosis}

Very small to large species with body size varying from about 1.0 to $5.0 \mathrm{~mm}$. Eyes separated on frons and face, sometimes very narrowly; ommatidia of subequally small. One or two pairs of vertical bristles, sometimes not prominent. Ocellar tubercle with 2 pairs of bristles. Antenna with postpedicel conical; stylus apical. Palpus flattened, small, usually with some short subapical setae. Thorax greatly varying in ground-colour and degree of tomentosity from uniformly yellow to black and from largely shining to largely or entirely tomentose; scutum usually distinctly longer than broad; postpronotal lobe well differentiated; postpronotal bristle usually very prominent; mesonotal setation varying. Mid leg raptorial, mid femur thickened and armed with rows of spine-like setae ventrally, mid tibia usually with more or less prominent apical spur. Wings normally developed; without pattern; Rs rather long, originating beyond midway of vein $R_{1}$; vein $R_{1+2}$ long, meeting costa beyond wing midway; vein $R_{2+3}$ complete, meeting costa close to wing apex; $\mathrm{A}_{1}$ present; crossvein $\mathrm{CuA}_{2}$ present, recurrent; crossvein bm-cu oblique; cells br and bm of subequal length or cell bm slightly longer; cell cup present. Abdomen with segments 1-7 usually unmodified; no squamiform setae and gland-like intersegmental structures. Terminalia: epandrium not divided; left epandrial lamella separated from hypandrium; left surstylus undifferentiated from epandrial lamella; right epandrial lamella usually larger; right surstylus usually present, barely differentiated from epandrial lamella; cerci separated; hypandrium usually with 2 bristles on apical portion; phallus very short; two rod-shaped apodemes (i.e. ejaculatory plus ventral apodeme) present. Female usually similar to male in all respects except sexual differences; terminalia long; tergite 8 separated from sternite 8 ; cercus long, slender.

\section{Remarks}

The genus Platypalpus is the largest group of Tachydromiinae and one of the most speciose genera of Empidoidea on the whole. Currently about 550 species of Platypalpus are known worldwide but about $75 \%$ of them were described from the Palaearctic and Nearctic Regions (Yang et al. 2007). Platypalpus have been divided into several more or less natural species groups (Chvála 1975) and this classification of the genus is quite applicable to the Oriental representatives as well (Grootaert \& Shamshev 2006).

In contrast to the Palaearctic Region, few species of Platypalpus are found in the Oriental Region at low altitudes. Having a similar habitat and niche as Elaphropeza, Platypalpus probably comes into competition with Elaphropeza that is likely more adapted to tropical conditions. However as soon as one samples at altitudes above $500 \mathrm{~m}$, various species of Platypalpus are found and the number of Elaphropeza species drops.

After relatively intensive sampling in Singapore, only three females belonging to a single species of Platypalpus were found and we do not expect many more species to occur here. For a key and descriptions of the actually known Southeast Asian Platypalpus, we refer to Grootaert \& Shamshev (2006). Although the species in Singapore is known from females only, we describe it since it has many distinct characters that make it easily recognisable from the single related species $P$. hualuang Grootaert \& Shamshev described from Northeast Thailand and males are normally very similar in coloration and tomentosity. 
Platypalpus singaporensis sp. nov.

Figs 10, 19, 244

\title{
Diagnosis
}

Species of the $P$. luteus group with 2 pairs of verticals. Body almost uniformly yellowish, except for mesonotum with two pale brown vittae down dorsocentral bristles; antenna pale yellow, postpedicel ellipsoid, about twice as long as wide; stylus 2.0 times as long as postpedicel; acrostichals and dorsocentrals multiserial, hardly separated; 2 notopleurals; anepisternum (= mesopleuron) above with row of short brown setae; tarsomeres 3 and 4 of fore tarsus somewhat flattened, but not produced with posterior wing-like protuberance.

\section{Description}

\author{
Male \\ Unknown.

\section{Female} \\ LeNGTH. Body $3.3 \mathrm{~mm}$; wing $2.0 \mathrm{~mm}$.
}

HEAD. Entirely yellow in ground-colour (ocellar tubercle with slight brownish tinge). Occiput with 2 pairs of black verticals, further clothed with rather short bristly hairs, longer setae on lower part. Ocellar tubercle with 2 long, black bristles. Frons pale yellow, widened toward ocellar tubercle, above antennae about 1.5 times as wide as anterior ocellus, pollinose. Face below antennae nearly as broad as frons. Antenna entirely pale yellow; postpedicel ellipsoid (Fig. 19), about 2.0 times as long as wide; stylus nearly 2.0 times as long as postpedicel. Palpus brown, elongate, about as long as postpedicel, with 1 long brown apical, 1 subapical and 1 subbasal setae. Proboscis yellow, long, as long as head is high.

Thorax. Almost entirely yellow; scutum with 2 brownish vittae down dorsocentrals; pleura yellowishbrown; long bristles black, short hairs brown. Postpronotal lobe with 1 moderately long bristle and several setulae. Mesonotum with 2 long notopleurals, 1 postalar and 4 scutellars (outer pair very short, inner pair long); acrostichals and dorsocentrals short, multiserial, hardly separated, 1 pair of prescutellar dorsocentrals long; anepisternum (= mesopleuron) with row about 8 brown setae along upper border.

LEGS. Uniformly yellow. Fore femur thickened, with very short anteroventral and posteroventral bristles and long dorsal hairs near base. Length of fore femur, fore tibia and fore tarsus (mm): 0.6/0.6/0.52; fore tarsomeres $(\mathrm{mm}): 0.2 / 0.1 / 0.06 / 0.05 / 0.09$. Fore tarsus slightly shorter than fore tibia; tarsomere 1 with some longer hair-like setae near base; tarsomeres 3-5 flattened, but not produced posteriorly; tarsomere 5 with long posterior seta at tip. Mid femur incrassate, 1.5 times wider than fore femur, with 2 rows of black ventral spinules (posterior ones longer) and row of 8-10 brown, posteroventral bristles about 3/4 as long as femur is wide. Mid tibia with short, flattened, yellow apical spur. Mid tarsus about 3/4 of length of mid tibia. Hind leg ordinary.

WING. Hyaline, with yellowish veins, bearing 2 long costal bristles. Veins $\mathrm{R}_{4+5}$ and $\mathrm{M}_{1+2}$ divergent near middle, convergent just before meeting wing margin. Crossveins $\mathrm{m}$-cu and $\mathrm{r}-\mathrm{m}$ contiguous. Calypter brown, with ciliae brown basally and pale apically. Halter with brown stem and white knob.

AвDOMEN. With tergite 1 very narrow, tergites $2-5$ wide as usual and brown, tergites 6-8 pale; sternites pale, only sternite 8 and cercus brownish. 


\section{Material examined}

Holotype $q$

SINGAPORE: Sime forest, 3 June 2005, forest, Mal 1 (reg. 25134, leg. P.G.; in ZRC).

\section{Paratypes}

SINGAPORE: 1 , , Sime forest, 6 May 2005, Mal 1 (reg. 25127, leg. P.G.); 1 \%, Sime forest, 12 August 2005, Mal 1 (reg. 25293, leg. P.G.).

\section{Etymology}

The new species is dedicated to Singapore.

\section{Distribution}

Singapore.

\section{Habitat and seasonal occurrence}

Forest, recorded from May until August.

\section{Remarks}

Platypalpus singaporensis sp. nov. belongs to the P. luteus group as indicated by the long yellow proboscis and many other features (Grootaert \& Shamshev 2006). It is however aberrant because it lacks the broadened fore tarsi like other members of the group. Platypalpus singaporensis sp. nov. has to be compared mainly with $P$. hualuang Grootaert \& Shamshev, a similar species from Northeast Thailand. There are however so many crucial differences that show the plasticity of the P. luteus group. Remarkable is the presence in $P$. singaporensis sp. nov. of a row of about 8 setae along the upper margin of the anepisternum. A feature that is unique in Platypalpus. However, in P. hualuang one or two short yellowish setae are present, a character that we overlooked in the original description of this species.

In P. hualuang, the following characters are different: antenna onion-shaped (Fig. 20), palpus small, round, pale yellow; a pair of short pale yellow ocellar bristles; two pairs of short, pale verticals; 1 notopleural; a brown median band on mesonotum; fore tibia not swollen in basal half and without black dorsal bristles; tarsi paler than tibiae, almost white; fore tarsus very long, longer than tibia; fore tarsomere 1 with a long white bristle near base; fore tarsomere 3 and 4 flattened and widened, due to a wing-like posterior protuberance; mid femur with about 6 posteroventral bristles about half as long as femur is wide; mid tarsus long, as long as mid tibia.

Platypalpus singaporensis sp. nov. differs from $P$. hualuang as follows: antenna ellipsoid; palpus elongate, brown; a pair of long black ocellar bristles; two pairs of long black verticals; a narrow brown vitta on each row of dorsocentrals, median area of mesonotum yellow; 2 notopleurals; fore tibia swollen in basal half and dorsally with some long black bristles; fore tarsus distinctly shorter than fore tibia; all tarsi yellow, not paler than tibiae; fore tarsomere 1 without long basal pale ventral bristle, only with longer ventral pubescence; fore tarsomeres 3,4 and 5 flattened, but not widened; mid femur with a row of 8-10 brown posteroventral bristles that are at least $3 / 4$ as long as femur is wide; mid tarsus short, about $3 / 4$ length of mid tibia. 
Genus Tachydromia Meigen, 1803

Sicus Latreille, 1797: 158. Type-species: Musca cimicoides Fabricius, 1781, by subsequent designation of Latreille (1810: 443) [= Musca arrogans Linnaeus, 1761]. Pre-occupied by Sicus Scopoli, 1763 [Diptera, Conopidae].

Coryneta Meigen, 1800: 27. Type-species: Tachydromia connexa Meigen, 1822, by subsequent designation of Coquillett (1910: 528). Suppressed by I.C.Z.N., 1963: 339 (Opinion 678).

Tachydromia Meigen, 1803: 269. Type-species: Musca cimicoides Fabricius, sensu Curtis, 1833: pl. 477 (by designation of Curtis 1833), misidentification [= Tachydromia connexa Meigen, 1822].

Sicodus Rafinesque, 1815: 130. Type-species: Musca cimicoides Fabricius, 1781, automatic [= Musca arrogans Linnaeus, 1761]. Replacement name for Sicus Latreille, 1796.

Danistes Gistel, 1848: XI. Type-species: Musca cimicoides Fabricius, sensu Curtis, 1833, automatic [= Tachydromia connexa Meigen, 1822]. An unnecessary new name for Tachydromia Meigen, 1803.

Tachista Loew, 1864: 7, 15. Type-species: Musca cimicoides: sensu Meigen, 1803 (by subsequent designation of Coquillett 1903: 258), misidentification [= Tachydromia connexa Meigen, 1822].

Tachysta: authors, error or emendation.

\section{Recognition}

Recognised by the following combination of characters: eyes broadly separated on frons, contiguous on face, bare; postpronotal lobe well differentiated; scutum usually distinctly longer than broad; fore femur thickened, mid legs more or less slender; wing often banded or spotted, with veins $\mathrm{A}_{1}$ and $\mathrm{CuA}_{2}$ absent (cell cup absent).

\section{Diagnosis}

Small to medium-sized (1.0 to $3.5 \mathrm{~mm}$ ), usually largely shining, ant-like flies. Eyes separated on frons, contiguous on face; ommatidia somewhat enlarged below. One pair of vertical bristles. Ocellar tubercle with 1 pair of bristles. Antenna with postpedicel conical or subglobular; stylus apical or subapical. Palpus varying in shape and length, usually with black subapical seta (sometimes absent). Thorax usually black in ground-colour and largely shining, with greatly reduced setation; scutum usually distinctly longer than broad; postpronotal lobe well differentiated; postpronotal bristle prominent or absent; mesonotal setation variable. Fore femur and tibia thickened; mid leg more or less slender, in males often modified. Wings normally developed or reduced (in non-Oriental species); usually with distinct pattern, banded, spotted or clouded; Rs rather short, originating before or near midway of vein $\mathrm{R}_{1}$; vein $\mathrm{R}_{1}$ long, meeting costa beyond or near wing midway; vein $\mathrm{R}_{2+3}$ complete (except male of $T$. ocellata Shamshev \& Grootaert), meeting costa closer to wing apex; $\mathrm{A}_{1}$ absent; crossvein $\mathrm{CuA}_{2}$ absent; crossvein bm-cu usually transverse; cell br shorter than cell bm, rarely both cells of subequal length (male of T. ocellata); cell cup absent. Abdomen with segments 1-7 unmodified (in Oriental species); no squamiform setae and gland-like intersegmental structures. Terminalia rotated $45-90^{\circ}$ to right, of varying structure; epandrium not divided; left epandrial lamella separated from hypandrium; left surstylus usually undifferentiated from epandrial lamella; right epandrial lamella usually larger; right surstylus usually present, barely differentiated or undifferentiated from epandrial lamella; cerci separated; hypandrium usually with 2 bristles on apical portion; phallus very short; two rod-shaped apodemes (i.e. ejaculatory and ventral apodemes) present. Female usually similar to male but with unmodified structure and vestiture of mid leg, rarely (T. ocellata) with different pattern and venation of wing; terminalia long; tergite 8 separated from sternite 8; cercus long, slender.

\section{Remarks}

Species of Tachydromia are likely among the most attractive flies within the Hybotidae owing to their external appearance and behaviour. They are usually found running about quickly on tree-trunks, logs, 
stones, sand, or leaves of lower herbage resembling in some respects small hymenopterans or ants (Chvála 1970). The group is worldwide in distribution and currently includes 110 species, of which 18 species are known from the Oriental Region. The Oriental species of Tachydromia were recently revised by Shamshev \& Grootaert (2005b, 2008, 2009a) and Grootaert \& Shamshev (2009a). The genus is recently also reported for the first time in Australia and six species are now known in the Australasian region (Grootaert \& Shamshev 2011).

Only a single species is reported in Singapore so far. Females are observed sporadically, but males are very rare. We do not expect many more species of Tachydromia to occur here in Singapore, because it is quite rare in the whole tropical Oriental Region, except perhaps in mountains where more species are found (Shamshev \& Grootaert 2008).

The updated key given below is based on the key compiled by Shamshev \& Grootaert (2008), but it includes a species described from the South China (Yang \& Grootaert 2006), two species of Tachydromia recently described from Malaysia (Shamshev \& Grootaert 2009a) and correctly distinguishes males and females of $T$. ocellata.

\section{Updated key to species of Tachydromia of the Oriental Region}

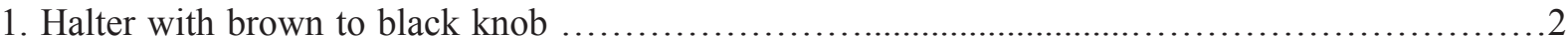

- Halter entirely yellow or at most stem brownish ..................................................

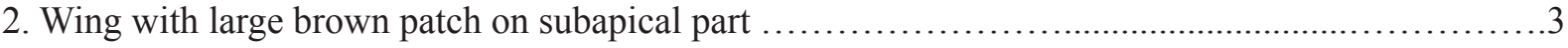

- Wing brownish infuscate leaving subapical part whitish, brown along anterior margin ..............5

3. Fore femur with brown elongate ventral patch basally; hind femur brown on apical 1/4. Male: fore tibia mostly bare posteriorly but with rather long curved thin setae along sides of bare space (Thailand) T. tigeri Shamshev \& Grootaert, 2008

- Fore and hind femora entirely yellow. Male: fore tibia unmodified ...4

4. Tibiae almost entirely yellow, only fore tibia with subapical ventral brown patch (Viet Nam) ...... T. achterbergi Grootaert \& Shamshev, 2009

- Tibiae almost entirely dark brown, only hind tibia brownish yellow apically (China, Guangdong).... T. guangdongensis Yang \& Grootaert, 2006

5. Fore femur almost entirely yellowish, indistinctly brownish clouded posteriorly on subapical part; hind femur broadly brownish on middle part; hind tibia dark brown on about apical half. Male: fore tibia slightly curved (viewed dorsally), with ventral spinules becoming stronger on apical half and several spinule-like setulae posteriorly near middle (Thailand)........ T. phu Shamshev \& Grootaert, 2008

- Fore femur largely brownish; hind femur pale yellow on basal $1 / 5$, otherwise dark brown to black. Male: fore tibia unmodified.

6. Postpedicel brownish yellow, paler than scape and pedicel. Male: Right cercus with very long seta at tip (Thailand)........................................... phanensis Shamshev \& Grootaert, 2008

- Antenna entirely brownish. Male: Right cercus with several moderately long marginal setae apically (Viet Nam)...................................................T. annamensis Grootaert \& Shamshev, 2009

7. Wing with 2 broad brownish bands separated along entire length or connected somewhere......8

- Wing with more or less distinct brownish patch closer to wing apex or (rarer) lacking prominent

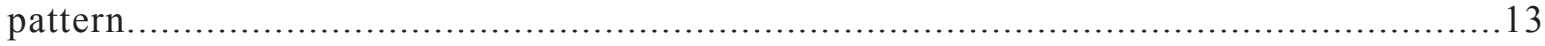

8. Antenna yellow. Hind femur brownish on apical part, hind tibia black brown on apical 1/6-1/5....9 
- Antenna dark brown to black (sometimes basal segments somewhat darker). Hind femur and tibia largely blackish brown...

9. Fore tibia contrastingly black on apical $1 / 3$. Male: cerci with numerous very long setae (Thailand; Singapore)

T. luang Shamshev \& Grootaert, 2005

- Fore tibia entirely yellow. Male: cerci covered with scattered short to moderately long setae (Malaysia)

T. malaysiensis Shamshev \& Grootaert, 2009

10. Palpus pale yellow (China, Henan).

T. henanensis Saigusa \& Yang, 2002

- Palpus dark.

11. Hind femur brown on apical $2 / 3$ (Thailand).

T. monocercus Shamshev \& Grootaert, 2008

- Hind femur entirely blackish brown.

12. Laterotergite with thin finger-like process. Wing with bands connected on cells $r_{1}$ and $r_{4+5}$. (China, Henan).

T. digitiformis Saigusa \& Yang, 2002

- Laterotergite unmodified. Wing with 2 broad brown bands separated along the whole length (India).

13. Hind femur entirely yellow.

- Hind femur at least partly brown to black.

14. Fore tarsomeres 4 and 5 brown. Hind tibia brownish on about basal half (Thailand; Viet Nam)... ..T. doi Shamshev \& Grootaert, 2008

- Only fore tarsomere 5 darkened on apical half. Hind tibia entirely yellow (Thailand). T. terricoloides Shamshev \& Grootaert, 2005

15. Occiput with flattened silvery white setae on lower part. Hind femur entirely black. Wing almost entirely uniformly brownish infuscate, darker anteriorly, paler basally (Malaysia).....

T. pahangiensis Shamshev \& Grootaert, 2009

- Occiput with pale hair-like setae on lower part. Hind femur brown on apical part. Wing with different pattern..

16. Palpus yellowish brown. Fore tibia almost entirely brownish, extreme base yellow. Wing largely finely infuscate, somewhat deeper on middle part along veins (Thailand).

T. thaica Shamshev \& Grootaert, 2005

- Palpus pale yellow. Fore tibia at most brownish apically. Wing with 1 or 2 brownish patches on subapical part.

17. Wing with 2 brownish patches on subapical part; vein $\mathrm{R}_{2+3}$ incomplete; male (Thailand)

T. ocellata Shamshev \& Grootaert, 2008

- Wing with 1 brownish patch on subapical part; vein $\mathrm{R}_{2+3}$ complete.

18. Only fore tarsomere 5 darkened on apical part; hind tibia yellow (Taiwan)...T. bistigma (Bezzi, 1912)

- Fore tarsomeres 4 and 5 brown; hind tibia partly brown to black.

19. Mid tibia brown; hind tibia brown on apical 1/4; female....T. ocellata Shamshev \& Grootaert, 2008

- Mid tibia yellow; hind tibia blackish on basal 2/3 (China, Henan)...

T. longyuwanensis Saigusa \& Yang, 2002 
Tachydromia luang Shamshev \& Grootaert, 2005

Figs 11, 21, 27-30, 245

Tachydromia luang Shamshev \& Grootaert, 2005b: 115.

\section{Diagnosis}

Medium-sized species with thorax largely brown (not black), subshining, finely pollinose, and prothoracic sclerites yellowish brown; palpus yellow, small, rounded, with very long, black apical bristle; legs with male fore tibia in apical $1 / 3$ and hind tibia in apical $1 / 6$ contrastingly black, otherwise pale yellow; wing with two broad brown bands connected along costa; male terminalia with left cercus bilobed, bearing very long bristles.

\section{Material examined}

SINGAPORE: 1 (holotype), Loyang mangrove, tree trunk, 18 April 1985 (leg. D.H. Murphy; in ZRC); 1 ㅇ, Chek Jawa, 2 December 2003, mangrove, Mal 1 (reg. 23097, leg. P.G.); 2 우, Nee Soon, 11 December 2003, swamp forest, Mal 2 (reg. 23121, leg. P.G.); 2 우, Nee Soon, 24 March 2005, swamp forest, Mal 1 (reg. 25028, leg. P.G.); 1 q, Nee Soon, 15 July 2005, swamp forest, Mal 2 (reg. 25259, leg. P.G.); 1 क , Nee Soon, 28 October 2005, swamp forest, Mal 1 (reg. 25403, leg. P.G.); 1 \%, Nee Soon, 3 December 2005, swamp forest, Mal 1 (reg. 25436, leg. P.G.); 1 + , Nee Soon, 25 January 2006,

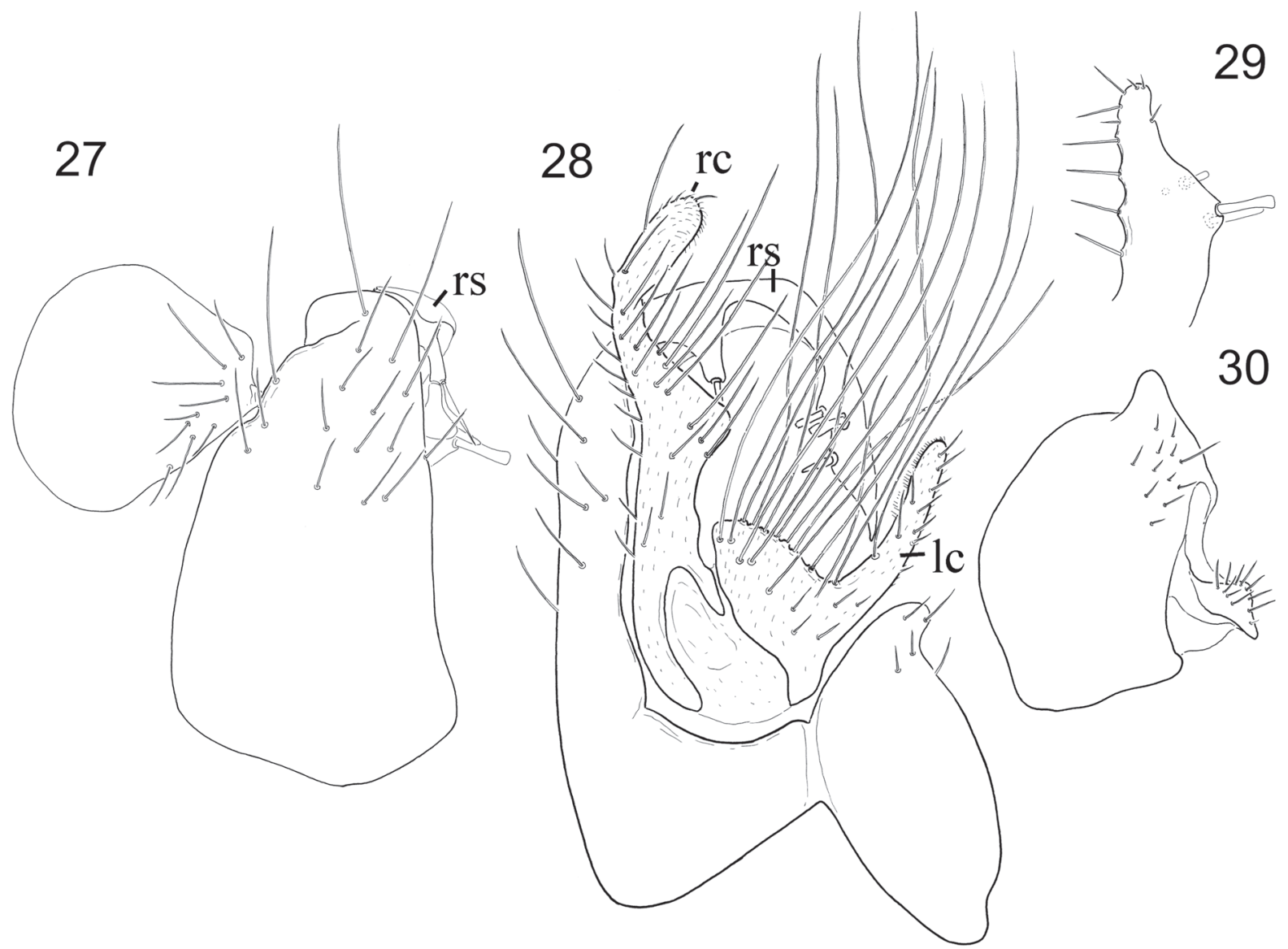

Figs 27-30. Tachydromia luang Shamshev \& Grootaert, 2005, ô terminalia. 27. right epandrial lamella, lateral view. 28. epandrium with cerci, dorsal view. 29. left surstylus, lateral view. 30. detail of tip right surstylus, dorsal view (after Shamshev \& Grootaert 2005). 
swamp forest, Mal 1 (reg. 26020, leg. P.G.); 1 q, Sime forest, 1 April 2005, forest, Mal 1 (reg. 25040, leg. P.G.); 1 q, Sime forest, 16 September 2005, forest, Mal 1 (reg. 25352, leg. P.G.); 1 \%, Sime forest, 14 October 2005, forest, Mal 3 (reg. 25386, leg. P.G.); 1 ㅇ, Sime forest, 3 December 2005, forest, Mal 1 (reg. 25434, leg. P.G.); 1 q, Sime forest, 8 February 2006, forest, Mal 2 (reg. 26027, leg. P.G.); 1 , Sime forest, 17 February 2006, forest, Mal 1 (reg. 26034, leg. P.G.).

\section{Distribution}

Singapore, Thailand (Loei and Petchabun Provinces).

\section{Habitat and seasonal occurrence}

Tachydromia luang has been recorded in only four localities: Loyang and Chek Jawa are mangroves, while Nee Soon and Sime forest are terrestrial rain forests; records almost throughout the year.

\section{Remarks}

Although there is such an apparent disjunctive distribution, there is little doubt that the species from Singapore and Northeast Thailand are conspecific. Furthermore, the Singaporean species was found in a mangrove and in rain forest while the Thai specimens were recorded from a mixed deciduous forest at an altitude of $500 \mathrm{~m}$ (FIRS Na Haeo, Loei province) and also from Petchabun and Sakhon Nakhon provinces. This phenomenon of disjunctive occurrence in mangrove or coastal forests and in mountains is observed in Empis (Coptophlebia) (Daugeron \& Grootaert 2003), in Platypalpus (see this paper) and various other hybotid and dolichopodid species (Grootaert 2009).

Tribe Drapetini

The tribe Drapetini is diagnosed by the following apomorphies: compound eyes with ommatrichia, loss of tergite 10 in females (correlated with sternite 10 positioned below the cerci), and loss of wing vein $\mathrm{CuA}_{2}$ (Sinclair \& Cumming 2006). The Drapetini currently includes 18 genera, of which 9 genera (Chersodromia Walker, Crossopalpus Bigot, Drapetis Meigen, Elaphropeza Macquart, Megagrapha Melander, Nanodromia Grootaert, Pontodromia Grootaert, Sinodrapetis Yang, Gaimari \& Grootaert, and Stilpon Loew) have been recorded from the Oriental Region, but only seven genera of Drapetini are currently known from Singapore. Megagrapha and Sinodrapetis are lacking. Almost all these groups are worldwide in distribution but Nanodromia and Pontodromia are found in the Oriental and Australasian regions only.

Genus Chersodromia Walker, 1849

Chersodromia Walker, 1849: 1157. Type-species: Tachypeza brevipennis Zetterstedt, [1838], by subsequent designation of Rondani (1856: 147) [= Chersodromia arenaria (Haliday, 1833)]. Coloboneura Melander, 1902: 229. Type-species: C. inusitata Melander, 1902, by monotypy. Halsanalotes Becker, 1902: 41. Type-species: H. amaurus Becker, 1902, by monotypy. Thinodromia Melander, 1906: 370. Type-species: T. inchoata Melander, 1906, by monotypy.

\section{Recognition}

Chersodromia is recognised from other drapetine genera that occur in the Oriental Region by the following combination of features: eyes widely separated or contiguous on face, gena distinctly extended below eye, cells br and bm subequal in length, vein $\mathrm{A}_{1}$ very weak or absent, and legs (at least hind tibia) bristly. 


\section{Diagnosis}

Very small to quite large $(1.0-4.0 \mathrm{~mm})$ usually black and densely greyish pollinose, rarely pale yellow (C. Alavicaput group) flies. Frons broad, with sides divergent above. Eyes usually widely separated or contiguous (C. flavicaput group) on face. Vertical bristles usually very prominent, 1 or 2 pairs, but sometimes practically absent. Ocellar tubercle with 2 pairs of bristles. Antenna with pedicel bearing long ventral subapical seta; postpedicel varying in shape, often with dorsoapical extension; stylus arising apically or dorsoapically, arista-like, long. Gena distinctly extended below eye. Palpus small, usually with short subapical seta and sometimes with sensory pit. Thorax usually largely densely pollinose. Postpronotal bristle prominent. Mesonotal bristles prominent but sometimes acrostichal and dorsocentral bristles little differentiated or greatly reduced in number; 2 long setae sometimes present between mid and hind coxae. Legs short, robust, with femora of subequal width; mid leg lacking secondary sexual characters in male; hind tibia with distinct bristles. Wings normally developed or sometimes reduced (non Oriental species); lacking colour pattern (in Oriental species), hyaline, finely infuscate or milkywhite; Rs very long, originating close to humeral crossvein or near middle of $R_{1} ; R_{1}$ usually long and meeting costa at least near middle of wing, sometimes short (C. flavicaput group); $\mathrm{R}_{2+3}$ usually long and meeting costa beyond wing midway, sometimes very short and meeting costa before wing midway (C. flavicaput group); veins $\mathrm{R}_{4+5}$ and $\mathrm{M}_{1+2}$ parallel; $\mathrm{A}_{1}$ present as fold or absent; crossvein $\mathrm{Cu}_{2}$ absent; crossvein bm-cu oblique or nearly transverse; cells br and bm of subequal length. Abdomen usually with tergites 1-7 unmodified, rarely tergite 2 modified (C. glandula sp. nov.); no squamiform setae; glandlike intersegmental structures absent. Terminalia with epandrium completely divided; left epandrial lamella fused to hypandrium; left surstylus differentiated from epandrial lamella, undivided or divided; right surstylus differentiated or barely differentiated from epandrial lamella; cerci separated; hypoproct unmodified; hypandrium setose subapically; phallus very short or sometimes elongate (C. flavicaput group); usually two rod-shaped apodemes (i.e. ejaculatory and ventral apodemes) present, rarely only one (some species of $C$. flavicaput group). Female usually similar to male, except some slight differences in setation of legs; terminalia short or elongate; tergite 8 separated from sternite 8 ; cercus rather short, slender or ovate.

\section{Remarks}

The genus Chersodromia belongs to the unique complex of the empidoids inhabiting the narrow intertidal and supralittoral zones of the sea shores (Grootaert 1992, 1994; Shamshev \& Grootaert 2004a, 2005a, 2005c; Ulrich 2004). The representatives of this ecological group usually occupy very specialised niches, e.g. reef-flats, sandy beaches, crab holes, wet rocks, the mangrove directly exposed to the sea, etc., and only rarely penetrate inland (Chvála 1995; Grootaert et al. 2007). Currently, 65 species of Chersodromia are known worldwide, including 6 species described here. 10 species are recorded now from the Oriental Region. Chvála (1977) subdivided Chersodromia into four species groups. However this classification is based on Palaearctic species and it does not work for the Oriental representatives of the genus.

There are four 'yellow' Chersodromia known in the Oriental Region and they probably form a natural species group. Provisionally we refer to them as the C. flavicaput group. They do not occur on sandy beaches as most Chersodromia, but are found in forests and one species in mangroves. Within that group, $C$. bulohensis sp. nov., C. flavicaput and C. obscura form a distinct subgroup characterised in having two rod-shaped apodemes, the left surstylus with a strong apical bristle and a set of spinules. Chersodromia sylvicola sp. nov. does not have these characters and therefore this species appears to belong to a different branch that is closer to the Chersodromia with dark body ground-colour. For a further discussion on this group please refer to Grootaert et al. (2007).

The remaining species of Chersodromia belong to various groups sensu Chvála (1977), but some species are intermediate. For example, $C$. malaysiana sp. nov. belongs to the $C$. cursitans group; $C$. nigripennis Shamshev \& Grootaert appears to have an intermediate position between the $C$. incana and C. cursitans 
groups; C. singaporensis Shamshev \& Grootaert belongs to the C. speculifera group and probably is closely related to three species of Chersodromia described from Papua New Guinea (Grootaert 1992).

\section{Key to species of Chersodromia from the Oriental Region}

1. Body largely yellow to pale yellow; wing with vein $\mathrm{R}_{2+3}$ very short, meeting costa before middle of wing; not on sandy beaches.

- Body entirely brown to black; wing with vein $\mathrm{R}_{2+3}$ long, meeting costa beyond middle of wing; on sandy beaches.

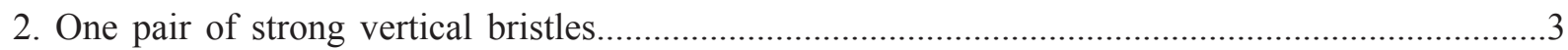

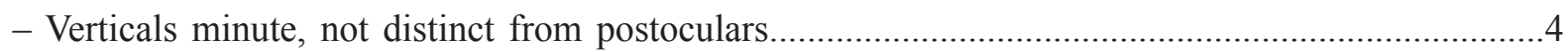

3. Scutum in anterior third with brown median vitta broadly connected near middle with broad brown area on each side, leaving sides of notopleural and prescutellar depressions yellow. Hind tibia with 3 long bristles on apical half (Thailand)......... . obscura Grootaert, Cumming \& Shamshev, 2007

- Mesonotum uniformly yellowish. Hind tibia with 4 long bristles on apical half (Singapore).

.C. sylvicola sp. nov.

4. Hind tibia with 5 long bristles on apical half (Papua New Guinea; Thailand).

C. flavicaput Grootaert, Cumming \& Shamshev, 2007

- Hind tibia with 3 bristles on apical half (Singapore).

C. bulohensis sp. nov.

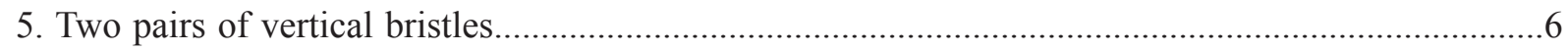

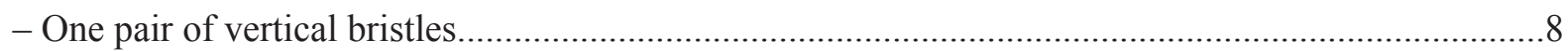

6. Halter pale. Abdominal tergite 2 thickened posteriorly (Singapore; Malaysia)........C. glandula sp. nov.

- Halter at least with brownish yellow knob. Abdominal tergite 2 unmodified..........................................

7. Palpus brownish. Postpedicel conical, without dorsoapical extension (Singapore).

C. nigripennis Shamshev \& Grootaert, 2005

- Palpus white. Postpedicel with distinct dorsoapical extension (Malaysia)............. . pasir sp. nov. [The Palaearctic C. luanchuanensis Yang, An \& Gao, 2002 from China (Henan) will also key out here.]

8. Halter with darkened knob (Singapore; Malaysia).

C. malaysiana sp. nov.

- Halter pale

9. Palpus pale yellow (Malaysia)

C. tiomanensis sp. nov.

- Palpus brownish (Singapore).

C. singaporensis Shamshev \& Grootaert, 2005

\section{Chersodromia flavicaput group}

This group could be charactirised in the combination of the following characters (Grootaert et al. 2007): body very pale, almost white; eyes touching on the face, wing with vein $R_{1}$ very short and ending well before middle of wing, $\mathrm{R}_{2+3}$ meeting costa before or near middle of wing, consequently, Rs shorter than in other Chersodromia species. 


\section{Chersodromia bulohensis sp. nov.}

Figs 31-36

\section{Diagnosis}

Occiput pale yellowish in ground-colour; stylus dorsoapical; no distinct vertical bristles; thorax with anepisternum (= mesopleuron) and anepimeron (= pteropleuron) pale brown, katepisternum (= sternopleuron) white; wing with cell br slightly longer than cell bm; hind tibia with only 3 bristles in apical half.

\section{Description}

\section{Male}

LeNGTH. Body $1.4 \mathrm{~mm}$; wing $1.0 \mathrm{~mm}$.

HEAD. (Fig. 31) With occiput dark yellowish in ground-colour; face, gena, palpus and proboscis pale yellow, ocellar tubercle brown; eyes black; with yellowish setation. Frons broadly triangular; in front view as wide as pedicel. Eyes almost touching on face; ommatidia enlarged anteriorly and on lower half of eye. Face linear. Ocellars long, as long as postpedicel. Occiput concave above neck; verticals reduced, not prominent, probably two pairs of minute bristles present. Gena broad. Antenna uniformly yellow; pedicel with long ventral seta; postpedicel about as long as pedicel, with rather long slender dorsoapical extension; stylus dorsoapical, at least 4.0 times as long as basal antennomeres combined. Palpus small, white, fusiform with longer pale subapical seta and some setulae.

ThORAX. Pale yellow in ground-colour; mesonotum with faint pattern: anterior third with brown median vitta connected near middle with broad brown area at each side, leaving postpronotal lobes, sides of notopleural and prescutellar depressions yellow; pleura with anepisternum and anepimeron yellow, katepisternum and meron (= hypopleuron) almost white; setation yellowish. Postpronotal lobe with 1 long inclinate bristle. Mesonotum with 1 short presutural supra-alar, 2 notopleurals, 1 postsutural supraalar, 1 postalar and 4 scutellars (apical pair long, lateral pair minute); acrostichals reduced, 3 setulae on one line; 3 long dorsocentrals.

Legs. Pale yellow. Fore femur thickened; with row of short brown posteroventral bristles and long ventral bristles near base. Fore tibia with distinct ventral subapical bristle. Mid femur half as stout as fore femur, with long pale ventral bristle near base and strong brown anterior subapical bristle. Mid tibia with some spinule-like setae on apical half and long posteroventral subapical bristle. Hind femur stouter than mid femur, with very long fine basal ventral bristle. Hind tibia (Fig. 33) with 3 brown bristles slightly longer than wdith of tibia (1 anterodorsal, 1 dorsal and 1 anterodorsal preapical).

WiNG. (Fig. 32) Normally developed, faintly yellowish tinged, with largely pale brown veins, $\mathrm{R}_{2+3}$ darker. Costal bristle rather short, brown. Vein Rs rather long, nearly 2.0 times as long as crossvein bm-cu. $\mathrm{R}_{2+3}$ very short, only slightly longer than distal portion of $\mathrm{R}_{1}$ (between $\mathrm{Rs}$ and meeting point with costa), meeting costa before middle of wing. $\mathrm{M}_{1+2}$ curving anteriorly just before ending near wing tip. Crossvein bm-cu strongly oblique. Crossvein $\mathrm{r}-\mathrm{m}$ slightly beyond cell $\mathrm{bm}$. Anal vein absent. Calypter minute. Halter with dusky knob.

ABDomen. Yellowish white, with short pale setation; no gland-like structures.

Terminalia. Elongate (Figs 34-36), largely yellow, hypandrium brown. Cerci with unmodified setation. Epandrium completely divided. Right epandrial lamella with strong apical seta. Right surstylus not prominent. Left epandrial lamella fused with hypandrium, bearing several short setae apically. Left surstylus consisting of 2 lobes; lower lobe short, elongate oval, with several short, unmodified setae; 

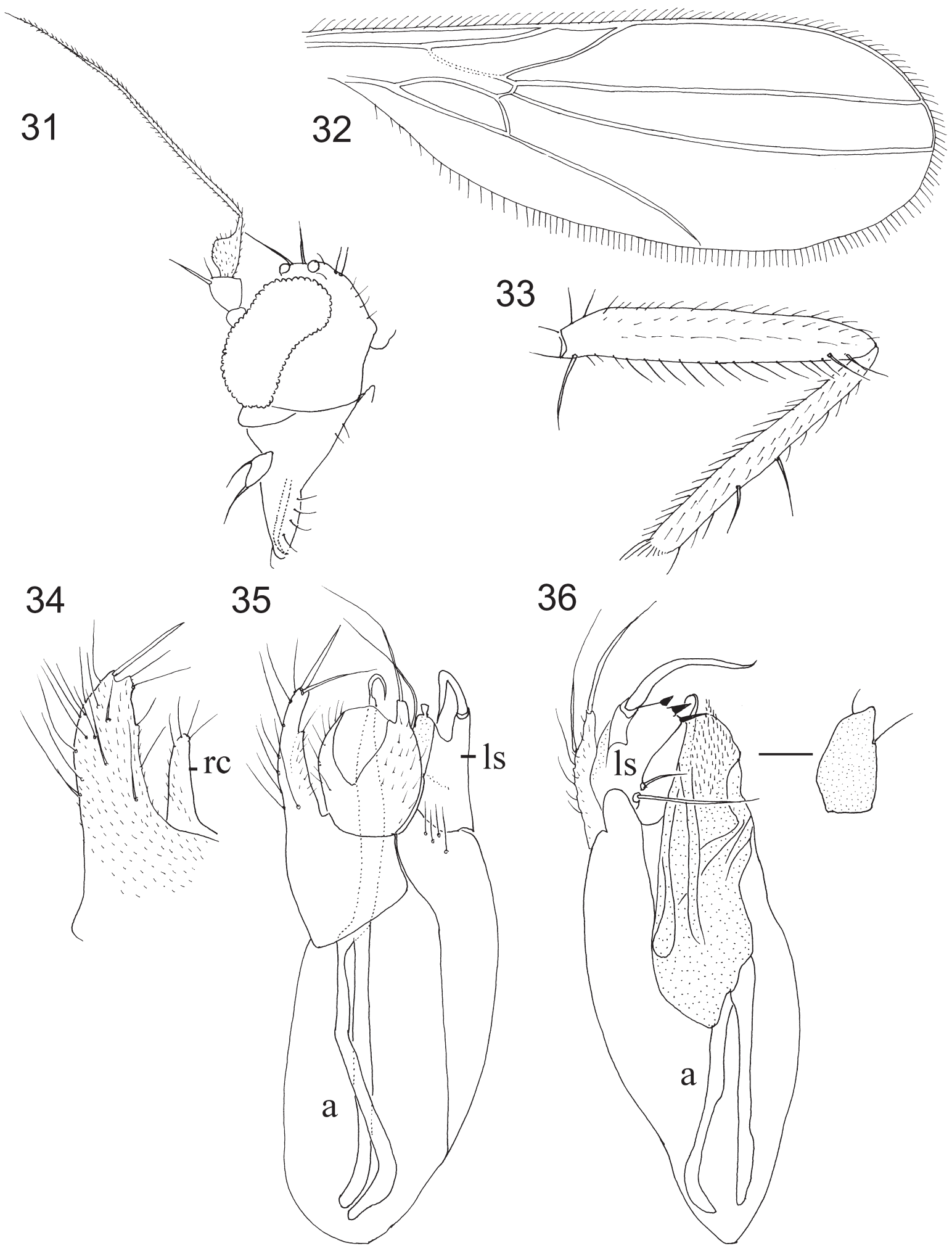

Figs 31-36. Chersodromia bulohensis sp. nov., §. 31. head, lateral view. 32. wing, dorsal view. 33. hind femur and tibia, anterior view. 34. right epandrial lamella, lateral view. 35. epandrium with cerci, dorsal view. 36. hypandrium with detail of left surstylus, ventral view. 
upper lobe bearing 3 apical spines and 1 long seta near middle mounted on tubercle (Fig. 36). Phallus short. Two rod-shaped apodemes present.

Female

Unknown.

\section{Material examined}

Holotype ${ }^{\lambda}$

SINGAPORE: Sungei Buloh, 9 December 2002, sweep netting along border of mangrove (reg. 22057, leg. P.G.; in ZRC).

\section{Etymology}

The name refers to the type locality Sungei Buloh.

\section{Distribution}

Singapore.

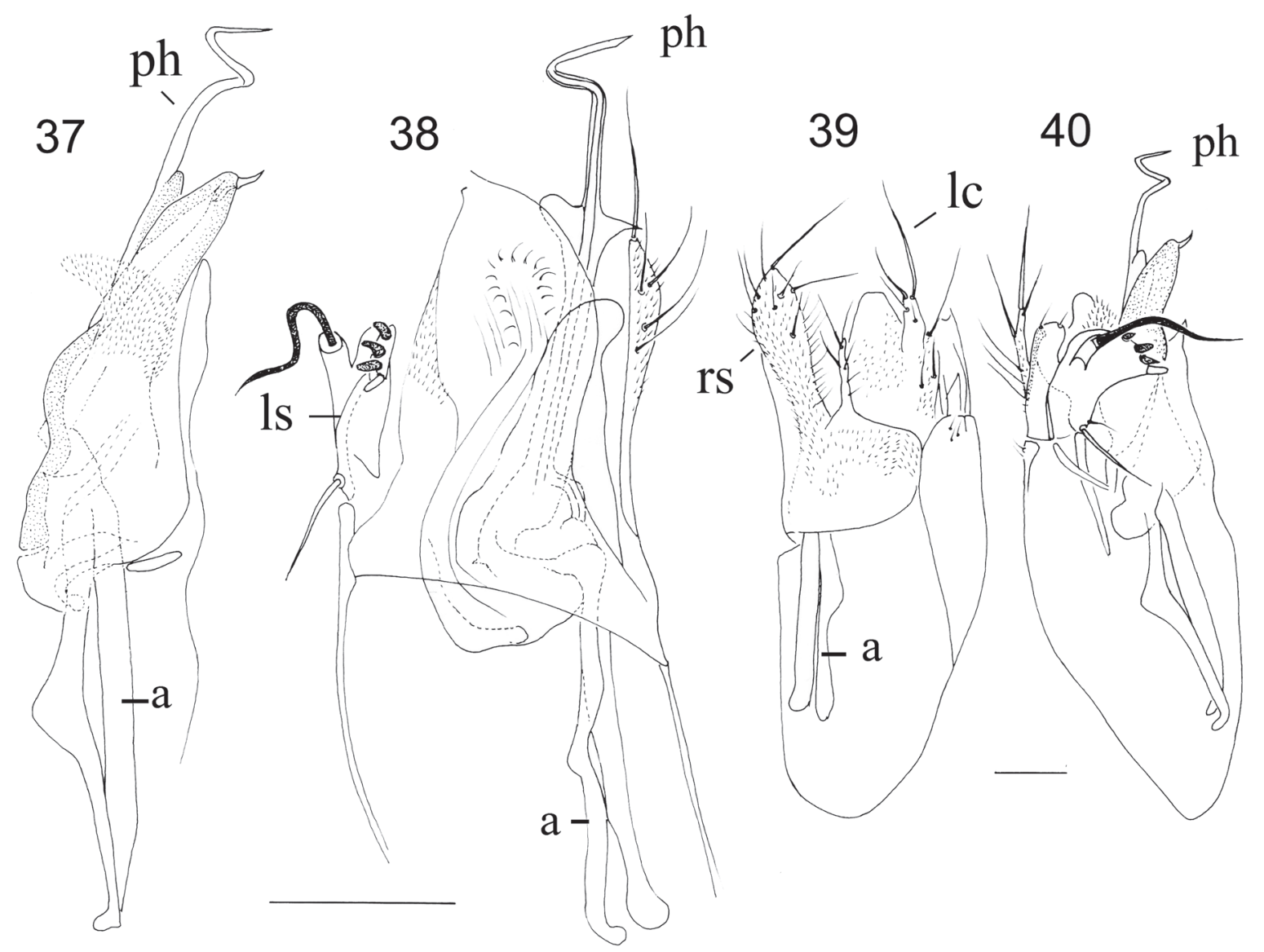

Figs 37-40. Chersodromia flavicaput Grootaert, Cumming \& Shamshev, 2007, ô terminalia. 37. hypandrium with phallus, ventral view. 38. tip of hypandrium, ventral view. 39. epandrium with cerci, dorsal view. 40. left epandrial lamella and hypandrium, lateral view. Scale bars $=0.1 \mathrm{~mm}$ (after Grootaert et al. 2007). 


\section{Habitat and seasonal occurrence}

This species was collected on the edge of mangroves with a single record in early December.

\section{Remarks}

Chersodromia bulohensis sp. nov. belongs to the species groups with a faint pattern on the scutum and a strong curved seta on the left dorsal surstylus. Additionally, the spines on the left surstylus are stronger than in C. flavicaput Grootaert, Cumming \& Shamshev (Figs 37-40), the cerci are larger, and the hind tibia bears 3 long bristles.

Chersodromia flavicaput Grootaert, Cumming \& Shamshev, 2007

Figs $37-40$

Chersodromia flavicaput Grootaert, Cumming \& Shamshev, 2007: 56.

\section{Diagnosis}

Pale yellow species belonging to the $C$. flavicaput group. Occiput pale yellowish, almost white. No distinct vertical bristles. Three pairs of acrostichals. Hind tibia with 5 long bristles in apical half.

\section{Distribution}

Papua New Guinea, Thailand.

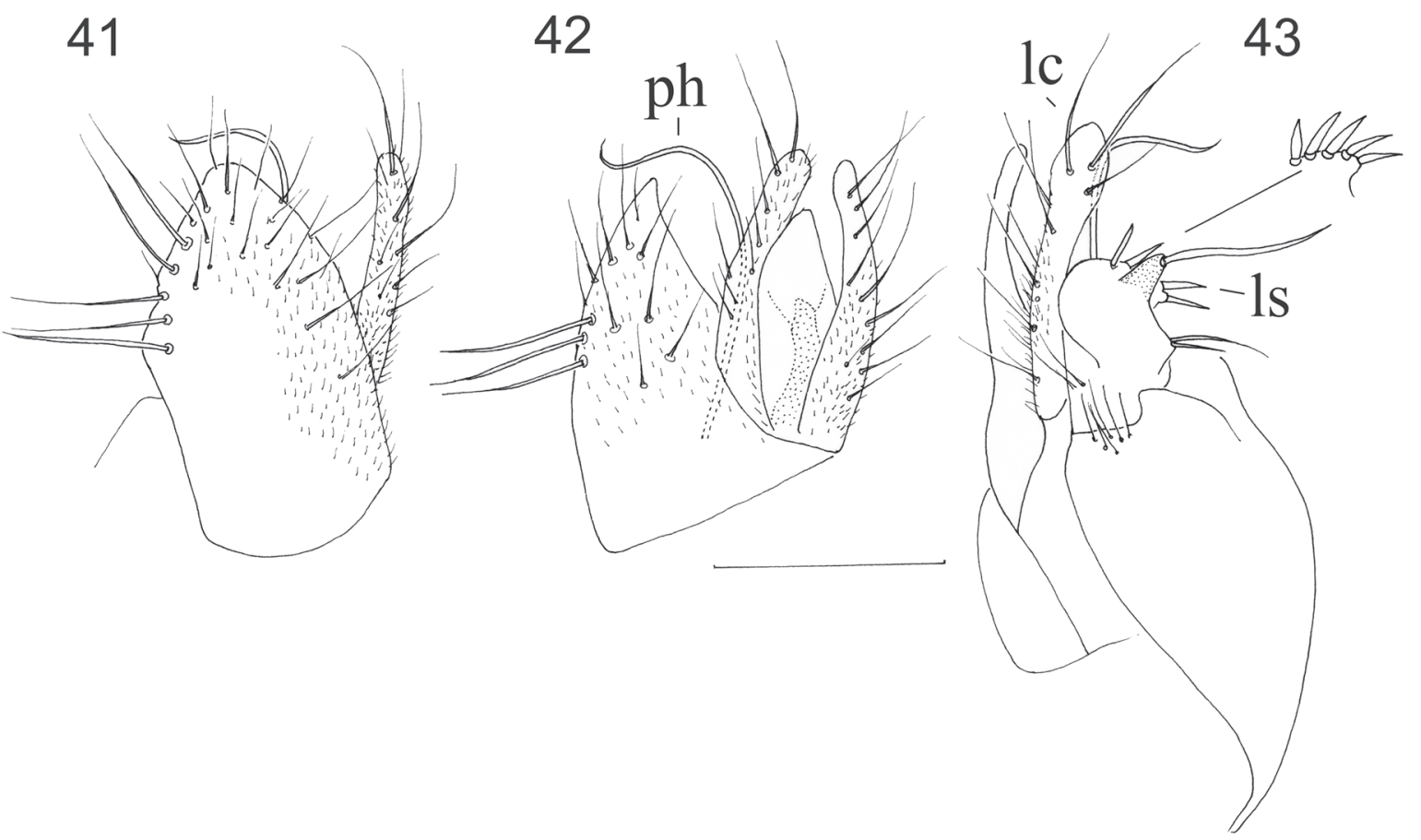

Figs 41-43. Chersodromia obscura Grootaert, Cumming \& Shamshev, 2007, ठ terminalia. 41. right epandrial lamella, lateral view. 42. epandrium with cerci, dorsal view. 43. left epandrial lamella fused to hypandrium with detail of surstylus. $\mathrm{lc}=$ left cercus, $1 \mathrm{~s}=$ left surstylus, $\mathrm{ph}=$ phallus. Scale bar $=0.1$ mm (after Grootaert et al. 2007). 


\section{Habitat and seasonal occurrence}

Rain forest, April-June.

\section{Remarks}

See under C. obscura.

Chersodromia obscura Grootaert, Cumming \& Shamshev, 2007

Figs 41-43

Chersodromia obscura Grootaert, Cumming \& Shamshev, 2007: 59.

\section{Diagnosis}

Pale yellow species belonging to the $C$. flavicaput group. Occiput dark yellowish in ground-colour. One pair of distinct vertical bristles. No acrostichals. Hind tibia with only 3 long bristles on apical half.

\section{Distribution}

Thailand.

\section{Habitat and seasonal occurrence}

River banks in bamboo forest, April.

\section{Remarks}

Chersodromia obscura differs from C. flavicaput in having only 3 long bristles on the hind tibia while the latter has 5 bristles. In addition C. obscura has a pair of distinct vertical bristles, no acrostichals, stronger male cerci, longer spines on left surstylus, and tip of phallus is less coiled.

\section{Chersodromia sylvicola sp. nov.}

Figs 44-51

\section{Diagnosis}

Occiput pale yellowish; 1 pair of strong verticals longer than ocellars; antennal stylus apical, postpedicel fusiform; hind tibia with 4 bristles on apical half.

\section{Description}

\section{Male}

LENGTH. Body $1.2 \mathrm{~mm}$; wing $0.98 \mathrm{~mm}$.

HEAD. Entirely pale-yellowish in ground-colour, almost white, including frons, occiput, ocellar tubercle, face, gena, palpus and proboscis; eyes and ocelli contrastingly black; with pale yellowish setation. Frons broadly triangular, above antennae as wide as pedicel. Eyes contiguous on face; ommatidia enlarged anteriorly and on lower half of eye. Anterior and posterior pair of ocellars long (as long as basal antennal segments combined). One pair of strong verticals, slightly longer than ocellars. Gena narrow. Occiput concave above neck, pale yellowish. Antenna (Fig. 44) yellow, stylus brown; pedicel with long seta ventrally; postpedicel fusiform, as long as pedicel; stylus apical, about 2.5 times as long as basal segments combined. Palpus small, white, with subapical seta and some additional setulae; small round sensory pit present.

THORAx. Pale yellow in ground-colour; mesonotum and pleura uniformly yellowish without colour pattern; with yellowish setation. Postpronotal lobe with 1 long inclinate bristle. Mesonotum with 1 
short presutural supra-alar, 2 notopleurals, 2-3 minute postsutural supra-alars, 1 postalar and 2 apical scutellars (shorter than base of scutellum); acrostichals inconspicuous, 4 pairs almost on one line; 3 long dorsocentrals and 1 short prescutellar.

LEGs. Uniformly pale yellow. Fore femur thickened on basal 3/4; with row of pale posteroventral bristles and 2 long ventral bristles near base. Fore tibia with distinct ventral preapical bristle. Mid femur half as stout as fore femur, with strong brown, anterior preapical bristle. Mid tibia with some spinule-like

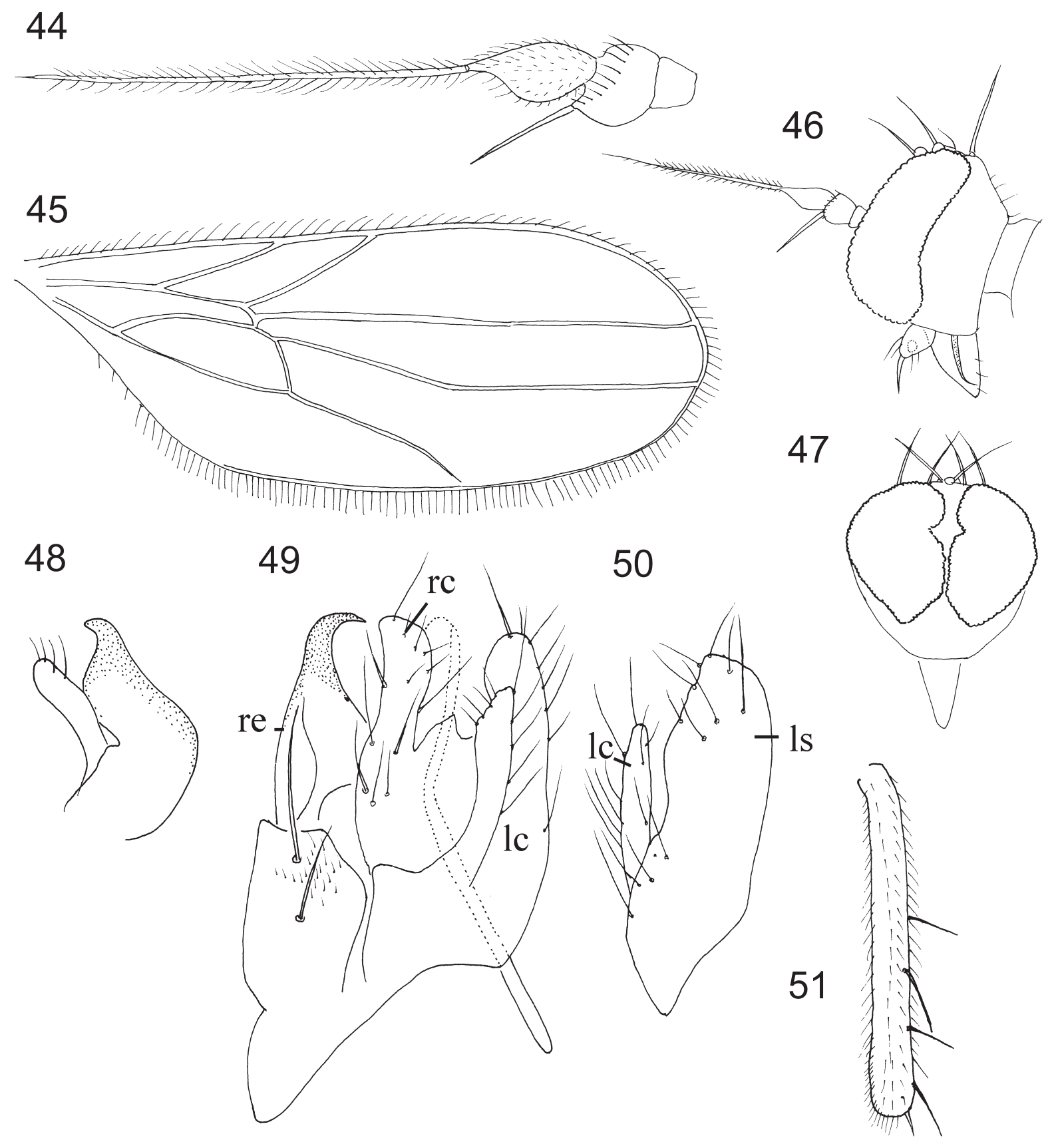

Figs 44-51. Chersodromia sylvicola sp. nov., ô. 44. antenna, lateral view. 45. wing, dorsal view. 46. head, lateral view. 47. head, frontal view. 48. right epandrial lamella, lateral view. 49. epandrium with cerci, dorsal view. 50. left surstylus, lateral view. 51. hind tibia, anterior view. 
setae on apical half and 1 long posteroventral subapical bristle. Hind femur slightly stouter than mid femur, with 1 very long thin ventral bristle near base. Hind tibia (Fig. 51) with 4 long yellowish bristles somewhat longer than width of tibia, with 1 anterodorsal, 2 dorsal and 1 short ventral subapical bristles.

WING. (Fig. 45) Normally developed, faintly yellowish grey tinged, with pale veins. Costal bristle rather short, pale brown. Vein Rs rather long, nearly 1.5 times as long as crossvein bm-cu. $\mathrm{R}_{2+3}$ short, about 2.0 times as long as distal portion of R1 (between Rs and meeting point with costa), meeting costa before middle of wing. $\mathrm{R}_{4+5}$ and $\mathrm{M}_{1+2}$ straight and parallel near wing tip. Crossvein bm-cu strongly oblique. Crossveins r-m and bm-cu separated. Cell br somewhat shorter than cell bm. Anal vein absent. Calypter minute, brown, with 2 brown cilia. Halter with white knob.

AвDOMEn. White, with pale short setation; tergite 1 weakly sclerotised, following tergites normally sclerotised; no intersegmental gland-like structures and squamiform setae. Terminalia (Figs 48-50) elongate. Cerci rather stout, with unmodified setation. Epandrium completely divided. Right epandrial lamella with unmodified setation. Right surstylus bilobed (Fig. 48). Left epandrial lamella fused with hypandrium, with unmodified setation. Left surstylus not prominent. Phallus short, tubiform, ending in fine tip. One rod-shaped apodeme present.

\section{Female}

Unknown.

\section{Material examined}

Holotype $\widehat{\sigma}$

SINGAPORE: Nee Soon, 8 July 2005, Mal. 2 (reg. 25206, leg. P.G.; in ZRC).

\section{Etymology}

The name refers to its occurrence in the forest.

\section{Distribution}

Singapore.

\section{Habitat and seasonal occurrence}

Forest, single record from beginning of July.

\section{Remarks}

Although Chersodromia sylvicola sp. nov. is also a yellow species that we consider belonging to the $C$. flavicaput group, it is quite distinct from the three other known yellow species (C. bulohensis sp. nov., C. flavicaput and C. obscura) that resemble one another very much. The main difference from the latter three species is the presence of one pair of long vertical bristles, only one rod-shaped genitalic apodeme and the absence of a faint colour pattern (darker vitta) on the scutum. 


\section{Non Chersodromia flavicaput group}

\section{Chersodromia glandula sp. nov.}

Figs 52-54

\section{Diagnosis}

Characterized by 2 pairs of vertical bristles; antenna yellow; palpus brownish; thorax brownish; halter pale; legs almost uniformly yellow, only tarsomeres 4 and 5 somewhat brownish; abdominal tergite 2 broadened, thickened posteriorly.

\section{Description}

\section{Male}

LENGTH. Body 1.6-2.1 mm, wing 1.5-1.9 mm.

HeAD. Brownish in ground-colour, with black bristles, greyish pollinose. Frons rather broad, somewhat widened toward ocellar tubercle, in middle nearly 2.5 times as broad as anterior ocellus. Face below antennae somewhat broader than frons, widened in lower part. Eyes rather narrow. Ocellar tubercle and
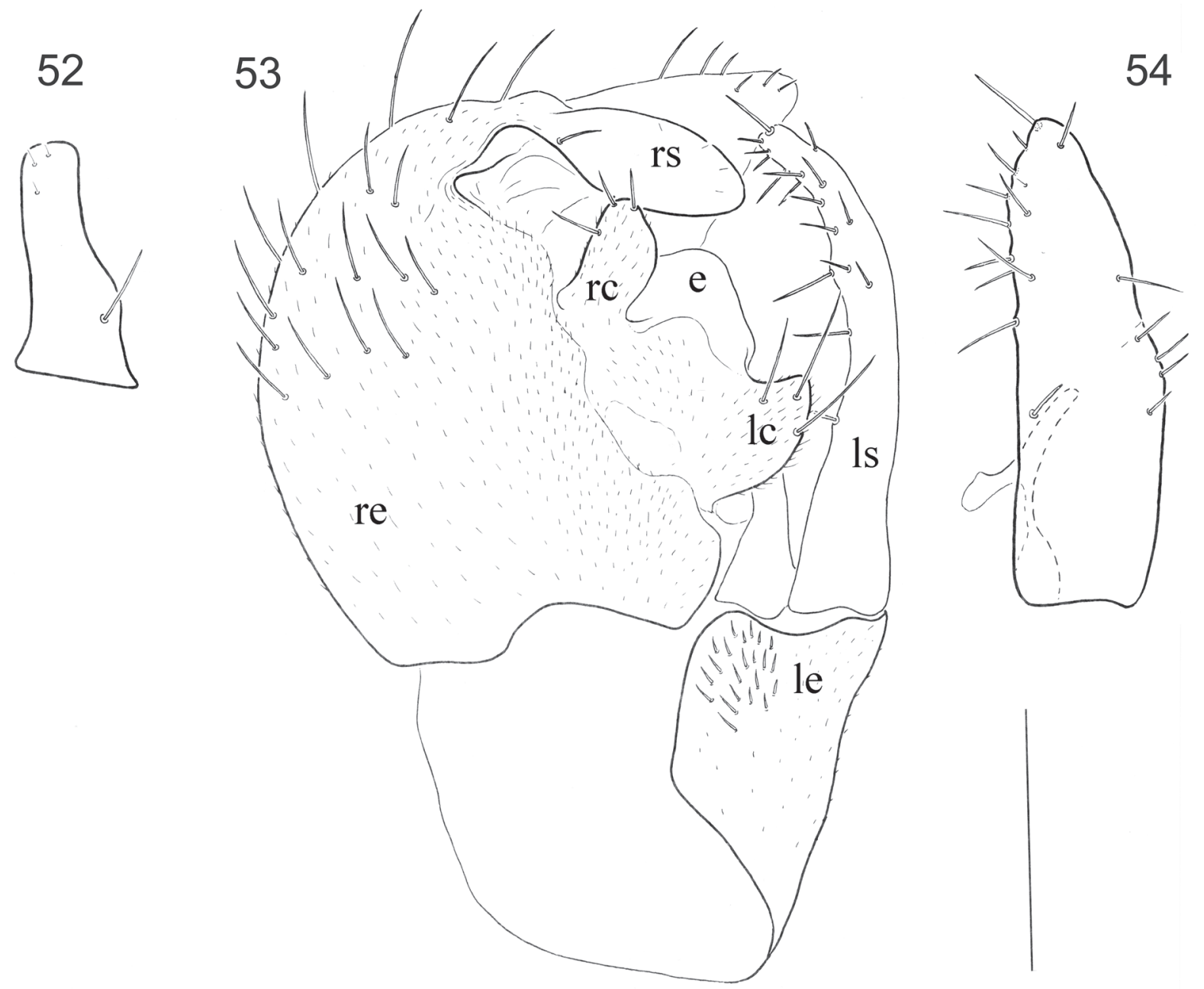

Figs 52-54. Chersodromia glandula sp. nov., ô terminalia. 52. right surstylus, dorsal view. 53. epandrium and cerci, dorsal view. 54. left surstylus, lateral view. Scale bar $=0.1 \mathrm{~mm}$. 
vertex with 2 pairs of equally long bristles. Occiput with 1 row of short postoculars and rather numerous bristles of different lengths. Gena deep, with 3-4 marginal setae. Antenna yellow; postpedicel conical, about 2.5 times longer than wide, with very small dorsoapical extension; stylus nearly 2.0 times as long as postpedicel. Palpus rather small, brownish, elongate oval, with several black setae including 1 long subapical; sensory pit absent.

Thorax. Brownish in ground-colour with sutures darker in varying extent, entirely densely greyish pollinose, with black setation; spiracles brown. Postpronotal bristle long, inclinate. Mesonotum more or less evenly covered with short hair-like setae but main bristles very prominent, including 1 presutural supra-alar, 3-4 notopleurals, 1-2 postalars and 4 scutellars (inner pair cruciate); acrostichals hardly distinguishable from scutal setation, complete, arranged in 2-3 rows on anterior part, becoming more numerous and multiserial toward scutellum, 4 prescutellars longer; dorsocentrals indistinguishable from scutal setation on anterior part, represented by 4 pairs of almost equally long bristles posteriorly, complete; 2 long setae present between mid and hind coxae.

Legs. Almost uniformly yellow, only tarsomeres 4 and 5 somewhat brownish, mostly with black setation. Fore coxa with intermixed pale and black setae of different lengths, latter longer nearer to outer margin of coxa. Fore femur somewhat thickened, with 1 row of short anteroventral and 1 row of similar posteroventral bristles, bearing 1 longer anterior subapical bristle and some setae around tip. Fore tibia spindle-like, bearing 1 moderately long anteroventral and 1 similar posteroventral seta subapically, with 1 short anterodorsal bristle on basal third. Fore tarsus somewhat longer than fore tibia, with tarsomeres 2-5 somewhat dilated, with unmodified setation. Mid coxa with several setae of different lengths including 1 long subapical bristle directed posteriorly. Mid femur slender, with 1 row of posteroventral, moderately long (becoming shorter toward apex of femur) bristles throughout, 1 row of shorter anteroventral bristles, 2 long, thin setae near extreme base, 1 anterior subapical bristle and some prominent setae around apex. Mid tibia with 1 row of anteroventral spinules, 1 short anterodorsal bristle on basal third and circlet of 3 subapical setae. Mid tarsus somewhat dilated, distinctly longer than mid tibia. Hind coxa with brush of several long apical setae directed posteriorly. Hind femur with 1 row of very short (2 subapicals somewhat longer) anteroventral bristles, 1 row of thin posteroventral bristles (somewhat longer in apical half of femur) and 1 anterior subapical bristle. Hind tibia with 3 long anterodorsal, 3 similar dorsal and 2 anteroventral bristles, bearing 2 shorter subapical setae. Hind tarsus slender, somewhat longer than hind tibia.

WING. Normally developed, somewhat milky white, covered with uniform microtrichia, with pale to yellowish veins. Costal vein somewhat thickened meeting with $\mathrm{R}_{1}$, bearing ordinary setulae along anterior margin. One black, moderately long costal bristle present. $\mathrm{R}_{1}$ meeting costa beyond middle of wing. $\mathrm{R}_{4+5}$ and $\mathrm{M}_{1+2}$ parallel and straight in apical part. $\mathrm{A}_{1}$ present, very fine, fold-like. Halter pale.

ABdominal SCLERItes. Mostly pale brown, tergites 1 and 2 somewhat darker, especially on middle part. Tergite 1 narrow, tergite 2 broadened, thickened posteriorly; tergites 1-7 covered with brownish tomentum, bearing dark, short setae concentrated along lateral margins. Sternites covered with brownish setulae. Intersegmental gland-like structures or squamiform setae absent.

TERminALiA. Small, pale brown, subglobular (Figs 52-54). Both cerci unbranched, bearing several long setae, lacking spines. Hypoproct sclerotised, somewhat enlarged. Epandrium completely divided. Left epandrial lamella small, fused to hypandrium, with numerous short setae on apical part. Left surstylus (Fig. 54) consisting of two entirely separated sclerites; upper sclerite rather conical, elongate, with 1 long seta at apex and several other setae of different lengths; lower sclerite hardly prominent, digitiform. Right epandrial lamella very large, convex, clothed in numerous setae, with moderately large ventral lobe bearing several ordinary setae. Right surstylus subrectangular (Fig. 52), rather short, with several 
unmodified setae. Hypandrium with several minute setulae on apical part. Phallus short, two apodemes present (not on drawing).

\section{Female}

Unknown.

\section{Material examined.}

Holotype $\sigma^{A}$

SINGAPORE: Chek Jawa, 15 December 2005, mangrove, sweeping (reg. 25452, leg. P.G.; in ZRC).

Paratypes

SINGAPORE: 1 ð, Pulau Ubin/jetty, 15 December 2005, beach, sweeping (reg. 25451, leg. P.G.).

MALAYSIA: $4 \widehat{\delta} \widehat{\jmath}$, Johor province, Sedili kecil, 12 October 2000, beach, sweeping (reg. 20046, leg. P.G. \& N. Evenhuis).

\section{Sequences in Genbank}

${ }^{7}$, Chek Jawa, 15 December 2005, mangrove, sweeping (reg. 25452, leg. P. Grootaert) quoted in Lim et al. (2009) as Chersodromia sp. Si1330 has been sequenced.

\section{Etymology}

The specific name refers to the modified abdominal tergite 2 .

\section{Distribution}

Malaysia, Singapore.

\section{Habitat and seasonal occurrence}

Found on beach and in mangrove, from October to December.

\section{Remarks}

This species can be readily recognised among other species of Chersodromia due to the modified abdominal tergite 2 which is broadened and thickened posteriorly. Abdominal modifications are quite common among Drapetini (Shamshev et al. 2006; Grootaert \& Shamshev 2009b) but this is the first record for Chersodromia.

\section{Chersodromia malaysiana sp. nov.}

Figs 55-57

\section{Diagnosis}

Small species with one pair of vertical bristles; palpus and proboscis brown; thorax brown; halter with brownish knob; legs brownish yellow.

\section{Description}

\section{Male}

LENGTH. Wing 1.2-1.3 mm.

HEAD. Black. Occiput subshining, finely pollinose. Two long, cruciate vertical bristles present. Frons subshining, slightly broadened toward ocellar tubercle. Anterior and posterior ocellars equally long, former proclinate and cruciate, latter lateroclinate. Antenna brown; pedicel with circlet of subequally 
short setae; postpedicel globular, with long dorsoapical projection; stylus nearly 2.0 times longer than scape, pedicel and postpedicel combined. Gena narrow. Palpus and proboscis brown.

Thorax. Brown. Prothoracic episterna lacking setae above fore coxa. Postpronotal bristle long. Mesonotum with 2 notopleural, 1 postsutural supra-alar, 1 postalar and 4 scutellar bristles (inner pair very long, cruciate; outer pair very short); acrostichals short, biserial; dorsocentrals long, 3 pairs, surrounded by additional setulae.

LEGs. Brownish yellow, mid and hind femora somewhat darker. Coxae and trochanters with unmodified setation. Fore femur somewhat thickened. Fore tibia spindle-like, with several erect setulae. Fore basitarsus with long posteroventral bristle on about middle. Mid femur with row of posteroventral spinule-like setae becoming longer toward base and with 1 anterior subapical bristle. Mid tibia with row of black ventral spinules (1 subapical longer) on apical half and some fine dorsal and anterodorsal setae. Hind femur with 1-2 longer anteroventral subapical and 1 anterior subapical bristles. Hind tibia with short but pointed apical projection; bearing 4 dorsal, 2 anterodorsal and 2 anteroventral bristles of different lengths on apical half. Hind tarsus unmodified.

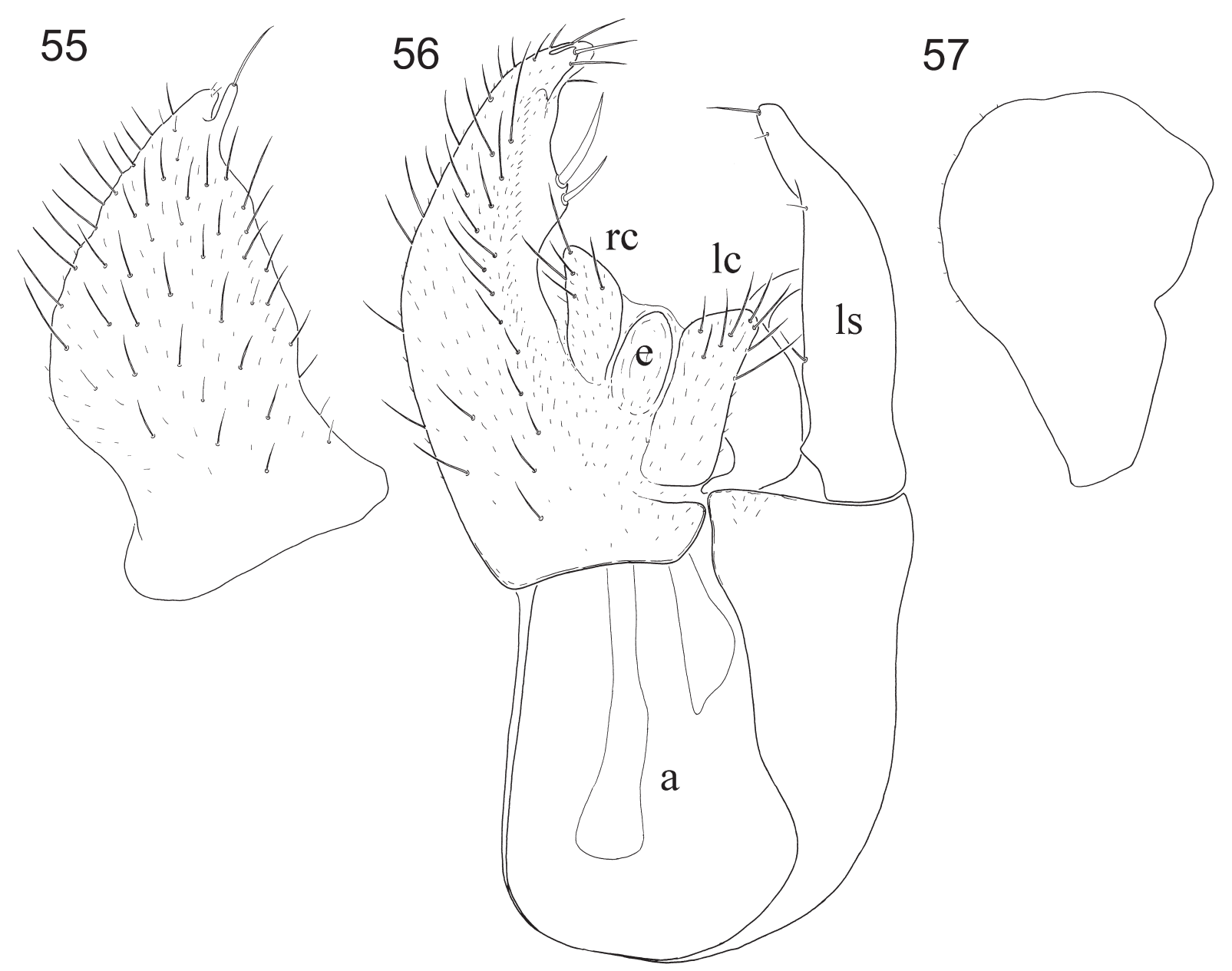

Figs 55-57. Chersodromia malaysiana sp. nov., đ̊ terminalia. 55. right epandrial lamella, lateral view. 56. epandrium and cerci, dorsal view. 57. left surstylus, lateral view. 
WiNG. Normally developed, finely brownish infuscate, covered with uniform microtrichia. Costal vein with short setulae along anterior margin. Costal bristle long, brownish. Costal index: 29/15/25. Vein Rs originating before middle of cell $r_{1}$ (closer to humeral crossvein), long, longer than crossvein bm-cu. $R_{1}$ thickened near costa. $R_{2+3}$ evenly bowed toward costa, almost straight. $R_{4+5}$ and $M_{1+2}$ parallel on apical part. Vein $\mathrm{A}_{1}$ absent. Crossveins bm-cu and r-m contiguous. Crossvein bm-cu oblique. Halter with pale stem and brownish knob.

ABdomen. With tergites weakly sclerotised, unmodified, brownish; with scattered unmodified setulae, tergite 7 with longer posteromarginal setae. Gland-like structures absent.

Terminalia. (Figs 55-57). Cerci broadly separated, short, left cercus somewhat longer than right one, with unmodified setae. Epandrium completely divided. Left epandrial lamella fused to hypandrium, with several short setae on apical part. Left surstylus (Fig. 57) with upper lobe subglobular in upper part, with minute marginal setulae. Right epandrial lamella subtriangular, with short slender process near apex (Fig. 55); covered with numerous unmodified setae of different lengths, bearing 2 rather short spine-like setae on upper margin. Right surstylus not prominent. Hypandrium with several long setae on upper part. Phallus short. Two rod-shaped apodemes present.

\section{Female}

Mid tibia lacking ventral spinules. Cercus elongate oval, brownish. Otherwise as in male.

\section{Material examined}

Holotype $\widehat{\sigma}$

SINGAPORE: Chek Jawa, 22 December 2005, mangrove, Mal 1 (reg. 25455, leg. P.G.; in ZRC).

\section{Paratypes}

SINGAPORE: 1 q, Pulau Ubin/jetty, 15 December 2005, beach, sweeping (reg. 25451, leg. P.G.).

MALAYSIA: 1 ðै, Pulau Tioman, Monkey Bay, 14 July 2005, beach, sweeping (reg. 25216, leg. P.G.).

\section{Etymology}

The specific name refers to the Malaysian Peninsula.

\section{Distribution and seasonal occurrence}

Malaysia, Singapore.

\section{Habitat and seasonal occurrence}

Found on beaches and mangroves from July and December.

\section{Remarks}

This species belongs to the C. cursitans group sensu Chvála (1977). In having a single pair of vertical bristles the new species could be compared with $C$. singaporensis and $C$. tiomanensis sp. nov. However, C. tiomanensis sp. nov. can be readily distinguished from C. malaysiana sp. nov. by its pale yellow palpus. Chersodromia singaporensis has entirely pale halters.

\section{Chersodromia nigripennis Shamshev \& Grootaert, 2005}

Figs 58-62

Chersodromia nigripennis Shamshev \& Grootaert, 2005c: 3. 


\section{Diagnosis}

Rather small species (about $2.0 \mathrm{~mm}$ ) with 2 pairs of vertical bristles; very narrow face; black antennae; conical postpedicel with apical stylus; brownish palpi, halters and legs, and usually deeply infuscate wings.

\section{Material examined}

SINGAPORE: 1 ○, Chek Jawa, 12 September 2005, mangrove, sweeping (reg. 25343, leg. P.G.); 2 우, Chek Jawa, 15 December 2005, mangrove, sweeping (reg. 25452, leg. P.G.); 2 $\lambda \hat{\jmath}, 2$ 우의, Sungei Buloh (SBWR01), 19 May 2009, mangrove, Mal. (reg. 29073, leg. P.G.).

\section{Distribution}

Singapore.

\section{Seasonal occurrence and habitat}

On beaches in front of mangroves; with flight records in March, May, September, and NovemberDecember (most records).
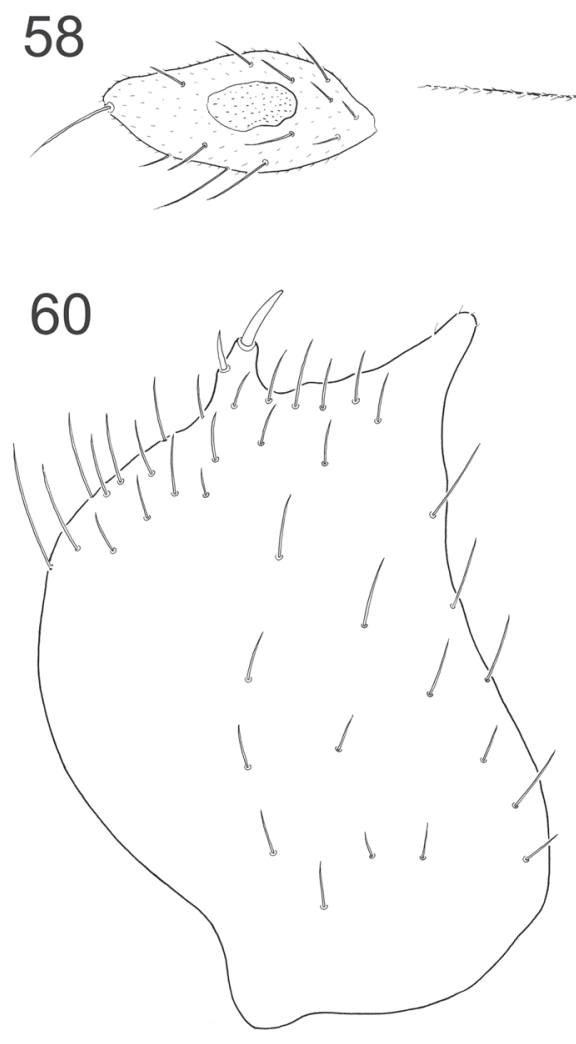
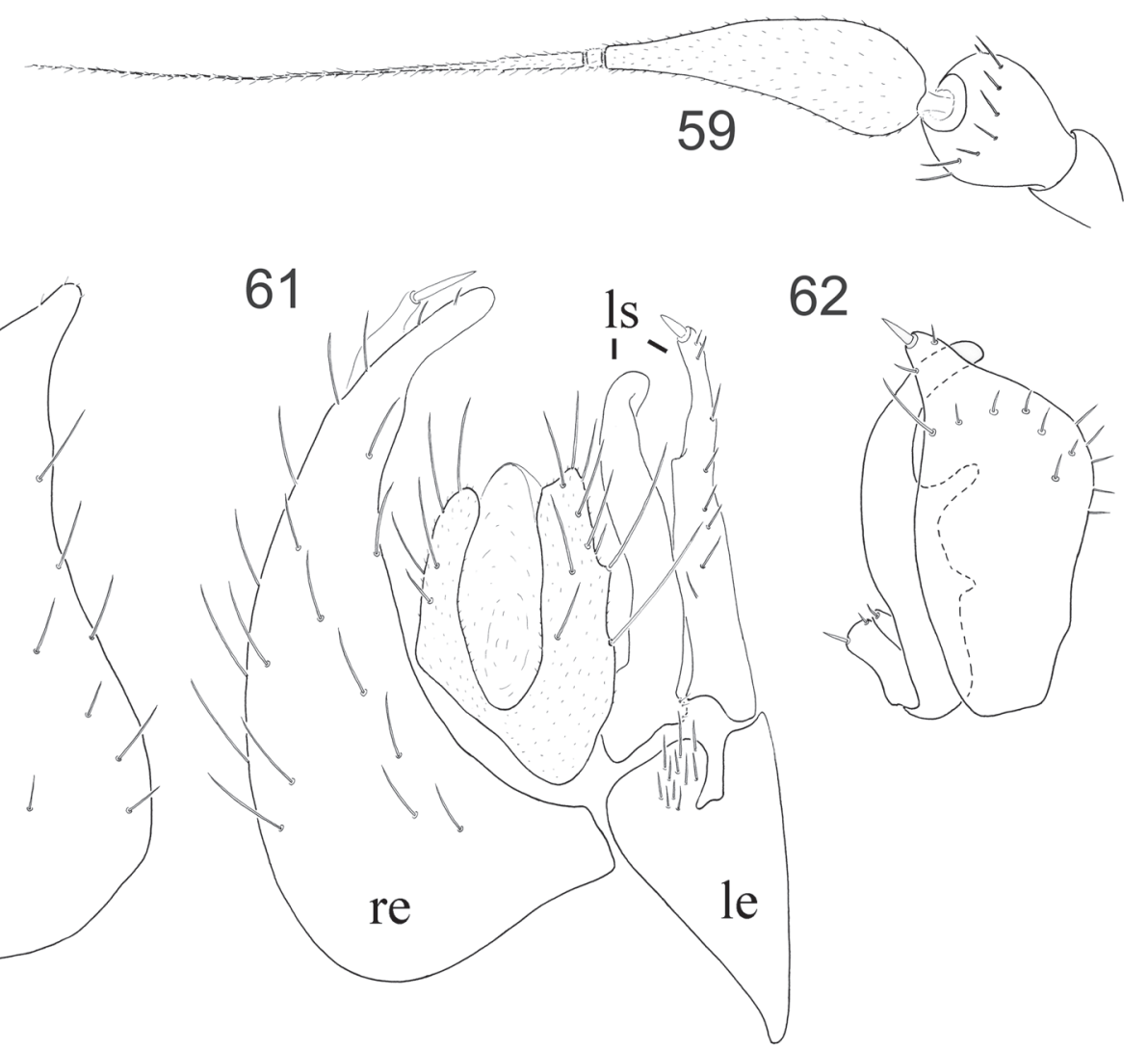

62

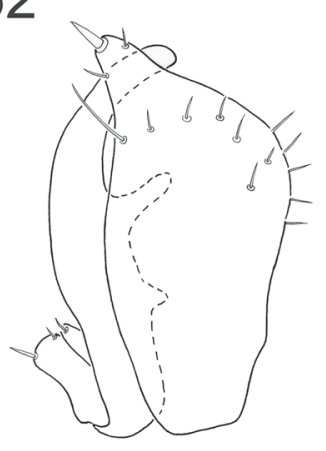

Figs 58-62. Chersodromia nigripennis Shamshev \& Grootaert, 2005, §ิ. 58. palpus, lateral view. 59. antenna, lateral view. 60. right epandrial lamella, lateral view. 61. epandrium and cerci, dorsal view. 62. left surstylus, lateral view. (after Shamshev \& Grootaert 2005). 


\section{Remarks}

This species is likely to show dark-winged (most common) and pale-winged forms. We supposed that the dark wings are a local homochromatic adaptation as a camouflage on a black background. The paler specimens might have an advantage on the white sandy patches (Shamshev \& Grootaert 2005c). Chersodromia nigripennis appears to have an intermediate position between the $C$. incana and $C$. cursitans groups (sensu Chvála, 1977).

\section{Chersodromia pasir sp. nov.}

Figs 63-65

\section{Diagnosis}

Small species with 2 pairs of vertical bristles; postpedicel with distinct dorsoapical extension; palpus white, elongate; legs largely pale brown; halter with brownish yellow knob.

\section{Description}

\section{Male}

Length. Body $1.6 \mathrm{~mm}$, wing $1.5 \mathrm{~mm}$.

HEAD. Largely black in ground-colour, gena brown. Frons greyish pollinose, rather narrow, widened toward ocellar tubercle, in middle nearly 1.5 times as broad as anterior ocellus. Face almost linear, widened in lower part, narrow, in middle nearly 2.5 times narrower than frons. Ocellar tubercle and vertex with 2 pairs of long, black bristles (partly missing). Occiput greyish pollinose, broadly subshining round neck, with some scattered pale setulae longer in lower part. Gena moderately broad. Antenna brown; postpedicel with distinct dorsoapical extension, about 2.0 times longer than wide, stylus nearly 2.0 times as long as postpedicel. Palpus moderately large, white, elongate, with several inconspicuous setae including 1 longer subapical one; sensory pit present.

THORAX. Brownish in ground-colour, entirely finely greyish pollinose, with black setation. Postpronotal bristle long. Mesonotal bristles very prominent, presutural supra-alar lacking, 3 notopleurals (2 longer), 1 postalar and 4 scutellars (inner pair cruciate); acrostichals arranged in 1-2 irregular rows, short, scattered, 2 bristles on prescutellar depression longer; dorsocentrals uniserial, becoming somewhat longer toward scutellum, complete, some additional setulae present on supra-alar space; two long setae present between mid and hind coxae.

Legs. Largely pale brown; mid and hind coxae at apex, fore and mid femora at apex, fore and mid tibiae at extreme base and all tarsi paler. Fore coxa with intermixed pale and dark setae of different lengths, latter longer nearer to outer margin of coxa. Fore femur somewhat thickened, with 1 row of short anteroventral and 1 row of similar posteroventral bristles, bearing 1 longer anterior subapical bristle and some setae around tip. Fore tibia spindle-like, bearing 1 long anteroventral and 1 similar posteroventral bristle on subapical part, with some erect dorsal setulae. Fore tarsus nearly as long as fore tibia, with tarsomeres 2-5 somewhat dilated, clothed mostly in unmodified setulae, tarsomere 1 with some ventral spinule-like setulae. Mid and hind coxae with unmodified setation. Mid femur slender, with hardly prominent rows of anteroventral and posteroventral bristles throughout, bearing 2 long, yellow, thin setae near extreme base, 1 anterior subapical bristle and some prominent setae round apex. Mid tibia with 1 row of anteroventral spinules, 2 anterodorsal bristles and circlet of 3 subapical setae. Mid tarsus distinctly longer than mid tibia, with tarsomeres 2-5 somewhat dilated, clothed mostly in unmodified setulae, tarsomere 1 with some ventral spinule-like setulae. Hind femur with 1 row of very short ( 2 subapicals somewhat longer) anteroventral bristles, 1 row of thin posteroventral bristles (somewhat longer on apical half of femur), some prominent posterodorsal bristles, 3 erect dorsal bristles near extreme base and 1 anterior subapical bristle. Hind tibia somewhat sinuate, narrowed basally, with 
3 anteroventral, 2 anterodorsal, 3 dorsal (concentrated in apical part of tibia) and 2 subapical bristles. Hind tarsus slender, somewhat longer than hind tibia, with unmodified setulae.

Wing. Normally developed, deeply infuscate, covered with uniform microtrichia. Costal vein with moderately long setulae along anterior margin. One long costal bristle present. $\mathrm{R}_{1}$ meeting costa at middle of wing. $\mathrm{R}_{4+5}$ and $\mathrm{M}_{1+2}$ parallel and straight on apical part. $\mathrm{A}_{1}$ present, very fine, fold-like. Halter with brownish yellow knob and pale stem.

AвDOMEN. Unmodified, mostly pale brown and with scattered dark setulae, pregenital segments darker and with longer bristles. Intersegmental gland-like structures or squamiform setae absent.
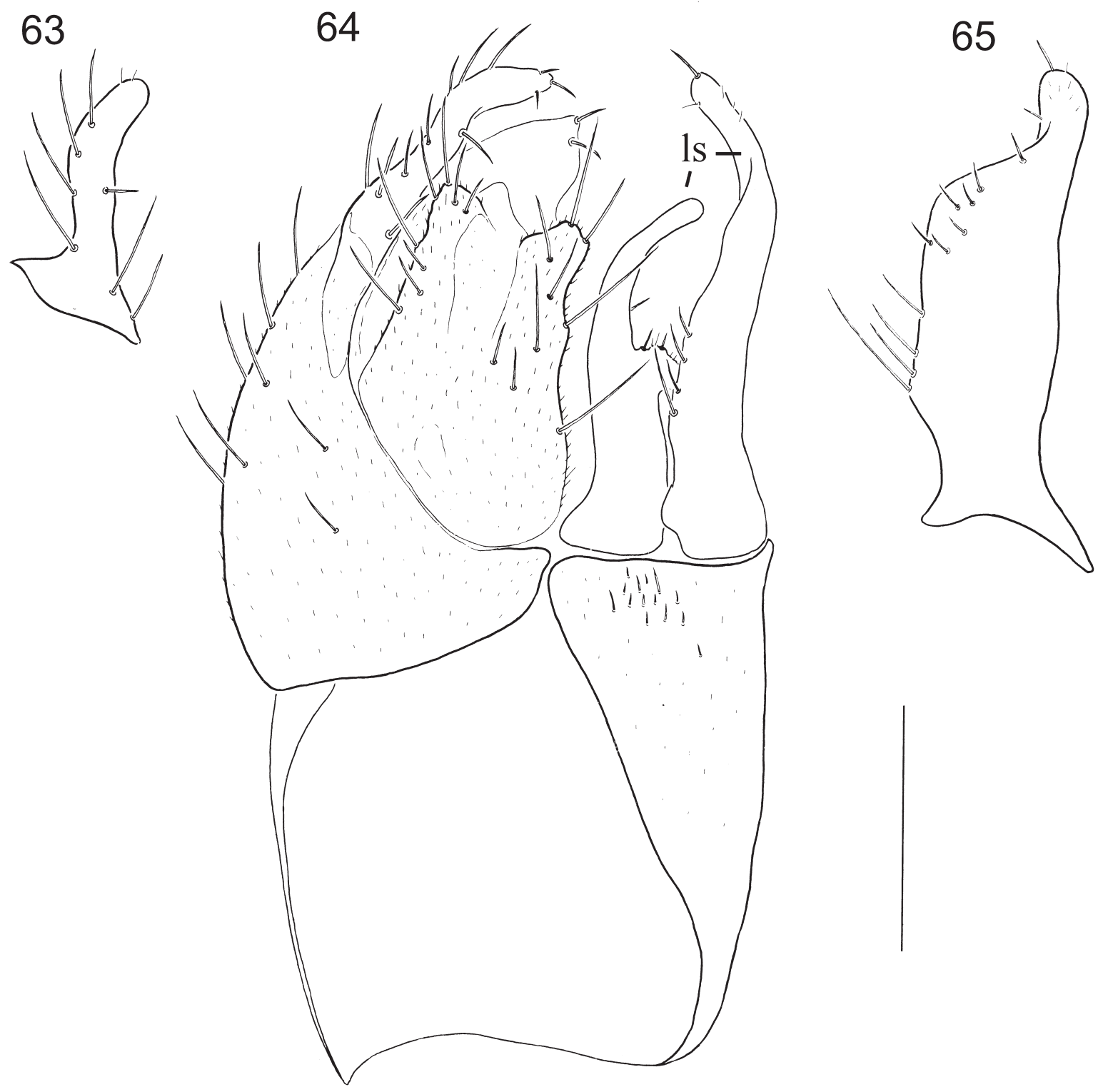

Figs 63-65. Chersodromia pasir sp. nov., $\widehat{\jmath}$ terminalia. 63. right surstylus, dorsal view. 64. epandrium and cerci, dorsal view. 65. left surstylus, lateral view. Scale bar $=0.1 \mathrm{~mm}$. 
Terminalia. Moderately large, brown (Figs 63-65). Both cerci unbranched, bearing several long setae, lacking spines, elongate, of subequal length. Epandrium completely divided. Left epandrial lamella small, fused to hypandrium, with numerous short setae on subapical part. Left surstylus consisting of two entirely separated sclerites; upper sclerite rather subrectangular with narrowed apical part, bearing several setae of different lengths; lower sclerite long, digitiform in apical half, with additional process bearing several short setae. Right epandrial lamella large, convex, clothed in numerous setae, with moderately large ventral lobe bearing several unmodified setae. Right surstylus rather digitiform, short, with several unmodified long setae. Hypandrium with 4 setae of different lengths on subapical part. Phallus short; two apodemes present (not on drawing).

\section{Female}

Unknown.

\section{Material examined}

Holotype $\widehat{\delta}$

MALAYSIA: Johor province, Sedili kecil, 12 October 2000, beach, sweeping (reg. 20046, leg. P.G. \& N. Evenhuis; in ZRC).

\section{Etymology}

The specific name 'pasir' means 'sand' in Malay and Indonesian.

\section{Distribution}

Malaysia.

Seasonal occurrence and habitat. This species is found on beaches in October.

\section{Remarks}

This species is similar to $C$. nigripennis differing primarily from the latter by the elongate white palpi and paired left surstylus.

Chersodromia singaporensis Shamshev \& Grootaert, 2005

Figs 66-69

Chersodromia singaporensis Shamshev \& Grootaert, 2005c: 6.

\section{Diagnosis}

Rather small (about $1.5 \mathrm{~mm}$ ) species with 1 pair of vertical bristles, broad face, brown basal antennal segments, postpedicel having long dorsoapical extension, brownish palpus, katepisternum largely shining, brownish yellow legs, pale halteres and finely infuscate wings.

\section{Material examined}

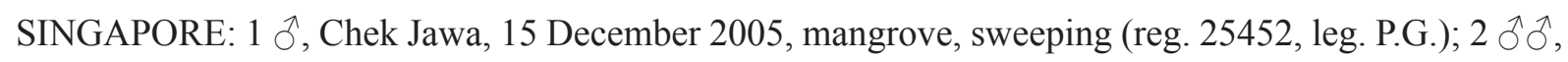
1 , Chek Jawa, 22 December 2005, mangrove, Mal 1 (reg. 25455, leg. P.G.).

\section{Distribution}

Singapore. 


\section{Habitat and seasonal occurrence}

Only found on white sandy beaches or in mangroves with at least sandy patches; rarely in the burrows of Ghost crabs, Ocypode sp. Flight period is from October and December (most records).

\section{Remarks}

This species belongs to the $C$. speculifera group sensu Chvála (1977) but, actually, is closely related to three species of Chersodromia described from Papua New Guinea (Grootaert 1992). All these species differ from $C$. singaporensis by pale yellowish (C. flavipyga Grootaert, 1992) or yellowish-white $(C$. micra Grootaert) to pale whitish (C. nigripyga Grootaert, 1992) palpus and by the lack of a presutural supra-alar (= posthumeral) bristle.

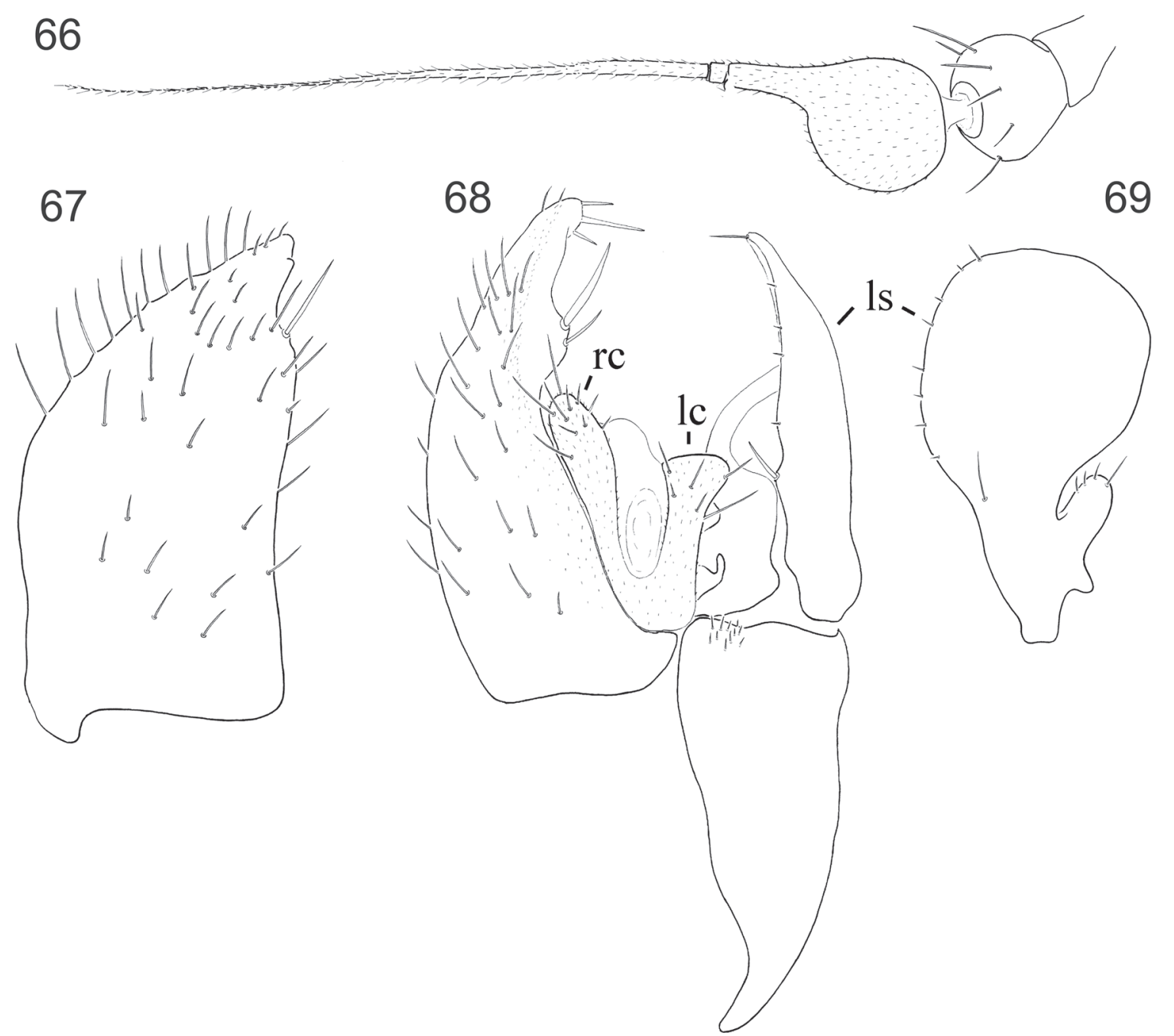

Figs 66-69. Chersodromia singaporensis Shamshev \& Grootaert, 2005, §. 66. antenna, lateral view. 67. right epandrial lamella, lateral view. 68. epandrium and cerci, dorsal view. 69. left surstylus, lateral view. (after Shamshev \& Grootaert 2005). 


\section{Chersodromia tiomanensis sp. nov.}

Figs 70-72

\section{Diagnosis}

Small species with single pair of vertical bristles; palpus pale yellow; scutum brownish yellow on prescutellar depression and anterior corners; legs almost uniformly yellow; halter pale.

\section{Description}

\section{Male}

LeNGTH. Wing 1.2-1.3 mm.

HeAD. Brown. Occiput subshining, finely pollinose. Two long, cruciate vertical bristles present. Frons subshining, slightly broadened toward ocellar tubercle. Anterior and posterior ocellars equally long, former proclinate and cruciate, latter lateroclinate. Antenna brownish (postpedicel somewhat paler); pedicel with circlet subequally short setae; postpedicel with lower margin convex and with short dorsoapical extension, about 2.0 times (1.7-1.8) longer than wide; stylus nearly 3.0 times longer than postpedicel and about 1.5 times longer than scape, pedicel and postpedicel combined. Gena narrow. Palpus pale yellow.

THORAX. With scutum largely brownish leaving brownish yellow spaces on prescutellar depression and on anterior corners; scutellum brownish; pleura yellow to brownish yellow. Prothoracic episterna
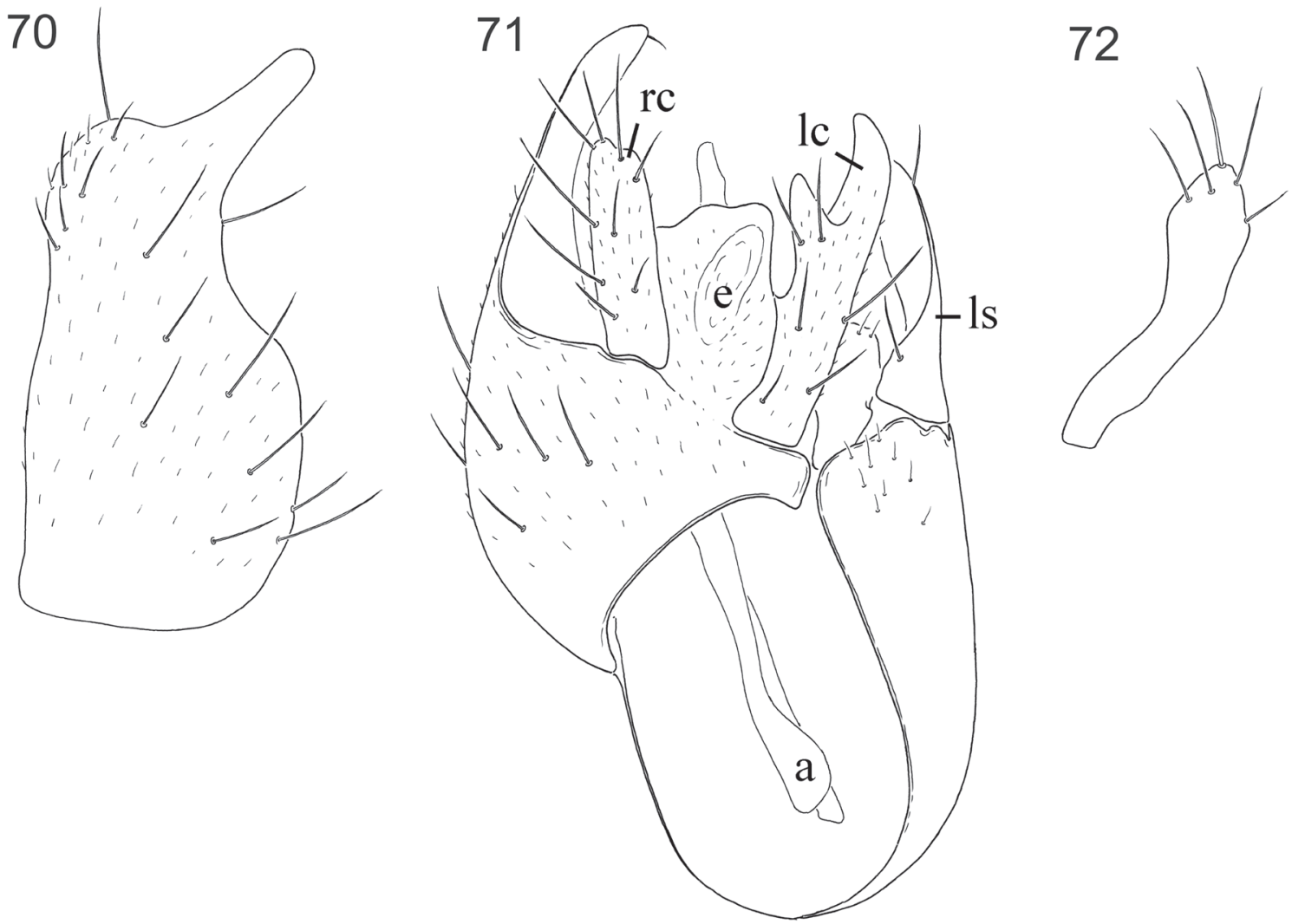

Figs 70-72. Chersodromia tiomanensis sp. nov., đ̂ terminalia. 70. right epandrial lamella, lateral view. 71. epandrium and cerci, dorsal view. 72. left surstylus, lateral view. 
lacking setae above fore coxa. Postpronotal bristle long. Mesonotum with 2 notopleurals, 1 postsuturalsupra-alar, 1 postalar and 4 scutellars (inner pair very long, cruciate; outer pair very short); acrostichals short, biserial; dorsocentrals long, 3 pairs, surrounded by additional setulae.

Legs. Almost uniformly yellow, only tarsomere 5 brownish. Coxae and trochanters with unmodified setation. Fore femur somewhat thickened. Fore tibia spindle-like, with several erect setulae. Fore and mid tarsi with erect setulae. Mid femur with row of posteroventral spinule-like setae becoming longer toward base and with 1 anterior subapical bristle. Mid tibia with row of black ventral spinules (1 subapical longer) and some fine dorsal and anterodorsal setae. Hind femur with 1-2 longer anteroventral subapical and 1 anterior subapical bristles. Hind tibia with short but pointed apical projection; bearing 4 dorsal, 4 anterodorsal, 2-3 anteroventral bristles of different lengths on apical half. Hind tarsus unmodified.

WING. Normally developed, hyaline, covered with uniform microtrichia; veins yellowish to brownish yellow. Costal vein with short setulae along anterior margin. Costal bristle long, brownish. Costal index: $26 / 17 / 23$. Vein Rs originating before middle of cell $r_{1}$ (closer to humeral crossvein), long, longer than crossvein bm-cu. $\mathrm{R}_{2+3}$ almost straight. $\mathrm{R}_{4+5}$ and $\mathrm{M}_{1+2}$ slightly convergent near wing margin. $\mathrm{A}_{1}$ absent. Crossveins bm-cu and r-m contiguous. Crossvein bm-cu oblique. Halter pale.

ABDOMEN. With tergites weakly sclerotised, brownish, with scattered unmodified setulae; tergite 7 with longer posteromarginal setae. Gland-like structures absent.

Terminalia. (Figs 70-72) Cerci broadly separated; left cercus moderately long, branched into two tapered lobes, with several unmodified setae; right cercus moderately long, shorter than left cercus, digitiform, with several unmodified setae. Epandrium completely divided. Left epandrial lamella fused to hypandrium, with several short setae on apical part. Left surstylus with upper lobe short, digitiform, with several long unmodified setae. Right epandrial lamella subtriangular, covered with numerous unmodified setae of different lengths. Right surstylus not prominent. Hypandrium with 3 moderately long, closely set setae. Phallus somewhat elongate. Two rod-shaped apodemes present.

\section{Female}

Mid tibia lacking ventral spinules. Cercus elongate oval, brownish. Otherwise as in male.

\section{Material examined}

Holotype $\curvearrowright$

MALAYSIA: Pulau Tioman, Monkey Bay, 14 July 2005, sandy beach, sweeping (reg. 25216, leg. P.G.; in ZRC).

\section{Paratypes}

MALAYSIA: $1 \hat{\jmath}, 9$, $q$, Pulau Tioman, Monkey Bay, 14 July 2005, beach, sweeping (reg. 25216, leg. P.G.).

\section{Etymology}

The species is named after its type locality, Pulau Tioman.

\section{Distribution}

Malaysia.

\section{Habitat and seasonal occurrence}

This species is found on beaches in July. 


\section{Remarks}

The new species is similar to C. singaporensis and C. malaysiana sp. nov. However, both these species have brownish palpi.

Genus Pontodromia Grootaert, 1994

Pontodromia Grootaert, 1994: 149. Type-species: P. nambis Grootaert, 1994, by original designation.

\section{Recognition}

Pontodromia is recognised from other drapetine genera that occur in the Oriental Region by the following combination of features: eyes contiguous on face; gena narrow; scutum with pair of long presutural dorsocentrals; Rs originating far beyond halfway along $\mathrm{R}_{1}$, nearly as long as crossvein bm-cu; cell br shorter than cell bm; vein $\mathrm{A}_{1}$ absent.

\section{Diagnosis}

Medium-sized (about $2.5 \mathrm{~mm}$ ) brownish flies. Frons broad, with sides divergent above. Eyes contiguous on face, lower ommatidia enlarged. One pair of vertical bristles. Ocellar tubercle with 2 pairs of bristles. Antenna with pedicel bearing long ventral subapical seta; postpedicel with dorsoapical extension; stylus arising dorsoapically, arista-like, long. Gena narrow. Palpus small, with short subapical seta; lacking sensory pit. Postpronotal bristle very prominent. Mesonotal bristles very prominent; 1 pair of long presutural dorsocentrals; no setae between mid and hind coxae. All legs with secondary sexual characters; fore coxa with strong spine-like setae basally and patch of 'sensory' spinules on inner side. Wings normally developed; finely infuscate. Rs short, originating beyond midway of $\mathrm{R}_{1} ; \mathrm{R}_{1}$ meeting costa before middle of wing; $R_{2+3}$ complete, meeting costa beyond middle of wing. $R_{4+5}$ and $M_{1+2}$ parallel near wing margin; $\mathrm{A}_{1}$ absent; crossvein $\mathrm{CuA}_{2}$ absent; crossvein bm-cu oblique; cell br shorter than cell bm. Abdomen with tergites 1-7 unmodified; no squamiform setae; gland-like intersegmental structures absent. Terminalia with epandrium completely divided; left epandrial lamella fused to hypandrium; left surstylus barely differentiated from epandrial lamella, undivided; right surstylus differentiated from epandrial lamella; cerci separated; hypoproct unmodified; hypandrium setose subapically; phallus short; two rod-shaped apodemes (i.e. ejaculatory and ventral apodemes) present. Female similar to male, legs unmodified; terminalia elongate; tergite 8 separated from sternite 8 ; cercus elongate ovate.

\section{Remarks}

The genus Pontodromia includes a single species from Papua New Guinea (Grootaert 1994) and a new species described below which represents a new generic record for the Oriental Region.

\section{Pontodromia pantai sp. nov.}

Figs 73-78

\section{Diagnosis}

Fore tibia at middle with a anterodorsal bristle twice as long as tibia is wide. Left cercus bifurcate with right branch bearing five strong spines.

\section{Description}

Male

LenGth. Wing 1.6-1.7 mm. 

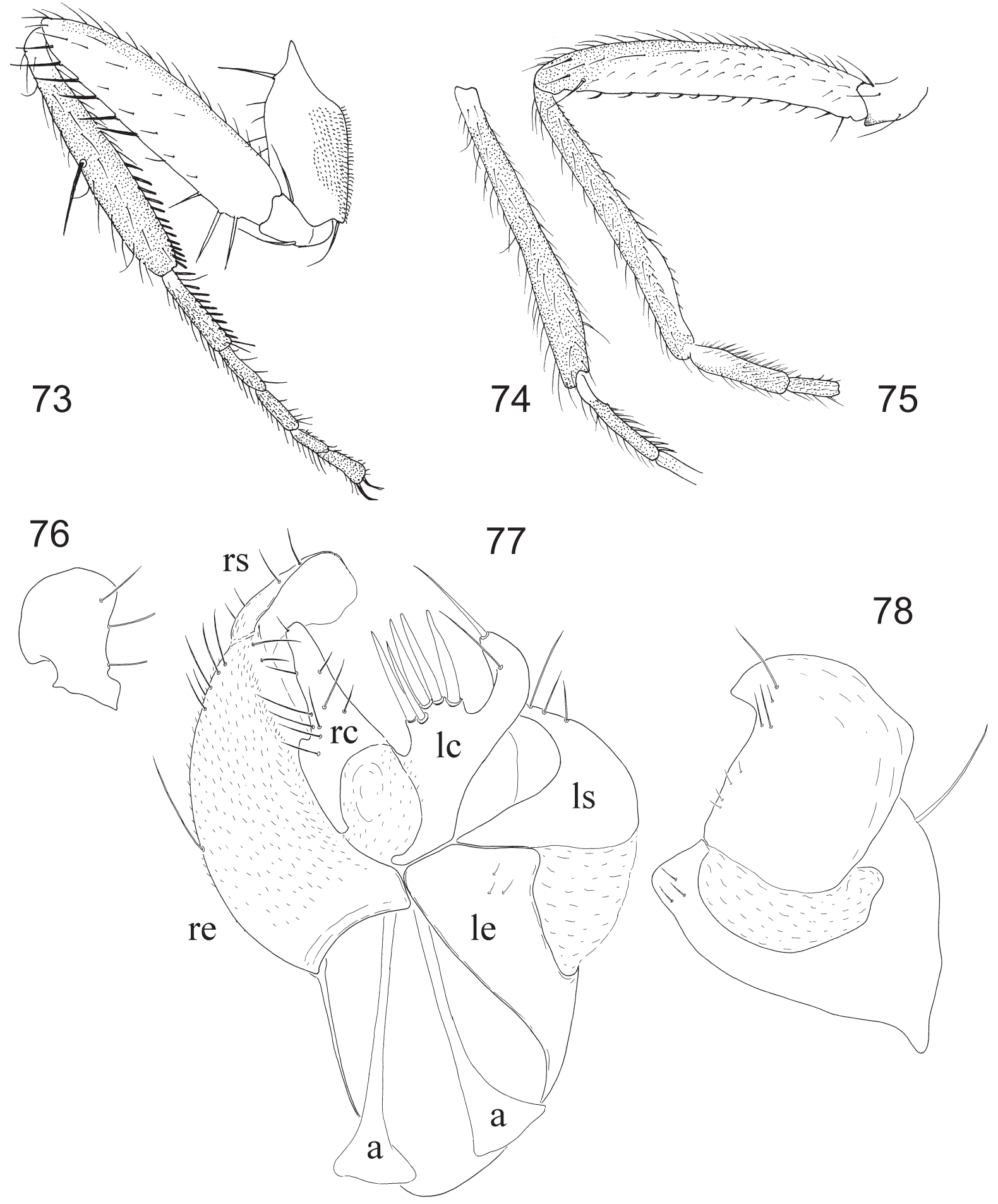

Figs 73-78. Pontodromia pantai sp. nov., Ô. 73. fore leg, anterior view. 74. mid tibia, anterior view. 75. mid leg, posterior view. 76. right surstylus, dorsal view. 77. epandrium and cerci, dorsal view. 78. left surstylus, lateral view. 
HeAd. Black. Occiput subshining, finely pollinose. Two short vertical bristles present. Frons subshining, broadened towards ocellar tubercle. Anterior and posterior ocellars equally very long, black, former proclinate, latter lateroclinate. Antenna brown (postpedicel somewhat paler); pedicel with moderately long lower seta; postpedicel with lower margin somewhat convex, short, nearly 2.0 times longer than wide, with short dorsoapical extension; stylus nearly 4.0 times longer than postpedicel and about 2.0 times as long as scape, pedicel and postpedicel combined. Gena narrow. Palpus brownish yellow, small, rounded, with moderately long, fine seta. Proboscis brownish yellow.

THORAx. Brown, scutum somewhat paler on prescutellar depression. Prothoracic episterna lacking long seta just above fore coxa. Postpronotal bristle long, inclinate. Mesonotum with 1 long presutural supraalar, 2 notopleurals, 1 postsutural supra-alar, 1 postalar and 2 cruciate scutellars; acrostichals very short, arranged in 2 close rows; dorsocentrals short, uniserial, with 1 long median and 1 similar prescutellar pairs.

Legs. With fore tarsus, mid and hind femora in apical part and mid and hind tibiae and tarsi brownish, otherwise brownish yellow to yellow. Fore coxa with strong bristle at base. Fore femur (Fig. 73) swollen, thicker than mid femur, on apical half with long posteroventral bristles, ventrally at base with 3 strong, pale bristles. Fore tibia swollen, at middle with 1 anterodorsal bristle twice as long as width of tibia. Mid femur ventrally with minute bristles, except for pair of more prominent bristles at base. Mid tibia with anteroventral excavation on apical third (Fig. 75). Tarsomere 1 somewhat flattened at base, further densely haired. Hind femur dorsally flattened from base to tip; at base rim of flattened area bears some distinctly erect bristles. Hind tarsomere 1 long and slender, nearly as long as following tarsomeres together.

WING. Normally developed, brownish infuscate, covered with uniform microtrichia. Costal vein with rather long setulae along anterior margin. Costal bristle long, brownish. Costal index: 33/19/36. Vein Rs originating far beyond middle of cell $r_{1}$, short, somewhat shorter than crossvein bm-cu. $\mathrm{R}_{1}$ thickened. $\mathrm{R}_{2+3}$ almost straight. $\mathrm{R}_{4+5}$ and $\mathrm{M}_{1+2}$ divergent on middle part of wing but parallel near wing margin. $\mathrm{A}_{1}$ absent. Crossvein bm-cu strongly oblique. Crossvein r-m far beyond middle of cell bm. Halter brownish.

AbDomen. Tergites weakly sclerotised, unmodified; with inconspicuous unmodified setation. Sternites undivided, subrectangular, brownish. Gland-like structures absent.

Terminalia. (Figs 76-78) Cerci separated, rather short; left cercus divided into 2 lobes, with left lobe digitiform, bearing 1 very long apical seta and 1 subapical seta, right lobe with five long spines. Epandrium completely divided. Left epandrial lamella fused to hypandrium, with 3 setulae in apical part. Left surstylus subrectangular, with several setae of different lengths (Fig. 78). Right epandrial lamella subtriangular; with several unmodified setae of different lengths. Right surstylus very prominent, separated from epandrial lamella, small, as in Fig. 76, with 3 long unmodified setae. Hypandrium with 1 very long seta apically. Phallus short. Two rod-shaped apodemes present.

\section{Female}

Legs unmodified. Abdominal segment 8 very narrow, elongate, with tergite and sternite separated; sternite 8 with apical part somewhat hinged. Cercus elongate oval, brownish. Otherwise as in male.

\section{Material examined}

Holotype $\widehat{\sigma}$

SINGAPORE: Sungei Buloh, 28 March 2005, mangrove, sweeping (reg. 25037, leg. P.G.; in ZRC). 
Paratypes

SINGAPORE: 1 ภ, Sungei Buloh, 27 November 2003, mangrove, sweeping (reg. 23090, leg. P.G.); 7 ふô, 4 우오, Sungei Buloh, 28 March 2005, mangrove, sweeping (reg. 25037, leg. P.G.).

MALAYSIA: 11 ふぇ, 19 우오, Pulau Tioman, Monkey Bay, 14 July 2005, beach, sweeping (reg. 25216, leg. P.G.).

\section{Etymology}

The specific name 'pantai' means 'beach' or 'coast' in Malay.

\section{Distribution}

Malaysia (Johor), Singapore.

\section{Habitat and seasonal occurrence}

This species occurs on sandy beaches and in mangroves. Adults probably occur the entire year, but uncommon in disturbed habitats.

\section{Remarks}

Pontodromia pantai sp. nov. is very similar to the Papua New Guinean species P. nambis. A readily distinguishing character in P. pantai sp. nov. is the male fore tibia with a strong anterodorsal bristle twice as long as width of tibia. Such a bristle is absent in $P$. nambis. The left bifurcate cercus with right branch bearing five strong spines in P. pantai sp. nov., whereas the left branch in $P$. nambis bears only two spines. Additional undescribed species of Pontodromia are known from Thailand and Indonesia.

Genus Crossopalpus Bigot, 1857

Crossopalpus Bigot, 1857: 557, 563. Type-species: Platypalpus ambiguus Macquart, 1827, by monotypy [= ? Crossopalpus flexuosus (Loew, 1840)].

Eudrapetis Melander, 1918: 187 (as subgenus of Drapetis). Type-species: Drapetis spectabilis Melander, 1902 , by original designation.

Therinopsis Vimmer, 1939: 64. Type-species: Therinopsis richardsi Vimmer, 1939, by monotypy [= Crossopalpus humilis (Frey, 1913)].

\section{Recognition}

The genus Crossopalpus can be distinguished from other genera of the Drapetini by the following combination of characters: head close-set upon thorax, gena very broad; anterior ocellars reduced, posterior ocellars long; antennae upturned, pedicel usually with very long seta beneath, postpedicel more or less rounded ventrally; wing with Rs very short, shorter than crossvein bm-cu; abdominal tergites without squamiform setae.

\section{Diagnosis}

Small to medium-sized (1.5-2.5 mm) largely shining black robust flies. Head closely set upon thorax. Frons with sides divergent above. Face very narrow. One pair of vertical bristles. Ocellar tubercle with anterior ocellars reduced, posterior ocellars long. Antennae upturned, pedicel usually with single very long seta beneath, postpedicel more or less rounded ventrally; stylus arising apically, arista-like, long. Gena greatly produced. Palpus varying in size and setation; lacking sensory pit. Thorax largely shining. Postpronotal bristle not prominent. Mesonotal bristles very prominent but usually evenly covered with hair-like setulae; no setae between mid and hind coxae; anepisternum (= mesopleuron) bare. Legs 
short, robust, hind tibia often with prominent bristles and apical projection. Wings normally developed, usually hyaline; Rs short, originating near midway of $\mathrm{R}_{1} ; \mathrm{R}_{1}$ meeting costa at middle of wing; $\mathrm{R}_{2+3}$ complete, meeting costa beyond middle of wing; $\mathrm{R}_{4+5}$ and $\mathrm{M}_{1+2}$ more or less parallel or convergent near wing margin; $\mathrm{A}_{1}$ absent; crossvein $\mathrm{CuA}_{2}$ absent; crossvein bm-cu somewhat oblique or transverse; cell br shorter than cell bm. Abdomen with some tergites modified or unmodified; squamiform setae absent; gland-like intersegmental structures absent or present. Terminalia with epandrium completely divided or undivided; left epandrial lamella fused to hypandrium; left surstylus differentiated from epandrial lamella, divided; right surstylus differentiated from epandrial lamella; cerci separated; epiproct unmodified; hypandrium setose subapically or bare; phallus short; two rod-shaped apodemes (i.e. ejaculatory and ventral apodemes) present. Female similar to male or lacking abdominal modifications; terminalia rather shortened; tergite 8 separated from sternite 8 ; cercus elongate ovate.

\section{Remarks}

Including a new species described in this paper, the world fauna of Crossopalpus includes 83 species, 15 of them are recorded from the Oriental Region. Formally, Crossopalpus is recorded here for the first time from Singapore but in the key given below we also include two species that we believe to likely occur here.

In the Palaearctic Region the species of Crossopalpus inhabit different biotopes occurring in heaps of cut sedge and litter, under dead leaves, in grass tufts, on human or animal dung, on trees and bushes, and on the sandy or swampy banks of lakes and rivers (Chvála 1975). Working in Viet Nam, Tran et al. (2006) found that $C$. hirsutipes Collin is an important predator of the leafminer Liriomyza sativae Blanchard (Diptera: Agromyzidae) in greenhouses.

\section{Key to species of Crossopalpus from Singapore}

1. Abdominal tergite 3 with thickened hind margin. Hind tibia with numerous outstanding pale hair-like setae (2.0-3.0 times as long as tibia is thick), lacking prominent bristles (South India; Cambodia; Viet Nam; Thailand)..................................................... hirsutipes Collin, 1960

- Abdominal tergite 3 unmodified. Hind tibia with short setulae, bearing strong bristles subapically..2

2. Hind tibia with 2 black, short, closely set, subapical bristles. Scutum at least with 3 pairs of moderately long prescutellar dorsocentral bristles (Philippines)..........C. exul (Osten-Saken, 1882)

- Hind tibia with 4 bristles anteriorly near apex (2 black and spine-like). Scutum with 1 pair of long prescutellar dorsocentral bristles (Singapore).

C. temasek sp. nov.

Crossopalpus exul (Osten-Sacken, 1882)

Elaphropeza exul Osten-Sacken, 1882: 113.

Crossopalpus exul Shamshev \& Grootaert, 2007: 162.

\section{Diagnosis}

Antenna and palpus brown; anepisternum largely shining; scutum evenly covered with short pale hairlike setulae; legs almost uniformly dusky yellow.

\section{Re-description}

Female

Length. Body $2.2 \mathrm{~mm}$. 
HeaD. Occiput black, densely greyish pollinose. Ocellar tubercle with 1 pair of short thin bristles. One pair of short vertical bristles present. Antenna entirely brown; pedicel with circlet of subequally short setulae and 1 long seta beneath; postpedicel 1.5 times longer than wide; stylus subapical, normally pubescent, brown, very long, 7.4 times longer than postpedicel. Gena greatly produced. Proboscis brownish yellow. Palpus brown, small, rounded.

THORAX. Uniformly black, with pleura almost entirely shining, large bristles black; katepisternum (= sternopleuron) narrowly along lower margin and suture with meron (= hypopleuron) tomentose, anepisternum (= mesopleuron) and meron with small tomentose patch in lower part, scutellum and metanotum entirely tomentose. Prothoracic episternum with 1 long yellow upturned bristle just above fore coxa. Postpronotal bristle not prominent. Mesonotum with 2 notopleurals, 1 postsutural supra-alar, 1 postalar and 6 scutellars (1 pair long, 2 pairs short thin); scutum evenly covered with short pale hairlike setulae but at least 3 pairs (scutum partly obscured by pin) of moderately long dorsocentral bristles present.

LeGs. (one hind leg missing) Almost uniformly dusky yellow, fore tibia rather brownish yellow. Coxae and trochanters with unmodified setation. Fore femur with inconspicuous setation, finely pubescent ventrally. Fore tibia lacking prominent bristles (except subapicals). Mid femur with 1 anterior subapical bristle, finely pubescent ventrally. Mid tibia lacking prominent bristles (except subapicals). Hind femur with inconspicuous setation, finely pubescent ventrally. Hind tibia with 2 black, short, closely set, subapical bristles; apical projection prominent, subtriangular, elongate, clothed in dense brownish setulae. Hind tarsomere 1 somewhat thickened.

WING. (one wing missing, another partly shrunken) Normally developed, finely uniformly infuscate, covered with uniform microtrichia; veins brownish. Costal vein with short setulae along anterior margin. Costal bristle long, brown. Costal section between $R_{1}$ and $R_{2+3}$ nearly as long as between $R_{2+3}$ and $R_{4+5}$. Vein Rs shorter than crossvein bm-cu. $\mathrm{R}_{2+3}$ meeting costa beyond middle of wing. Crossvein bm-cu oblique. Crossvein r-m somewhat beyond middle of cell bm. Halter pale.

ABDOMEN. Brownish, covered with short, intermixed, pale and dark bristly hairs; apical segments upturned. Cercus brownish.

\section{Male \\ Unknown.}

\section{Material examined}

, Philippinen [hand-written]; 349; Elaphropeza exul O. S. / Type [hand-written by Osten-Saken]; coll. Oldenberg; Holotypus [red]; Typus [dark red, crossed] (Deutsches entomologisches Institut, Müncheberg, Germany).

\section{Distribution}

Philippines.

\section{Habitat and seasonal occurrence}

No data.

\section{Remarks}

Shamshev \& Grootaert (2007) have already indicated that this species actually belongs to the genus Crossopalpus. Here we present a re-description of $C$. exul that is based on examination of the holotype. Currently, this species is known only after the holotype. 
Crossopalpus hirsutipes Collin, 1960

Figs 79-83

Crossopalpus hirsutipes Collin, 1960: 387.

Crossopalpus hirsutipes - Smith 1967: 2 (in key), figs 5, 6 - Pont 1995: 80 (type material) — Shamshev et al. 2006: 232, figs 1-7 (re-description).

\section{Diagnosis}

Antenna with postpedicel black, scape and pedicel brownish yellow. Palpus black. Thorax with anepisternum partly shining; scutum shining, covered with uniform hair-like setulae intermixed with long black bristles. Legs quite variable in colour but coxae entirely and femora almost entirely (except for apical part) black, otherwise legs yellow to brownish yellow in varying extent, lacking prominent bristles (except for circlets of subapical ones); hind femur with anteroventral and anterodorsal hairlike setae as long as femur is thick; hind tibia bearing long, spur-like apical projection, on all sides with numerous outstanding pale hair-like setae (2.0-3.0 times as long as tibia is thick) giving them

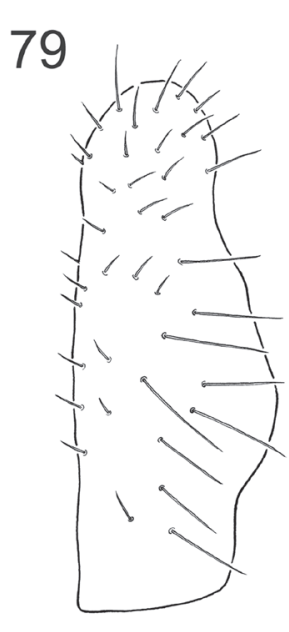

82

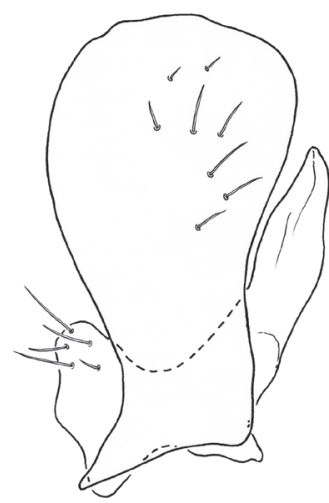

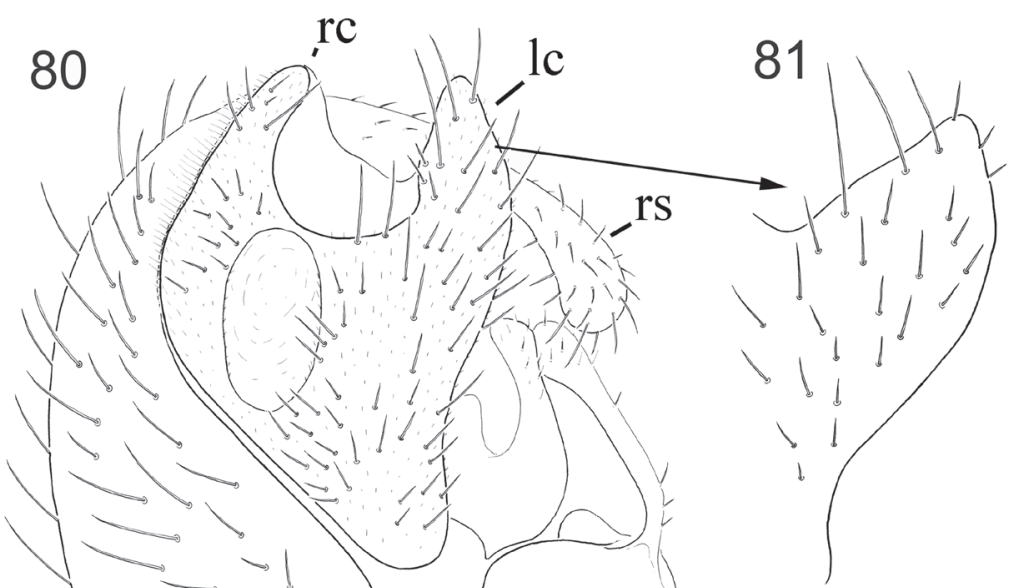

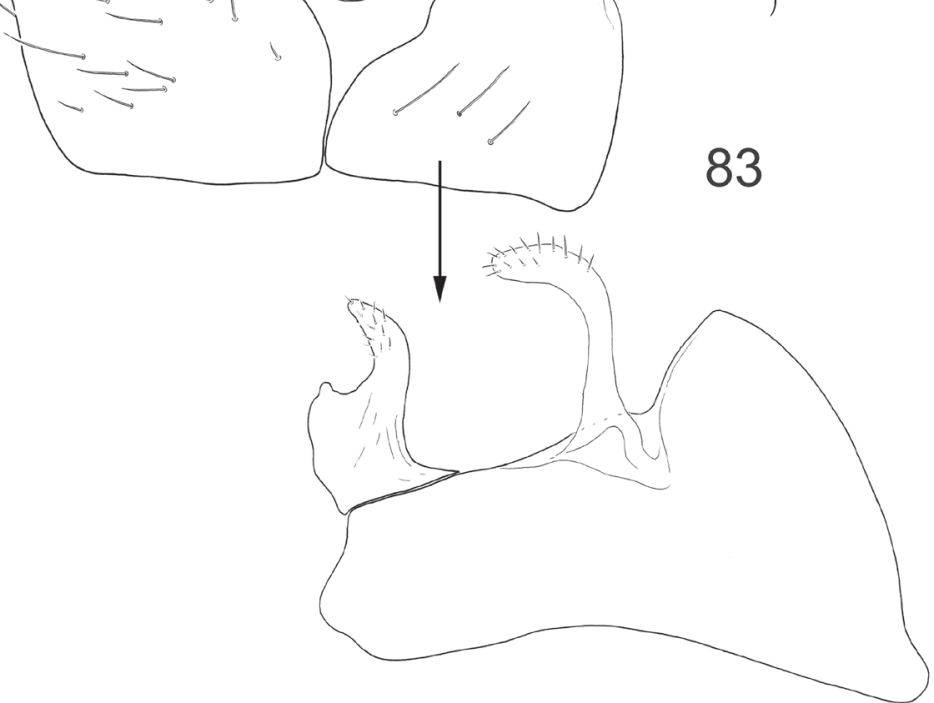

Figs 79-83. Crossopalpus hirsutipes Collin, 1960, § terminalia. 79. right surstylus dorsal view. 80. epandrium and cerci, dorsal view. 81. tip of left cercus, lateral view. 82. lower lobe of right surstylus. 83. left epandrial lamella, lateral view (after Shamshev et al. 2006). 
very shaggy appearance. Wing with $\mathrm{R}_{4+5}$ and $\mathrm{M}_{1+2}$ somewhat sinuate, converging toward wing apex. Abdomen shining, with tergite 3 thickened on hind margin; bearing hairs on last four tergites decidedly longer than length of each tergite. Female resembling male, except for sexual differences.

\section{Distribution}

Cambodia, South India, Thailand, Viet Nam.

\section{Habitat and seasonal occurrence}

In Cambodia this species is recorded in July, August and December.

\section{Remarks}

This species has a wide distribution in the Oriental Region and consequently its occurrence in Singapore is quite possible.

\section{Crossopalpus temasek sp. nov.}

Figs 84-86

\section{Diagnosis}

Species with 2 very short vertical bristles; antenna and palpus brown; legs almost uniformly brownish yellow, hind tarsomere 1 brown; hind tibia with 4 bristles anteriorly near apex; halter yellow; male abdominal tergite 5 narrow.

\section{Description}

\section{Male}

LENGTH. Wing 1.5-1.6 mm.

HeAD. Black. Occiput subshining, finely pollinose. Two very short vertical bristles present. Frons subshining, broadened towards ocellar tubercle. Posterior ocellars black, very long, lateroclinate. Antenna brown; pedicel with long lower seta; postpedicel with lower margin somewhat convex, very short, nearly 1.5 times longer than wide; stylus 6.0-6.5 times longer than postpedicel and 3.0-3.5 times longer than scape, pedicel and postpedicel combined. Palpus brown.

THORAX. Black. Prothoracic episterna with 1 long upturned bristle just above fore coxa and some setulae in upper part. Postpronotal bristle not prominent. Mesonotum with 2 notopleurals, 1 postsutural supraalar, 1 postalar and 4 scutellars (inner pair very long, cruciate; outer pair very short); scutum covered with short, pale, uniform (except for 1 pair of long prescutellars) setulae.

LEGS. Almost uniformly brownish yellow, hind tarsomere 1 brown. Fore coxa with black spinules near apex. Fore femur somewhat thickened. Mid femur with 1 anterior subapical bristle. Fore and mid tibiae with long black anteroventral and posteroventral subapical bristles. Hind femur evenly thickened, with 2 long anteroventral subapical bristles. Hind tibia with elongate, pointed apical projection; bearing 4 bristles anteriorly near apex ( 2 black, spine-like). Hind basitarsus somewhat thickened, with unmodified setation.

WING. Normally developed, finely infuscate, covered with uniform microtrichia. Costal vein with short setulae along anterior margin. Costal bristle moderately long, brownish. Costal index: 34/17/25. Vein Rs originating before middle of cell $\mathrm{rl}$ (closer to humeral crossvein), short, nearly as long as crossvein bm-cu. $\mathrm{R}_{2+3}$ almost straight. $\mathrm{R}_{4+5}$ and $\mathrm{M}_{1+2}$ parallel near wing margin. $\mathrm{R}_{4+5}$ somewhat sinuate. $\mathrm{A}_{1}$ absent. Crossvein bm-cu somewhat oblique. Crossvein $\mathrm{r}-\mathrm{m}$ beyond middle of cell bm. Halter yellow. 
AвDOMEN. With unmodified inconspicuous setation. Tergite 5 narrow, otherwise tergites unmodified. Sternites undivided. Gland-like structure present between tergites 4 and 5 .

Terminalia. Dark brown (Figs 84-86) Cerci (Fig. 85) separated, with unmodified setae; left cercus very large, elongate oval, with additional finger-like process in about middle; right cercus short, bacilliform. Epandrium fused. Left epandrial lamella fused with hypandrium, lacking setae. Left surstylus (Fig. 86) undivided, short, broadened in apical part, with scattered short setae. Right epandrial lamella large, with numerous setae of different lengths. Right surstylus (Fig. 84) divided into 3 lobes, with unmodified setae. Hypandrium lacking setation. Phallus short. Two rod-shaped apodemes present.

\section{Female}

Abdominal tergite 5 unmodified. Gland-like structure lacking. Postabdomen somewhat upturned. Tergite 8 separated from sternite 8 ; sternite 8 membranous in apical part. Cercus elongate oval, brownish. Otherwise as in male.

\section{Material examined}

Holotype $\widehat{\sigma}$

SINGAPORE: Clementi woods, 23 April 2005, drains, sweeping (reg. 25084, leg. P.G.; in ZRC).

\section{Paratypes}

SINGAPORE: 1 §, 1 क , Chek Jawa, 19 November 2003, mangrove, sweeping (reg. 23080, leg. P.G.); 1 \&, Clementi woods, 23 April 2005, drains, sweeping (reg. 25084, leg. P.G.); 1 +, Labrador Park, 3
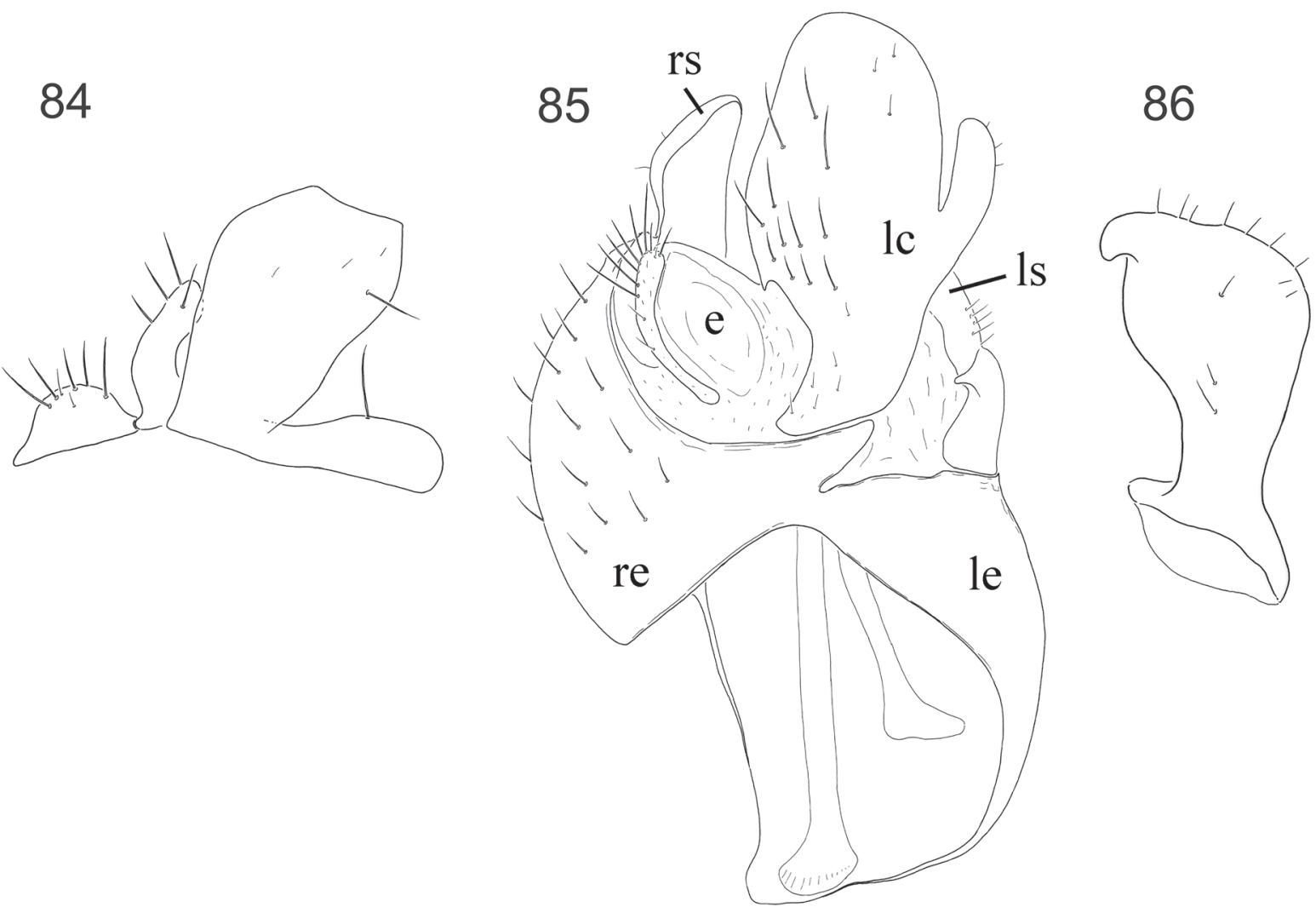

Figs 84-86. Crossopalpus temasek sp. nov., つ̂ terminalia. 84. right surstylus, dorsal view. 85. epandrium and cerci. 86. left surstylus, lateral view. 
April 2005, drains, sweeping (reg. 25043, leg. P.G.); 1 , Sime forest, 22 April 2005, forest, Mal 2 (reg. 25075, leg. P.G.); 1 Ô, Sungei Buloh, 28 March 2005, mangrove, sweeping (reg. 25037, leg. P.G.); 2

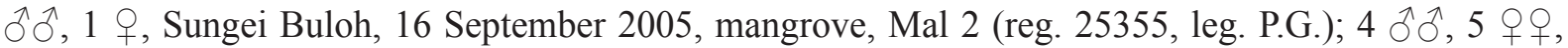

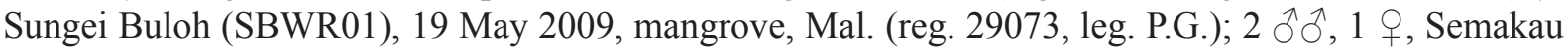
20 May 2009, beach forest, sweeping (reg. 29097, leg. P.G.).

\section{Etymology}

The species is named after the old name for Singapore that was 'temasek' or 'city by the sea'.

\section{Distribution}

Singapore.

\section{Habitat and seasonal occurrence}

This species is found in mangroves and drains, recorded in March, April, September and November.

\section{Remarks}

The new species differs from $C$. exul and C. hirsutipes by the characters given in the key. In addition the hind tibia bears strong subapical bristles resemblingthe ones of $C$. bisetus Yang, Gaimari \& Grootaert, 2004 and C. yunnanensis Yang, Gaimari \& Grootaert, 2004 known from China (Yunnan and Taiwan). However, in C. bisetus veins $\mathrm{R}_{4+5}$ and $\mathrm{M}_{1+2}$ are convergent apically and the hind tibia bears only 2 subapical bristles, and in C. yunnanensis the hind tibia lacks an apical projection.

\section{Genus Drapetis Meigen, 1822}

Drapetis Meigen, 1822: 91. Type-species: D. exilis Meigen, 1822, by monotypy.

Caecula Gistl, 1848: IX. An unnecessary new name for Drapetis. Type-species: Drapetis exilis Meigen, 1822, automatic.

Arbicola Gistl, 1848: 152. An unnecessary new name for Drapetis. Type-species: Drapetis exilis Meigen, 1822, automatic.

\section{Recognition}

The genus Drapetis can be distinguished from other genera of the Drapetini by the following combination of the characters: head close-set upon thorax, gena very narrow, antennae upturned, postpedicel more or less rounded ventrally; wing with Rs long, abdominal tergites with squamiform setae, intersegmental modifications present.

\section{Diagnosis}

Small (about $1.5 \mathrm{~mm}$ ) shining black robust flies. Head closely set upon thorax. Frons with sides divergent above. Eyes contiguous on face. One pair of vertical bristles. Ocellar tubercle with 2 pairs of bristles. Antennae upturned, pedicel with circlet of subequally short setae; postpedicel usually short and rather ovate with lower margin convex; stylus arising apically, arista-like, long. Gena linear. Palpus small, with short subapical seta; lacking sensory pit. Thorax largely shining, anepisternum with small hairs or bristles at least in upper posterior corner or bare. Postpronotal bristle not prominent. Mesonotal bristles very prominent but acrostichals and dorsocentrals undifferentiated; no setae between mid and hind coxae. Legs short, robust, lacking prominent bristles. Wings normally developed; finely infuscate; Rs long, originating before midway of $\mathrm{R}_{1} ; \mathrm{R}_{1}$ meeting costa at middle of wing; $\mathrm{R}_{2+3}$ complete, meeting costa beyond middle of wing; $\mathrm{R}_{4+5}$ and $\mathrm{M}_{1+2}$ more or less parallel near wing margin; $\mathrm{A}_{1}$ present as fold; crossvein $\mathrm{CuA}_{2}$ 
absent; crossvein bm-cu somewhat oblique or transverse; cell br shorter than cell bm. Abdomen with some tergites modified or unmodified; squamiform setae present; gland-like intersegmental structures absent. Terminalia with epandrium completely divided; left epandrial lamella fused to hypandrium; left surstylus differentiated from epandrial lamella, divided; right surstylus differentiated from epandrial lamella; cerci separated; hypoproct unmodified; hypandrium setose subapically or bare; phallus short; usually two rod-shaped apodemes (i.e. ejaculatory and ventral apodemes) present. Female similar to male; terminalia elongate; tergite 8 separated from sternite 8 ; cercus elongate ovate.

\section{Remarks}

Currently, Drapetis includes about 80 species worldwide, with 18 species known from the Oriental Region. In contrast to its sister genus Elaphropeza, Drapetis is not common in Singapore. Locally, however, representatives of this genus can be very abundant and several species coexist. This is particularly true for the mangrove at Chek Jawa where wrack mainly composed of decomposing green algae is washed onto the shoreline and wild boars dig in the sand. At this site we found three species of Drapetis together in large numbers. They were active on sand that was disturbed by the wild boars and that was enriched with pieces of decomposed wrack. Four of the five species of Drapetis that we recorded in Singapore are mangrove species. Drapetis hutan sp. nov. is the single record of a species occurring in rain forest. This would suggest that Drapetis having a mainly Palaearctic distribution, radiated and thrived in mangroves in Southeast Asia and was less successful in rain forests.

\section{Key to species of Drapetis from Singapore}

1. Postpedicel ventrally rounded with dorsoapical stylus (Fig. 105), at most 1.5 times as long as wide. Palpus and proboscis brownish yellow. Halter yellow. Hind femur brownish in apical 2/3, otherwise legs yellow.

D. mandai sp. nov.

- Postpedicel elongate, almost conical, 2.5-3.0 times as long as wide with nearly apical stylus (Fig. 93). Different combination of characters.

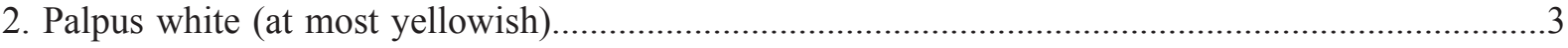

- Palpus black

3. Labrum brown. Hind femur swollen, with row of long pale brown anteroventral bristles on apical quarter.

D. laut sp. nov.

- Labrum white. Hind femur slender, with only 2-3 dark subapical anteroventral bristles.

D. bakau sp. nov.

4. Halter pale. Hind femur yellow in male; hind tibia weakly curved and as long as hind femur, hind tarsomere 1 with 2-3 black ventral spinules at base.

D. pantai sp. nov.

- Halter with dark brown knob. Hind femur completely black; hind tibia strongly curved and much shorter than femur; hind tarsomere 1 without ventral spinules at base.

D. hutan sp. nov.

Drapetis bakau sp. nov.

Figs 87-91, 93

\section{Diagnosis}

Rather small species; antenna yellow; palpus pale yellow; legs yellow. Halter pale.

\section{Description}

Male

LeNGTH. Wing 1.5-1.6 mm. 
HEAD. Black. Occiput subshining, finely pollinose. Two short, yellow vertical bristles present. Frons subshining, broadened towards ocellar tubercle. Anterior ocellars short, yellow; posterior ocellars minute. Antenna (Fig. 88) yellow (in darker specimens with brownish tinge); pedicel with moderately long ventral seta; postpedicel with lower margin somewhat convex, rather long, 2.5-2.8 times longer than wide; stylus nearly 2.0 longer than postpedicel and about 1.3 times longer than scape, pedicel and postpedicel combined. Palpus pale yellow.

Thorax. Brown. Prothoracic episternum with 1 long upturned bristle just above fore coxa and some setulae on upper part. Postpronotal bristle not prominent. Mesonotum with 2 notopleurals, 1 postsutural supra-alar, 1 postalar and 4 scutellars (inner pair very long, cruciate; outer pair very short); scutum entirely covered with short, pale uniform (except for 1 pair of long prescutellars) setulae.
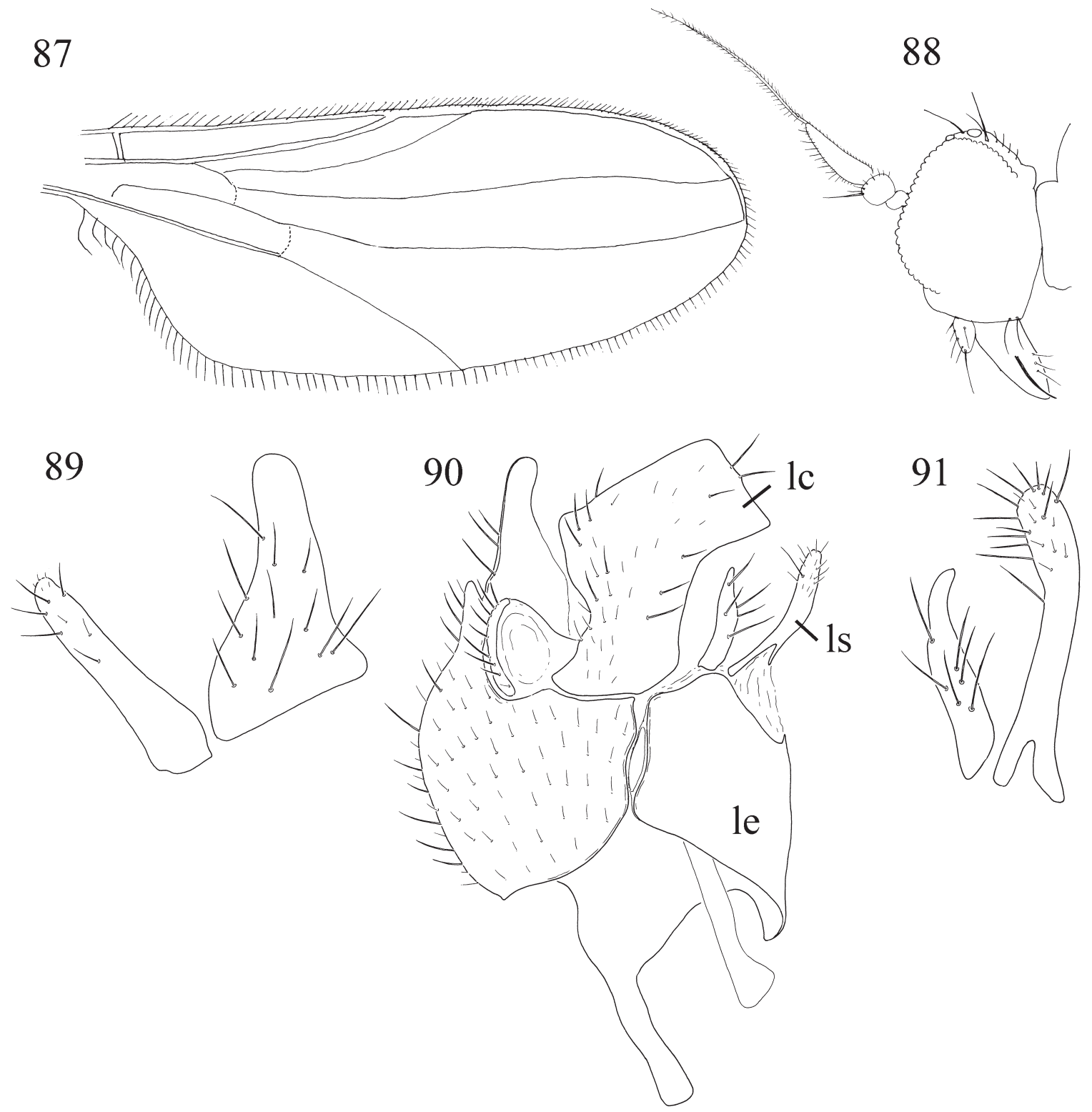

Figs 87-91. Drapetis bakau sp. nov., đ̂. 87. wing, dorsal view. 88. head, lateral view. 89. right surstylus, dorsal view. 90. epandrium and cerci, dorsal view. 91. left surstylus, lateral view. 
LEgS. Including coxae uniformly yellow. Coxae and trochanters with unmodified setation. Fore femur somewhat thickened. Femora and tibiae mostly with inconspicuous setation; mid femur with 1 anterior subapical bristle; hind femur (Fig. 93) with 2 longer anteroventral subapical bristles. Hind tibia with slightly prominent apical projection. Tarsi of all legs unmodified, with ordinary setation.

WING. (Fig. 87) Normally developed, hyaline, covered with uniform microtrichia; veins yellowish to brownish yellow. Costal vein with short setulae along anterior margin. Costal bristle short, brownish. Costal index: 40/9/43. Vein Rs originating before middle of cell rl (closer to humeral crossvein), nearly as long as crossvein bm-cu. $R_{1}$ thickened. $R_{2+3}$ evenly bowed toward costa. $R_{4+5}$ and $M_{1+2}$ convergent in apical part. $\mathrm{A}_{1}$ absent. Crossvein bm-cu somewhat oblique. Crossvein $\mathrm{r}-\mathrm{m}$ beyond middle of cell $\mathrm{bm}$. Halter pale.

AвDOMEN. With tergite 1 pale yellow, tergites 2-7 brownish, rectangular, of subequal width, with scattered setulae, tergites 3 and 4 with squamiform setae laterally; segment 8 brown. Sternites not divided. Glandlike structure present between tergites 3-4 and 4-5.

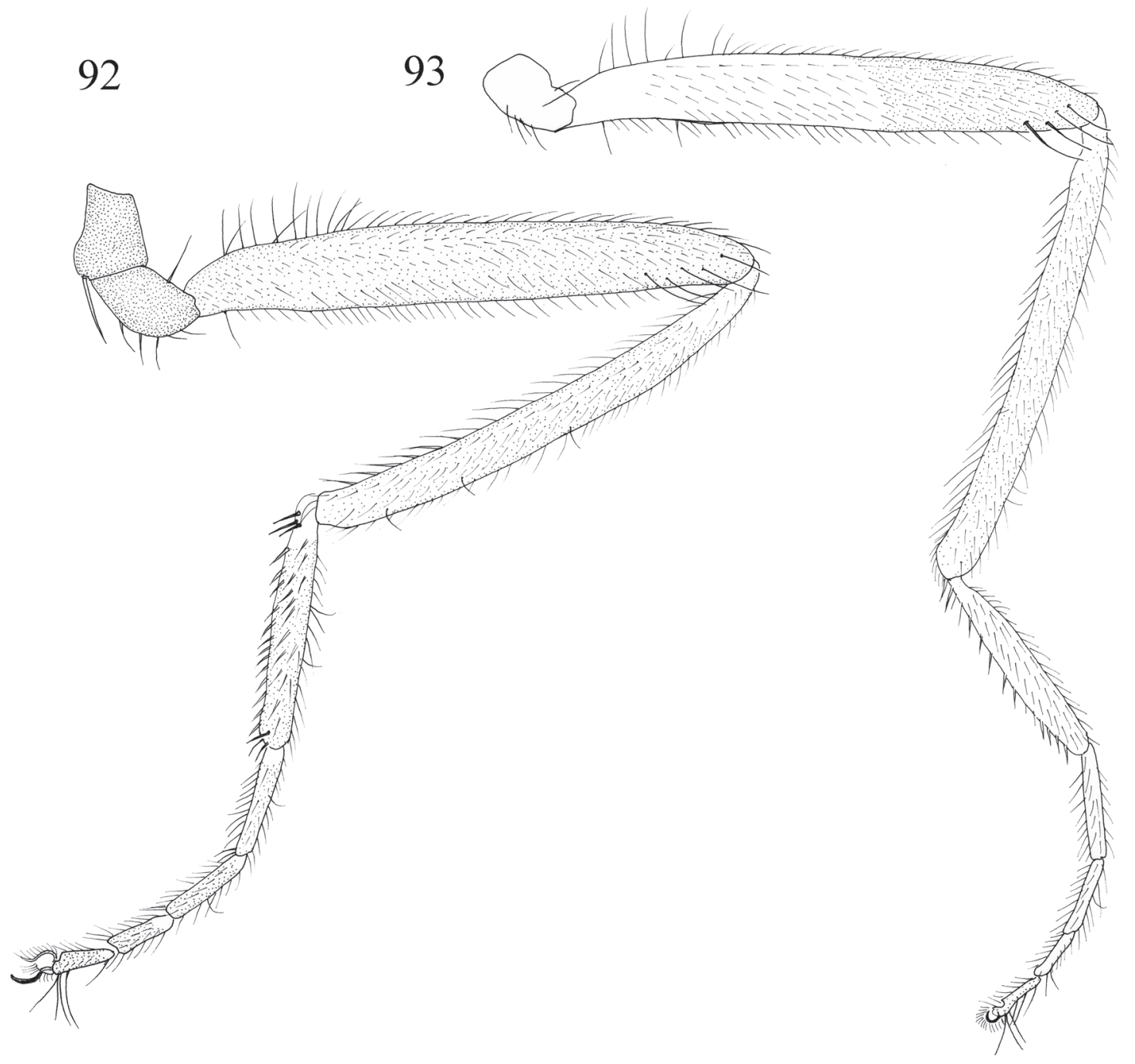

Figs 92-93. Hind leg of Drapetis, $\widehat{O}$, anterior view. 92. D. pantai sp. nov. 93. D. bakau sp. nov. 
Terminalia. Rather large, brown (Figs 89-91). Cerci separated; left cercus broad, subrectangular, bent in middle, with numerous unmodified setae of different lengths; right cercus greatly reduced, represented as narrow, bacilliform sclerite bearing several short setulae. Epandrium completely divided. Left epandrial lamella fused to hypandrium, lacking setae apically. Left surstylus (Fig. 96) bilobed; upper lobe digitiform, with numerous unmodified setae apically; lower lobe somewhat shorter, with several unmodified setae. Right epandrial lamella (Fig. 95) subtriangular, covered with numerous unmodified setae of different lengths. Right surstylus bilobed (Fig. 94); upper lobe digitiform, with several short setae; lower lobe subtriangular, with several unmodified setae. Hypandrium reduced, lacking setation. Phallus short. Two rod-shaped apodemes present.

\section{Female}

Abdominal segment 8 with sclerites separated; sternite 8 brown, with completely separated apical part. Cercus elongate oval, brownish. Otherwise as in male.

\section{Material examined}

Holotype $\widehat{\sigma}$

SINGAPORE: Chek Jawa, 19 November 2003, mangrove, sweeping (reg. 23080, leg. P.G.; in ZRC).

\section{Paratypes}

SINGAPORE: 15 ふึ, 15 우, Chek Jawa, 19 November 2003, mangrove, sweeping (reg. 23080, leg. P.G.); 8 §ð, 5 우, Chek Jawa, 12 September 2005, mangrove, sweeping (reg. 25343, leg. P.G.); 1 ठ, Chek Jawa, 15 December 2005, mangrove, sweeping (reg. 25452, leg. P.G.); 3 $\partial^{\lambda}, 12$ q , Chek Jawa,

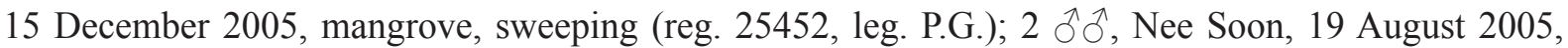
swamp forest, Mal 2 (reg. 25297, leg. P.G.); 1 ठ̊, Sime forest, 1 July 2005, forest, sweeping (reg. 25191, leg. P.G.).

MALAYSIA: 18 ふぇ, 6 우, Pulau Tioman, Juara, 20 July 2005, river, sweeping (reg. 25246, leg. P.G.);

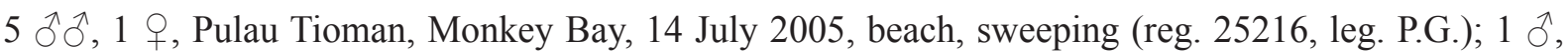

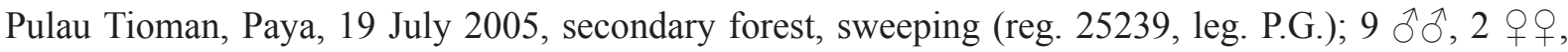
Pulau Tioman, Paya, 19 July 2005, secondary forest, sweeping (reg. 25238, leg. P.G.).

\section{Etymology.}

The specific name 'bakau' means 'mangrove' in Malay.

\section{Distribution}

Malaysia, Singapore.

\section{Habitat and seasonal occurrence}

This species occurs in mangroves, and rarely in terrestrial forest, with records from July, August, September, November and December.

\section{Remarks}

The new species is similar to D. pantai sp. nov. and the main distinguishing features are indicated in the key to species. 
Drapetis hutan sp. nov.

Figs 94-97

\section{Diagnosis}

Small species; antenna brownish; palpus and proboscis brownish yellow; mid femur largely brownish yellow, hind femur dark brown; halter with brownish knob.

\section{Description}

Male

LENGTH. Wing $1.4 \mathrm{~mm}$.

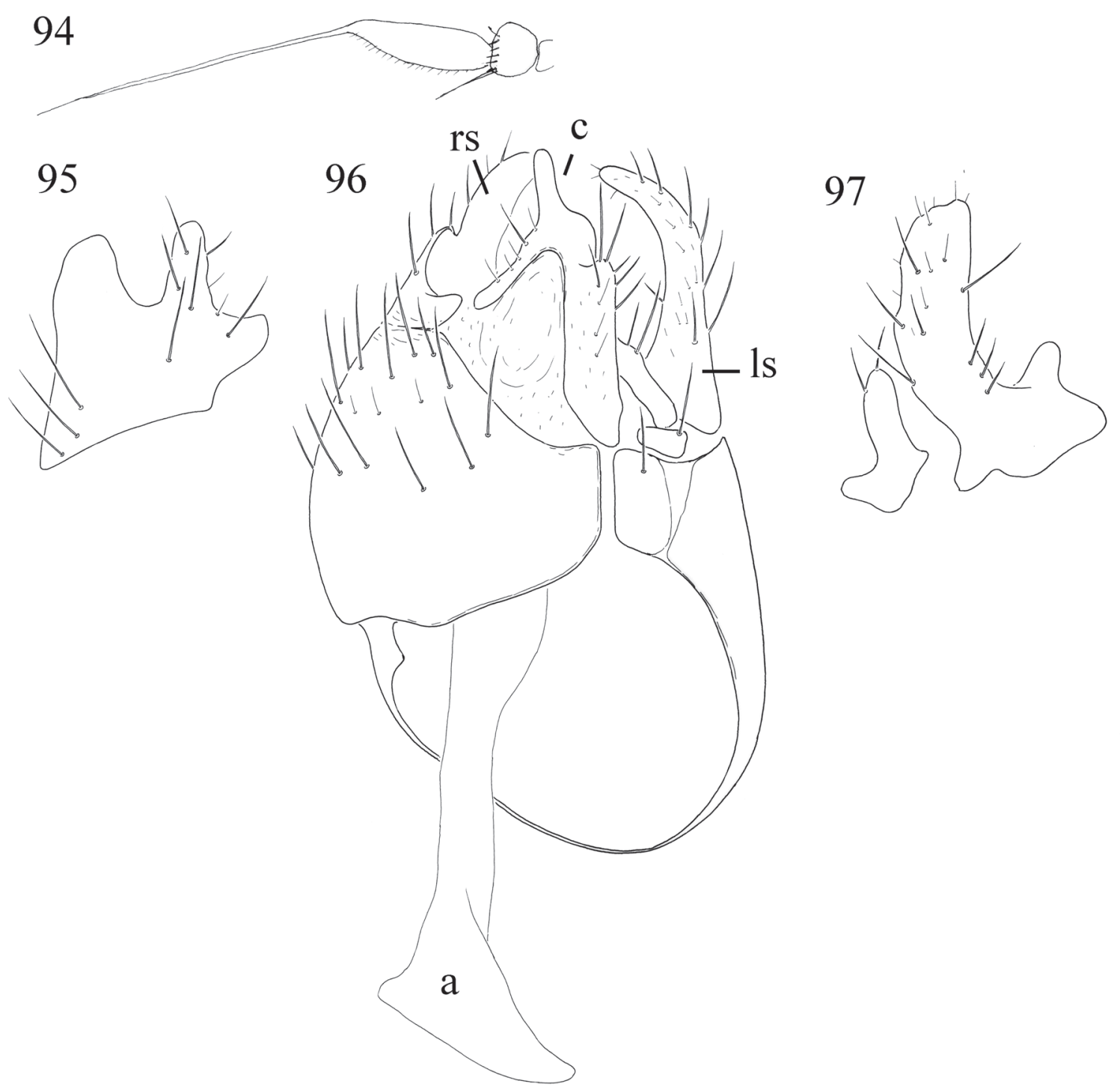

Figs 94-97. Drapetis hutan sp. nov., ðึ. 94. antenna, lateral view. 95. right surstylus, dorsal view. 96. epandrium and cerci. 97. left surstylus, lateral view. 
HEAD. Black. Occiput subshining, finely pollinose. Two pairs of vertical bristles present (inner longer). Frons subshining, strongly broadened towards ocellar tubercle, very narrow above antennae, narrower than anterior ocellus. Anterior ocellars very short, inclinate; posterior ocellars long, lateroclinate. Antenna (Fig. 94) brownish (postpedicel somewhat paler); pedicel with short lower seta; postpedicel with lower margin somewhat convex, 2.6 times longer than wide; stylus 2.5 times longer than postpedicel and 1.4 times longer than scape, pedicel and postpedicel combined. Gena very narrow. Palpus and proboscis brownish yellow.

Thorax. Black, with black setation. Prothoracic episternum with short setulae above fore coxa. Postpronotal bristle not prominent. Mesonotum with 2 notopleurals, 1 postsutural supra-alar, 1 postalar and 4 scutellars (inner pair very long, cruciate; outer pair very short); scutum entirely covered with short, pale uniform (except for 1 pair of long prescutellars) setulae.

Legs. Short, with mid femur brownish yellow (except base) and hind femur brownish (except base), otherwise yellow. Mid coxa with several rather long and strong setae anteriorly; mid trochanter with 3 black spinules. Fore femur thickened. Fore tibia spindle-like. Mid femur with row of spinule-like ventral setulae and 1 long anterior subapical bristle. Hind femur evenly thickened, with 1 longer anteroventral subapical bristle. Hind tibia thickened, arched, with slightly prominent apical projection. Tarsi of all legs unmodified, with unmodified setation.

WING. Normally developed, hyaline, covered with uniform microtrichia. Costal vein with rather long setulae along anterior margin. Costal bristle long, brown. Costal index: 22/11/20. Vein Rs originating before middle of cell $r_{1}$ (closer to humeral crossvein), somewhat longer than crossvein bm-cu. $R_{1}$ thickened. $R_{2+3}$ evenly bowed toward costa, meeting costa beyond middle of wing. $R_{4+5}$ and $M_{1+2}$ strongly divergent, evenly bowed. $\mathrm{A}_{1}$ absent. Crossvein bm-cu transverse. Crossvein r-m beyond middle of cell bm. Halter with pale stem and brownish knob.

АвDомEN. Tergites 4 and 5 with squamiform setae laterally. Gland-like structure present between tergites 4 and 5.

Terminalia. Brown (Figs 95-97). Cerci separated; left cercus broad, as in Fig. 102, with numerous unmodified short setae; right cercus greatly reduced, represented as narrow, bacilliform sclerite bearing several short setulae. Epandrium completely divided. Left epandrial lamella fused to hypandrium, with 1 long seta apically. Left surstylus (Fig. 97) bilobed; upper lobe long, digitiform, with internal process, bearing numerous unmodified setae; lower lobe short, with short unmodified setae. Right epandrial lamella subtriangular, covered with numerous unmodified long setae. Right surstylus deeply cleft as in Fig. 95, with several unmodified setae of different lengths. Hypandrium with 1 short seta apically. Phallus short. Ejaculatory apodeme very large, ventral apodeme greatly reduced.

\section{Female}

Unknown.

\section{Material examined}

Holotype ${ }^{\lambda}$

SINGAPORE: Nee Soon, 24 March 2005, swamp forest, Mal 1 (reg. 25028, leg. P.G.; in ZRC).

\section{Etymology}

The epithet 'hutan' means 'forest' in Bahasa Indonesia and Malaysia alluding to the occurrence of this species in the forest. 


\section{Distribution}

Singapore.

\section{Habitat and seasonal occurrence}

This species was collected in a swamp forest in March.

\section{Remarks}

This species is similar to D. mandai sp. nov. and the main distinguishing features are indicated in the key.

\section{Drapetis laut sp. nov.}

Figs 98-100

\section{Diagnosis}

Rather small species; antennal scape and pedicel brownish yellow, postpedicel brownish; palpus pale; legs brownish yellow; halter pale.

\section{Description}

\section{Male}

LENGTH. Wing 1.5-1.6 mm.
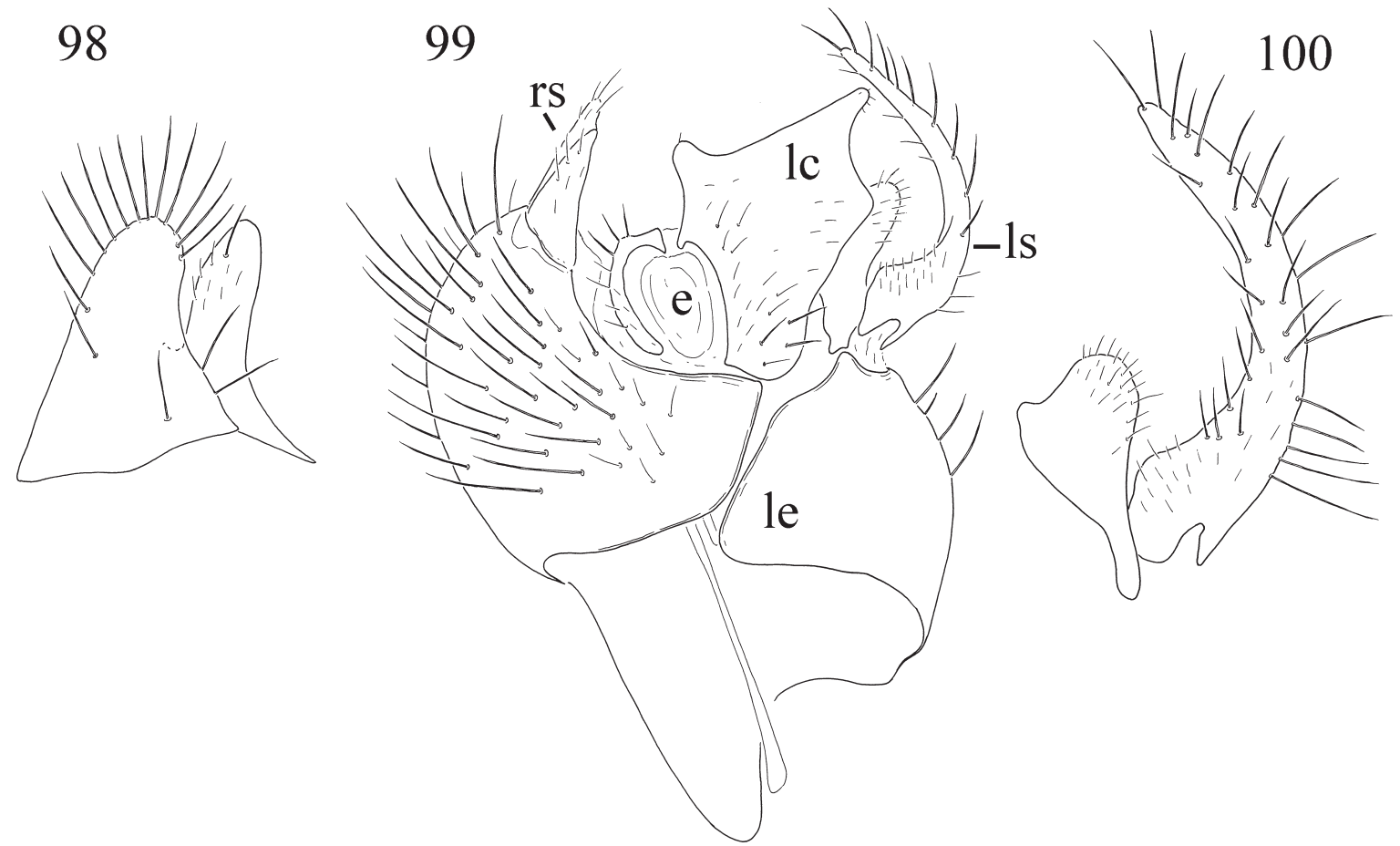

Figs 98-100. Drapetis laut sp. nov., § terminalia. 98. right surstylus, dorsal view. 99. epandrium and cerci, dorsal view. 100. left surstylus, lateral view. 
HeAD. Black. Occiput subshining, finely pollinose. Two long vertical bristles present. Frons subshining, broadened towards ocellar tubercle. Anterior ocellars long, yellow; posterior ocellars minute. Antenna with scape and pedicel brownish yellow, postpedicel brownish; pedicel with moderately long ventral seta; postpedicel with lower margin somewhat convex, rather long, about 2.0-2.2 times longer than wide; stylus nearly 3.0 longer than postpedicel and about 2.0 times longer than scape, pedicel and postpedicel combined. Palpus pale, with moderately long subapical seta.

Thorax. Black. Mesopleuron pubescent. Prothoracic episternum with 1 long upturned bristle just above fore coxa and some setulae on upper part. Postpronotal bristle not prominent. Mesonotum with 2 notopleurals, 1 postsutural-supra-alar, 1 postalar and 4 scutellars (inner pair very long, cruciate; outer pair very short). Scutum wholly covered with short, pale uniform (except for 1 pair of long prescutellars) setulae.

Legs. Brownish yellow, with hind femur, all tibiae and tarsi darker in different extents (in darker specimens hind femur and all tibiae brownish). Coxae and trochanters with unmodified setation. Fore femur somewhat thickened. Femora and tibiae mostly with inconspicuous setation; mid femur with 1 anterior subapical bristle; hind femur thickened in apical 2/3, with several longer anteroventral subapical bristles. Hind tibia with slightly prominent apical projection. Hind tarsomere 1 lacking prominent ventral spinules near base.

WING. Normally developed, hyaline, covered with uniform microtrichia; veins yellowish to brownish yellow. Costal vein with short setulae along anterior margin. Costal bristle short, brownish. Costal index: 52/15/41. Rs originating before middle of cell $r_{1}$ (closer to humeral crossvein), nearly as long as crossvein bm-cu. $\mathrm{R}_{1}$ thickened, meeting costa about middle of wing. $\mathrm{R}_{2+3}$ evenly bowed toward costa, meeting costa beyond middle of wing. $\mathrm{R}_{4+5}$ and $\mathrm{M}_{1+2}$ convergent in apical part. $\mathrm{R}_{4+5}$ slightly sinuate. $\mathrm{A}_{1}$ absent. Crossvein bm-cu somewhat oblique. Crossvein r-m somewhat beyond middle of cell bm. Halter pale.

ABDOMEN. With tergite 1 pale yellow, tergites 2-7 brownish, rectangular, of subequal width, with scattered setulae, tergites 3 and 4 with squamiform setae laterally; segment 8 brown; tergites 6 and 7 divided along midline. Sternite 2 divided, sternites 3 and 4 with excision posteriorly. Gland-like structures present between tergites 3-4 and 4-5.

Terminalia. Brown (Figs 98-100). Cerci separated; left cercus broad, as in Fig. 99, with numerous unmodified short setae; right cercus greatly reduced, represented as narrow, bacilliform sclerite bearing several short setulae. Epandrium completely divided. Left epandrial lamella fused to hypandrium, with 4 long setae apically. Left surstylus (Fig. 100) bilobed; upper lobe long, digitiform, with numerous long unmodified setae; lower lobe short, rather subtriangular, with several short unmodified setae. Right epandrial lamella (Fig. 98) subtriangular, covered with numerous unmodified long setae. Right surstylus bilobed; upper lobe subtriangular, with broadly rounded apex, bearing several long unmodified setae; lower lobe similar in shape to upper lobe but narrower, with short unmodified setae. Hypandrium lacking setation. Phallus elongate. Two rod-shaped apodemes present.

\section{Female}

Abdomen with tergites 6 and 7 undivided; segment 8 with separated tergite and sternite; sternite 8 undivided. Cercus elongate oval, brownish. Otherwise as in male.

\section{Material examined}

Holotype $\widehat{\sigma}$

SINGAPORE: Chek Jawa, 12 September 2005, mangrove, sweeping (reg. 25343, leg. P.G.; in ZRC). 
Paratypes

SINGAPORE: $6 \hat{\jmath}$, 10 우, Chek Jawa, 19 November 2003, mangrove, sweeping (reg. 23080, leg.

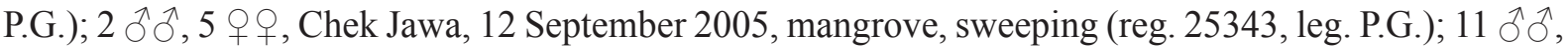
2 우, Chek Jawa, 15 December 2005, mangrove, sweeping (reg. 25452, leg. P.Grootaert); 4 우으, Chek Jawa, 15 December 2005, mangrove, sweeping (reg. 25452, leg. P.G.).

MALAYSIA: 1 q, Pulau Tioman, Juara, 20 July 2005, river, sweeping (reg. 25246, leg. P.G.).

\section{Sequences in Genbank}

J, Chek Jawa, 15 December 2005, mangrove, sweeping (reg. 25452, leg. P.Grootaert) quoted in Lim et al. (2009) as Drapetis sp. Si1328 has been sequenced.

\section{Etymology}

The specific name 'laut' means 'sea' in Malay.

\section{Distribution and seasonal occurrence}

Malaysia, Singapore.

\section{Habitat and seasonal occurrence}

This species occurs in mangroves, with records from July (single case), September, November and December.

\section{Remarks}

The new species is similar to D. pantai sp. nov. and the main distinguishing features are indicated in the key.

\section{Drapetis mandai sp. nov.}

Figs 101-104

\section{Diagnosis}

Small species; antennal scape and pedicel brownish yellow, postpedicel yellow; palpus and proboscis brownish yellow; hind femur largely brownish, otherwise legs yellow; halter yellow.

\section{Description}

\section{Male}

LeNGTH. Wing $1.4 \mathrm{~mm}$.

HEAD. Black. Occiput subshining, finely pollinose. Two pairs of vertical bristles present (inner pair longer). Frons subshining, strongly broadened toward ocellar tubercle, very narrow above antennae, narrower than anterior ocellus. Two pairs of equally short ocellars, anterior pair cruciate. Antenna (Fig. 101) with scape and pedicel brownish yellow, postpedicel yellow; pedicel with short lower bristle; postpedicel with lower margin somewhat convex, 2.0 times longer than wide; stylus 3.5 times longer than postpedicel and 1.8 times longer than scape, pedicel and postpedicel combined. Palpus and proboscis brownish yellow.

THORAX. Black, with black setation. Prothoracic episternum with short setulae above fore coxa. Postpronotal bristle not prominent. Mesonotum with 2 notopleurals, 1 postsutural supra-alar, 1 postalar and 4 scutellars (inner pair very long, cruciate; outer pair very short); scutum entirely covered with short, pale uniform (except for 1 pair of long prescutellars) setulae. 
Legs. Short, with hind femur brownish in apical 2/3, otherwise yellow. Mid coxa with several rather long and strong setae anteriorly; mid trochanter with 3 black spinules. Fore femur thickened. Fore tibia spindle-like. Mid femur with row of spinule-like ventral setulae and 1 long anterior subapical bristle. Hind femur evenly thickened, with several longer anteroventral subapical bristles. Hind tibia thickened, arched, with slightly prominent apical projection. Tarsi of all legs unmodified, with unmodified setation.

WING. Normally developed, hyaline, covered with uniform microtrichia. Costal vein with rather long setulae along anterior margin. Costal bristle long, brown. Costal index: 24/11/22. Vein Rs originating before middle of cell $r_{1}$ (closer to humeral crossvein), somewhat longer than crossvein bm-cu. $R_{1}$ thickened. $R_{2+3}$ evenly bowed toward costa, meeting costa beyond middle of wing. $R_{4+5}$ and $M_{1+2}$ strongly divergent, evenly bowed. $\mathrm{A}_{1}$ absent. Crossvein bm-cu transverse. Crossvein r-m beyond middle of cell bm. Halter yellow.

ABDOMEN. Tergites 4 and 5 with hardly prominent squamiform setae. Gland-like structure present between tergites 4 and 5 .

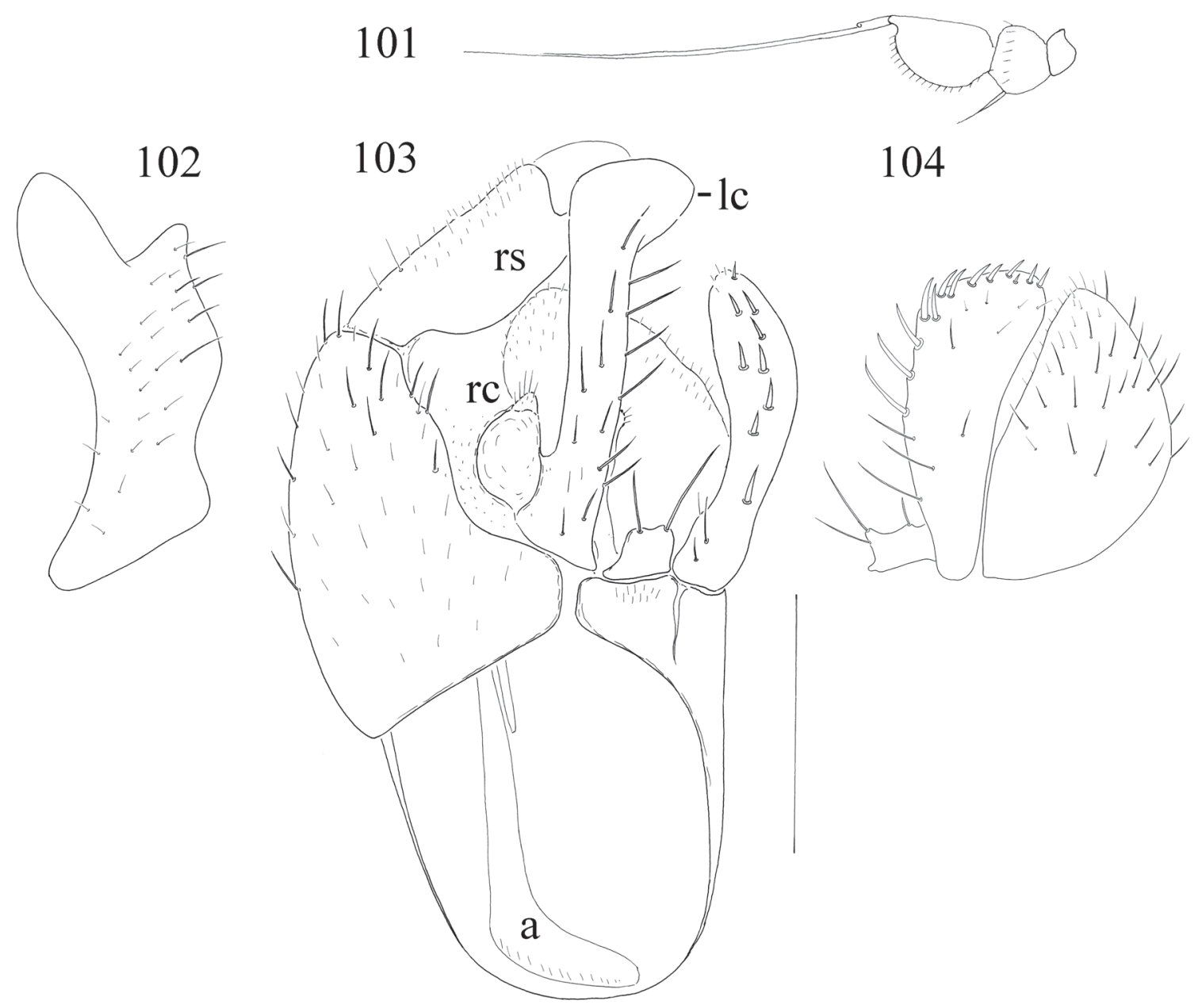

Figs 101-104. Drapetis mandai sp. nov., ठ̊. 101. antenna, lateral view. 102. right surstylus, dorsal view. 103. epandrium and cerci. 104. left surstylus, lateral. Scale bar $=0.1 \mathrm{~mm}$. 
Terminalia. Brown (Figs 102-104). Cerci separated; left cercus long, digitiform, broadened in apical part, with moderately long unmodified setae; right cercus greatly reduced, represented as small subtriangular sclerite bearing several short setulae. Epandrium completely divided. Left epandrial lamella fused to hypandrium, with several very short setae apically. Left surstylus (Fig. 104) with upper lobe rather large, elongate oval, covered with numerous long unmodified setae; middle lobe long, truncate, with several spines apically; lower lobe small, with 3 long unmodified setae. Right epandrial lamella (Fig. 103) subtriangular, covered with numerous unmodified setae of different lengths. Right surstylus (Fig. 102) represented by one lobe, long, divided at apex, with several unmodified setae of different lengths. Hypandrium lacking setation. Phallus elongate. Two rod-shaped apodemes present.

\section{Female}

Unknown.

\section{Material examined}

Holotype $\widehat{O}$

SINGAPORE: Mandai mangrove, 9 October 2000, mangrove, sweeping (reg. 20038, leg. P.G. \& N. Evenhuis; in ZRC).

\section{Etymology}

The new species is named after its type locality.

\section{Distribution}

Singapore.

\section{Habitat and seasonal occurrence}

This species occurs in mangroves with a single record from October.

\section{Remarks}

This species is similar to D. hutan sp. nov. and the main distinguishing features are indicated in the key.

Drapetis pantai sp. nov.

Figs 92, 105-107

\section{Diagnosis}

Rather small species; antenna brownish yellow; palpus brownish; legs brownish yellow, hind tarsomere 1 with some longer ventral spinules near base; halter pale.

\section{Description}

\section{Male}

LENGTH. Wing 1.5-1.6 mm.

HEAD. Black. Occiput subshining, finely pollinose. Two long vertical bristles present. Frons subshining, broadened towards ocellar tubercle. Anterior ocellars long, yellow; posterior ocellars minute. Antenna brownish yellow, postpedicel somewhat darker; pedicel with moderately long lower seta; postpedicel with lower margin somewhat convex, rather long, 2.5-2.8 times longer than wide; stylus nearly 3.0 longer than postpedicel and about 1.5 times longer than scape, pedicel and postpedicel combined. Palpus brownish, with moderately long subapical seta. 
Thorax. Black. Anepisternum pubescent. Prothoracic episternum with 1 long upturned bristle just above fore coxa and some setulae on upper part. Postpronotal bristle not prominent. Mesonotum with 2 notopleurals, 1 postsutural supra-alar, 1 postalar and 4 scutellars (inner pair very long, cruciate; outer pair very short); scutum entirely covered with short, pale uniform (except for 1 pair of long prescutellars) setulae.

LEGs. Brownish yellow with hind femur, all tibiae and tarsi darker in different extent (in darker specimens hind femur and all tibiae brownish). Coxae and trochanters with unmodified setation. Fore femur somewhat thickened. Femora and tibiae mostly with inconspicuous setation. Mid femur with 1 anterior subapical bristle. Hind femur slender, with 3-4 longer anteroventral subapical setae (Fig. 92). Hind tibia with slightly prominent apical projection. Hind tarsomere 1 with some longer ventral spinules near base.

WING. Normally developed, hyaline, covered with uniform microtrichia; veins yellowish to brownish yellow. Costal vein with short setulae along anterior margin. Costal bristle short, brownish. Costal index: $50 / 16 / 47$. Vein Rs originating before middle of cell $r_{1}$ (closer to humeral crossvein), nearly as long as crossvein bm-cu. $\mathrm{R}_{1}$ thickened, meeting costa about middle of wing. $\mathrm{R}_{2+3}$ evenly bowed toward costa, meeting costa beyond middle of wing. $\mathrm{R}_{4+5}$ and $\mathrm{M}_{1+2}$ convergent in apical part. $\mathrm{R}_{4+5}$ slightly sinuate. $\mathrm{A}_{1}$ absent. Crossvein bm-cu somewhat oblique. Crossvein r-m near middle of cell bm. Halter pale.
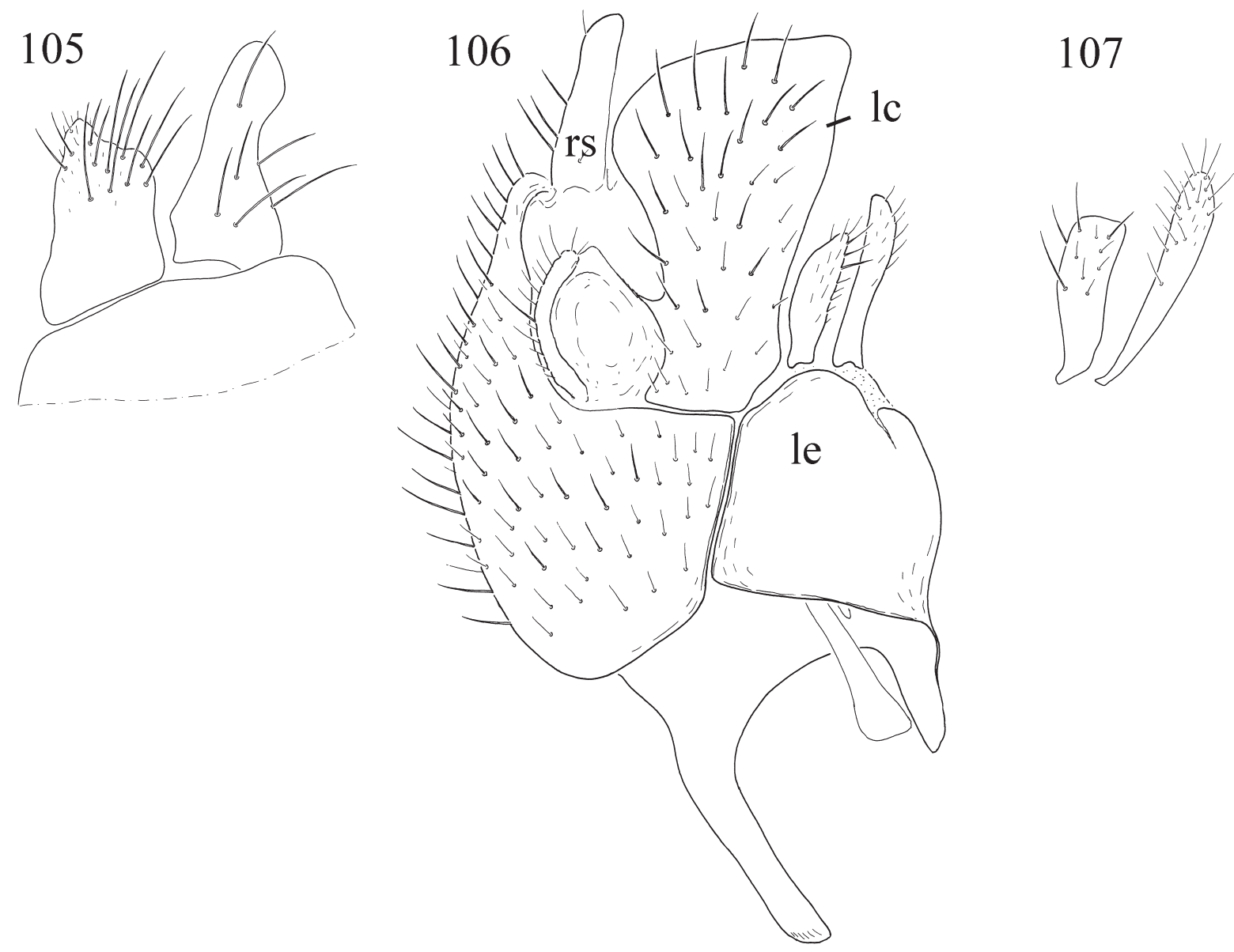

Figs 105-107. Drapetis pantai sp. nov., đ̊ terminalia. 105. right surstylus, dorsal view. 106. epandrium and cerci, dorsal view. 107. left surstylus, lateral view. 
AвDOMEN. With tergite 1 pale yellow, tergites 2-7 brownish, rectangular, of subequal width, with scattered setulae, tergites 3 and 4 with squamiform setae laterally; segment 8 brown. Sternite 2 divided, sternites 3 and 4 with excision posteriorly. Gland-like structures present between tergites 3-4 and 4-5.

Terminalia. Small, black (Figs 105-107). Cerci separated; left cercus broad (Fig. 106), subrectangular, with numerous unmodified setae of different lengths; right cercus greatly reduced, represented as narrow, bacilliform sclerite bearing several short setulae. Epandrium completely divided. Left epandrial lamella fused to hypandrium, lacking setae in apical part. Left surstylus (Fig. 107) bilobed; upper lobe rather digitiform, with numerous unmodified setae; lower lobe somewhat shorter and broader, truncate, with several unmodified setae. Right epandrial lamella (Fig. 106) subtriangular, covered with numerous unmodified setae of different lengths. Right surstylus bilobed (Fig. 105); upper lobe broad, with several long unmodified setae; lower lobe somewhat narrower and longer, with unmodified setae. Hypandrium reduced, lacking setation. Phallus short. Two rod-shaped apodemes present.

\section{Female}

Unknown.

\section{Material examined}

Holotype $\delta^{\wedge}$

SINGAPORE: Chek Jawa, 15 December 2005, mangrove, sweeping (reg. 25452, leg. P.G.; in ZRC).

\section{Paratypes}

SINGAPORE: $1 \partial^{\lambda}$, Chek Jawa, 15 December 2005, mangrove, sweeping (reg. 25452, leg. P.G.).

MALAYSIA: $3 \widehat{\jmath}$, Pulau Tioman, Juara, 20 July 2005, river, sweeping (reg. 25244, leg. P.G.).

\section{Etymology}

The specific name 'pantai' means beach or coast in Malay.

\section{Distribution}

Malaysia, Singapore.

\section{Habitat and seasonal occurrence}

This species is found in mangroves, recorded in July and December.

\section{Remarks}

This species resembles representatives of the $D$. assimilis and $D$. convergens groups (sensu Kovalev 1972). However, the new species is likely a member of a hitherto unrecognised group within Drapetis, defined on the basis of the following features: prothoracic episternum with 1 long upturned bristle just above fore coxa, tergites 3 and 4 with squamiform setae.

Genus Elaphropeza Macquart, 1827

Elaphropeza Macquart, 1827: 86. Type-species: Tachydromia ephippiata Fallén, 1815, by monotypy. Ctenodrapetis Bezzi, 1904: 351 (as subgenus of Drapetis). Type-species: Drapetis (Ctenodrapetis) ciliatocosta Bezzi, 1904 by subsequent designation of Melander (1928: 309). 


\section{Recognition}

The genus Elaphropeza can be distinguished from other genera of the Drapetini by the following combination of characters: occiput convex, antennae not upturned, postpedicel conical, its lower margin as straight as upper, stylus apical, anepisternum bare, wing with shortened cell br, abdominal tergites with squamiform setae, intersegmental modifications present between tergites 3-5 or 4-5.

\section{Diagnosis}

Small flies with body length 1.5-3.0 mm. Frons with sides divergent above. Face linear, narrow. Two pairs of vertical bristles, outer pair often only slightly prominent. Ocellar tubercle with 2 pairs of bristles but posterior pair usually minute. Antenna with pedicel bearing circlet of subequally short setae; postpedicel conical, of varying lengths; stylus terminal, arista-like, usually long. Gena not extended or, sometimes, barely extended below eye. Palpus elongate-ovate, usually small and with distinct apical seta but sometimes (E. palpata de Meijere, 1911) long, strip-like, lacking apical seta. Thorax usually yellow, often with brownish black markings forming specific pattern, but sometimes uniformly brown to black, shining. Prothoracic episternum with (or without) 1 long upturned bristle just above fore coxa and usually 1 short bristle in upper part. Postpronotal bristle usually not prominent but sometimes present. Mesonotal bristles usually very prominent. Anepisternum bare. Legs long, slender, sometimes slightly thickened; hind tibia always with apical projection clothed in dense brownish setulae, lacking prominent bristles or bearing 1-2 (rarely more, E. palpata) anterodorsal bristles about middle and (or) 1-2 curved subapical bristles; also, sometimes 2 posterodorsal bristles present. Wings usually normally developed or sometimes narrow, with axillary lobe greatly reduced; more or less infuscate, hyaline or with distinct pattern; Rs originating before halfway along $\mathrm{R}_{1}$, longer than crossvein bm-cu; $\mathrm{R}_{2+3}$ evenly curved, complete; $\mathrm{R}_{4+5}$ and $\mathrm{M}_{1+2}$ parallel or slightly divergent near wing apex, usually both more or less straight; $\mathrm{A}_{1}$ very weak, fold-like or absent; crossvein $\mathrm{CuA}_{2}$ absent; crossvein bm-cu transverse or oblique; cell br always markedly shorter than cell bm but varying in length, usually about as long as half of cell bm, sometimes distinctly shorter. Halter with knob yellow to black. Abdomen with tergites $1-5$ varying in shape and degree of sclerotisation; tergites 3 and 4 often broadest; tergite 5 usually very narrow; tergites 6-7 usually unmodified, of subequal width but sometimes modified; segment 8 always short, partially concealed by segment 7 , rarely modified. Squamiform setae usually present on tergites 3, 4 and 5, or 4 and 5, sometimes restricted to one of these tergites or rarely absent $(E$. lanuginosa Bezzi, 1914). Sternites usually unmodified, weakly sclerotised, sternites 3-5 often divided along midline. Gland-like intersegmental structures present between tergites 4 and 5 or between tergites 3, 4 and 5. Gland-like structures usually simple plate-like, but sometimes vessel-like. Terminalia rotated $90^{\circ}$ to right; epandrium completely divided. Left epandrial lamella small and fused to hypandrium; left surstylus divided into 3 lobes, upper lobe without surstylar comb but sometimes with spines; right epandrial lamella usually large, positioned ventrally; right surstylus absent or present; if present, undivided, usually differentiated from and weakly articulated with epandrium; cerci separated or fused (sometimes incompletely) forming single lobe, sometimes bearing spines; hypandrium usually with 2 setae on apical portion; phallus very short or elongate and coiled, sometimes greatly double spiralled; one or two rod-shaped apodemes (i.e. ejaculatory and ventral apodemes) present. Female similar to male, sexual dimorphism slightly prominent, usually including only lack of ventral spinules on mid tibia; terminalia short to elongate; tergite 8 not fused or fused laterally with sternite 8 ; sternite 8 with or without folded apex; cercus elongate-ovate or broad-ovate.

\section{Remarks}

Elaphropeza is second large genus of Tachydromiinae after Platypalpus and the largest group among Drapetini genera. It has clear circumtropical distribution and currently includes 212 named species worldwide: Palaearctic - 4, Nearctic - 2, Afrotropics - 22, Australasia - 16, Neotropics - 35, Oriental - 133 (Freitas-Silva \& Ale-Rocha 2009; Grootaert \& Shamshev 2009b; Shamshev \& Grootaert 2007, 
2009b). However, it is evident that this number is far from the real number of included species, because the genus has been only studied very locally.

Elaphropeza is very diverse and quite common in Singapore, with 52 described species (Shamshev \& Grootaert 2007). However, thanks to the 'Singapore Mangrove Insects Project' during which 11 mangrove sites in Singapore were intensively sampled during four weeks in May-June 2009, additional data on 25 species of Elaphropeza were recorded. Among them we found 8 new species for science and the males of $E$. modesta and E. feminata are recorded for the first time. That is why we give below the new data on the Elaphropeza with descriptions of new species.

Adult Elaphropeza are leaf-dwellers. Although nothing is known about the feeding habits of the adults, the strong hook-shaped labrum suggests that they are predators like most other Tachydromiinae. A short note by Patnaik \& Satpay (1984) suggests that the larvae are (hyper)parasites on other Diptera. However, this observation needs confirmation. The ovipositor appear not adapted for digging in soil, lacking shovel-like spines (acanthae) like in most Dolichopodidae and some Brachystomatidae, but that leaves open all kinds of speculation.

Most species of Elaphropeza have a habitat preference. A number of species with a black thorax occurs in sun-lit areas such as swamps where they are found on the leaves of short grasses. In Nee Soon, E. neesoonensis was observed exclusively in the sunny-exposed marshland and was never caught in the surrounding forest. In the forest, species generally have a completely yellow thorax. A similar phenomenon occurs in forest-dwelling Platypalpus and many Dolichopodidae.

Most Elaphropeza are terrestrial, but in the present study we found 43 species of Elaphropeza occurring in mangroves. Twenty-two species are found exclusively in mangroves and two species that are dominant in mangroves have a few records in terrestrial forests. Dominant mangrove species are E. limosa, E. monospina, E. murphyi, E. asexa, E. crassicercus, E. malayensis, E. feminata and E. riatanae. The other species are found with less than 10 individuals. Ubiquist or eurytope species such as E. biuncinata (2 ind. in mangroves of a total of 106 in other habitats in Singapore) and E. bicaudata (9 ind. in mangroves of a total of 230 in Singapore), that are dominant in terrestrial habitats, occur only in very small numbers in mangroves. Apparently adaptation to the marine environment is specific so that even ubiquist species that can tolerate anthropogenic habitats are rare in marine habitats.

Shamshev \& Grootaert (2007) arranged all species of Elaphropeza into two informal species groups, namely the E. ephippiata and E. biuncinata groups, keyed below. We follow that subdivision again here. Within these proposed groups, the species are further divided into species complexes. The subdivision of the E. ephippiata group is based on the presence of anterodorsal bristles on the hind tibia. Within this group two species complexes are recognised: 1) hind tibia lacking prominent bristles; 2) hind tibia with 1-2 anterodorsal bristles in middle.

The subdivision of the E. biuncinata group is based on the presence of curved subapical bristles on the hind tibia. Within this group three species complexes are recognised: 1) hind tibia with 2 curved subapical bristles (Fig. 113); 2) hind tibia with 1 curved subapical bristle; 3) hind tibia lacking prominent bristles.

It should be noted that this classification of the species complexes does not reflect completely (especially in the E. ephippiata group) the phylogenetic relationships of the species included. The application of the classification proposed was stimulated rather for practical purposes. All species of Elaphropeza treated below are arranged following this subdivision.

The key to species is solely based on the version presented in our earlier paper (Shamshev \& Grootaert 2007) and, thus, it is not limited to the species of Singapore but can be used for the whole Oriental 
Region. An updated key includes, besides new species described herein, some corrections, which could improve its diagnostic value, and three recently described species from Viet Nam (Grootaert \& Shamshev 2009b).

\section{Key to Elaphropeza species groups of the Oriental Region}

1. Proepisternum bare just above fore coxa. Abdominal tergite 3 with unmodified setae, lacking squamiform setae.

E. ephippiata group

- Proepisternum with long upturned bristle just above fore coxa. Abdominal tergite 3 with numerous squamiform setae. E. biuncinata group

\section{Updated key to species of Elaphropeza from the Oriental Region}

1. Thorax entirely black or, rarely (E. limosa Shamshev \& Grootaert and E. shufenae sp. nov.) brownish (no paler markings on mesonotum or pleura).

- Thorax yellow to reddish yellow (sometimes with brown or black markings)..................................22

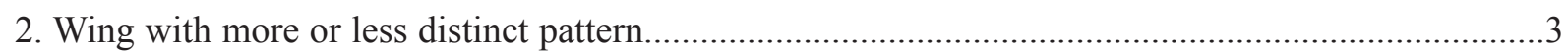

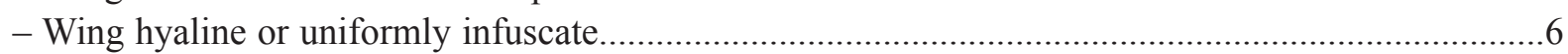

3. Hind tibia with 1 anterodorsal bristle. Postpedicel very short, 1.5 times as long as wide. All legs with tarsomere 5 black. Wing hyaline along anterior and posterior margins, otherwise brownish, including wing apex (Indonesia, Java).....

E. strigifera (de Meijere, 1911)

- Hind tibia lacking anterodorsal bristles. Postpedicel long, 3-4 times longer than wide. Legs wholly yellow. Wing with different pattern.

4. Wing deeply infuscate on basal half, with 2 brown spots in apical portion of cell $r_{1}$ and in basal part of cell $\mathrm{r}_{2+3}$; apical half finely infuscate. Halter with brown knob (Singapore).

E. darrenyeoi Shamshev \& Grootaert, 2007

- Wing with more or less distinct dark band in middle. Halter yellow..

5. Antenna wholly brownish yellow. Hind tibia lacking prominent bristles. Abdomen with tergite 3 and 4 bearing squamiform setae. Male: Right surstylus long, narrow, overlapping cerci (Singapore) E. singaporensis Shamshev \& Grootaert, 2007

- Antenna with scape and pedicel yellow. Hind tibia bearing 2 straight subapical anterior bristles of different lengths. Abdomen with tergites 3, 4 and 5 bearing squamiform setae. Male: Right surstylus large, rather elongate oval, not overlapping cerci (Singapore)...E. sime Shamshev \& Grootaert, 2007

6. Mid tibia with 1 long black flattened subapical posteroventral bristle; hind tibia narrowed in apical 1/3 with 1 strong anterodorsal bristle vertically sitting on tubercle and several appressed setae (Singapore).

E. pauper Shamshev \& Grootaert, 2007

- Mid tibia with ordinary subapical bristles. Hind tibia unmodified, with or without unmodified posteroventral bristles..

[Elaphropeza sp. 51 recorded from Singapore and known only from a female specimen would key out here]

7. Hind tibia lacking anterodorsal bristles.

- Hind tibia with 1 or 2 anterodorsal bristles.

8. Halter dark.

- Halter yellow. 
9. Fore and hind tibiae and hind femur, except broadly at base, wholly dark brown; otherwise legs brownish yellow (India: West Bengal) E. bicoloripes Brunetti, 1913

- Legs almost wholly yellow, only tarsomere 5 blackish or brownish near apex of hind femur above and hind tibia near base.

10. Palpus yellow. Acrostichal bristles biserial, dorsocentrals uniserial. Legs with tarsomere 5 blackish (Malaysia).

E. belumut Shamshev \& Grootaert, 2007

- Palpus brown. Acrostichal and dorsocentral bristles multiserial. Legs with hind femur near apex above and hind tibia near base brownish (Singapore).....E. chekjawa Shamshev \& Grootaert, 2007

11. Larger, about $3.0 \mathrm{~mm}$. Stylus 1.5 times longer than postpedicel. Abdominal tergites 4 and 5 with squamiform setae (Singapore).

E. temasek Shamshev \& Grootaert, 2007

- Smaller, about $1.5 \mathrm{~mm}$. Stylus as long as postpedicel. Only abdominal tergite 5 with squamiform setae.

12. Legs with tarsomeres 3-5 brownish yellow. Male: cerci forming single tapered lobe (Singapore)... E. neesoonensis Shamshev \& Grootaert, 2007

- Legs with tarsomere 5 black, remaining tarsomeres yellowish. Male: cerci forming single digitiform sinuate lobe (Singapore)... E. yeoi Shamshev \& Grootaert, 2007

13. Hind tibia with 1 anterodorsal bristle .14

- Hind tibia with 2 anterodorsal bristles .19

14. Antenna entirely brown. Thorax brownish...... 15

- Antenna entirely or partly yellow. Thorax black. .16

15. Antennal stylus nearly as long as postpedicel. Palpus brownish yellow. Male: cerci separated, epandrium with scattered moderately long setae (Singapore)

..E. shufenae sp. nov.

- Antennal stylus nearly 1.5 times as long as postpedicel. Palpus yellow. Male: cerci entirely fused into one digitiform lobe; epandrium with numerous very long setae (Figs 124-126) (Singapore)

E. limosa Shamshev \& Grootaert, 2007

16. Fore tarsomeres 2-5 with dark rings at apex of each segment (Singapore).

E. meieri Shamshev \& Grootaert, 2007

- Fore tarsus entirely yellow or with tarsomere 5 brown.

17. Fore tarsus entirely yellow. Abdomen reddish yellow in basal half and black apically (Sri Lanka) E. basalis Bezzi, 1904

- Fore tarsomere 5 brown. Abdominal tergites 1-3 represented by pairs of long triangular lateral sclerites

18. Antenna entirely yellow. Two pairs of vertical bristles present (China, Guangxi).....

E. liui Yang \& Gaimari, 2005

- Antenna with postpedicel brownish yellow. One pair of vertical bristles present (China, Guangxi)..

E. guangxiensis (Yang \& Yang, 1992)

19. Mid tibia with 1 anterodorsal bristle at middle. Acrostichal bristles lacking (Nepal).

E. kala (Smith, 1965)

- Mid tibia lacking prominent bristles (except subapicals). Acrostichal bristles present, multiserial. 
20. Antenna with postpedicel dark brown, scape and pedicel paler, brownish yellow. Hind femur brownish on apical 2/3 (China: Guangdong).

E. nankunshanensis Yang \& Grootaert, 2006

- Antenna entirely blackish. Hind femur black on apical half.

21. Palpus brown. Tibiae and tarsi dark, wholly brown (China, Guangxi)

E. maoershanensis Yang \& Grootaert, 2006

- Palpus yellow. Tibiae and tarsi almost wholly yellow, only tarsomere 5 brown (China, Henan)...

..E. henanensis Saigusa \& Yang, 2002

22. Occiput yellow, sometimes with dark spot near neck; rarely light brownish yellow (E. ferruginea Brunetti)

- Occiput black.

23. Palpus elongate, strap-like, black on apical third. Larger (about $3.0 \mathrm{~mm}$ ) (Indonesia, Java; Singapore; Cambodia).

E. palpata de Meijere, 1911

- Palpus short ovate, wholly yellow. Smaller (about $2.0 \mathrm{~mm}$ ).

24. Fore tibia with 1-2 short but distinct dorsal bristles .25

- Fore tibia lacking dorsal bristles..

25. Mid tibia with 1 anterodorsal bristle. .26

- Mid tibia lacking prominent bristles (except subapicals)...

26. Scutellum smoothly arched. Hind tibia with only 1 anterodorsal bristle. Abdominal tergites 4 and 5 with squamiform setae (Singapore)

E. bezzii Shamshev \& Grootaert, 2007

- Scutellum truncate. Hind tibia with 1 anterodorsal and 2 curved subapical bristles. Abdominal tergites 3, 4 and 5 with squamiform setae (Singapore)....E. combinata Shamshev \& Grootaert, 2007

27. Scutum wholly yellow. Hind tibia lacking prominent bristles (Sri Lanka)

E. distincta Senior-White, 1922

- Scutum with indistinct brownish patch above wing base. Hind tibia with 1 anterodorsal and 1 short straight subapical bristle.....

28. Anterior ocellar bristles long, posterior ocellars minute. Tarsomere 5 of all legs brown (Singapore) E. ngi Shamshev \& Grootaert, 2007

- Anterior and posterior ocellar bristles subequally moderately long. Legs wholly yellow (Singapore) E. spicata Shamshev \& Grootaert, 2007

29. Hind tibia lacking prominent bristles

- Hind tibia with curved subapical bristle(s), or with anterodorsal bristle(s) in middle.......32

30. Scutum uniformly yellow. Scutellum blackish. Halter pale yellow (India: W Bengal)

E. ferruginea Brunetti, 1913

- Scutum with brownish patch on each side. Scutellum yellow. Halter with dark knob............31

[Elaphropeza sp. 50 recorded from Singapore and known only from a female specimen would key out here]

31. Scutum with short narrow patch above wing base. Anepisternum (= mesopleuron) with large brown spot (Singapore).

E. benitotani Shamshev \& Grootaert, 2007

- Scutum with brownish patch just behind anterior corner. Anepisternum yellow (Singapore).

.E. sylvicola Shamshev \& Grootaert, 2007 
32. Hind tibia with curved subapical bristle(s), no anterodorsal bristle(s) in middle.

- Hind tibia without curved subapical bristle(s) but with anterodorsal bristle(s) in middle part (rarely, E. luteoides Shamshev, Grootaert, short straight subapical bristle present).

33. Hind tibia with 1 curved subapical bristle.

- Hind tibia with 2 curved subapical bristles..

34. Scutellum smoothly arched (Singapore). E. flavicaput Shamshev \& Grootaert, 2007

- Scutellum truncate at apex.

35. Male: right epandrial lamella with unmodified setation, bearing numerous moderately long setae ( $\mathrm{Si}$ ngapore).

E. monacantha Shamshev \& Grootaert, 2007

- Male: right epandrial lamella with 3 very long unmodified subapical setae and 2 very long squamiform setae (Fig. 163) (Singapore)

E. collini sp. nov.

[Females of these species unknown]

36. Wing darkened on basal half. Hind femur brown on apical $2 / 3$......

- Wing uniformly finely infuscate. Hind femur entirely yellow..

37. Scutum broadly brown along margin but yellow on prescutellar depression. Wing brownish infuscate on basal half, border between darker basal half and paler apical half indistinct (Singapore).

E. spiralis Shamshev \& Grootaert, 2007

- Scutum with brownish patch on anterior corner, otherwise yellow. Wing yellowish infuscate on apical half, border between darker basal half and paler apical half distinct (Singapore).

E. yangi Shamshev \& Grootaert, 2007

38. Scutum with 2 elongate brownish spots on each side. Male genitalia: Figs 110-112 (Singapore) E. melanderi Shamshev \& Grootaert, 2007

- Scutum uniformly yellow (Philippines, Singapore).

E. biuncinata (Melander, 1928)

[Elaphropeza sp. 57 recorded from Singapore and known only from a female specimen would key out here]

39. Hind tibia with 1 anterodorsal bristle.

- Hind tibia with 2 (sometimes 3) anterodorsal bristles in middle.

40. Scutellum, metanotum and metapleuron black (Taiwan).

E. xanthocephala Bezzi, 1912

- Thorax entirely yellow.

41. Antenna with postpedicel yellow. Halter with dark knob (Singapore)

E. luteoides Shamshev \& Grootaert, 2007

- Antenna with postpedicel brown. Halter yellow (Indonesia: Java).

E. lutea (de Meijere, 1919)

42. Postpedicel yellow. Thorax entirely yellow to reddish yellow. Acrostichals biserial (Nepal).

E. coei (Smith, 1965)

- Postpedicel black. Thorax with meron (= hypopleuron) and scutellum black. Acrostichals multiserial.

43. Fore tibia and all tarsi (except hind basitarsus) brownish. Metapleuron yellow (Sri Lanka).........

E. nigropunctata Senior-White, 1922

- Legs wholly yellow. Metapleuron brown (Nepal). E. ukhalo (Smith, 1965) 


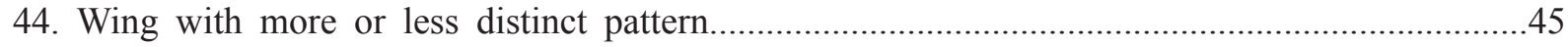

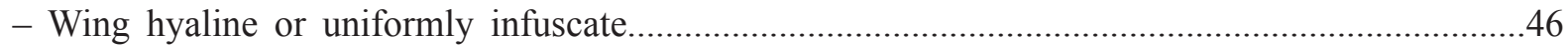

45. Thorax brown, except prosternum, entire anepisternum and postalar callus yellow. Hind tibia lacking prominent bristles. Wing darkened on basal half (darker in middle of cell $r_{1}$ and in basal part of cell $r_{2+3}$ ), otherwise almost hyaline (Singapore)....E. pluriacantha Shamshev \& Grootaert, 2007

- Thorax entirely yellow. Hind tibia with 3 anterodorsal bristles. Wing brownish infuscate, darker near middle of anterior margin (Sri Lanka). E. fulvithorax van der Wulp, 1897

46. Hind tibia lacking prominent bristles.

- Hind tibia with subapical bristle(s) and/or with anterodorsal bristle(s).................................54

47. Cross-vein bm-cu strongly oblique. Scutum with blackish spot above wing base and median vitta in anterior part (Indonesia, Java). E. obliquinervis de Meijere, 1914

- Cross-vein bm-cu transverse or somewhat oblique. Scutum uniformly coloured or with different pattern.

48. Scutum uniformly yellow coloured.

- Scutum with distinct brown pattern.

49. Prothoracic episterna lacking long upturned bristle just above fore coxa. Abdominal tergite 3 lacking squamiform setae. Antennal stylus normally pubescent. Halter entirely yellow. Male: abdominal segment 8 unmodified (Singapore).............E. sivasothii Shamshev \& Grootaert, 2007

- Prothoracic episterna with 1 long upturned bristle just above fore coxa. Abdominal tergite 3 with squamiform setae. Different combination of characters............................50

50. Halter with dark knob. Acrostichal bristles extending to base of scutellum. Metanotum reddish yellow. Legs entirely yellow. (Male unknown. Sri Lanka)........E. plumicornis Senior-White, 1922

- Halter entirely yellow. Different combination of characters..............................................51

51. Abdominal tergites 3 and 4 with squamiform setae; gland-like structure present between tergites 3 and 4. Acrostichal bristles lacking on prescutellar depression. Legs entirely yellow. Male: segment 8 unmodified (Viet Nam)...........................E. hirsutiterga Grootaert \& Shamshev, 2009

- Abdominal tergites 3, 4 and 5 with squamiform setae; gland-like structures present between tergites 3-4 and 4-5. Scutum entirely covered with setae. Legs with tarsomere 5 darkened. Male: segment 8 modified.

52. Metanotum reddish yellow. Male: abdominal segment 8 with slightly prominent projection bearing several moderately long strong setae (Viet Nam).......E. cattiensis Grootaert \& Shamshev, 2009

- Metanotum brownish yellow. Male: abdominal segment 8 with short, broad projection bearing several marginal spinules (Viet Nam). E. vietnamensis Grootaert \& Shamshev, 2009

53. Scutum broadly brown along margin but yellow on prescutellar depression. Male: mid femur with ventral tubercle near base (Malaysia, P. Tioman).....E. tiomanensis Shamshev \& Grootaert, 2007

- Scutum with broad brown median vitta. Mid femur slender in both sexes.

E. acanthi Shamshev \& Grootaert, 2007

[Elaphropeza sp. 58 recorded from Singapore and known only from a female specimen would key out here]

54. Hind tibia with curved subapical bristle(s), no anterodorsal bristle(s).

- Hind tibia without curved subapical bristles, but with anterodorsal bristle(s) in middle part. 


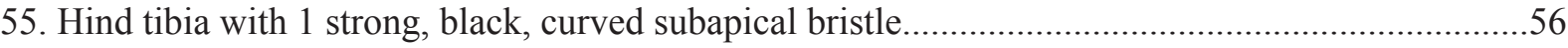

- Hind tibia with 2 strong, black, curved subapical bristles.....................................................57

56. Metanotum entirely brown (Singapore)

E. crassicercus Shamshev \& Grootaert, 2007

- Metanotum largely yellow (Singapore).

E. luanae Shamshev \& Grootaert, 2007

[Elaphropeza sp. 46 recorded from Singapore and known only from a female specimens would key out here]

57. Scutum with brownish spot above wing base (Sri Lanka).......E. notatithorax Senior-White, 1922

- Scutum uniformly yellow.

58. Stylus 4.0-4.5 times as long as postpedicel. Metanotum brownish yellow to brownish (Indonesia, Java; Singapore; Malaysia; Thailand).

E. hirsutitibia de Meijere, 1914

- Stylus nearly 2.0 times as long as postpedicel. Metanotum yellow (Singapore)

E. murphyi Shamshev \& Grootaert, 2007

59. Hind tibia with 1 anterodorsal bristle.

- Hind tibia with 2 anterodorsal bristles.

60. Scutum with brown pattern

- Scutum entirely yellow.

61. Scutellum entirely yellow.

- Scutellum entirely or in middle dark brown...

62. Abdominal sternite 4 with 2 tubercles. Elongate brownish patch on anterior corner of scutum and above notopleural depression (Singapore)......E. bulohensis Shamshev \& Grootaert, 2007

- Abdominal sternite 4 ordinary. Scutum with large brown elongate subtriangular patch on each side. Male genitalia: Figs 166-168 (Singapore).

E. kranjiensis sp. nov.

63. Scutellum dark brown in middle. Scutum with dark brown median vitta abbreviated behind and spot above notopleuron (Philippines).

E. uniseta Melander, 1918

- Scutellum wholly brown to black. Scutum with different pattern.

64. Postpedicel long, about 5.0 times longer than wide. Scutum with small brownish patch above wing base including postalar callus (Singapore).

E. riatanae Shamshev \& Grootaert, 2007

- Postpedicel shorter, 2.0-3.0 times longer than wide. Scutum with complicated pattern.....

65. Antenna brownish yellow. Hind tarsomere 1 with spine-like ventral seta near base. Veins $\mathrm{R}_{4+5}$ and $\mathrm{M}_{1+2}$ somewhat divergent near wing apex. Smaller (about $2.0 \mathrm{~mm}$ ) (Singapore).....

E. monospina Shamshev \& Grootaert, 2007

- Antenna with scape and pedicel yellow, postpedicel black. Hind tarsomere 1 with unmodified setation. Veins $\mathrm{R}_{4+5}$ and $\mathrm{M}_{1+2}$ parallel near wing apex. Larger (2.8-3.3 mm) (Taiwan).....E. pictithorax Bezzi, 1912

66. Hind tibia with long pointed apical projection. Scutellum and metanotum brown. Acrostichal bristles lacking on prescutellar depression. Halter yellow (Taiwan)........E. calcarifera Bezzi, 1907

- Hind tibia with short, rounded apical projection. Different combination of characters.

67. Scutellum entirely yellow..

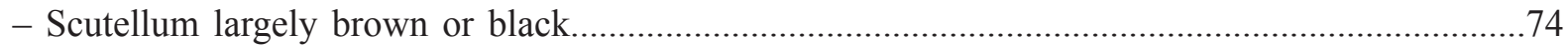

68. Acrostichal bristles extending to base of scutellum. Halter darkened. 
- Acrostichal bristles lacking on prescutellar depression. Halter yellow. .70

69. Postpedicel about 6.0 times longer than wide. Metanotum reddish-yellow (Singapore)

E. asiophila Shamshev \& Grootaert, 2007

- Postpedicel about 4.5 times longer than wide. Metanotum brownish (Singapore).

E. ubinensis Shamshev \& Grootaert, 2007

[Elaphropeza sp. 49 recorded from Singapore and known only from a female specimen would key out here]

70. Fore tibia and tarsus, mid and hind tarsomere 5 brownish. Abdominal tergites 4 and 5 with squamiform setae. Male: cerci broadly fused, digitiform; right epandrial lamella truncate apically, lacking spines.

E. furca Shamshev \& Grootaert, 2007

- Legs with only tarsomere 5 brown. Abdominal tergite 4 with slightly flattened setae, tergite 5 with squamiform setae.

71. Postpedicel nearly 4.0 times as long as wide. Male: fore tibia with black subapical spine or

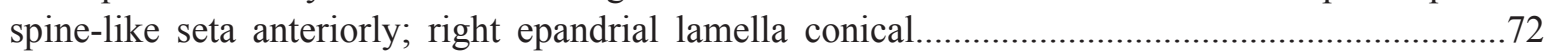

- Postpedicel nearly 3.0 times as long as wide. Male: fore tibia with unmodified setation; right epandrial lamella truncate apically.....

72. Antennal stylus nearly as long as postpedicel. Male: fore tibia with black subapical spine anteriorly; right epandrial lamella 4 brownish subapical spines (3 spines closer to each other and 1 spine aside) (Fig. 137) (Singapore)

E. chanae sp. nov.

- Antennal stylus nearly 1.5 times as long as postpedicel. Male: fore tibia with black subapical spinelike seta anteriorly; right epandrial lamella with unmodified setation, lacking spines (Fig. 141) (Singapore).

E. gohae sp. nov.

73. Larger: 2.1-2.2 mm. Male: right epandrial lamella with 3 black spines apically (Figs 133-135) (Malaysia, Singapore).

E. malayensis Shamshev \& Grootaert, 2007

- Smaller: 1.7-1.8 mm. Male: right epandrial lamella with unmodified setation, lacking spines (Figs 145-147) (Singapore).

E. lowi sp. nov.

74. Scutellum brown medially. Stylus as long as scape, pedicel and postpedicel combined (Taiwan).....

E. marginalis Bezzi, 1912

- Scutellum entirely brown or black. Stylus as long as or longer than scape, pedicel and postpedicel combined.

75. Stylus nearly 2.0 times as long as scape, pedicel and postpedicel combined.. .76

- Stylus at most as long as scape, pedicel and postpedicel combined. .78

76. Thorax with hypopleuron largely brown. Halter with dark knob (Singapore).

E. singulata Shamshev \& Grootaert, 2007

- Thorax with hypopleuron yellow. Halter yellow.

77. Antennal stylus thick, with densely long pubescence. Veins $\mathrm{R}_{4+5}$ and $\mathrm{M}_{1+2}$ divergent near wing-apex. Smaller (about $1.5 \mathrm{~mm}$ ) (Philippines).

E. aristalis (Melander, 1918)

- Antennal stylus with normal pubescence. Veins $\mathrm{R}_{4+5}$ and $\mathrm{M}_{1+2}$ parallel near wing-apex. Larger (2.5$2.7 \mathrm{~mm}$ ) (Taiwan)

E. kerteszi Bezzi

78. Legs with fore tibia and tarsus wholly brown, hind femur near apex above brownish (Singapore) E. riatanae Shamshev \& Grootaert, 2007 
- Legs only with tarsomere 5 brown to black.

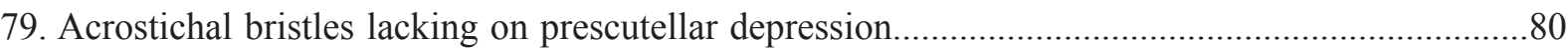

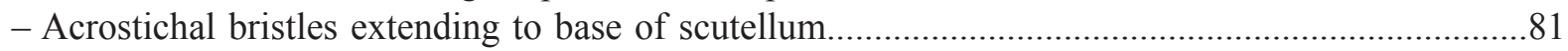

80. Larger (about $2.5 \mathrm{~mm}$ ). Male: cerci narrowly fused; right epandrial lamella with unmodified setae subapically; left surstylus with shallow notch apically (Figs 153-155). Female: abdominal segment 8 modified (Singapore)..................................... feminata Shamshev \& Grootaert, 2007

- Smaller (about $2.0 \mathrm{~mm}$ ). Male: cerci entirely fused forming single subrectangular lobe; right epandrial lamella bearing 4 short subapical spine-like setae, left surstylus produced apically (Figs 157-158). Female: unknown (Singapore)............................. s. semakau sp. nov.

81. Antenna entirely yellow. Male genitalia: Figs 149-151 (Singapore).

E. modesta Shamshev \& Grootaert, 2007

- Antenna with scape and pedicel yellow, postpedicel brown (Taiwan)

E. melanura Bezzi, 1912

82. Scutum entirely yellow.

- Scutum with more or less distinct pattern......

83. Scutellum with black spot in middle or wholly black

- Scutellum entirely yellow.

84. Scutellum entirely black. Hind tibia with 2 posterodorsal bristles in middle

E. demeijerei Shamshev \& Grootaert, 2007

- Scutellum with black spot in middle. Hind tibia lacking posterodorsal bristles (Taiwan).

.E. scutellaris Bezzi, 1912

85. Halter dark

- Halter pale yellow.

86. Fore tibia with 1 short anterodorsal bristle. Metanotum brown medially. Wing with veins $\mathrm{R}_{2+3}, \mathrm{R}_{4+5}$ and $\mathrm{M}_{1+2}$ dark brown (Singapore)..............E. asexa Shamshev \& Grootaert, 2007

- Fore tibia lacking prominent anterodorsal bristles. Metanotum wholly yellow. Wing with veins yellowish to brownish yellow. Male genitalia: Figs 118-120 (Philippines; Singapore; Malaysia)...

E. bicaudata (Melander, 1928)

87. Legs with tibiae and tarsi brownish

- Legs with tarsomere 5 blackish.

88. Metapleuron entirely reddish yellow (Nepal).

E. litoralis (Smith, 1965)

- Metapleuron blackish on upper part (Sri Lanka)

E. abdominenotata Senior-White, 1922

89. Veins $\mathrm{R}_{4+5}$ and $\mathrm{M}_{1+2}$ divergent near wing apex (Philippines).........E. acrodactyla (Melander, 1928)

- Veins $R_{4+5}$ and $M_{1+2}$ parallel near wing apex (Taiwan)

E. formosae Bezzi, 1907

90. Scutellum entirely yellow. Scutum with single, more or less distinct spot on each side [except $E$. equalis Shamshev \& Grootaert and, sometimes, E. variata (Melander)]......................................91

- Scutellum entirely black or with black spot in middle. Scutum with different pattern (except $E$. scutellaris Bezzi).

91. Antennal stylus very thick, with densely long pubescence.

- Antennal stylus with normal pubescence. 
92. Mid tibia with 1 anterodorsal bristle at middle. Legs with fore tarsomeres 2-5 and mid and hind tarsomere 5 black (Nepal).

- Mid tibia lacking prominent bristles (except subapicals). Legs wholly yellow (Philippines).

E. cuneipennis (Melander, 1918)

93. Halter with dark knob.

- Halter yellow.

94. Hind tarsomere 1 with tooth and bristle at base. Scutal spots rounded (Sri Lanka)

E. metatarsata Bezzi, 1904

- Hind tarsomere 1 unmodified. Scutal spots subtriangular, longer than wide (Indonesia, Java)

E. binotata (de Meijere, 1911)

95. Katepisternum (= sternopleuron) and hypopleuron with brownish patch on lower part. .97

- Katepisternum and hypopleuron yellow.....

96. Mesonotum with large elliptical black spot above wing base. Hind tarsomere 5 long slender (Nepal).

E. sanguensis (Smith, 1965)

- Mesonotum with brownish spot on notopleural depression, postalar callus and before scutellum on line of dorsocentral bristles. Hind tarsomere 5 somewhat thickened (Singapore).

E. equalis Shamshev \& Grootaert, 2007

97. Fore and mid tibiae and almost entire tarsi of all legs dark brown, tarsomere 5 black (China: Guangxi).

E. anae Yang \& Gaimari, 2005

- Legs entirely yellow (Burma; India).

E. variata (Melander, 1918)

98. Hind tibia with long sharply pointed apical projection. Scutum with complicated pattern. Hind tibia and tarsus dark brown (Taiwan)

E. longicalcaris (Saigusa, 1965)

- Hind tibia with slightly prominent, more or less rounded projection. Scutum with simple pattern. Hind tibia and tarsus yellow.....

99. Scutellum wholly black.

- Scutellum with black spot in middle.

100. Scutum with broad black vitta running to base of scutellum (Taiwan)...E. lanuginosa Bezzi, 1914 - Scutum black on middle (India: Maharashtra).

E. discoidalis (Bezzi, 1904)

101. Antenna with stylus about 4.0 times longer than postpedicel. Scutum with distinct median vitta disappearing before prescutellar depression and elongate lateral spots (Indonesia: Java).

E. lineola de Meijere, 1911

- Antenna with stylus about 2.5 times longer than postpedicel. Scutum with indistinct lateral spots and indistinct vitta on anterior margin (Taiwan).

E. scutellaris Bezzi, 1912

[Notes. Elaphropeza sp. 44 recorded from Singapore and known only from a female specimens would key out here.]

\section{Elaphropeza biuncinata group}

Members of this group are characterised by the following combination of characters: male genitalia with one rod-shaped apodeme (Fig. 111); phallus in the form of a long tight coil (Fig. 114); a long upturned bristle present just above fore coxa (Fig. 6); abdominal tergites 3, 4 and 5 with squamiform setae; abdominal glands present between tergites 3-4 and 4-5. Additionally, in species of this group the 


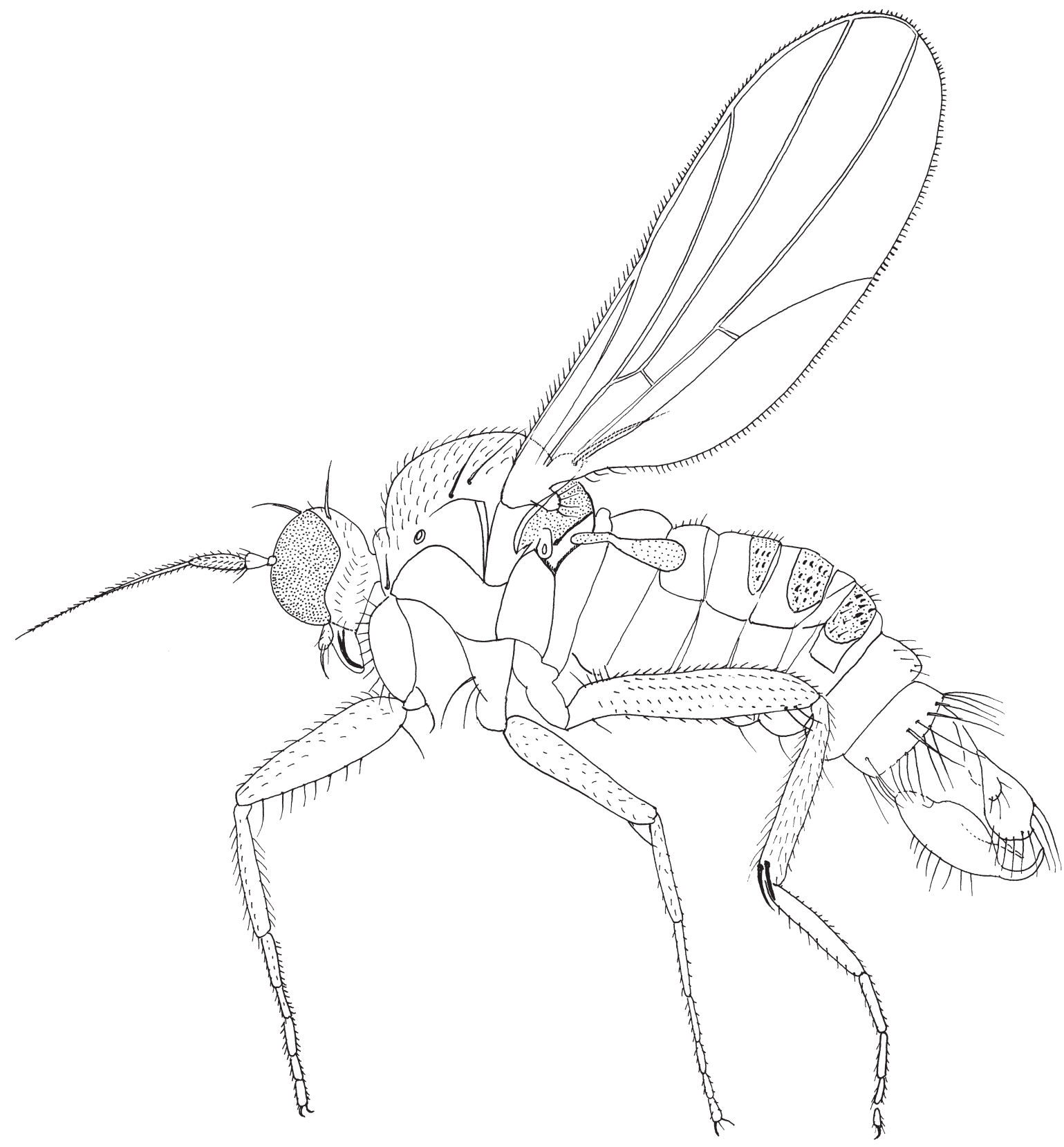

Fig. 108. Elaphropeza biuncinata (Melander, 1928), đ̂, habitus. (after Shamshev \& Grootaert 2007). 
hind tibia lacks anterodorsal bristles (except E. combinata sp. nov.), cerci are separated (Fig. 111) and the right surstylus is very prominent (Figs 111). In females, sclerites of abdominal segment 8 are fused antero-laterally and sternite 8 is not folded apically (Fig. 115).

\section{Species Complex 1. - Hind tibia with 2 curved subapical bristles.}

Elaphropeza biuncinata (Melander, 1928)

Drapetis (Elaphropeza) biuncinata Melander, 1928: 313 (male).

Elaphropeza biuncinata - Shamshev \& Grootaert 2007: 14 (re-description), figs 1-9, 209, 211, 219-221, $239,241,251,258$.

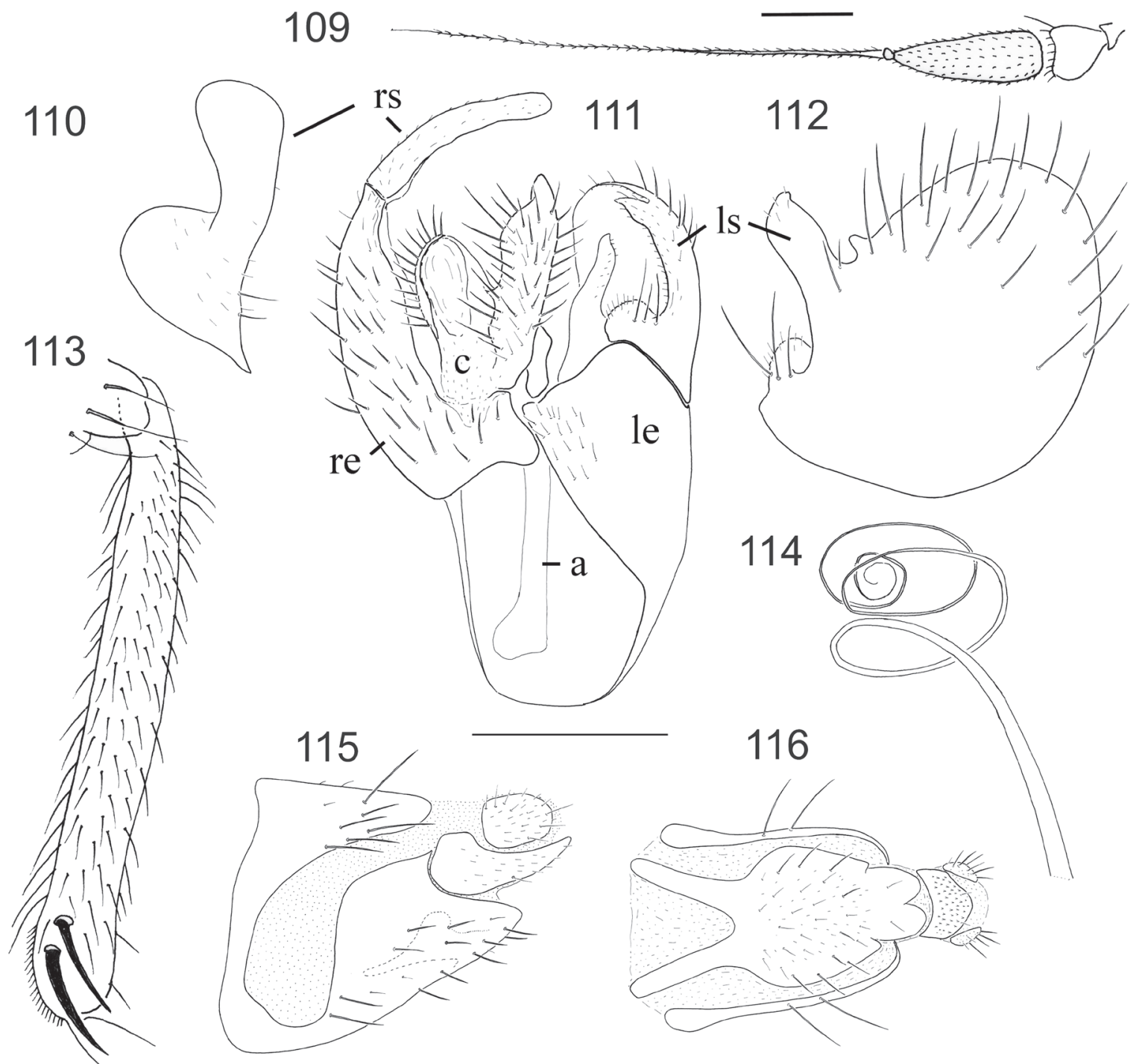

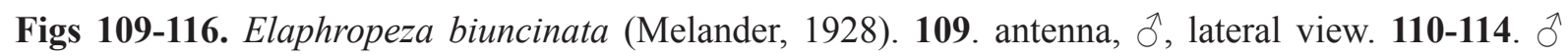
terminalia. 110. right surstylus, dorsal view. 111. epandrium and cerci, dorsal view. 112. left surstylus, lateral view. 113. hind tibia, male, posterior view; 114. phallus. 115. female ovipositor, lateral view; 116. female ovipositor, ventral view. Scale bar $=0.1 \mathrm{~mm}$ (after Shamshev \& Grootaert 2007). 


\section{Diagnosis}

Occiput largely yellow, broadly darkened above neck. Antenna with postpedicel nearly 3.0 times longer than wide; stylus normally pubescent, about 3.0-3.5 times longer than postpedicel and nearly 2.0 times as long as scape, pedicel and postpedicel combined. Thorax almost uniformly yellow, katepisternum (= sternopleuron) and meron (= hypopleuron) along lower margin and entire metanotum usually brownish; acrostichal and dorsocentral bristles undifferentiated. Legs uniformly yellow; hind tibia bearing 2 black curved subapical anteroventral bristles. Wing uniformly finely infuscate; halter dark.

\section{Material examined}

SINGAPORE: $2 \AA \hat{\partial}$, Semakau, 20 May 2009, beach forest, sweeping (reg. 29097, leg. P.G.); 1 , Kranji (KNT01), 12 May 2009, mangrove, Mal. (reg. 29052, leg. P.G.).

\section{Distribution}

Malaysia, Philippines and Singapore.

\section{Habitat and seasonal occurrence}

This is one of the most common species of Elaphropeza in Singapore, with records from all forest types. The species was already known in Singapore from Bukit Timah, Nee Soon, Chek Jawa and Sime forest. Here we add records from Semakau and Kranji. Elaphropeza biuncinata is present throughout the year. In the first half of the year there are short, small peaks nearly every month that probably reflect a onemonth generation time interval. It is abundant and continuously present from the beginning of August until mid of December. The sex ratio is almost $1 / 1$ suggesting a similar activity pattern for females and males.

\section{Elaphropeza murphyi Shamshev \& Grootaert, 2007}

Elaphropeza murphyi Shamshev \& Grootaert, 2007: 31.

\section{Diagnosis}

Occiput black, postpedicel 3.0-3.5 times longer than wide; thorax and legs uniformly yellow, hind tibia with 2 curved subapical bristles.

\section{Material examined}

SINGAPORE: 1 +, Pulau Ubin (PU02), 2 June 2009, mangrove, Mal. (reg. 29135, leg. P.G.).

\section{Distribution}

Singapore.

\section{Habitat and seasonal occurrence}

Elaphropeza murphyi is exclusively found in mangroves and was previously recorded from Chek Jawa and Sungei Buloh. It is not very common and most records are from mid October until the end of December. Nonetheless there are single records in May and June. Few males have been found and the sex ratio is $5 / 1$ females to males.

\section{Species Complex 2. - Hind tibia with 1 curved subapical bristle.}

\section{Elaphropeza crassicercus Shamshev \& Grootaert, 2007}

Elaphropeza crassicercus Shamshev \& Grootaert, 2007: 37. 


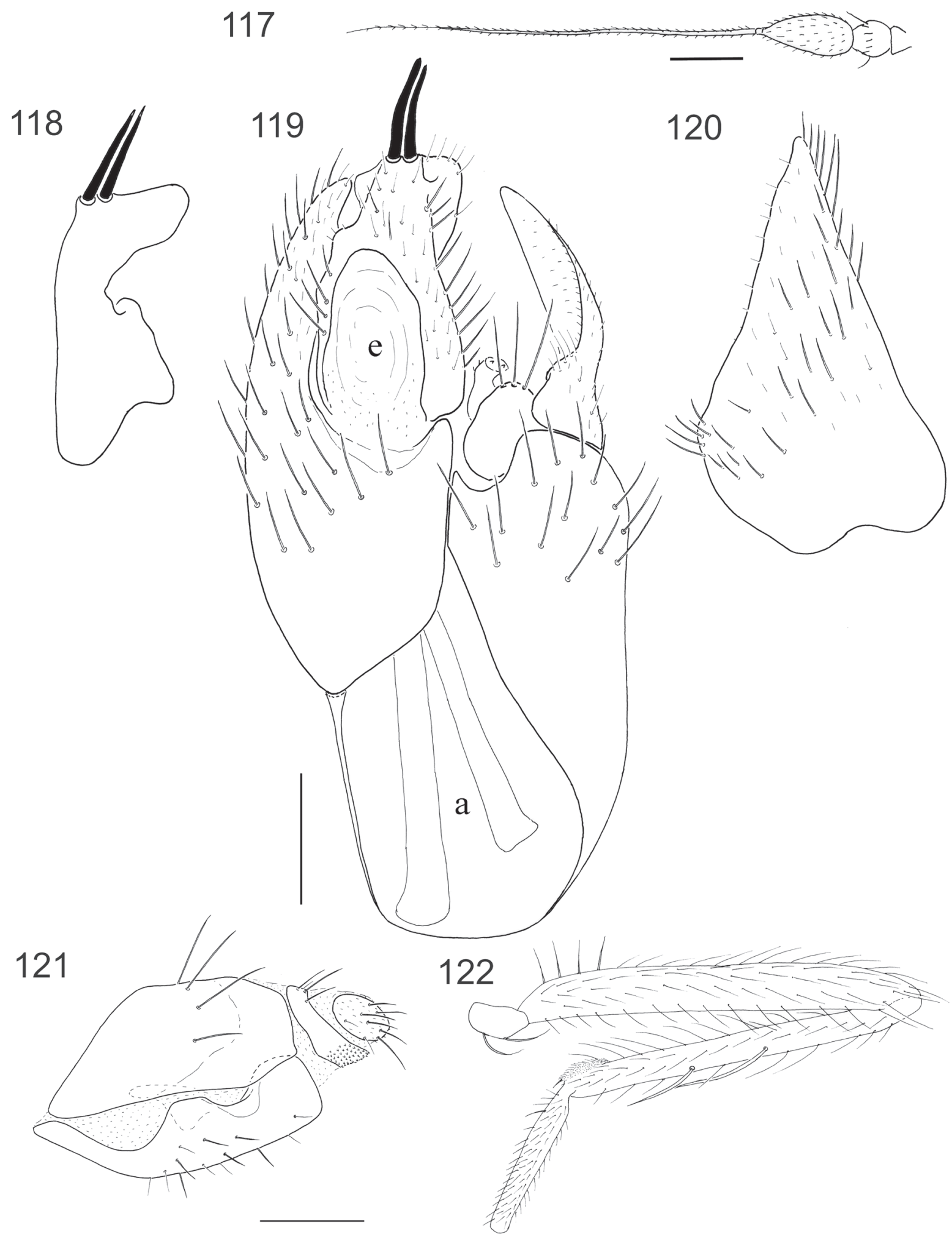

Figs 117-122. Elaphropeza bicaudata (Melander, 1928). 117. antenna, $\widehat{\jmath}$, lateral view. 118. cerci, lateral view. 119. epandrium and cerci, dorsal view. 120. left surstylus, lateral view. 121. + ovipositor, lateral view. 122. hind femur and tibia, $\hat{\partial}$, anterior view. Scale bar $=0.1 \mathrm{~mm}$ (after Shamshev \& Grootaert 2007). 


\section{Diagnosis}

Occiput black, postpedicel about 2.5 times longer than wide; metanotum brown, otherwise thorax yellow; legs yellow, hind tibia with 1 black curved subapical anteroventral bristle.

\section{Material examined}

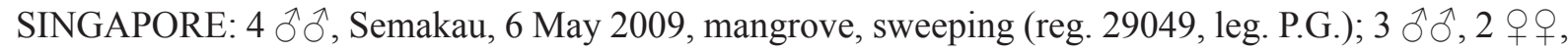
Semakau 20 May 2009, beach forest, sweeping (reg. 29097, leg. P.G.); 1 q, Kranji (KNT01), 12 May 2009, mangrove, Mal. (reg. 29052, leg. P.G.); 1 , Kranji (KNT01), 19 May 2009, mangrove, Mal. (reg. 29075, leg. P.G.); 1 \&, Kranji (KNT01), 26 May 2009, mangrove, Mal. (reg. 29103, leg. P.G.); 1 ð,, Kranji (KNT01), 2 June 2009, mangrove, Mal. (reg. 29128, leg. P.G.); 1 , , Pulau Ubin (PU02), 2 June 2009, mangrove, Mal. (reg. 29135, leg. P.G.); 2 ડㅅ, 1 ㅇ, Semakau (SMK04), 13 May 2009, mangrove, Mal. (reg. 29067, leg. P.G.); 1 đ, Sungei Cina (SCI02), 26 May 2009, mangrove, Mal. (reg. 29123, leg. P.G.); 1 §̂, Sungei Cina (SCI01), 26 May 2009, mangrove, Mal. (reg. 29154, leg. P.G.).

\section{Distribution}

Singapore.

\section{Habitat and seasonal occurrence}

This is a fairly common species that occurs in beach forests, mangroves and all types of terrestrial forests. Previously this species was reported from Kranji, Sungei Biloh, Sime forest and Nee Soon (Shamshev \& Grootaert 2007). It is present throughout the year, but with a higher activity in the second half of the year. The sex ratio of $0.5 / 1$ indicates that females have a different activity pattern than males.

\section{Species Complex 3. - Hind tibia lacking prominent bristles.}

No new information was found on that group since Shamshev \& Grootaert (2007).

\section{Elaphropeza ephippiata group}

Members of this group are characterised by the following combination of characters: two male genitalic rod-shaped apodemes (ventral and ejaculatory) present (Fig. 119); phallus short; long upturned bristle just above fore coxa absent; abdominal tergites 4 and/or 5 with squamiform setae (rarely absent); abdominal glands present between tergites 4 and 5. Additionally, in species of this group the hind tibia bears usually 1-2 anterodorsal bristles (but with quite numerous exceptions) (Fig. 122), cerci are usually fused to form a single lobe (Fig. 123) and the right surstylus is usually not prominent. In females, sclerites of abdominal segment 8 (Fig. 121) are separated (except in E. feminata sp. nov.) and sternite 8 is folded apically.

Species Complex 1. - Hind tibia lacking prominent bristles.

Elaphropeza temasek Shamshev \& Grootaert, 2007

Elaphropeza temasek Shamshev \& Grootaert, 2007: 59.

\section{Diagnosis}

Rather large species with entirely black thorax; postpedicel 4.0-4.5 times longer than wide, antenna wholly brown; acrostichal and dorsocentral bristles few in number; legs almost uniformly brownish yellow, mid and hind tibiae lacking anterodorsal bristles; tergites 4 and 5 with squamiform setae.

\section{Material examined}

SINGAPORE: 1 ð̊, Kranji (KNT01), 26 May 2009, mangrove, Mal. (reg. 29103, leg. P.G.). 


\section{Distribution}

Singapore.

\section{Habitat and seasonal occurrence}

Elaphropeza temasek is exclusively observed in the mangrove of Sungei Buloh Wetland Reserve and the adjacent Kranji Nature trail. It is rare (7 records only) in comparison to other species of Elaphropeza in Singpore. It is active throughout the year and due to its rarity no peak activity is observed.

Elaphropeza sivasothii Shamshev \& Grootaert, 2007

Elaphropeza sivasothii Shamshev \& Grootaert, 2007: 66.

\section{Diagnosis}

Occiput black, postpedicel nearly 3.0 times longer than wide, stylus about 1.5 times longer than postpedicel; thorax yellow, acrostichals and dorsocentrals multiserial; tarsomere 5 of all legs brown, hind tibia lacking prominent bristles.

\section{Material examined}

SINGAPORE: 1 ð̊, Semakau (SMK02), 20 May 2009, mangrove, Mal. (reg. 29088, leg. P.G.); 1 ô, Semakau (Semakau), 20 May 2009, beach forest, sweeping (reg. 29097, leg. P.G.); 1 §̂, Semakau (SMK05), 20 May 2009, mangrove, Mal. (reg. 29091, leg. P.G.); 1 đ, 4 $q$ , Pulau Ubin (PU02), 2 June 2009, mangrove, Mal. (reg. 29135, leg. P.G.).

\section{Distribution}

Singapore.

\section{Habitat and seasonal occurrence}

This is a rare species that was recorded previously only by net sweeping at Sungei Buloh, Kranji beach forest and at the mangrove of Chek Jawa on Pulau Ubin. This species is most recently also found on Semakau and was collected by Malaise trap.

\section{Species Complex 2. - Hind tibia with 1-2 anterodorsal bristles in middle part.}

Elaphropeza limosa Shamshev \& Grootaert, 2007

Figs 123-127

Elaphropeza limosa Shamshev \& Grootaert, 2007: 78.

\section{Diagnosis}

Thorax entirely brownish; antenna brown, postpedicel about 4.0 times longer than wide, stylus nearly 1.5 times longer than postpedicel; acrostichals and dorsocentrals multiserial; hind tibia with 1 anterodorsal bristle; halter with black knob.

\section{Material examined}

SINGAPORE: 1 ô, Lim Chu Kan (LCK01), 12 May 2009, mangrove, Mal. (reg. 29054, leg. P.G.); 1 ô, Lim Chu Kan (LCK03), 26 May 2009, mangrove, Mal. (reg. 29106, leg. P.G.); 1 ô, Lim Chu Kan (LCK01), 2 June 2009, mangrove, Mal. (reg. 29130, leg. P.G.); 1 †, Kranji (KNT01), 2 June 2009, mangrove, Mal. (reg. 29128, leg. P.G.); 1 क, Kranji (KNT01), 26 May 2009, mangrove, Mal. (reg. 


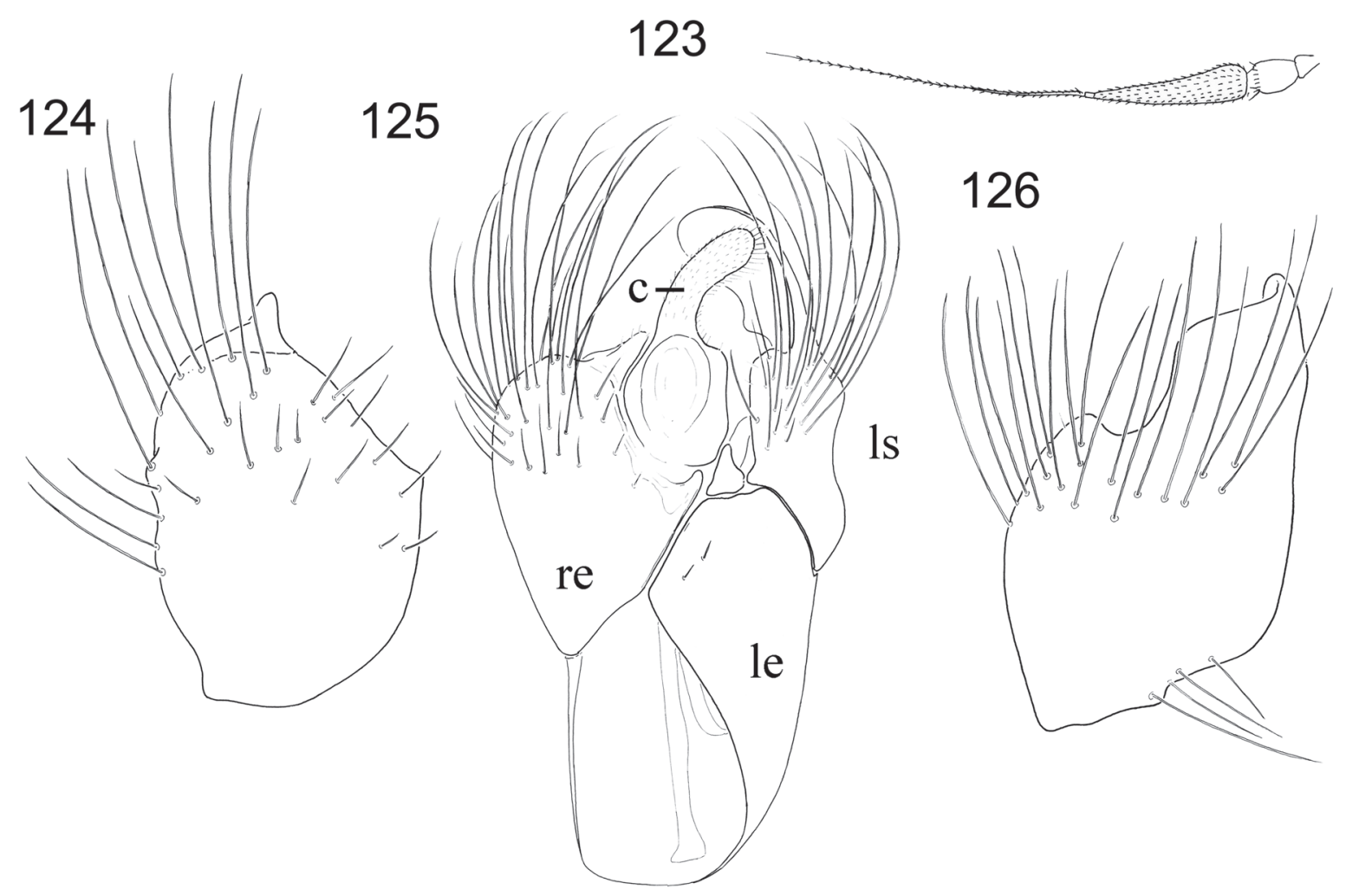

Figs 123-126. Elaphropeza limosa Shamshev \& Grootaert, 2007, §.. 123. antenna, lateral view. 124. right epandrial lamella, lateral view, 125. epandrium and cerci, dorsal view. 126. left surstylus, lateral view. (after Shamshev \& Grootaert 2007).

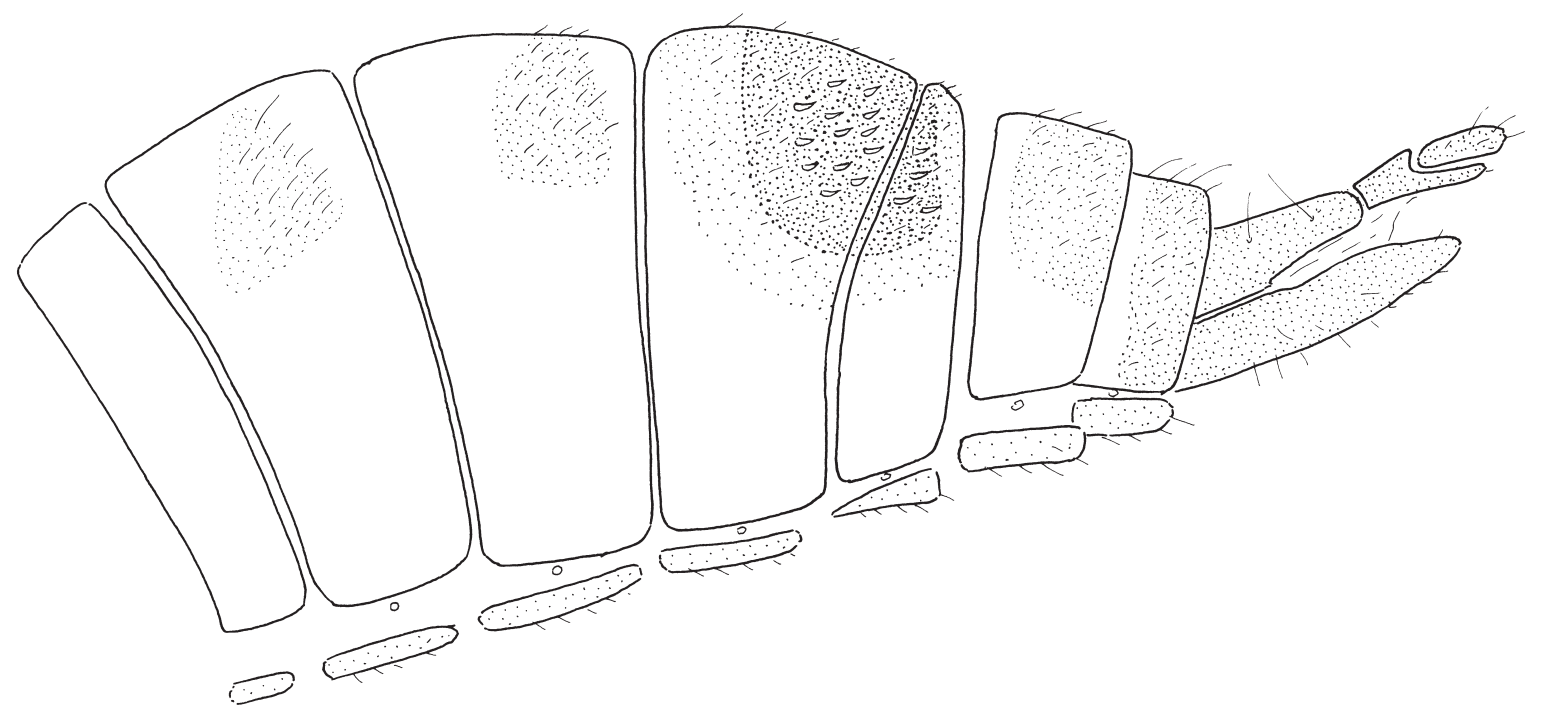

Fig. 127. Elaphropeza limosa Shamshev \& Grootaert, 2007, + abdomen, lateral view. 
29103, leg. P.G.); 1 ㅇ, Semakau (SMK02), 20 May 2009, mangrove, Mal. (reg. 29088, leg. P.G.); 1 ㅇ, Pulau Ubin (PU02), 26 May 2009, mangrove, Mal. (reg. 29110, leg. P.G.).

\section{Distribution}

Singapore.

\section{Habitat and seasonal occurrence}

This is a common species that is only found in mangrove. It was previously also recorded from Lim Chu Kan and Sungei Buloh.

\section{Remarks}

The bristling on right epandrial lamella and on left surstylus is longer and denser than originally shown in figs 121-123 (Shamsev \& Grootaert 2007).

\section{Elaphropeza shufenae sp. nov.}

Figs 128-131

\section{Diagnosis}

Thorax entirely brownish; antenna brownish, postpedicel about 4.0 times longer than wide, stylus nearly as long as postpedicel; acrostichals and dorsocentrals undifferentiated; hind tibia with 1 anterodorsal bristle; halter dark.

\section{Description}

\section{Male}

LENGTH. Body 1.6-1.7 mm, wing 1.3-1.5 mm.

HEAD. Black, mostly with dark brown setation. Eye with hind margin slightly concave. Anterior ocellars long, proclinate; posterior ocellars minute. Two pairs of inclinate verticals (inner pair longer). Antenna (Fig. 128) entirely brownish. Pedicel with circlet of equally minute setulae. Postpedicel nearly 4.0 times longer than wide. Stylus normally pubescent, brown, nearly as long as postpedicel and about 1.5 times shorter than scape, pedicel and postpedicel combined. Proboscis brownish yellow. Palpus yellow, small, rounded; with scattered setulae.

Thorax. Entirely brown, with brown bristles. Proepisternum lacking long upturned bristle just above fore coxa, with 1 short upturned bristle in upper part. Postpronotal bristle not prominent. Mesonotum with 2 equally long notopleurals, 1 shorter postsutural supra-alar, 1 similar postalar and 4 scutellars (inner pair very long, cruciate; outer pair very short). Acrostichals and dorsocentrals undifferentiated, scutum evenly covered with uniform setulae, except 2 pairs of long prescutellars (posterior pair longer and nearly as long as apical scutellars).

Legs. Almost entirely yellow, tibiae and tarsi (especially tarsomere 5) with some brownish tinge. Coxae and trochanters with unmodified setation. Fore femur slightly thickened, with rows of short antero- and posteroventral setulae and 1 long pale bristle near base. Fore tibia lacking prominent bristles (except subapicals). Mid femur with spinule-like, short ventral setae, 1 longer seta near base and 1 anterior subapical bristle. Mid tibia with 2 rows of slightly prominent ventral spinules, lacking prominent bristles (except subapicals). Hind femur evenly thickened, with 1 row of short anteroventral and posteroventral setae (latter sitting on small tubercles in basal part) and 3-4 erect dorsal bristles near base. Hind tibia somewhat thickened, bearing 1 long anterodorsal bristle near middle; apical projection small, pointed, clothed in dense brownish setulae. 
WING. Normally developed, distinctly brownish infuscate, covered with uniform microtrichia; veins yellowish brown. Costal vein with moderately long setulae along anterior margin. Basal costal bristle rather long, brown. Costal index: 22/19/20/10. $\mathrm{R}_{4+5}$ and $\mathrm{M}_{1+2}$ somewhat divergent near wing apex, both straight. Crossvein bm-cu somewhat oblique. Crossvein r-m near middle of cell bm. Halter dark.

AbDomen. Tergite 1 almost entirely pale yellow, only very small brownish space bearing few minute setulae present on each side. Tergites 2 and 3 represented by 2 large subtriangular brownish spaces broadly separated along midline, with unmodified setae. Tergite 4 broad, darker, with numerous squamiform setae. Tergite 5 very narrow, bearing squamiform setae. Tergites 6-7 unmodified, tergite 6 with short posteromarginal bristles, tergite 7 with several long posteromarginal bristles. Segment 8 lacking setation. Sternites unmodified, weakly sclerotised, with scattered minute setulae. Gland-like structures present between tergites 4 and 5 .

Terminalia. Brown, moderately large, rather elongate (Figs 129-131). Cerci narrowly fused; right cercus digitiform, moderately long, covered with short unmodified setae; left cercus somewhat longer and broader than right cercus, with short unmodified setae. Epandrium completely divided. Right epandrial lamella (Fig. 129) conical, with numerous unmodified setae longer ventrally. Right surstylus not prominent. Left epandrial lamella fused to hypandrium, with numerous short setae apically. Left surstylus (Fig. 131) with upper lobe large, rather broadly oval, with scattered short submarginal setae. Hypandrium with 2 long setae. Phallus very short. Two rod-shaped apodemes present.

\section{Female}

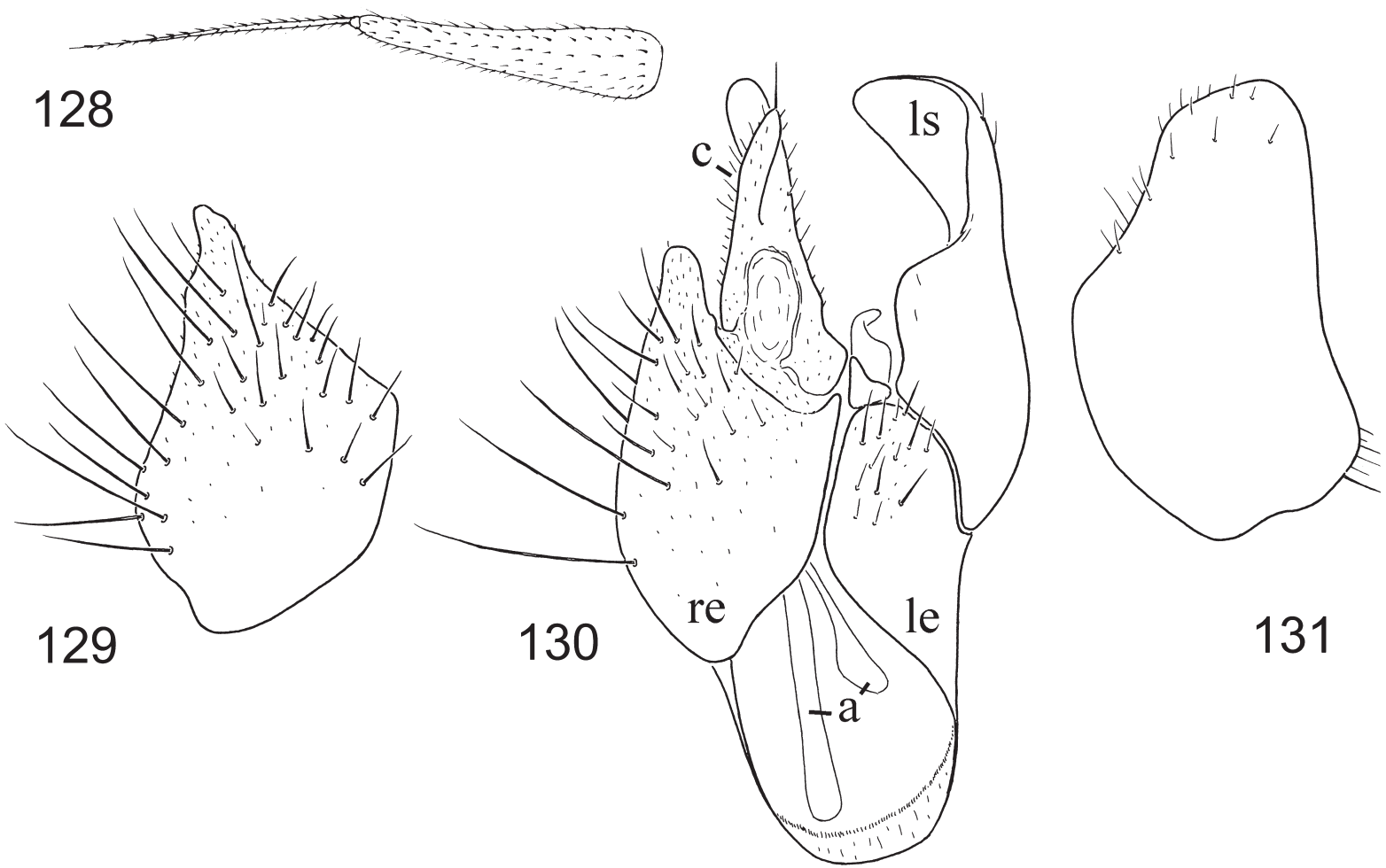

Figs 128-131. Elaphropeza shufenae sp. nov., $\widehat{\partial}$. 128. postpedicel and stylus of antenna, lateral view. 129. right epandrial lamella, lateral view. 130. epandrium and cerci, dorsal view. 131. left surstylus, lateral view. 
Mid tibia with unmodified ventral setation. Abdominal segment 8 elongate, very narrow, with sclerites separated; sternite 8 folded apically. Cercus elongate, brown.

\section{Material examined}

Holotype ${ }^{\lambda}$

SINGAPORE: Semakau (SMK02), 27 May 2009, mangrove, Mal. (reg. 29116, leg. P.G.; in ZRC).

\section{Paratypes}

SINGAPORE: $3 \widehat{\partial} \widehat{\jmath}, 1$ q, Semakau (SMK02), 13 May 2009, mangrove, Mal. (reg. 29065, leg. P.G.); 1 , Semakau (SMK02), 27 May 2009, mangrove, Mal. (reg. 29116, leg. P.G.); 5 우, Semakau (SMK02), 3 June 2009, mangrove, Mal. (reg. 29141, leg. P.G.); 1 +, Semakau (SMK03), 3 June 2009, mangrove, Mal. (reg. 29142, leg. P.G.).

\section{Etymology}

The species is dedicated to Ms. Shufen Yang for her very enthusiastic help during fieldwork in 2009.

\section{Distribution}

Singapore.

\section{Habitat and seasonal occurrence}

This species occurs in mangroves from May to June.

\section{Remarks}

In having entirely brownish thorax, the new species could be only compared with E. limosa. However, in $E$. limosa the antennal stylus is longer, about 1.5 times as long as the postpedicel (vs. nearly as long as postpedicel in the new species). Additionally, E. limosa is somewhat larger, the male has entirely fused cerci and right epandrial lamella and left surstylus covered with numerous very long setae.

Elaphropeza monospina Shamshev \& Grootaert, 2007

Elaphropeza monospina Shamshev \& Grootaert, 2007: 81.

\section{Diagnosis}

Occiput black, postpedicel nearly 3.0 times longer than wide, stylus about 2.0 times longer than postpedicel; scutum with brownish pattern; acrostichal and dorsocentral bristles multiserial; legs entirely yellow, hind tibia with 1 anterodorsal bristle, hind basitarsus with 1 spine-like ventral bristle near base.

\section{Material examined}

SINGAPORE: 1 , Semakau (SMK05), 13 May 2009, mangrove, Mal. (reg. 29068, leg. P.G.); 1 , Semakau (SMK03), 20 May 2009, mangrove, Mal. (reg. 29089, leg. P.G.); 1 ð,, Semakau (SMK02), 20 May 2009, mangrove, Mal. (reg. 29088, leg. P.G.); 1 §̋, 2 우, Semakau (SMK05), 20 May 2009, mangrove, Mal. (reg. 29091, leg. P.G.); 2 ô, 1 †, Semakau (SMK05), 27 May 2009, mangrove, Mal.

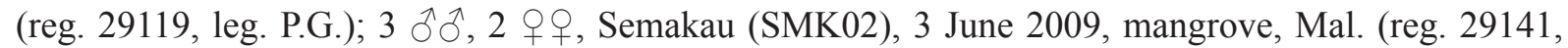

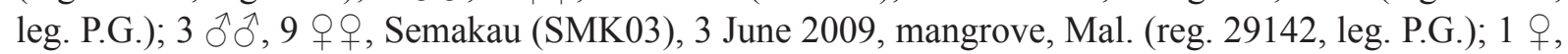
Kranji (KNT01), 12 May 2009, mangrove, Mal. (reg. 29052, leg. P.G.); 1 ○, Kranji (KNT01), 26 May 2009, mangrove, Mal. (reg. 29103, leg. P.G.); 2 J, Sungei Cina (CHC01), 19 May 2009, mangrove, Mal. (reg. 29083, leg. P.G.); 2 우, Mandai (MAN01), 12 May 2009, mangrove, Mal. (reg. 29056, leg. P.G.); 1 क, Mandai (MAN01), 26 May 2009, mangrove, Mal. (reg. 29107, leg. P.G.); 


\section{Distribution}

Malaysia, Singapore.

\section{Habitat and seasonal occurrence}

This is a common species in mangroves. It is present throughout the year with no marked peak activity. It has been also recorded from Chek Jawa, Sungei Buloh and Pasir Ris.

Elaphropeza asiophila Shamshev \& Grootaert, 2007

Elaphropeza asiophila Shamshev \& Grootaert, 2007: 85.

\section{Diagnosis}

Occiput black, postpedicel nearly 6.0 times longer than wide, stylus about 1.5 times shorter than postpedicel; thorax wholly reddish yellow, acrostichal and dorsocentral bristles multiserial; tarsomere 5 of all legs dark brown, fore tibia and fore tarsomeres 2-4 brownish, hind tibia with 1 anterodorsal bristle near middle.

\section{Material examined}

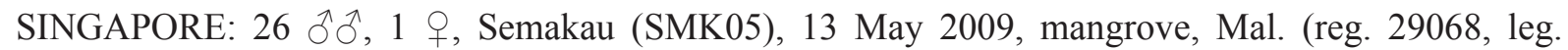
P.G.); 2 우, Semakau (Semakau), 6 May 2009, mangrove, sweeping (reg. 29049, leg. P.G.); 2 ठ Semakau (SMK02), 13 May 2009, mangrove, Mal. (reg. 29065, leg. P.G.); 6 ỗ, Semakau (Semakau), 20 May 2009, beach forest, sweeping (reg. 29097, leg. P.G.); 3 ô $\widehat{\jmath}$, Semakau (SMK02), 20 May 2009, mangrove, Mal. (reg. 29088, leg. P.G.); 10 ふึ ô, 1 ㅇ, Semakau (SMK05), 20 May 2009, mangrove, Mal. (reg. 29091, leg. P.G.); 1 ô, Semakau (SMK02), 27 May 2009, mangrove, Mal. (reg. 29116, leg. P.G.);

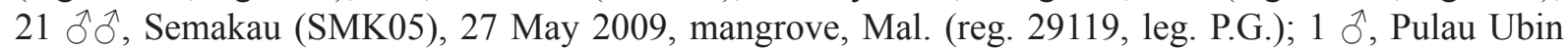

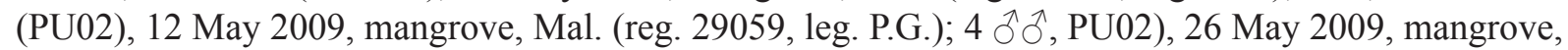
Mal. (reg. 29110, leg. P.G.); 6 क , Pulau Ubin (PU02), 2 June 2009, mangrove, Mal. (reg. 29135, leg. P.G.); 1 +, Pasir Ris (PSR01), 19 May 2009, mangrove, Mal. (reg. 29085, leg. P.G.).

\section{Distribution}

Malaysia, Singapore.

\section{Habitat and seasonal occurrence}

Originally this species was only recorded from Chek Jawa. It is now found quite abundantly in the mangroves at Semakau, Pulau Ubin and Pasir Ris, with all records from May.

Elaphropeza riatanae Shamshev \& Grootaert, 2007

Elaphropeza riatanae Shamshev \& Grootaert, 2007: 88.

\section{Diagnosis}

Occiput black, postpedicel about 5.0 times longer than wide; mesonotum yellow with brown scutellum; acrostichal and dorsocentral bristles multiserial; legs with brownish pattern, hind tibia with 1 anterodorsal bristle near middle; abdominal tergites 4 and 5 with squamiform setae.

\section{Material examined}

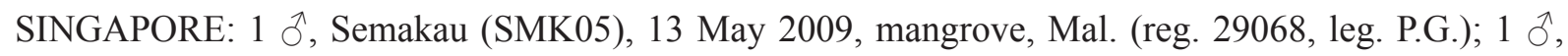
Semakau (SMK05), 20 May 2009, mangrove, Mal. (reg. 29091, leg. P.G.); 1 §, Semakau (SMK01), 27 May 2009, mangrove, Mal. (reg. 29115, leg. P.G.); 1 O, Semakau (SMK03), 3 June 2009, mangrove, 
Mal. (reg. 29142, leg. P.G.); 1 क, Pulau Ubin (PU02), 2 June 2009, mangrove, Mal. (reg. 29135, leg. P.G.); 1 q, Pulau Ubin (PU02), 2 June 2009, mangrove, Mal. (reg. 29135, leg. P.G.).

\section{Distribution}

Singapore.

\section{Habitat and seasonal occurrence}

This is a rare species recorded only in mangroves. Previously it was recorded also from Sungei Buloh. All collection records are from May and June.

Elaphropeza furca Shamshev \& Grootaert, 2007

Fig. 246

Elaphropeza furca Shamshev \& Grootaert, 2007: 90.

\section{Diagnosis}

Occiput black, postpedicel about 3.0 times longer than wide, stylus about as long as postpedicel; thorax yellow, acrostichals biserial, dorsocentrals uniserial; legs partly brownish, hind tibia with 1 anterodorsal bristle; abdominal tergites 4 and 5 with squamiform setae.

\section{Material examined}

SINGAPORE: 1 §, Semakau, 6 May 2009, mangrove, sweeping (reg. 29049, leg. P.G.); 3 $ᄋ$, Semakau (SMK03), 13 May 2009, mangrove, Mal. (reg. 29066, leg. P.G.); 22 §ึ, 15 q , Semakau, 20 May 2009, beach forest, sweeping (reg. 29097, leg. P.G.); $4 \hat{\partial} \hat{\partial}, 1$ ㅇ, Sungei Buloh (SBWR01), 19 May 2009, mangrove, Mal. (reg. 29073, leg. P.G.); 1 , Kranji (KNT02), 12 May 2009, mangrove, Mal. (reg.

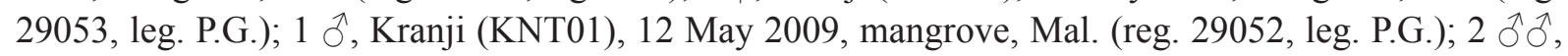

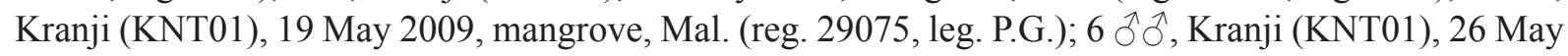
2009, mangrove, Mal. (reg. 29103, leg. P.G.); 1 đ̃, 1 क, Kranji (KNT01), 2 June 2009, mangrove, Mal. (reg. 29128, leg. P.G.); 3 $\widehat{\jmath}$, Kranji (KNT02), 2 June 2009, mangrove, Mal. (reg. 29129, leg. P.G.).

\section{Distribution}

Singapore.

\section{Habitat and seasonal occurrence}

This species is more common than previously thought. On several occasions it was found in anthropogenic conditions: the park at Kranji, the beach forest at the landfill of Semakau island and a patch of secondary forest at Bukit Timah. Future studies might show if it is a true colonizer. Collection records are from May and June.

Elaphropeza malayensis Shamshev \& Grootaert, 2007

Figs 132-135

Elaphropeza malayensis Shamshev \& Grootaert, 2007: 94.

\section{Diagnosis}

Occiput black, postpedicel 3.0 times longer than wide, stylus nearly 2.0 times longer than postpedicel; thorax yellow, acrostichals 2-serial, dorsocentrals 1-2-serial; tarsomere 5 of all legs brownish, hind tibia with 1 anterodorsal bristle; only tergite 5 with squamiform setae. 


\section{Material examined}

SINGAPORE: 1 क, Semakau (SMK05), 3 June 2009, mangrove, Mal. (reg. 29144, leg. P.G.); 1 đ, Sungei Buloh (SBWR01), 2 June 2009, mangrove, Mal. (reg. 29126, leg. P.G.); 1 +, Kranji (KNT01), 12 May 2009, mangrove, Mal. (reg. 29052, leg. P.G.); 1 \%, Kranji (KNT01), 19 May 2009, mangrove, Mal. (reg. 29075, leg. P.G.).

\section{Distribution}

Malaysia, Singapore.

\section{Habitat and seasonal occurrence}

This species occurs in mangroves and occasionally in terrestrial forests. Collection records are from May and June.

\section{Remarks}

This is a rare species that is generally represented by single females. Here we record the third known male specimen. Elaphropeza malayensis, E. chanae sp. nov., E. gohae sp. nov. and E. lowi sp. nov. all belong to a complex of species that are very closely related and quite difficult to separate (see key to
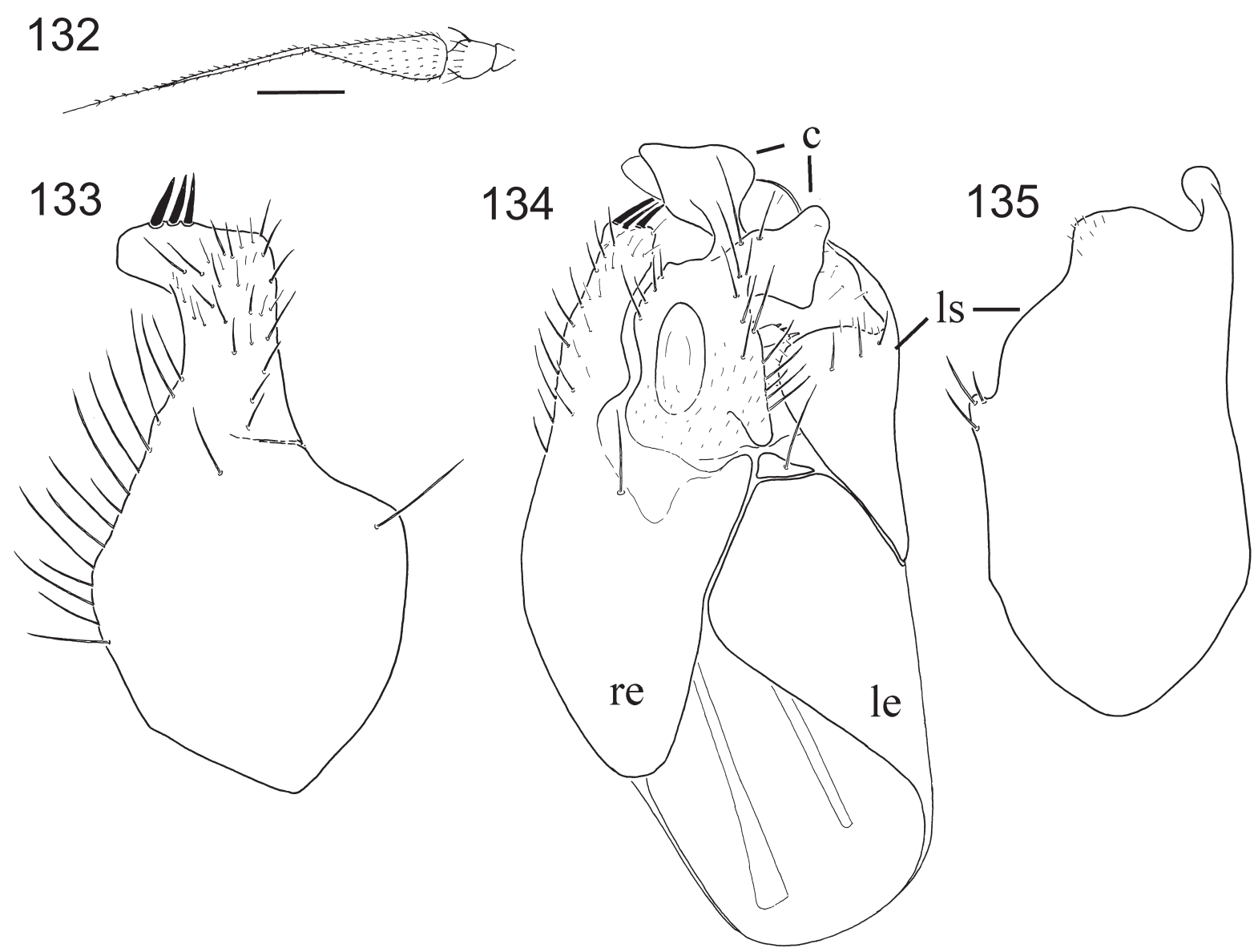

Figs 132-135. Elaphropeza malayensis Shamshev \& Grootaert, 2007, §ิ. 132. postpedicel and stylus of antenna, lateral view. 133. right epandrial lamella, lateral view. 134. epandrium with cerci, dorsal view. 135. left surstylus, lateral view. Scale bar $=0.1 \mathrm{~mm}$ (after Shamshev \& Grootaert 2007). 
species). There are differences in length of the postpedicel and stylus and the presence of biseriate or multiseriate acrostichals on the scutum. Male genitalia are similar but distinct especially in the presence/ absence of spine-like bristles on the right epandrial lamella (surstylus).

Elaphropeza chanae sp. nov.

Figs 136-139

\section{Diagnosis}

Antennal stylus subequal to pedicel; acrostichals 4-serial anteriorly, lacking on prescutellar depression; metanotum brownish yellow. Male: right epandrial lamella conical, with black spines; fore tibia with black subapical spine.

\section{Description}

\section{Male}

LeNGTH. Body 2.1, wing 2.0-2.1 mm.

OCCIPUT. Black. Anterior ocellars long, proclinate and cruciate; posterior ocellars minute. Inner verticals long, outer verticals somewhat shorter. Antenna (Fig. 136) with scape and pedicel yellow, postpedicel brownish in apical part and yellowish basally (yellow space varying, but no more than half of postpedicel). Pedicel with circlet of subequally short setulae. Postpedicel nearly 4.0 times longer than wide. Stylus normally pubescent, brown, subequal to postpedicel and nearly 1.5 times shorter than scape, pedicel and postpedicel combined. Proboscis brownish yellow. Palpus yellow, small, rounded.

THorax. Almost entirely yellow, only metanotum brownish yellow. Prothoracic episternum lacking long upturned bristle just above fore coxa, with 1 very short seta in upper part. Postpronotal bristle not prominent. Mesonotum with 2 long notopleurals, 1 shorter postsutural supra-alar, 1 similar postalar and 4 scutellars (apical pair very long, cruciate; lateral pair minute). Acrostichals arranged in 4 irregular rows anteriorly but 2-serial posteriorly, lacking on prescutellar depression; dorsocentrals arranged in 3-4 irregular rows anteriorly, becoming 1-serial toward scutellum, 2 prescutellar pairs long (posterior pair longer, nearly as long as apical scutellars).

Legs. Almost entirely yellow, only tarsomere 5 of all legs black. Coxae and trochanters with unmodified setation. Fore femur somewhat thickened, with rows of short anteroventral and posteroventral bristles, 2 longer pale setae near base. Fore tibia lacking prominent bristles (except subapicals), with subapical, black claw-like spine anteriorly. Mid femur with rows of spinule-like, short ventral setae. Mid tibia with hardly prominent ventral spinules, bearing subapical, black claw-like spine, lacking prominent bristles (except subapicals). Hind femur with row of short anteroventral setae and about 4 short erect dorsal setae near base. Hind tibia bearing 1 anterodorsal bristle, with slightly prominent rounded apical projection. Tarsi of all legs unmodified.

Wing. Uniformly finely infuscate. Basal costal bristle moderately long, brownish yellow. Costal index: 44/22/27/13. $\mathrm{R}_{4+5}$ and $\mathrm{M}_{1+2}$ somewhat divergent near wing apex, both straight. Crossvein bmcu transverse. Crossvein $\mathrm{r}-\mathrm{m}$ near middle of cell bm. Calypter brownish yellow, with several long concolorous setae. Halter pale yellow.

AвDomen. Tergite 1 entirely pale yellow. Tergites 2 and 3 brownish, of subequal width viewed dorsally, deeply concave anteriorly and divided along midline; with unmodified setation. Tergite 4 broadest, dark brown, subshining, with slightly flattened setae. Tergite 5 very narrow, concolorous with tergite 4 , bearing squamiform setae. Tergites 6 and 7 brownish yellow, with moderately long posteromarginal setae. Segment 8 with several short unmodified setae. 
Terminalia. Rather large, left surstylus brownish, right epandrial lamella yellowish brown apically and yellow basally (Figs 137-139). Cerci narrowly fused; right cercus short, digitiform, with several short setae, lacking spines; left cercus of complicated structure, as in Figure 138, with additional lobe produced internally, covered with unmodified setae of different lengths, lacking spines. Epandrium completely divided. Right surstylus not prominent. Right epandrial lamella (Fig. 137) conical, bearing 4 black subapical spines ( 3 spines closer to each other and 1 spine aside), with numerous moderately long setae longer along ventral margin. Left epandrial lamella fused to hypandrium, with 1 long seta apically. Left surstylus (Fig. 139) with upper lobe large, rather conical, broadly rounded apically, with scattered setulae on outer face but bearing some moderately long setae on inner face and several short strong setae near base dorsally. Hypandrium with 2 long setae apically. Phallus short. Two rod-shaped apodemes present.

\section{Female}

Similar to male except for fore and mid tibiae with unmodified ventral setation. Abdominal segments 6 and 7 with minute setulae; segment 8 unmodified, brownish, with scattered short setae. Cercus narrow, brownish.

\section{Material examined}

Holotype $\widehat{O}$

SINGAPORE: 1 ○, Semakau (SMK03), 3 June 2009, mangrove, Mal. (reg. 29142, leg. P.G.; in ZRC).
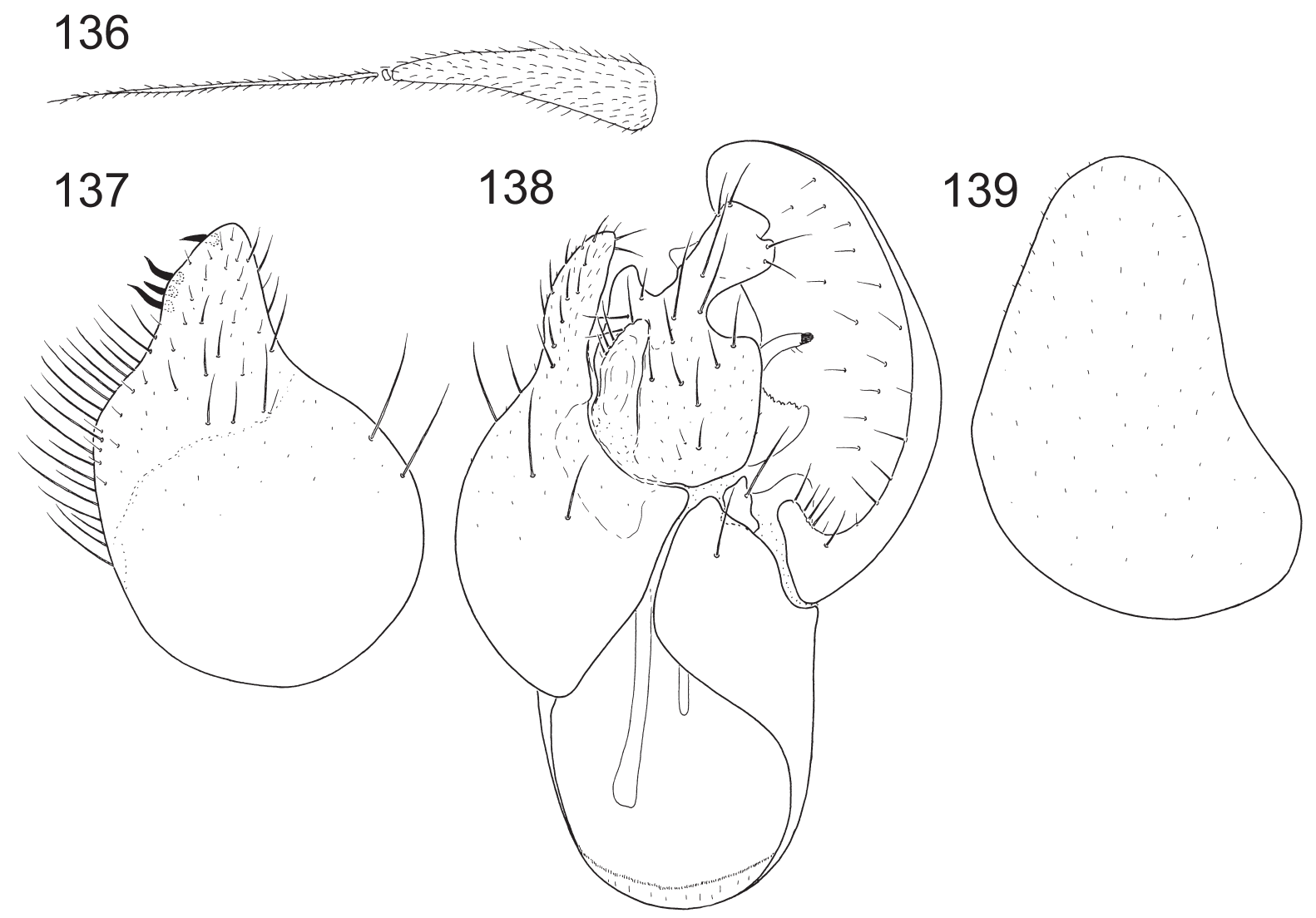

Figs 136-139. Elaphropeza chanae sp. nov., §̊. 136. postpedicel and stylus of antenna, lateral view. 137. right epandrial lamella, lateral view. 138. epandrium with cerci, dorsal view. 139. left surstylus, lateral view. 
Paratypes

SINGAPORE: 1 q, Semakau (SMK05), 27 May 2009, mangrove, Mal. (reg. 29119, leg. P.G.); 1 q, Semakau (SMK05), 13 May 2009, mangrove, Mal. (reg. 29068, leg. P.G.); 1 q, Semakau (SMK02), 20 May 2009, mangrove, Mal. (reg. 29088, leg. P.G.); 1 ㅇ, Semakau (SMK05), 20 May 2009, mangrove, Mal. (reg. 29091, leg. P.G.); 2 우, Semakau (SMK02), 27 May 2009, mangrove, Mal. (reg. 29116, leg. P.G.).

\section{Etymology}

The new species is dedicated to Dr. Lena Chan, Deputy Director of the National Biodiversity Centre at NParks. The Singapore Mangrove Insect Project was made possible thanks to her enthusiastic interest and help.

\section{Distribution}

Singapore.

\section{Habitat and seasonal occurrence}

This species occurs in mangroves, with collection records from May and June.

\section{Remarks}

The new species belongs to a difficult complex of species that also includes E. malayensis (see Remarks section) and E. furca. The main differences between these species are given in the key.

\section{Elaphropeza gohae sp. nov.}

Figs 140-143

\section{Diagnosis}

Antennal stylus 1.5 times as long as postpedicel; acrostichals 4-serial anteriorly, lacking on prescutellar depression; metanotum yellow. Male: right epandrial lamella conical, without black spines; fore tibia with black subapical spine-like seta anteriorly.

\section{Description}

\section{Male}

LeNGTH. Body 2.1-2.3, wing 1.9-2.0 mm.

OcciPut. Black. Anterior ocellars long, proclinate and cruciate; posterior ocellars minute. Inner verticals long, outer verticals somewhat shorter. Antenna (Fig. 140) with scape and pedicel yellow, postpedicel brownish in apical part and yellowish basally (extend of yellow variable, but no more than half of postpedicel). Pedicel with circlet of subequally short setulae. Postpedicel nearly 4.0 times longer than wide. Stylus normally pubescent, brown, about 1.5 times as long as postpedicel and nearly 1.5 times shorter than scape, pedicel and postpedicel combined. Proboscis brownish yellow. Palpus yellow, small, rounded.

Thorax. Entirely yellow. Prothoracic episternum lacking long upturned bristle just above fore coxa, with 1 very short seta in upper part. Postpronotal bristle not prominent. Mesonotum with 2 equally long notopleurals, 1 somewhat shorter postsutural supra-alar, 1 long postalar and 4 scutellars (apical pair very long, cruciate; lateral pair minute). Acrostichals arranged in 4 irregular rows anteriorly but 2-serial posteriorly, lacking on prescutellar depression; dorsocentrals arranged in 2-3 irregular rows anteriorly, becoming 1-serial toward scutellum, 2 prescutellar pairs long (posterior pair longer, nearly as long as apical scutellars). 
Legs. Almost entirely yellow, only tarsomere 5 of all legs black. Coxae and trochanters with unmodified setation. Fore femur somewhat thickened, with rows of short anteroventral and posteroventral bristles, 2 longer pale setae near base. Fore tibia with subapical black spine-like seta anteriorly, otherwise lacking prominent bristles. Mid femur with rows of spinule-like, short ventral setae. Mid tibia with hardly prominent ventral spinules, bearing subapical, black claw-like spine, lacking prominent bristles (except subapicals). Hind femur with row of short anteroventral setae and about 4 short, erect dorsal setae near base. Hind tibia bearing 1 anterodorsal bristle, with slightly prominent, rounded apical projection. Tarsi of all legs unmodified.

Wing. Uniformly finely infuscate. Basal costal bristle moderately long, brownish yellow. Costal index: 45/28/22/14. $\mathrm{R}_{4+5}$ and $\mathrm{M}_{1+2}$ somewhat divergent near wing apex, both straight. Crossvein bm$\mathrm{cu}$ transverse. Crossvein $\mathrm{r}-\mathrm{m}$ near middle of cell bm. Calypter brownish yellow, with several long concolorous setae. Halter pale yellow.

ABDomen. Tergite 1 entirely pale yellow. Tergites 2 and 3 brownish, of subequal width in dorsal view, deeply concave anteriorly and divided along midline; with unmodified setation. Tergite 4 broadest, dark brown, subshining, with slightly flattened setae. Tergite 5 very narrow, concolorous with tergite 4 , bearing squamiform setae. Tergites 6 and 7 brownish yellow, with moderately long posteromarginal setae. Segment 8 with several short unmodified setae.

TERMinalia. Rather large, left surstylus brownish, right epandrial lamella yellowish brown apically and yellow basally (Figs 141-143). Cerci almost entirely fused; right cercus short, slightly prominent,
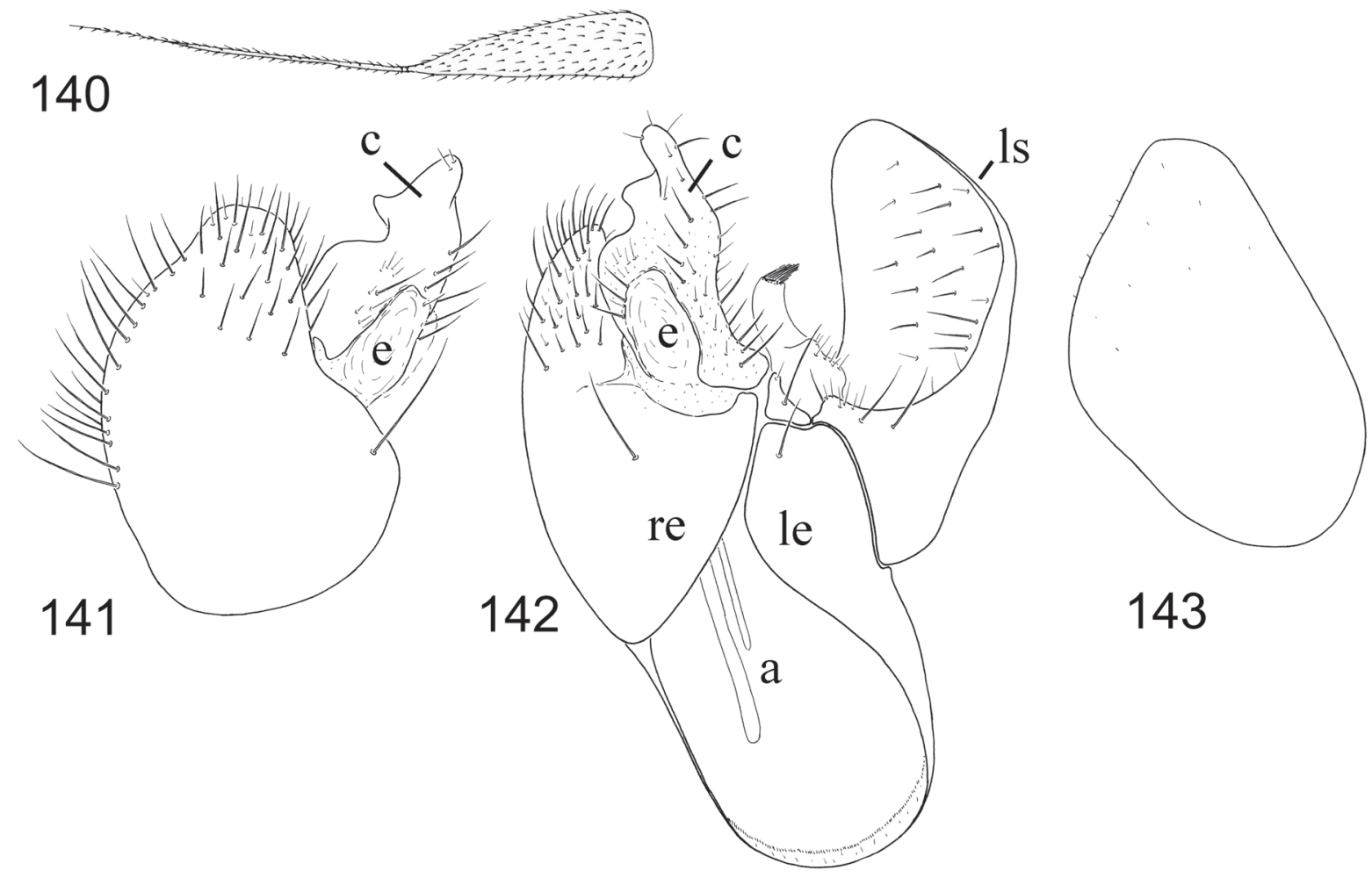

Figs 140-143. Elaphropeza gohae sp. nov., Ô. 140. postpedicel and stylus of antenna, lateral view. 141. right epandrial lamella and cerci, lateral view. 142. epandrium with cerci, dorsal view. 143. left surstylus, lateral view. 
with several short setae, lacking spines; left cercus (Fig. 142) longer than right cercus, digitiform, with additional lobe internally, bearing several setae of different lengths, lacking spines. Epandrium completely divided. Right epandrial lamella conical, broadly rounded apically, covered with numerous moderately long setae longer along ventral margin, lacking spines. Right surstylus not prominent. Left epandrial lamella fused to hypandrium, with 1 moderately long seta apically. Left surstylus (Fig. 143) with upper lobe large, broadly ovate, with scattered setulae on outer face but bearing some moderately long setae on inner face and several short strong setae near base dorsally. Hypandrium with 2 long setae apically. Phallus short. Two rod-shaped apodemes present.

\section{Female}

Similar to male but fore and mid tibiae with unmodified setation. Abdominal segments 6 and 7 with minute setulae; segment 8 unmodified, brownish, with scattered short setae. Cercus narrow, brownish.

\section{Material examined}

Holotype $\widehat{O}$

SINGAPORE: Semakau (SMK03), 3 June 2009, mangrove, Mal. (reg. 29142, leg. P.G.; in ZRC).

\section{Paratypes}

SINGAPORE: 1 ○ึ, Semakau (SMK02), 3 June 2009, mangrove, Mal. (reg. 29141, leg. P.G.); 4 q , Semakau (SMK03), 3 June 2009, mangrove, Mal. (reg. 29142, leg. P.G.); 3 đ̋, 6 우, Semakau (SMK05), 13 May 2009, mangrove, Mal. (reg. 29068, leg. P.G.); 1 §, Semakau (SMK02), 20 May 2009, mangrove, Mal. (reg. 29088, leg. P.G.); 2 ○ึ , Semakau (SMK05), 20 May 2009, mangrove, Mal. (reg. 29091, leg. P.G.); 1 Ĵ, 2 ㅇ, Semakau (SMK05), 27 May 2009, mangrove, Mal. (reg. 29119, leg. P.G.).

\section{Etymology}

The species is dedicated to Ms. Linda Goh responsible for the cell Marine biology at the National Biodiversity Centre at NParks. She also helped with great enthusiasm during fieldwork.

\section{Distribution}

Singapore.

\section{Habitat and seasonal occurrence}

This species occurs in mangroves, with collection records from May and June.

\section{Remarks}

The new species belongs to a difficult complex of species that also includes two species listed above, $E$. malayensis and E. furca. The main differences between these species are given in the key.

\section{Elaphropeza lowi sp. nov.}

Figs 144-147

\section{Diagnosis}

Rather small species; fore tibia without black subapical spine-like seta anteriorly; stylus 1.5 times as long as postpedicel; acrostichals 4-serial anteriorly, lacking on prescutellar depression; metanotum yellow. Male: right epandrial lamella truncate, without black spines.

\section{Description}

\section{Male}

LeNGTH. Body 1.7-1.8, wing 1.5-1.6 mm. 
HEAD. Occiput black. Anterior ocellars long, proclinate and cruciate; posterior ocellars minute. Inner verticals long, outer verticals somewhat shorter. Antenna (Fig. 144) with scape and pedicel yellow, postpedicel brownish in apical part and yellowish basally (yellow space varying, but no more than half of postpedicel). Pedicel with circlet of subequally short setulae. Postpedicel nearly 3.0 times longer than wide. Stylus normally pubescent, brown, about $1.5(1.5-1.7)$ times as long as postpedicel and nearly as long as scape, pedicel and postpedicel combined. Proboscis brownish yellow. Palpus yellow, small, rounded.

THORAx. Entirely yellow. Prothoracic episterna lacking long upturned bristle just above fore coxa, with 1 very short seta in upper part. Postpronotal bristle not prominent. Mesonotum with 2 notopleurals (anterior bristle somewhat longer), 1 postsutural supra-alar (nearly as long as posterior notopleural bristle), 1 similar postalar and 4 scutellars (apical pair very long, cruciate; lateral pair minute). Acrostichals arranged in 4 irregular rows closer to anterior margin of scutum otherwise 2-serial, lacking on prescutellar depression; dorsocentrals arranged in 2-3 irregular rows anteriorly, becoming uniserial toward scutellum, 2 prescutellar pairs long (posterior pair longer, nearly as long as apical scutellars).

LEgS. Almost entirely yellow, only tarsomere 5 of all legs black. Coxae and trochanters with unmodified setation. Fore femur somewhat thickened, with rows of short anteroventral and posteroventral bristles, 2 longer pale setae near base. Fore tibia with ordinary subapical yellowish seta anteriorly, otherwise lacking prominent bristles. Mid femur with rows of spinule-like, short ventral setae. Mid tibia with slightly prominent ventral spinules, bearing subapical black claw-like spine, lacking prominent bristles (except subapicals). Hind femur with row of short anteroventral setae and about 4 short erect dorsal setae near base. Hind tibia bearing 1 anterodorsal bristle, with slightly prominent, rounded apical projection. Tarsi of all legs unmodified.

WING. Uniformly finely infuscate. Basal costal bristle moderately long, brownish yellow. Costal index: 28/23/23/11. $\mathrm{R}_{4+5}$ and $\mathrm{M}_{1+2}$ somewhat divergent near wing apex, both straight. Crossvein bm-cu slightly oblique. Crossvein $\mathrm{r}-\mathrm{m}$ near middle of cell bm. Calypter brownish yellow, with several long concolorous setae. Halter pale yellow.

ABDOMEN. Tergite 1 entirely pale yellow. Tergites 2 and 3 brownish, of subequal width in dorsal view, deeply concave anteriorly and divided along midline; with unmodified setation. Tergite 4 broadest, dark brown, subshining, with slightly flattened setae. Tergite 5 very narrow, concolorous with tergite 4, bearing squamiform setae. Tergites 6 and 7 brownish yellow, with moderately long posteromarginal setae. Segment 8 with several short unmodified setae.

TERminalia. Rather large, left surstylus brownish, right epandrial lamella yellowish brown apically and yellow basally (Figs 145-147). Cerci almost entirely fused; right cercus short, slightly prominent, with several short setae, lacking spines; left cercus of complicated structure, as in Figure 146, branched and with additional lobe internally, bearing 1 strong, long, black subapical seta and several thinner setae of different lengths, lacking spines. Epandrium completely divided. Right epandrial lamella rather conical but truncate apically, bearing 2 stronger subapical setae, otherwise covered with numerous moderately long setae longer along ventral margin, lacking spines. Right surstylus not prominent (Fig. 145). Left epandrial lamella fused to hypandrium, with several moderately long setae apically. Left surstylus (Fig. 147) with upper lobe large, broadly ovate, with scattered setulae on outer face but bearing some moderately long setae on inner face and several short strong setae near base dorsally. Hypandrium with 2 long setae apically. Phallus short. Two rod-shaped apodemes present.

\section{Female}


Similar to male but fore and mid tibiae with unmodified setation. Abdominal segments 6 and 7 with minute setulae; segment 8 unmodified, brownish, with 4 moderately long posteromarginal setae. Cercus brownish.

\section{Material examined}

\section{Holotype $\widehat{\sigma}$}

SINGAPORE: Semakau (SMK03), 3 June 2009, mangrove, Mal. (reg. 29142, leg. P.G.; in ZRC).

\section{Paratypes}

SINGAPORE: 19 ふぇ, 6 우, Semakau (SMK05), 13 May 2009, mangrove, Mal. (reg. 29068, leg.

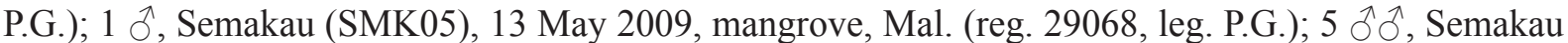
(SMK05), 27 May 2009, mangrove, Mal. (reg. 29119, leg. P.G.); 7 §ð, Semakau (SMK05), 20 May 2009, mangrove, Mal. (reg. 29091, leg. P.G.); 1 Ô, Semakau (SMK02), 3 June 2009, mangrove, Mal. (reg. 29141, leg. P.G.); 1 क, Pulau Ubin (PU02), 26 May 2009, mangrove, Mal. (reg. 29110, leg. P.G.).

\section{Etymology}

The species is dedicated to Mr. Jeffrey Low for his very enthusiastic help during fieldwork.

\section{Distribution}

Singapore.

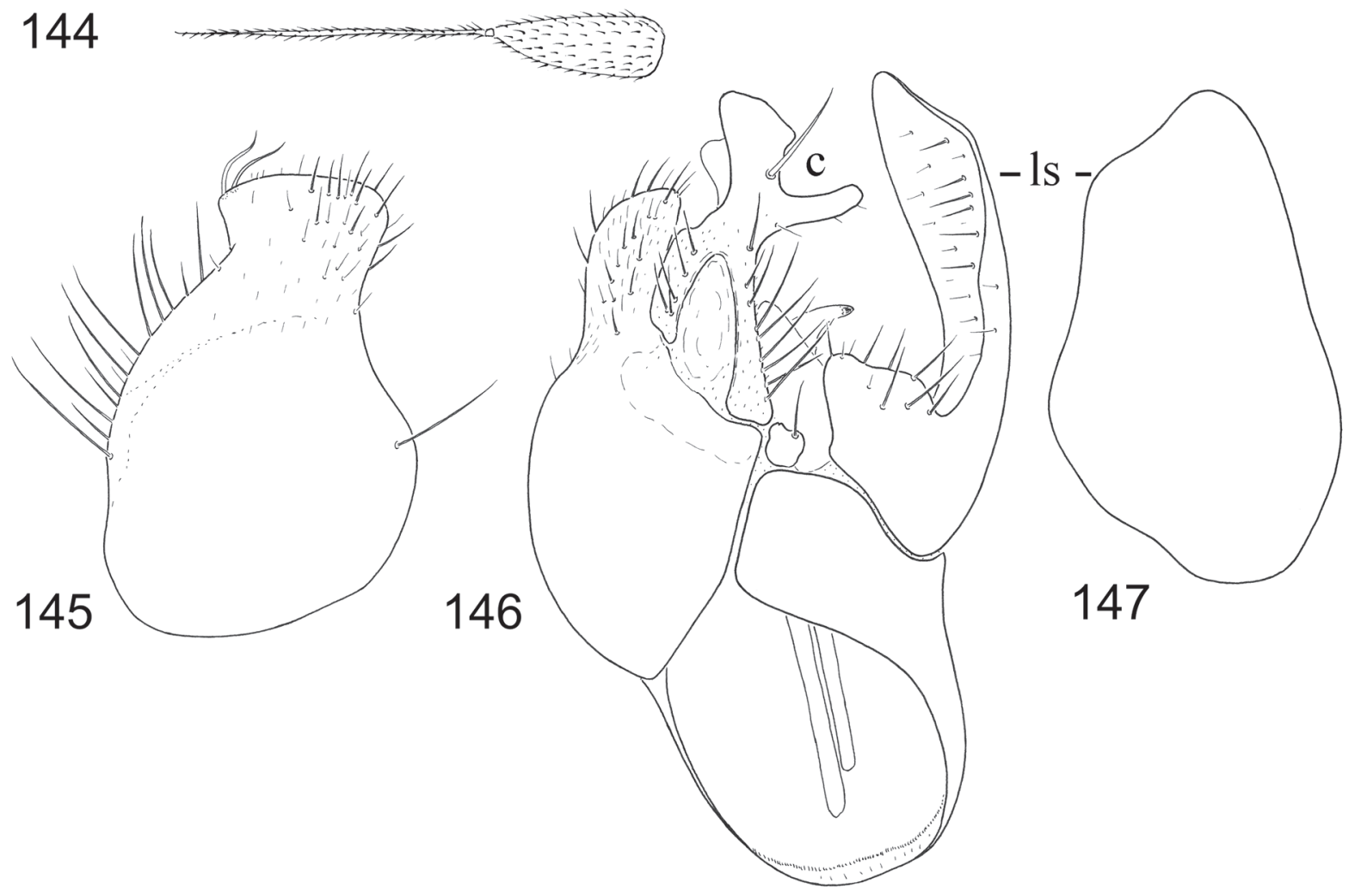

Figs 144-147. Elaphropeza lowi sp. nov., $\widehat{\jmath}$. 144. postpedicel and stylus of antenna, lateral view. 145. right epandrial lamella, lateral view. 146. epandrium with cerci, dorsal view. 147. left surstylus, lateral view. 


\section{Habitat and seasonal occurrence}

This species is known from mangroves, with collection records from May to June.

\section{Remarks}

See comments under P. malayensis and $P$. gohae.

Elaphropeza luteoides Shamshev \& Grootaert, 2007

Elaphropeza luteoides Shamshev \& Grootaert, 2007: 100.

\section{Diagnosis}

Occiput, antenna, thorax and legs entirely yellow, postpedicel very short, about 1.5 times longer than wide; hind tibia with 1 anterodorsal bristle.

\section{Material examined}

SINGAPORE: 1 ठૈ, Kranji (KNT01), 26 May 2009, mangrove, Mal. (reg. 29103, leg. P.G.).

\section{Distribution}

Singapore.

\section{Habitat and seasonal occurrence}

This species is known from swamp forests and mangroves; with two records from May.

\section{Remarks}

Elaphropeza luteoides was previously known only from the holotype male found at Nee Soon. The second record here is from mangrove at Kranji. It is clearly a quite rare species.

Elaphropeza ubinensis Shamshev \& Grootaert, 2007

Fig. 247

Elaphropeza ubinensis Shamshev \& Grootaert, 2007: 104.

\section{Diagnosis}

Occiput black; postpedicel brownish, long, nearly 4.5 times longer than wide; thorax almost wholly yellow only metanotum brownish; fore tibia and tarsus brownish yellow, hind tibia with 1 anterodorsal bristle.

\section{Description}

\section{Female}

(previously undescribed)

LEGS. Mid tibia lacking ventral spinules, otherwise as in male. Abdominal segment 8 rather elongate, yellow, with sclerites separated; sternite 10 and cercus yellow.

\section{Material examined}

SINGAPORE: 1 †, Pulau Ubin (PU02), 26 May 2009, mangrove, Mal. (reg. 29110, leg. P.G.); 1 ðૈ, Sungei Cina (CHC01), 12 May 2009, mangrove, Mal. (reg. 29060, leg. P.G.). 


\section{Distribution}

Singapore.

\section{Habitat and seasonal occurrence}

This species was previously only known from the holotype male found at Chek Jawa. So far it is known only from mangroves, with collection records from May and December.

\section{Remarks}

The female of E. ubinensis is recorded here for the first time.

Elaphropeza modesta Shamshev \& Grootaert, 2007

Figs 148-151

Elaphropeza modesta Shamshev \& Grootaert, 2007: 105 (female only).

\section{Diagnosis}

Occiput black, antenna entirely yellow with postpedicel about 2.5 times longer than wide; thorax with scutum and metanotum dark brown; legs with tarsomere 5 black, hind tibia with 1 anterodorsal bristle.

\section{Description}

\section{Male}

(previously undescribed)

LENGTH. Body 3.1-3.0 mm, wing 2.1-2.2 mm.

HEAD. Occiput black. Anterior ocellars long, proclinate; posterior ocellars minute. Inner verticals long, outer verticals shorter. Antenna (Fig. 148) entirely yellow (appearing somewhat darker subapically). Pedicel with circlet of subequally short setulae. Postpedicel about 2.5 times longer than wide. Stylus normally pubescent, brown, about 1.5 times longer than postpedicel and nearly as long as scape, pedicel and postpedicel combined. Palpus yellow, small, rounded.

Thorax. Almost entirely yellow, only scutellum and metanotum dark brown. Prothoracic episternum lacking long upturned bristle just above fore coxa, with 1-2 very short bristles in upper part. Postpronotal bristle not prominent. Mesonotum with 2-3 notopleurals (2 longer and stronger), 1-2 shorter postsutural supra-alar, 1 long postalar and 4 scutellars (apical pair very long, cruciate; lateral pair minute). Acrostichals and dorsocentrals undifferentiated, scutum evenly covered with short uniform setulae (except 2 pairs of long prescutellars).

LEGS. Quite robust, almost entirely yellow, only tarsomere 5 of all legs black. Coxae and trochanters with unmodified setation. Fore femur somewhat thickened, with rows of short anteroventral and posteroventral bristles, 2 longer pale setae near base and 1 strong brownish subapical bristle posteriorly. Fore tibia lacking prominent bristles (except subapicals). Mid femur with rows (3 basally otherwise 2 ) of spinulelike, short ventral setae. Mid tibia with slightly prominent ventral spinules, lacking subapical, black claw-like spine and prominent bristles (except subapicals). Hind femur with row of short anteroventral setae and about 4 short erect dorsal setae near base. Hind tibia bearing 1 anterodorsal bristle, with slightly prominent, rounded apical projection. Tarsi of all legs unmodified.

WING. Uniformly finely infuscate. Costal index: 55/37/36/16. $\mathrm{R}_{4+5}$ and $\mathrm{M}_{1+2}$ somewhat divergent near wing apex, both straight. Crossvein bm-cu transverse. Crossvein r-m near middle of cell bm. Calypter brownish yellow, with several long concolorous setae. Halter pale yellow. 
AвDOMEn. Tergite 1 entirely pale yellow. Tergites 2 and 3 brownish, of subequal width viewed dorsally, deeply concave anteriorly and divided along midline; with unmodified setation. Tergite 4 broadest, dark brown, with numerous squamiform setae. Tergite 5 very narrow, concolorous with tergite 4 , bearing squamiform setae. Tergites 6 and 7 brownish yellow, tergite 6 with numerous rather short posteromarginal bristles, tergite 7 with numerous long posteromarginal bristles.

TERMINALIA. Rather large, left surstylus dark brown, right epandrial lamella yellowish brown apically and yellow basally (Figs 149-151). Cerci narrowly fused; right cercus short, digitiform, with several short setae, lacking spines; left cercus unbranched, short, digitiform, with several setae of different lengths, lacking spines. Epandrium completely divided. Right surstylus not prominent. Right epandrial lamella subrectangular (Fig. 149), with short, digitiform apical projection, covered with numerous moderately long setae longer along ventral margin. Left epandrial lamella fused to hypandrium, with 3 moderately long setae apically. Left surstylus (Fig. 151) with upper lobe large, broadly ovate, with scattered setulae on outer face but bearing some moderately long setae on inner face and several short strong setae near base dorsally. Hypandrium with 2 long setae apically. Phallus short. Two rod-shaped apodemes present.

Female

See full description in Shamshev \& Grootaert (2007: 105).

\section{8}

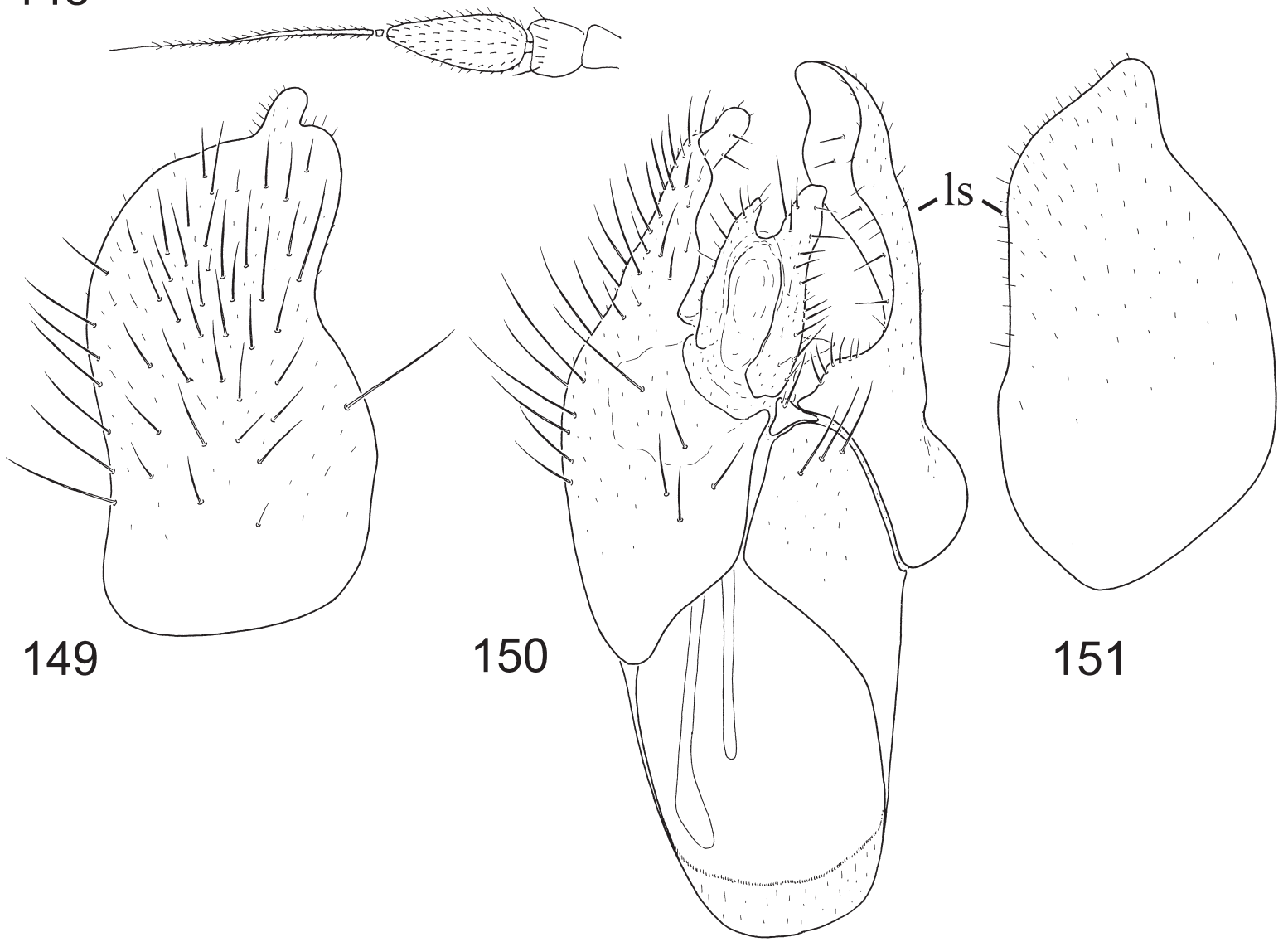

Figs 148-151. Elaphropeza modesta Shamshev \& Grootaert, 2007, ð. 148. postpedicel and stylus of antenna, lateral view. 149. right epandrial lamella, lateral view. 150. epandrium with cerci, dorsal view. 151. left surstylus, lateral view. (after Shamshev \& Grootaert 2007). 


\section{Material examined}

SINGAPORE: 2 $\widehat{\partial}$, Semakau (SMK05), 13 May 2009, mangrove, Mal. (reg. 29068, leg. P.G.); 1 ठૈ, Semakau (SMK02), 3 June 2009, mangrove, Mal. (reg. 29141, leg. P.G.); 1 ㅇ, Semakau (SMK03), 3 June 2009, mangrove, Mal. (reg. 29142, leg. P.G.).

\section{Distribution}

Singapore.

\section{Habitat and seasonal occurrence}

This a rare mangrove species, previously known only from Chek Jawa. Currently it is also known from Semakau, with collection records from March, May and December.

\section{Remarks}

The male sex of E. modesta is described here for the first time.

Elaphropeza feminata Shamshev \& Grootaert, 2007

Figs 152-155

Elaphropeza feminata Shamshev \& Grootaert, 2007: 107 (female only).

\section{Diagnosis}

Occiput black; postpedicel brownish in apical part and yellow basally, nearly 3.5 times longer than wide; thorax with scutellum and metanotum black; legs with tarsomere 5 black, hind tibia with 1 anterodorsal bristle. Male: left surstylus with shallow apical notch. Male: abdominal segment 8 modified.

\section{Description}

Male

(previously undescribed)

LENGTH. Body 2.4-2.5 mm, wing 2.0-2.1 mm.

HEAD. Occiput black. Anterior ocellars long, proclinate and cruciate; posterior ocellars minute. Inner verticals long, outer verticals somewhat shorter. Antenna (Fig. 152) with scape and pedicel yellow, postpedicel brownish in apical part and yellowish basally (yellow space varying, but no more than half of postpedicel). Pedicel with circlet of subequally short setulae. Postpedicel nearly 3.5 times longer than wide. Stylus normally pubescent, brown, at most 1.5 times longer than postpedicel and nearly as long as scape, pedicel and postpedicel combined. Palpus yellow, small, rounded.

Thorax. Almost entirely yellow, only scutellum and metanotum black. Prothoracic episternum lacking long upturned bristle just above fore coxa, with 1 very short bristle in upper part. Postpronotal bristle not prominent. Mesonotum with 2 subequally long notopleurals, 1 somewhat shorter postsutural supra-alar, 1 similar postalar and 4 scutellars (apical pair very long, cruciate; lateral pair minute). Acrostichals arranged in 4 irregular rows anteriorly but 2-serial posteriorly, lacking on prescutellar depression; dorsocentrals arranged in 2-3 irregular rows anteriorly, becoming uni-serial toward scutellum, prescutellar pair very long (nearly as long as apical scutellars).

LeGs. Almost entirely yellow, only tarsomere 5 of all legs black. Coxae and trochanters with unmodified setation. Fore femur somewhat thickened, with rows of short anteroventral and posteroventral bristles, 2 longer pale setae near base and 1 strong brownish subapical bristle posteriorly. Fore tibia lacking prominent bristles (except subapicals). Mid femur with rows (3 basally otherwise 2 ) of spinule-like, 
short ventral setae. Mid tibia with hardly prominent ventral spinules, bearing subapical, black claw-like spine, lacking prominent bristles (except subapicals). Hind femur with row of short anteroventral setae and about 4 short erect dorsal setae near base. Hind tibia bearing 1 anterodorsal bristle, with hardly prominent rounded apical projection. Tarsi of all legs unmodified.

WING. Uniformly finely infuscate. Costal index: 45/29/33/15. Basal costal bristle long, brownish yellow. $\mathrm{R}_{4+5}$ and $\mathrm{M}_{1+2}$ somewhat divergent near wing apex, both straight. Crossvein bm-cu slightly oblique to transverse. Crossvein $\mathrm{r}-\mathrm{m}$ near middle of cell bm. Calypter brownish yellow, with several long concolorous setae. Halter pale yellow.

AвDOMEN. Tergite 1 entirely pale yellow. Tergites 2 and 3 brownish, of subequal width in dorsal view, deeply concave anteriorly and divided along midline; with unmodified setation. Tergite 4 broadest, dark brown, subshining, with slightly flattened setae. Tergite 5 very narrow, concolorous with tergite 4, bearing squamiform setae. Tergites 6 and 7 yellow (sometimes with brownish tinge), former with moderately long, latter with longer posteromarginal setae.

TERMINALIA. Rather large, left surstylus dark brown, right epandrial lamella yellowish brown apically and yellow basally (Figs 153-155). Cerci narrowly fused; right cercus short, slightly prominent, with several short setae, lacking spines; left cercus unbranched, rather short, subrectangular, with several setae of different lengths, lacking spines. Epandrium completely divided. Right surstylus not prominent. Right epandrial lamella (Fig. 153) elongate oval, more or less truncated, with numerous moderately long setae longer along ventral margin. Left epandrial lamella fused to hypandrium, with 3 moderately long setae apically. Left surstylus (Fig. 155) with upper lobe large, broadly ovate, with shallow apical notch;

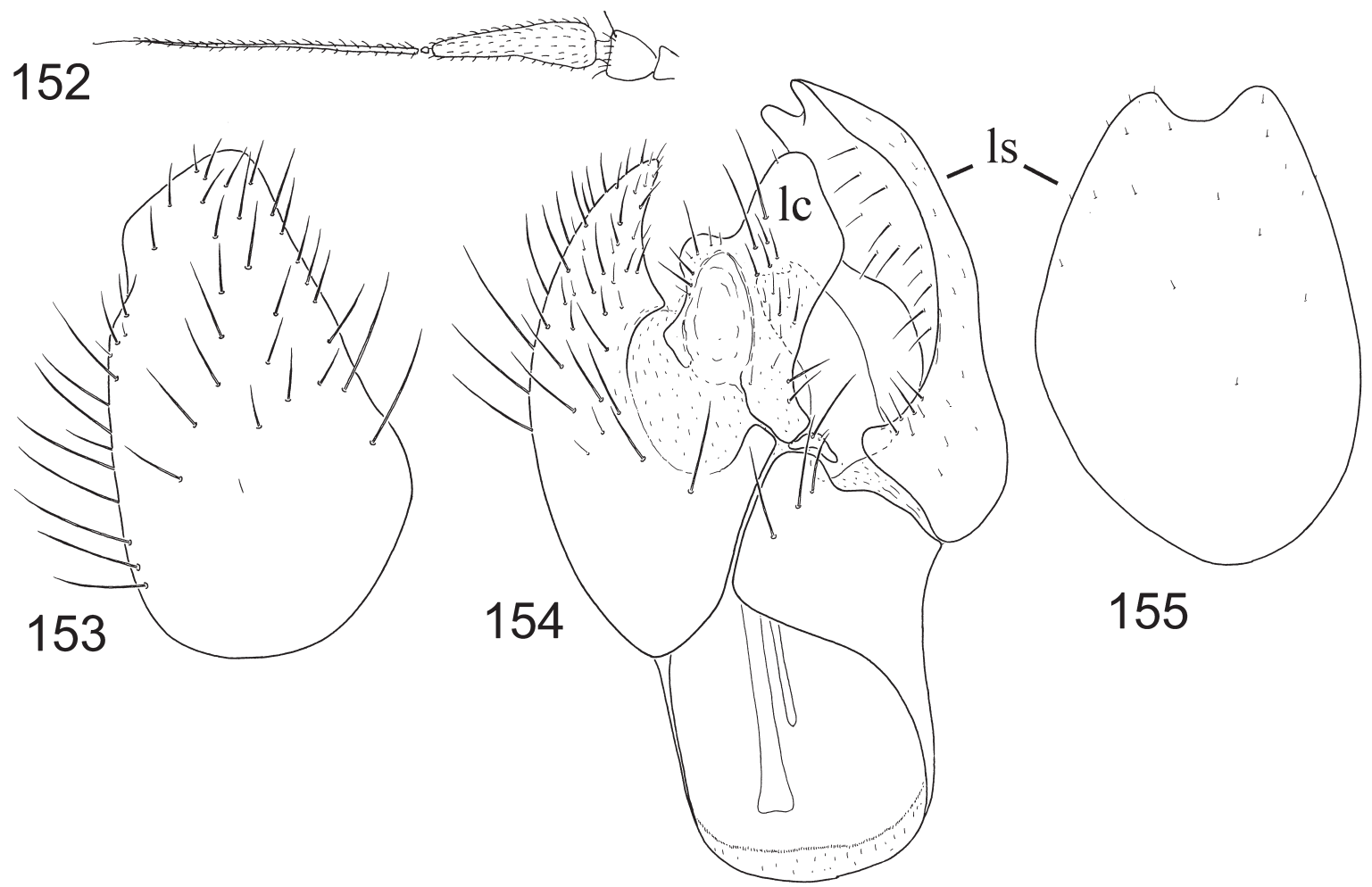

Figs 152-155. Elaphropeza feminata Shamshev \& Grootaert, 2007, đ. 152. postpedicel and stylus of antenna, lateral view. 153. right epandrial lamella, lateral view. 154. epandrium with cerci, dorsal view. 155. left surstylus, lateral view. (after Shamshev \& Grootaert 2007). 
scattered setulae on outer face but bearing some moderately long setae on inner face. Hypandrium with 2 long setae apically. Phallus short. Two rod-shaped apodemes present.

\section{Female}

See full description in Shamshev \& Grootaert (2007: 107).

\section{Material examined}

SINGAPORE: 1 q, Semakau (SMK05), 13 May 2009, mangrove, Mal. (reg. 29068, leg. P.G.); 2 우, Semakau (SMK05), 27 May 2009, mangrove, Mal. (reg. 29119, leg. P.G.); 4 우, Semakau (SMK03), 3 June 2009, mangrove, Mal. (reg. 29142, leg. P.G.); 1 , Semakau (SMK02), 27 May 2009, mangrove, Mal. (reg. 29116, leg. P.G.); 1 q, Semakau (SMK02), 3 June 2009, mangrove, Mal. (reg. 29141, leg. P.G.); 12 우, Pasir Ris (PSR02), 12 May 2009, mangrove, Mal. (reg. 29063, leg. P.G.); 4 우, Pasir Ris (PSR01), 19 May 2009, mangrove, Mal. (reg. 29085, leg. P.G.); 1 ô, 4 q $q$, Pasir Ris (PSR02), 20 May 2009, mangrove, Mal. (reg. 29086, leg. P.G.); 5 우, Pasir Ris (PSR01), 26 May 2009, mangrove, Mal. (reg. 29113, leg. P.G.); 3 우, Pasir Ris (PSR02), 26 May 2009, mangrove, Mal. (reg. 29114, leg. P.G.); 1 q, Pasir Ris (PSR02), 2 June 2009, mangrove, Mal. (reg. 29139, leg. P.G.); 1 q, Pasir Ris (PSR01), 2 June 2009, mangrove, Mal. (reg. 29138, leg. P.G.); 1 q, Kranji (KNT01), 2 June 2009, mangrove, Mal. (reg. 29128, leg. P.G.); 1 क, Pulau Ubin (PU02), 12 May 2009, mangrove, Mal. (reg. 29059, leg. P.G.); 4 우, Pulau Ubin (PU02), 26 May 2009, mangrove, Mal. (reg. 29110, leg. P.G.); 4 우, Pulau Ubin (PU02), 2 June 2009, mangrove, Mal. (reg. 29135, leg. P.G.); 3 우, Pulau Ubin (PU02), 2 June 2009, mangrove, Mal. (reg. 29135, leg. P.G.).

\section{Distribution}

\section{Singapore.}

\section{Habitat and seasonal occurrence}

A common mangrove species mainly represented by females. Collection records are from May, June, October and December.

\section{Remarks}

The male sex of E. feminata is described here for the first time. In our previous key to species we indicated that in this species acrostichal bristles are biserial (Shamshev \& Grootaert 2007: 12). Actually, as has been noted above, they are arranged in 4 irregular rows near the anterior margin of the scutum and become 2-serial posteriorly and lacking on the prescutellar depression.

\section{Elaphropeza semakau sp. nov.}

Figs 156-160

\section{Diagnosis}

Occiput black; postpedicel brownish in apical part and yellow basally, nearly 3.5 times longer than wide; thorax with scutellum and metanotum brown; legs with tarsomere 5 black, hind tibia with 1 anterodorsal bristle. Male: cerci entirely fused, left surstylus produced apically, right epandrial lamella bearing 4 short subapical spine-like setae.

\section{Description}

Male

LenGth. Body $1.9 \mathrm{~mm}$, wing $1.7 \mathrm{~mm}$. 
HEAD. Occiput black. Anterior ocellars long, proclinate and cruciate; posterior ocellars minute. Inner verticals long, outer verticals somewhat shorter. Antenna (Fig. 156) with scape and pedicel yellow, postpedicel brownish in apical part and yellowish basally (yellow space varying, but no more than half of postpedicel); pedicel with circlet of subequally short setulae; postpedicel 3.7 times longer than wide; stylus normally pubescent, brown, slightly (1.2 times) longer than postpedicel and slightly shorter (1.1 times) than scape, pedicel and postpedicel combined. Palpus yellow, small, rounded.

Thorax. Almost entirely yellow, only scutellum and metanotum brown. Prothoracic episternum lacking long upturned bristle just above fore coxa, with 1 very short bristle in upper part. Postpronotal bristle not prominent. Mesonotum with 2 subequally long notopleurals, 1 somewhat shorter postsutural supra-alar, 1 similar postalar and 4 scutellars (apical pair very long, cruciate; lateral pair minute). Acrostichals arranged in 4 irregular rows anteriorly but 2-serial posteriorly, lacking on prescutellar depression; dorsocentrals arranged in 2-3 irregular rows anteriorly, becoming uni-serial toward scutellum, prescutellar pair very long (nearly as long as apical scutellars).

LEGS. Almost entirely yellow, only tarsomere 5 of all legs black. Coxae and trochanters with unmodified setation. Fore femur somewhat thickened, with rows of short anteroventral and posteroventral bristles, 2 longer pale setae near base and 1 strong brownish subapical bristle posteriorly. Fore tibia lacking prominent bristles (except subapicals). Mid femur with rows of spinule-like, short ventral setae. Mid tibia with slightly prominent ventral spinules, bearing subapical, black claw-like spine, lacking prominent bristles (except subapicals). Hind femur with row of short anteroventral setae and about 4 short, erect dorsal setae near base. Hind tibia bearing 1 anterodorsal bristle, with slightly prominent rounded apical projection. Tarsi of all legs unmodified.

WING. Uniformly finely infuscate. Costal index: 34/22/24/12. Costal vein with moderately long setulae along anterior margin. Basal costal bristle long, brownish yellow. $\mathrm{R}_{4+5}$ and $\mathrm{M}_{1+2}$ somewhat divergent near wing apex, both straight. Crossvein bm-cu transverse. Crossvein r-m near middle of cell bm. Calypter brownish yellow, with several long concolorous setae. Halter pale yellow.

ABDOMEN. Tergite 1 entirely pale yellow. Tergites 2 and 3 brownish yellow, of subequal width in dorsal view, deeply concave anteriorly and divided along midline; with unmodified setation. Tergite 4 broadest, dark brown, subshining, with slightly flattened setae. Tergite 5 very narrow, concolorous with tergite 4, bearing squamiform setae. Tergites 6 and 7 brownish yellow, with moderately long posteromarginal setae.

Terminalia. Rather large, left surstylus brownish, right epandrial lamella yellowish brown apically and yellow basally (Figs 157-160). Cerci entirely fused forming single subrectangular lobe, with some unmodified setae of different lengths, lacking spines. Epandrium completely divided. Right surstylus not prominent. Right epandrial lamella (Fig. 157) conical, broadly ovate apically, bearing 4 short, subapical spine-like setae ( 3 setae closer to each other and 1 seta aside), with numerous moderately long setae. Left epandrial lamella fused to hypandrium, with 1 short seta apically. Left surstylus (Fig. 159) with upper lobe large, rather elongate oval and narrowly produced apical part, covered with scattered setulae on outer face but bearing some moderately long setae on inner face and several short strong setae near base dorsally. Hypandrium with 2 long subapical setae and numerous setae of different lengths apically (Fig. 160). Phallus short. Two rod-shaped apodemes present.

\section{Female}

Unknown. 
Material examined

Holotype $\widehat{\sigma}$

SINGAPORE: 1 ðૈ, Semakau (SMK01), 27 May 2009, mangrove, Mal. (reg. 29115, leg. P.G.; in ZRC).

\section{Etymology}

The species is named after Semakau Island that appears to have a very rich empidoid fauna (Grootaert, in litt.).

\section{Distribution}

Singapore.

\section{Habitat and seasonal occurrence}

This species occurs in mangroves, with a single record from May.
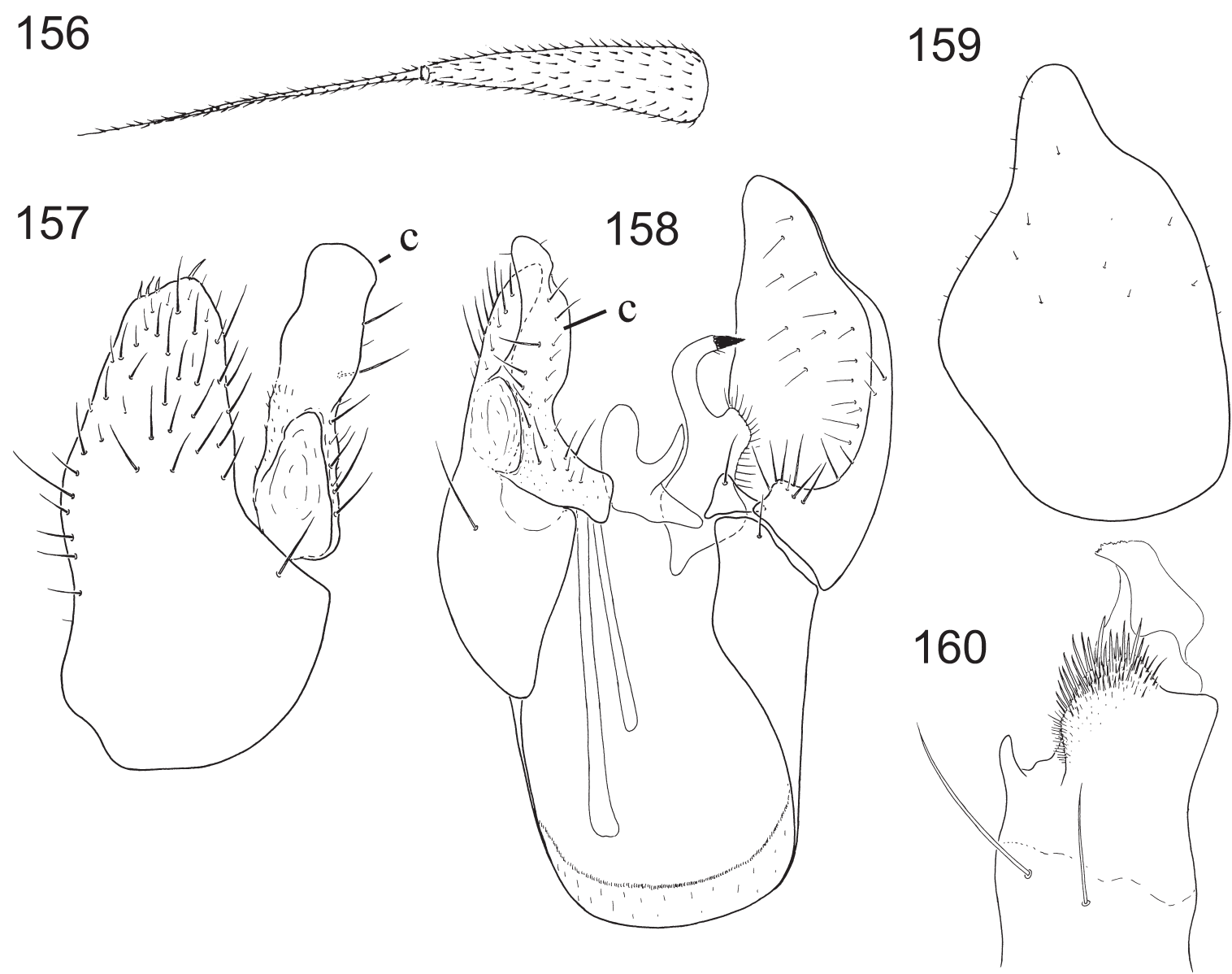

Figs 156-160. Elaphropeza semakau sp. nov., $\overbrace{}^{\lambda}$ 156. postpedicel and stylus of antenna, lateral view. 157. right epandrial lamella, lateral view. 158. epandrium with cerci, dorsal view. 159. left surstylus, lateral view. 160. tip of hypandrium, ventral view. 


\section{Remarks}

The new species is very similar to E. feminata differing from the latter only by the body size and the structure of the male terminalia. Elaphropeza semakau sp. nov. is smaller (1.9 mm vs. $2.4-2.5 \mathrm{~mm}$ in E. feminata) and in the new species the left surstylus is apically produced (with shallow notch in E. feminata), right epandrial lamella bears 4 short subapical spine-like setae, cerci are entirely fused forming single subrectangular lobe and, additionally, the apex of the hypandrium is covered with numerous spine-like setae. The females of $E$. feminata have modified abdominal segment 8 that may aid distinguish them from the females of $E$. semakau sp. nov. once they are collected.

\section{Elaphropeza singulata Shamshev \& Grootaert, 2007}

Elaphropeza singulata Shamshev \& Grootaert, 2007: 107.

\section{Diagnosis}

Occiput black; antenna entirely yellow, with postpedicel about 2.5 times longer than wide; scutellum, metanotum, meron and partly metapleuron brown; legs with tarsomere 5 brown, hind tibia with 1 anterodorsal bristle.

\section{Material examined}

SINGAPORE: 1 †, Semakau (SMK04), 19 May 2009, mangrove, Mal. (reg. 29090, leg. P.G.).

\section{Distribution}

Singapore.

\section{Habitat and seasonal occurrence}

This species was previously known from terrestrial forests: Sime forest, Bukit Timah and Nee Soon and now recorded from mangroves at Semakau. Occasional collection records are from March, May, July, August and November.

\section{Remarks}

This remains a very rare species, and is still only known from females.

Elaphropeza asexa Shamshev \& Grootaert, 2007

Elaphropeza asexa Shamshev \& Grootaert, 2007: 128.

\section{Diagnosis}

Occiput black, postpedicel brownish yellow, about 2.5 times longer than wide; thorax with metanotum brown in middle part; fore tibia with 1 short, hind tibia with 1-2 long anterodorsal bristles.

\section{Material examined}

SINGAPORE: 1 \%, Mandai (MAN01), 2 June 2009, mangrove, Mal. (reg. 29138, leg. P.G.); 1 , Sungei Cina (CHC01), 12 May 2009, mangrove, Mal. (reg. 29060, leg. P.G.).

\section{Distribution}

Singapore. 


\section{Habitat and seasonal occurrence}

This is a fairly common species, but never abundant. It is reported in all forest types studied here, but was most abundant in the mangroves of Sungei Buloh (Shamshev \& Grootaert 2007). Collection records are from throughout the year.

\section{Remarks}

This species remains only known from females.

Elaphropeza collini sp. nov.

Figs 161-164

\section{Diagnosis}

Occiput largely yellow, postpedicel about 2.5 times longer than wide, stylus about 4.0 times longer than postpedicel; thorax and legs entirely yellow; hind tibia with 1 black curved subapical anteroventral bristle. Male: right epandrial lamella with 3 very long unmodified subapical setae and 2 very long squamiform setae.

\section{Description}

Male

LeNGTH. Body $1.8 \mathrm{~mm}$, wing $1.5 \mathrm{~mm}$.

HEAD. Occiput largely yellow, broadly darkened above neck including ocellar tubercle and frons, with yellow to brownish yellow setation. Anterior ocellars long, proclinate and cruciate; posterior ocellars minute. Inner verticals long, inclinate; outer verticals slightly prominent. Antenna (Fig. 161) brownish yellow, scape and pedicel somewhat paler; pedicel with circlet of almost equally short setulae, 1 dorsal somewhat longer; postpedicel 2.7 times longer than wide; stylus normally pubescent, brown, 4.1 times longer than postpedicel and 2.4 times as long as scape, pedicel and postpedicel combined. Proboscis brownish yellow. Palpus yellow, small, rounded; with scattered brownish yellow setulae, bearing 1 longer and darker subapical seta.

THORAX. Almost entirely reddish yellow, with yellow to brownish yellow setation; metanotum brownish yellow. Scutellum truncate. Prothoracic episternum with 1 long upturned bristle just above fore coxa and 1 short bristle in upper part. Postpronotal bristle minute. Mesonotum with 2 notopleurals, 1 very short postsutural supra-alar, 1 postalar and 4 scutellars (apical pair very long, cruciate; lateral pair very short). Acrostichals and dorsocentrals multiserial, uniform (except for 1 pair of long prescutellars), extending to base of scutellum.

LEGs. Quite robust, entirely yellow, with yellow to brownish yellow setation. Coxae and trochanters with unmodified setation. Fore and hind femora and tibiae somewhat thickened. Fore femur with rows of short antero- and posteroventral bristles and 2 longer bristles near base. Fore tibia lacking prominent bristles (except subapicals). Mid femur with 2 rows of spinule-like, short ventral bristles (becoming shorter in apical part of femur), 1 long thin bristle near base and 1 anterior subapical bristle. Mid tibia with 1 row of black ventral spinules on about apical 2/3, lacking subapical, claw-like spine anteriorly and prominent bristles (except subapicals). Hind femur bearing 1 row of mostly short anteroventrals (4 subapicals longer) and 3-4 erect dorsal bristles near base. Hind tibia with 1 black, curved subapical anteroventral bristle; apical projection short, rounded, clothed in dense brownish setulae.

WING. normally developed, finely uniformly infuscate, covered with uniform microtrichia; veins yellowish to brownish yellow. Costal vein with moderately long setulae along anterior margin. Basal costal bristle long, brownish yellow. Costal index: 28/23/24/11. Vein Rs somewhat longer than crossvein 
bm-cu. $\mathrm{R}_{4+5}$ and $\mathrm{M}_{1+2}$ parallel near wing apex, somewhat sinuate. $\mathrm{CuA}_{1}$ reaching wing margin. $\mathrm{A}_{1}$ present as trace vein. Crossvein bm-cu oblique. Crossvein r-m near middle of cell bm. Calypter brownish yellow, with several long brownish setae. Halter darkened.

ABDOMEN. Tergite 1 with very narrow, slightly prominent brownish space. Tergite 2 narrow medially and broadened laterally. Tergite 3 broadest, with squamiform setae. Tergite 4 nearly as broad as tergite 2 and in middle about 2.0 times narrower than tergite 3, with squamiform setae. Tergite 5 narrowest, even somewhat narrower than tergite 2, with squamiform setae. Tergites 6-8 unmodified; tergite 6 with slightly prominent, tergite 7 with long posteromarginal bristles. Sternites 3-5 divided. Gland-like structures present between tergites 3-4 and 4-5.

Terminalia. Large, brownish yellow (Figs 162-164). Cerci divided; right cercus short, narrow, with few short bristles, lacking spines; left cercus unbranched, digitiform, rather short, with numerous moderately long bristles, lacking spines. Epandrium completely divided. Right epandrial lamella (Fig. 162) with 3 very long unmodified subapical setae and 2 very long squamiform setae. Right surstylus very small, subtriangular, with some minute setulae, lacking spines. Left epandrial lamella fused to hypandrium, with several moderately long bristles apically. Left surstylus (Fig. 164) with large, subglobular, with moderately long submarginal setae. Hypandrium with rod-shaped subapical projections (as in $E$. biuncinata), bearing 2 short setae apically. Phallus very long, double spiralled [not showen on Fig. 163]. One rod-shaped apodeme present.

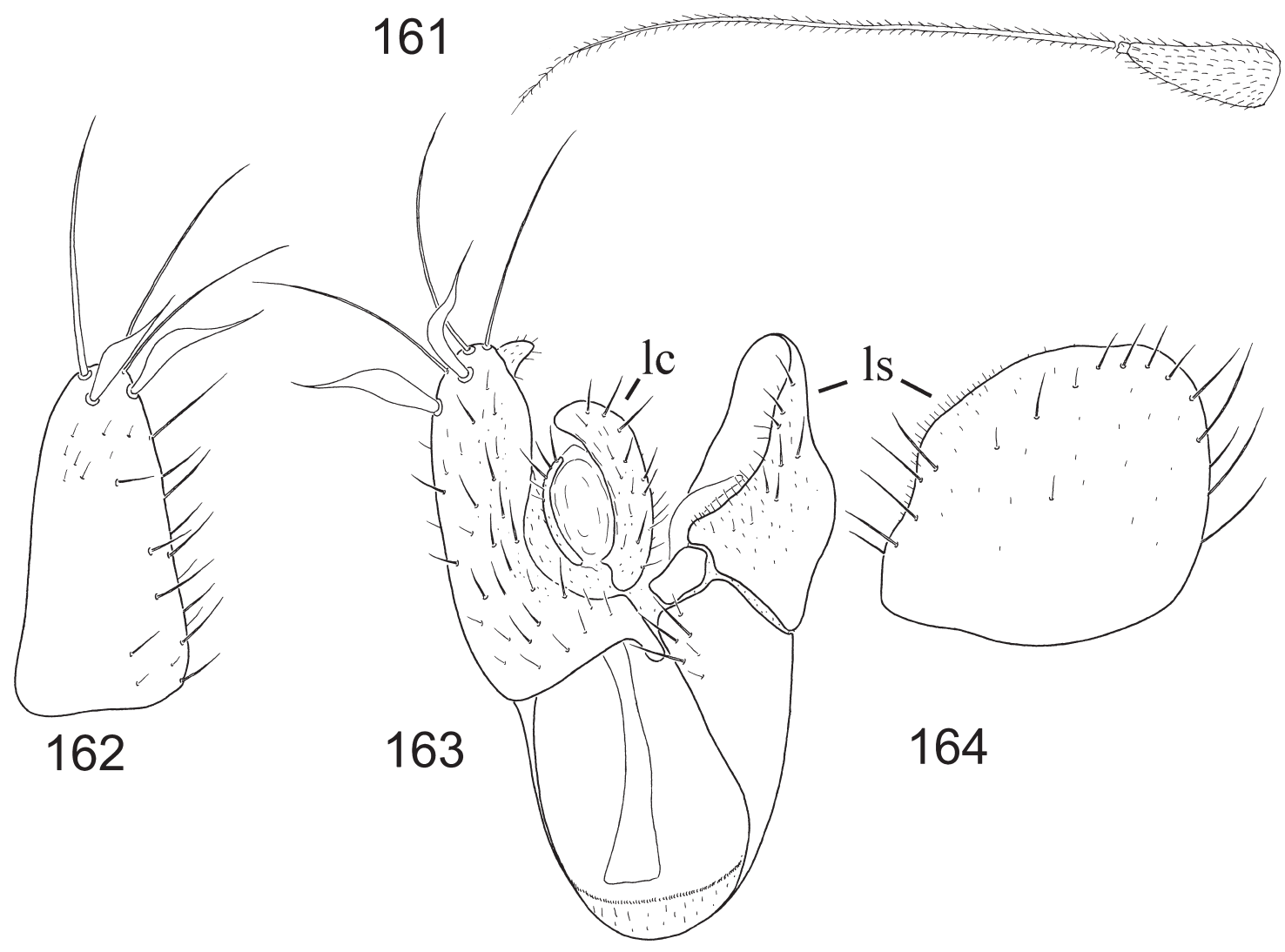

Figs 161-164. Elaphropeza collini sp. nov., $\widehat{\jmath}$. 161. postpedicel and stylus of antenna, lateral view. 162. right epandrial lamella, lateral view. 163. epandrium with cerci, dorsal view. 164. left surstylus, lateral view. 
Female

Unknown.

\section{Material examined}

Holotype $\hat{\sigma}$

SINGAPORE: Pulau Ubin (PU02), 2 June 2009, mangrove, Mal. (reg. 29135, leg. P.G.; in ZRC).

\section{Etymology}

The species is dedicated to Mr. Tong Hor Yee (Collin) for his very enthusiastic help during fieldwork in 2009.

\section{Distribution}

Singapore.

\section{Habitat and seasonal occurrence}

This species occurs in mangroves, with single record from June.

\section{Remarks}

The new species belongs to the E. biuncinata group and in the male it can be readily distinguished from all representatives of this unit by the unique vestiture of the right epandrial lamella ( 3 very long unmodified subapical setae and 2 very long squamiform setae). Additionally, in the new species the right surstylus is markedly small.

\section{Elaphropeza kranjiensis sp. nov.}

Figs 165-168

\section{Diagnosis}

Occiput black, antenna entirely brownish yellow with postpedicel about 3.5 times as long as wide; scutum with large brown elongate subtriangular patch on each side (anterior corner extending almost to level of anterior spiracle); legs with tarsomere 5 brownish, hind tibia with 1 anterodorsal bristle.

\section{Description}

\section{Male}

LeNGTH. Body $2.7 \mathrm{~mm}$, wing $2.6 \mathrm{~mm}$.

HEAD. Occiput black, with yellow to brownish yellow setation. Anterior ocellars moderately long, proclinate; posterior ocellars minute. Inner verticals moderately long, proclinate; outer verticals not prominent. Antenna (Fig. 165) entirely brownish yellow; pedicel with circlet of subequally short setulae; postpedicel narrow basally, nearly 3.5 times longer than wide; stylus normally pubescent, brown, about 3.5 times as long as postpedicel and nearly 2.0 times longer than scape, pedicel and postpedicel combined. Proboscis brownish yellow. Palpus yellow, small, elongate oval, with several dark setulae.

THORAX. Yellow with brownish markings, shining, with yellow to brownish yellow bristles; scutum with large brown elongate subtriangular patch on each side (anterior corner extending almost to level of anterior spiracle), metanotum entirely brown, meron (= hypopleuron) and anepimeron (= pteropleuron) brownish, katepisternum (= sternopleuron) brownish on lower part; anterior spiracle brown. Prothoracic episternum lacking long upturned bristle just above fore coxa, with 1 short seta in upper part. Postpronotal bristle minute. Mesonotum with 2 notopleurals (posterior bristle longer), 1 short postsutural supraalar, 1 minute postalar and 4 scutellars (apical pair very long, cruciate; lateral pair minute). Acrostichal 
bristles prominent in anterior part of scutum only, 2-serial, few in number; dorsocentral bristles uniserial, extending to base of scutellum (prescutellar pair long).

Legs. Long, slender, almost entirely yellow, only tarsomeres 5 brownish; clothed with yellow to brownish yellow setation. Coxae and trochanters with unmodified setation. Fore femur with numerous short setae ventrally. Fore tibia lacking prominent bristles (except subapicals). Mid femur with hardly prominent ventral setation. Mid tibia with slightly prominent ventral spinules, bearing subapical, black claw-like spine anteriorly, lacking prominent bristles (except subapicals). Hind femur bearing minute anteroventral setae (except circlet of subapicals); with small, dorsal subbasal tubercle armed with 4 short spine-like setae. Hind tibia bearing 1 anterodorsal bristle before middle; apical projection prominent, small, somewhat pointed, clothed in dense brownish setulae. Hind tarsomere 1 somewhat thickened.

WING. Normally developed, finely uniformly infuscate, covered with uniform microtrichia; veins largely yellowish brown, basal section of $\mathrm{M}_{1+2}$, crossveins $\mathrm{r}-\mathrm{m}$ and bm-cu (except base) pale. Costal vein with moderately long setulae along anterior margin. Basal costal bristle long, brown. Costal index: $57 / 33 / 49 / 13$. Vein Rs subequal to crossvein bm-cu. $R_{2+3}$ smoothly arched. $R_{4+5}$ and $M_{1+2}$ parallel near wing apex, $\mathrm{R}_{4+5}$ somewhat bowed. $\mathrm{CuA}_{1}$ reaching wing margin. Vein $\mathrm{A}_{1}$ present as fold. Crossvein $\mathrm{bm}-$ cu somewhat oblique. Crossvein r-m before middle of cell bm. Calypter brownish yellow, with several long concolorous cilia. Halter darkened.

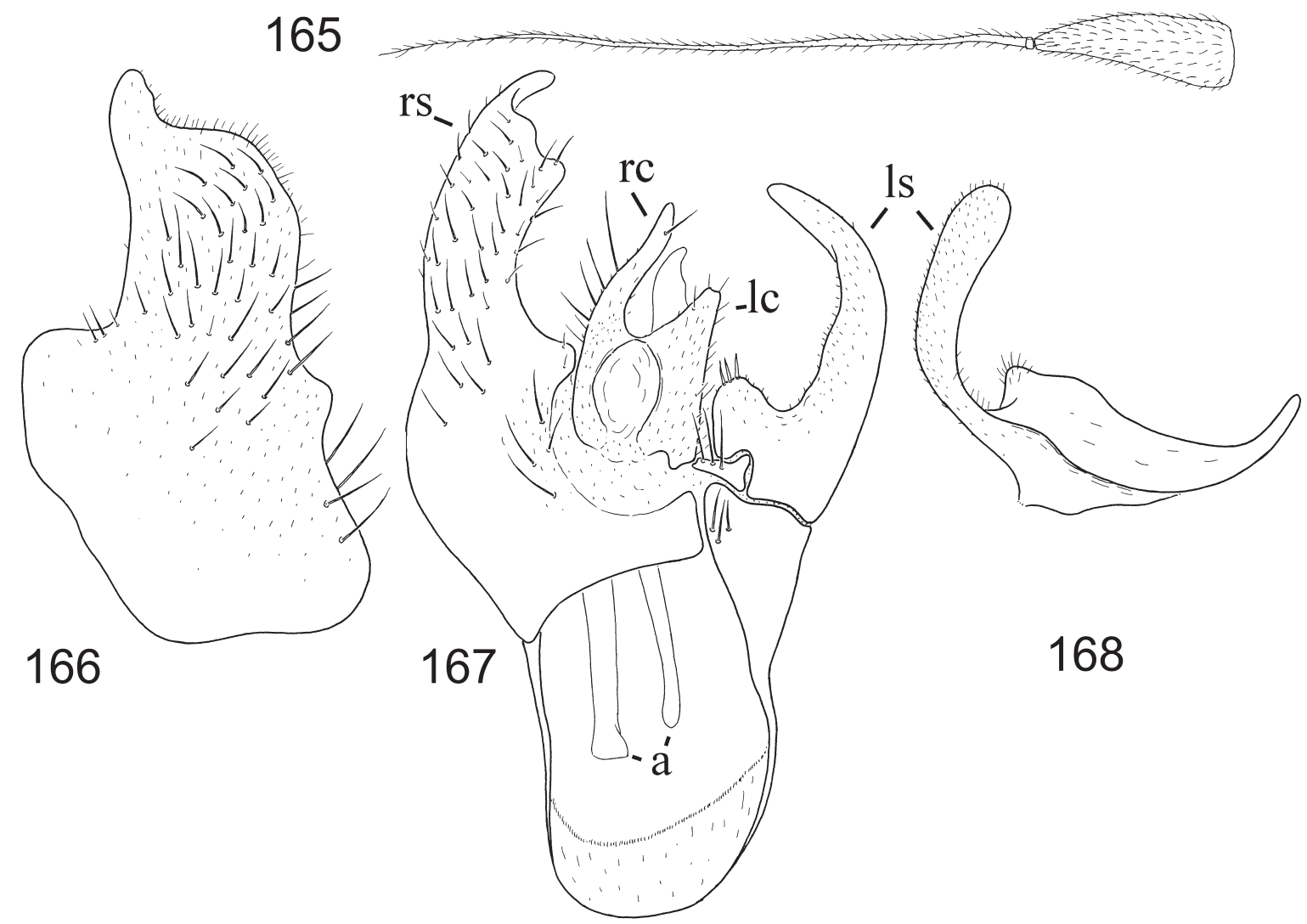

Figs 165-168. Elaphropeza kranjiensis sp. nov., $\widehat{\partial}$. 165. postpedicel and stylus of antenna, lateral view. 166. right epandrial lamella, lateral view. 167. epandrium with cerci, dorsal view. 168. left surstylus, lateral view. 
AвDOMEn. Tergite 1 entirely pale yellow. Tergites 2 and 3 with brownish lateral subtriangular spaces, otherwise pale yellow; bearing scattered unmodified setulae. Tergite 4 broadest, brown, with numerous squamiform setae. Tergite 5 somewhat narrower than tergite 4 , brown, bearing numerous squamiform setae. Tergite 6 with small brownish patch laterally, otherwise pale yellow, with minute posteromarginal bristles. Tergite 7 brown, with several long brown posteromarginal bristles. Segment 8 with several moderately long unmodified setae. Sternites brownish, unmodified, sternites 2-4 convex posteriorly, sternites 5-7 subrectangular, with scattered minute setulae. Gland-like structure between tergites 4 and 5, ampoule-like.

TERMinalia. Rather small, yellowish brown (Figs 166-168). Cerci separated; right cercus rather long, digitiform, somewhat narrowed apically, with several setae of different lengths, lacking spines; left cercus shorter, branched, with short setae. Epandrium completely divided. Right epandrial lamella as in Figure 166, covered with numerous setae of different lengths. Right surstylus not prominent. Left epandrial lamella fused to hypandrium, with 3 moderately long setae apically. Left surstylus (Fig. 168) moderately large, mostly covered with minute setulae, bearing short spine like setae near base dorsally. Hypandrium with 2 short setae. Phallus short. Two rod-shaped apodemes present.

\section{Female}

Unknown.

\section{Material examined}

Holotype $\widehat{\partial}$

SINGAPORE: Kranji (KNT01), 2 June 2009, mangrove, Mal. (reg. 29128, leg. P.G.; in ZRC).

\section{Etymology}

The species is named after the Kranji Nature trail that is a small strip of mangrove on the north of the island of Singapore.

\section{Distribution}

Singapore.

\section{Habitat and seasonal occurrence}

This species occurs in mangrove, with a single record from June.

\section{Remarks}

The new species could primarily be compared with E. bulohensis Shamshev \& Grootaert, 2007 known from Singapore. However, E. bulohensis has a different scutal pattern and modified abdominal sternite 4.

\section{Elaphropeza E59}

\section{Material examined}

SINGAPORE: 1 q, Pulau Ubin (PU02), 12 May 2009, mangrove, Mal. (reg. 29059, leg. P.G.).

\section{Remarks}

This female specimen resembles E. luteoides in having entirely yellow occiput, eyes deeply concave on posterior margin, entirely yellow antennae with very short postpedicel and very long stylus, subequally long anterior and posterior ocellar bristles, hind tibia with 1 anterodorsal bristle, and undifferentiated acrostichal and dorsocentral bristles. However, we would hesitate to associate it with this species. It should be noted that in E. luteoides the abdominal tergite 4 is broadest, undivided, dark brown, with 
squamiform setae and tergite 5 is very narrow, dark brown, with squamiform setae. In Elaphropeza E59 all abdominal tergites are brownish yellow, tergites 2-6 are divided along the midline, tergite 4 bears a few slightly flattened setae and only tergite 5 bears scattered squamiform setae. We realise that these differences may be a result of sexual dimorphism but the female is unknown for E. luteoides.

Genus Nanodromia Grootaert, 1994

Nanodromia Grootaert, 1994: 142. Type-species: N. cryptica Grootaert, 1994, by original designation.

\section{Recognition}

The genus Nanodromia can be distinguished from other genera of the Drapetini by the following combination of characters: postpedicel with dorsoapical extension, wing with Rs relatively short and originating closer to tip of $\mathrm{R}_{1}$ than humeral crossvein, cells br and bm of subequal length, abdominal tergites lacking squamiform setae, intersegmental modifications present, two rod-shaped genitalic apodemes.

\section{Diagnosis}

Small flies with body length about $1.5 \mathrm{~mm}$. Frons very broad, with sides divergent above. Eyes contiguous on face, lower ommatidia enlarged or ommatidia of subequal size. Two pairs of vertical bristles, but outer pair (sometimes both pairs) often hardly prominent. Ocellar tubercle with 2 pairs of bristles. Antenna with pedicel bearing long ventral subapical seta; postpedicel with dorsoapical extension; stylus arising dorsoapically, arista-like, long. Gena barely extended below eye. Palpus small, rounded, usually with short subapical seta. Thorax brown to black; sometimes modified ( $N$. narmkroi Grootaert \& Shamshev). Postpronotal bristle usually well prominent (except $N$. narmkroi). Mesonotal bristles very prominent but sometimes acrostichals and dorsocentrals weakly differentiated. Anepisternum bare, rarely setose ( $N$. narmkroi). Legs short; fore femur usually very thickened; mid legs usually with secondary sexual characters in male; hind tibia lacking prominent bristles. Wings usually normally developed or sometimes modified (non Oriental species); often with distinct pattern; Rs relatively short and originating closer to tip of $\mathrm{R}_{1}$ than humeral crossvein; $\mathrm{R}_{2+3}$ complete, meeting costa before middle of wing; $\mathrm{R}_{4+5}$ and $\mathrm{M}_{1+2}$ strongly divergent; $\mathrm{A}_{1}$ absent; crossvein $\mathrm{Cu} \mathrm{A}_{2}$ absent; crossvein bm-cu oblique; cells br and bm of subequal length; Halter with knob yellow to black. Abdomen with tergite 1 entirely pale; no squamiform setae; gland-like intersegmental structures present. Terminalia rotated $90^{\circ}$ to right; epandrium completely divided; left epandrial lamella usually very narrow, separated from hypandrium, sometimes completely reduced ( $N$. narmkroi); left surstylus undifferentiated from epandrial lamella, undivided, with unmodified setation; right epandrial lamella usually large, positioned ventrally; right surstylus present, slightly differentiated from epandrial lamella; cerci fused (sometimes incompletely), often bearing spines or papilla-like setae; hypandrium usually with 2 bristles on apical portion; phallus very short; two rod-shaped apodemes (i.e. ejaculatory and ventral apodemes) present. Female similar to male, but legs with unmodified structure and vestiture; terminalia short; tergite 8 fused laterally with sternite 8 ; sternite 8 without folded apex; cercus broad-ovate.

\section{Remarks}

The genus Nanodromia is known only from the Australasian (3 species from Papua New Guinea) and Oriental (6 species) regions (Grootaert 1992; Grootaert \& Shamshev 2003). Here Nanodromia is recorded for the first time from Singapore with three new species described below. There is an additional species with black legs known only from a single female (Singapore, Sime forest 17 February 2006, forest, reg. 26034) that remains undescribed. 
Nanodromia as its name indicates is a genus of very small flies, and hence identification is quite difficult. In addition many species resemble one another and leg colouration is sometimes variable. The position of the abdominal glands can be helpful in alcohol preserved specimens, but dissection of the male genitalia is often mandatory to confirm an unambiguous identification.

\section{Key to species of Nanodromia from the Oriental Region}

1. Scutum uniformly covered with hair-like setae (acrostichal and dorsocentral bristles undifferentiated).

- Acrostichal and dorsocentral bristles well differentiated in rows (Thailand; Malaysia; Singapore).. N. narmkroi Grootaert \& Shamshev, 2003

2. Legs uniformly yellow; mid femur with basal swelling (Fig. 1) and mid tibia curved in dorsoventral plane (Thailand).

N. narmjeud Grootaert \& Shamshev, 2003

- Legs with hind femur and (or) tibia brownish near middle (sometimes only faintly); mid femur slender or with basal swelling, but mid tibia always straight.

3. Hind tibia unmodified. Gland-like structures present between tergites 4 and 5 and 5 and 6 (Figs 176-177)......

- Hind tibia somewhat curved. Bladder-like structure opening between tergite 4 and 5 (Fig. 175).....5

4. Mid femur with strong black bristle in anterior fourth; some curved spine-like ventral bristles near tip (Thailand).

... p. phukhao Grootaert \& Shamshev, 2003

- Mid femur with yellow anterior preapical bristle only; without curved bristles ventrally (Singapore)

N. hutan sp. nov.

5. Hind tibia somewhat curved at tip; bearing squamiform setae on apical half (Fig. 174) (Thailand). .N. taksin Grootaert \& Shamshev, 2003

- Hind tibia only faintly twisted; lacking squamiform setae on apical half, but with single line of short spinules (Fig. 173) (Singapore). N. spinulosa sp. nov.

Nanodromia hutan sp. nov.

Figs 169-171

\section{Diagnosis}

Dark brown species with uniformly setose scutum; hind femur brown on middle. Male: mid femur and tibia slender; mid femur with short, yellow anterior preapical bristle; abdomen with intersegmental gland-like fields between tergites 4 and 5 and 5 and 6 .

\section{Description}

\section{Male}

LENGTH. Body $0.98 \mathrm{~mm}$, wing $0.90 \mathrm{~mm}$.

HeAD. Black. Frons triangular, strongly widened towards ocellar tubercle. Eyes contiguous on face, with uniform ommatidia. Ocellar tubercle with short yellow proclinate anterior ocellars and longer lateroclinate posterior ocellars. Two brown to black inclinate verticals about as long as postpedicel and twice as long as ocellars. Antenna with scape and pedicel yellow, postpedicel pale yellow; pedicel without long ventral seta; postpedicel rather subconical, with very short dorsal extension, nearly 2.5 times as long as wide; stylus dorsoapical, brown, about 4.0 times as long as postpedicel. Palpus small, subglobular, yellow, with short yellow subapical seta. 
THORAX. Black, subshining, with yellow setation. Postpronotal bristle short, slightly prominent. Mesonotum with 1 notopleural, 1 postsutural supra-alar, 1 postalar and 4 scutellars (inner pair long); acrostichals and dorsocentrals undifferentiated, scutum uniformly covered with numerous short setae arranged in more or less regular rows.

Legs. Largely yellow, with only hind femur broadly brownish on middle. Mid femur slender, bearing 1 yellow, anterior preapical bristle and 1 moderately long bristle near extreme base.

WING. With transverse brown band from base of wing to cross-veins and apex white. [When wings folded above abdomen, white base of wing covers white base of abdomen; brown transverse stripe covers brown apical tergites; tip of wing that surpasses abdomen is white (transparent) again).] Halter white.

ABDOMEN. With tergite 1 pale, tergite 2 narrowly brown along posterior margin; remaining tergites brown; sternites 1-2 pale, remaining sternites pale brown. Tergites with scattered pale setulae dorsally and short lateral bristles more numerous toward tergite 8 . Intersegmental gland-like structures present between tergites 4 and 5 and 5 and 6, plate-like.

Terminalia. Brown, rather large (Figs 169-171). Cerci (Fig. 170) fused, with several short unmodified setae. Epandrium completely divided. Left epandrial lamella fused with hypandrium, with slender process bearing spine and 2 moderately long setae (Fig. 171). Left surstylus undivided, subtriangular, with minute setulae. Right epandrial lamella (Fig. 169) large, elongate oval, with 1 spine and numerous long setae in upper part. Right surstylus undivided, long, narrow, bearing row of fairly long setae along upper margin. Hypandrium with 2 long setae apically. Phallus short. Two rod-shaped apodemes present.

\section{Female}

Similar to male.
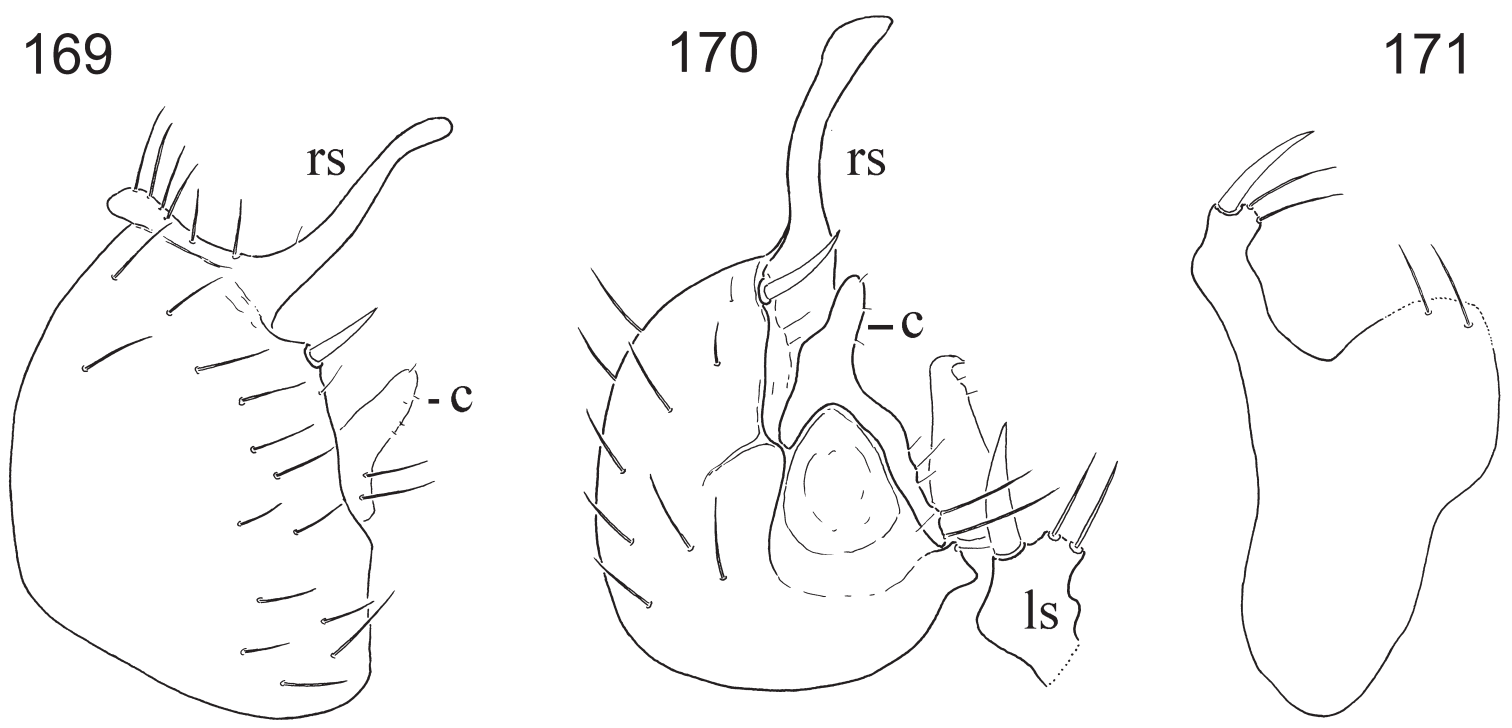

Figs 169-171. Nanodromia hutan sp. nov., ô terminalia. 169. right epandrial lamella, lateral view. 170. epandrium with cerci, dorsal view. 171. left surstylus, lateral view. 
Material examined

Holotype $\widehat{\sigma}$

SINGAPORE: Sime forest, 17 February 2006, forest, Mal 1 (reg. 26034, leg. P.G.; in ZRC).

Paratypes

SINGAPORE: 1 đึ, Nee Soon, 14 October 2005, swamp forest, Mal 1 (reg. 25388, leg. P.G.); 3 우, Sime forest, 17 February 2006, forest, Mal 1 (reg. 26034, leg. P.G.).

\section{Etymology}

The specific name 'hutan' means 'forest' in Malay.

\section{Distribution}

Singapore.

\section{Habitat and seasonal occurrence}

This species occurs in swamp forests, with occasional records from February and October.

\section{Remarks}

Nanodromia hutan sp. nov. is similar to N. phukhao Grootaert \& Shamshev known from Thailand, but the latter bears a thickened anterior preapical bristle on the mid femur.

Nanodromia narmjeud Grootaert \& Shamshev, 2003

Figs 178-180

Nanodromia narmjeud Grootaert \& Shamshev, 2003: 43.

\section{Diagnosis}

Species with undifferentiated acrostichal and dorsocentral bristles. Legs uniformly yellow; male mid femur with strong swelling on basal third. Bladder-like organ opening between tergites 4 and 5 .

\section{Distribution}

Thailand (Chantaburi and Trat Provs.).

\section{Habitat and seasonal occurrence}

This species occurs in low altitude rain forests, with collection records from March.

\section{Remarks}

Since this species was found at low altitude rain forests it is not unlikely that it will be found in Singapore as well.

\section{Nanodromia narmkroi Grootaert \& Shamshev, 2003}

Figs 176, 185-188

Nanodromia narmkroi Grootaert \& Shamshev, 2003: 49.

\section{Diagnosis}

Species with thorax somewhat flattened, mesonotum strongly convex on anterior corners; acrostichal and dorsocentral bristles well differentiated; the former minute, arranged in 2 rows, present on anterior part of scutum only; the latter long, uniserial, 5 per row, of different lengths; anepisternum with 3 fairly 


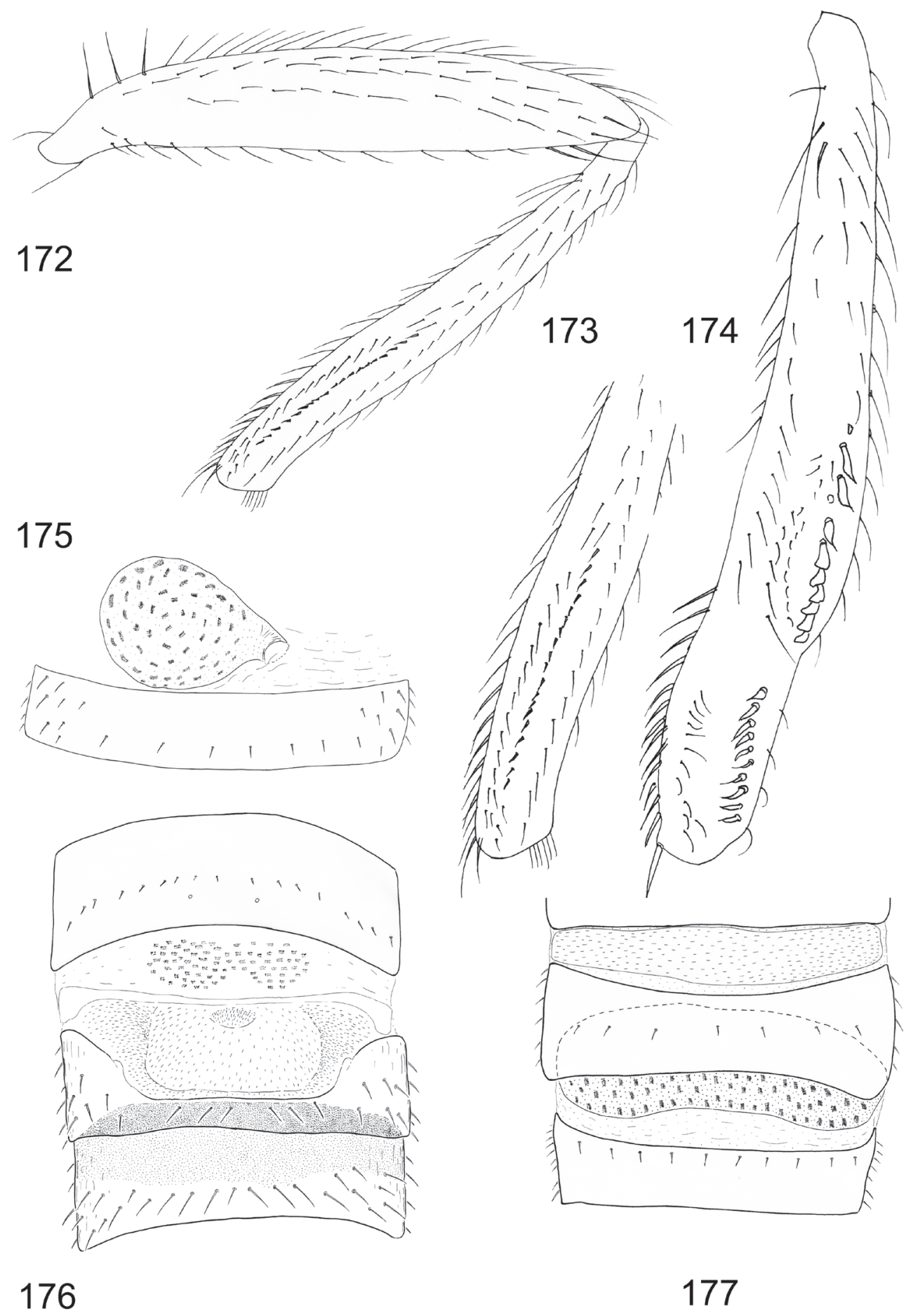

Figs 172-177. Nanodromia, đ̃. 172. N. hutan sp. nov., hind leg, anterior view. 173. N. hutan sp. nov., tip of hind tibia, dorsal view. 174. N. phukhao Grootaert \& Shamshev, 2003, hind tibia, dorsal view. 175. N. narmjeud Grootaert \& Shamshev, 2003, bladder-like gland between tergite 4 and 5, dorsal view. 176. $N$. narmkroi Grootaert \& Shamshev, 2003, gland-like fields between tergites 4-5 and 5-6, dorsal view. 177. N. phukhao Grootaert \& Shamshev, 2003, gland-like fields between tergites 4-5 and 5-6, dorsal view. (Figs 174-177 after Grootaert \& Shamshev 2003). 
long setae in upper hind corner. Legs uniformly yellow. Abdomen with gland-like structures between tergites 4 and 5 and 5 and 6 (Fig. 176).

\section{Material examined}

SINGAPORE: $2 \widehat{\partial} \widehat{\partial}, 1$ क, Pulau Ubin, Chek Jawa, 19 November 2003, sweeping in mangrove (reg.

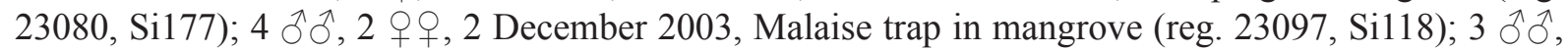
11 December 2003, Malaise trap in mangrove (reg. 23119, Si141), 1 J, 8 우, Chek Jawa, 11 October 2005, mangrove, Mal (reg. 25380, leg. P.G.); 1 ${ }^{1}, 11$ 우, Chek Jawa, 26 October 2005, mangrove, Mal 2 (reg. 25399, leg. P.G.); 4 우, Chek Jawa, 30 December 2005, mangrove, Mal 2 (reg. 25474, leg.

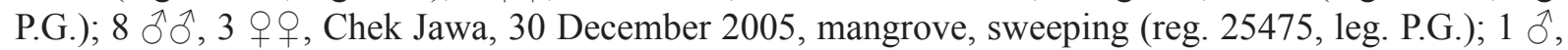

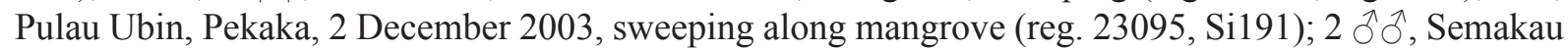
Island, 26 June 2005, beach, sweeping (reg. 25185, leg. P.G.). 2 ồ ${ }^{\lambda}$, Semakau (SMK02), 13 May 2009, mangrove, Mal. (reg. 29065, leg. P.G.); 12 đ̋ , Semakau (SMK05), 13 May 2009, mangrove, Mal. (reg. 29068, leg. P.G.); 1 Ĵ, Semakau (Semakau), 20 May 2009, beach forest, sweeping (reg. 29097, leg.

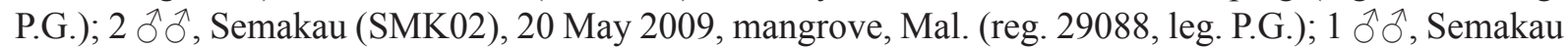
(SMK04), 27 May 2009, mangrove, Mal. (reg. 29118, leg. P.G.); 6 $\widehat{\jmath}$, Semakau (SMK05), 27 May 2009, mangrove, Mal. (reg. 29119, leg. P.G.); 1 \&, Semakau (SMK04), 27 May 2009, mangrove, Mal. (reg. 29118, leg. P.G.); 1 J, Semakau (SMK05), 3 June 2009, mangrove, Mal. (reg. 29144, leg. P.G.);

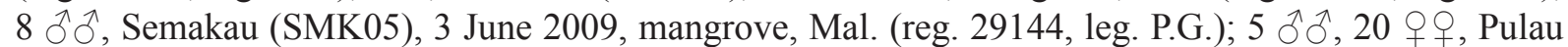
Ubin (PU02), 12 May 2009, mangrove, Mal. (reg. 29059, leg. P.G.); 5 ồ, Pulau Ubin (PU02), 26 May

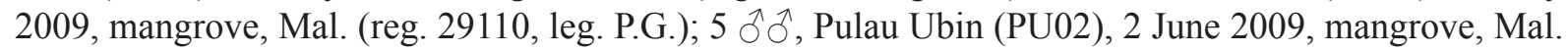
(reg. 29135, leg. P.G.).

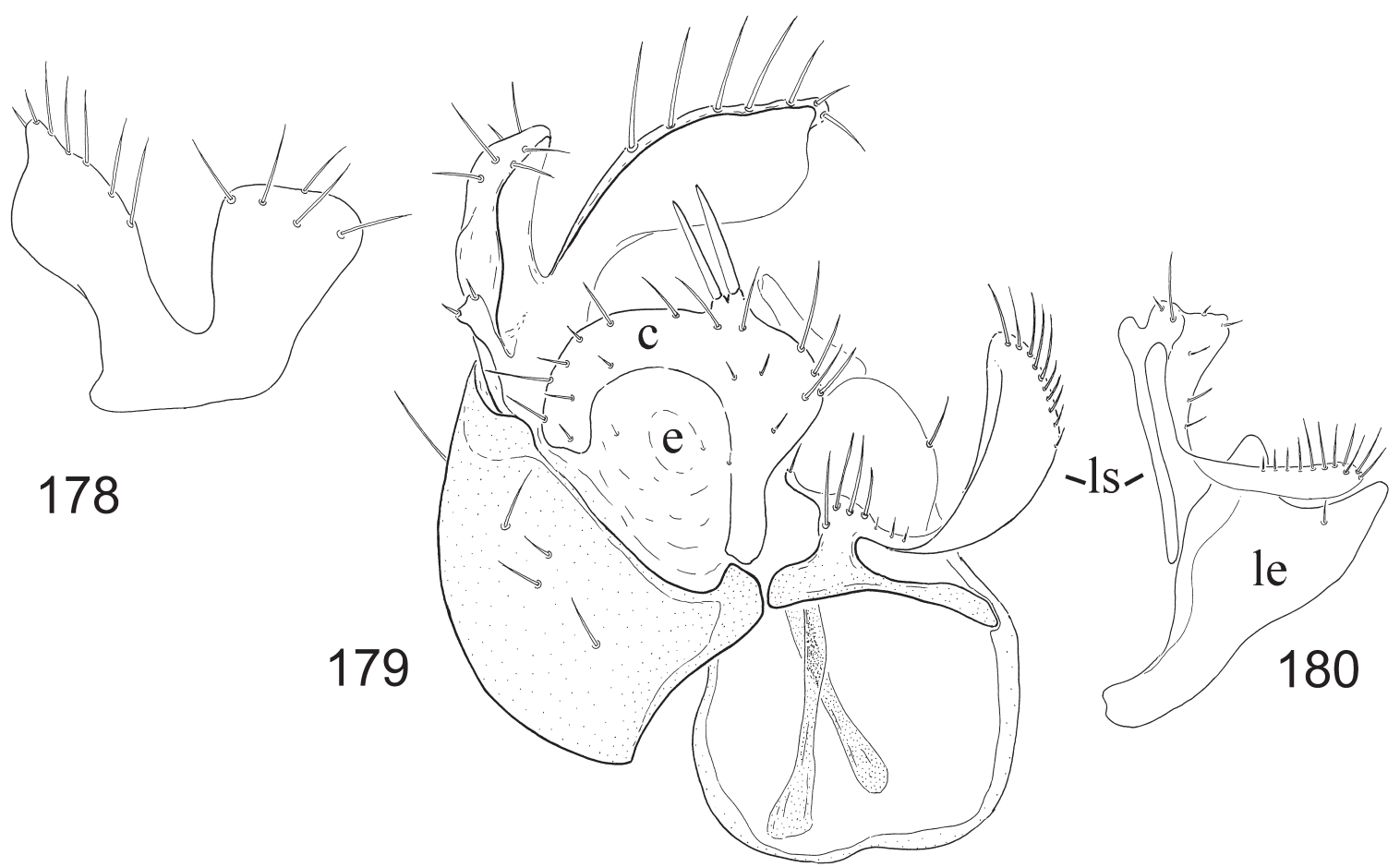

Figs 178-180. Nanodromia narmjeud Grootaert \& Shamshev, 2003, đ terminalia. 178. right surstylus, dorsal view. 179. epandrium with cerci, dorsal view. 180. left epandrial lamella and surstylus, lateral view. (after Grootaert \& Shamshev 2003). 

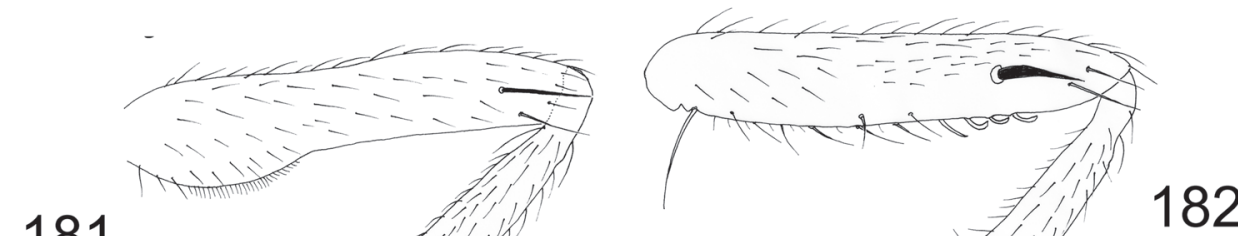

181
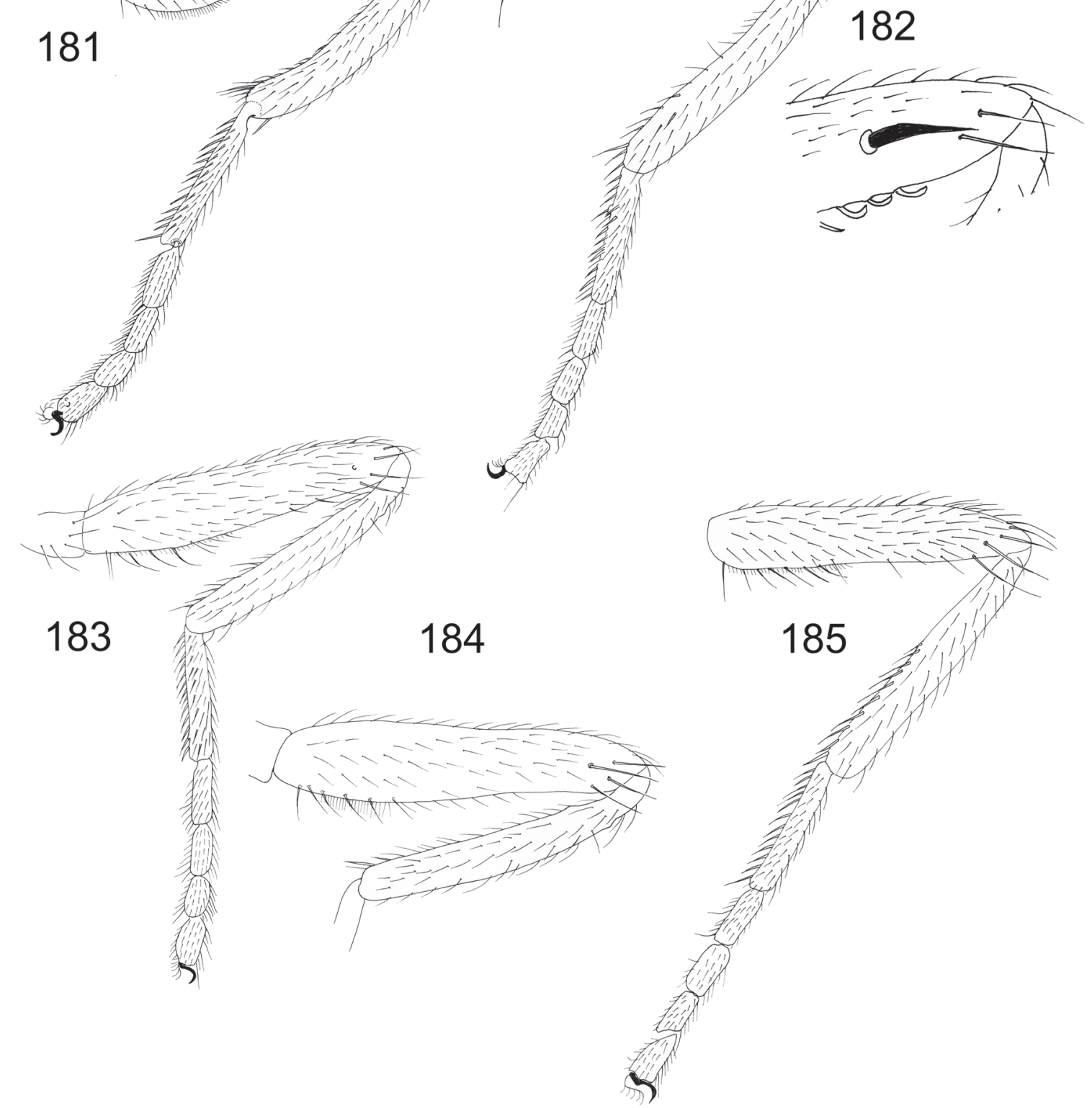

183

Figs 181-185. Nanodromia, đ̂, mid leg, anterior view. 181. N. narmjeud Grootaert \& Shamshev, 2003. 182. N. phukhao Grootaert \& Shamshev, 2003. 183. N. taksin Grootaert \& Shamshev, 2003. 184. N. spinulosa sp. nov. 185. N. narmkroi Grootaert \& Shamshev, 2003. (Figs 181-183, 185 from Grootaert \& Shamshev 2003). 
MALAYSIA: $6 \hat{\jmath} \hat{\jmath}$, Johor province, Sedili kecil, 12 October 2000, supralitoral, sweeping (reg. 20046, leg. P.G. \& N. Evenhuis).

\section{Sequences in Genbank}

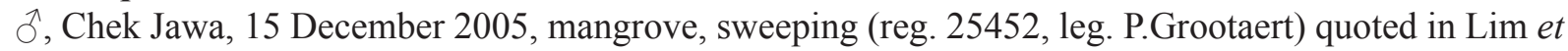
al. (2009) Nanodromia narmkroi has been sequenced.

\section{Distribution}

Malaysia (Johor), Singapore, South Thailand (Trang Prov.).

\section{Habitat and seasonal occurrence}

This species occurs in mangroves. It is present throughout the year, but most common from October to December.

\section{Remarks}

This is a common mangrove species. The name means 'brackish water' in Thai language. 'Narm' stands for water and the 'ar' in narm is pronounced as a long 'a' but then as a high tone. 'Kroi' means brackish.

Nanodromia phukhao Grootaert \& Shamshev, 2003

Figs 177, 182, 189-192

Nanodromia phukhao Grootaert \& Shamshev, 2003: 45.

\section{Diagnosis}

Species with undifferentiated acrostichal and dorsocentral bristles. Hind femur broadly brownish on middle. Male mid femur slender and bearing thick black anterior bristle at apical quarter, mid femur
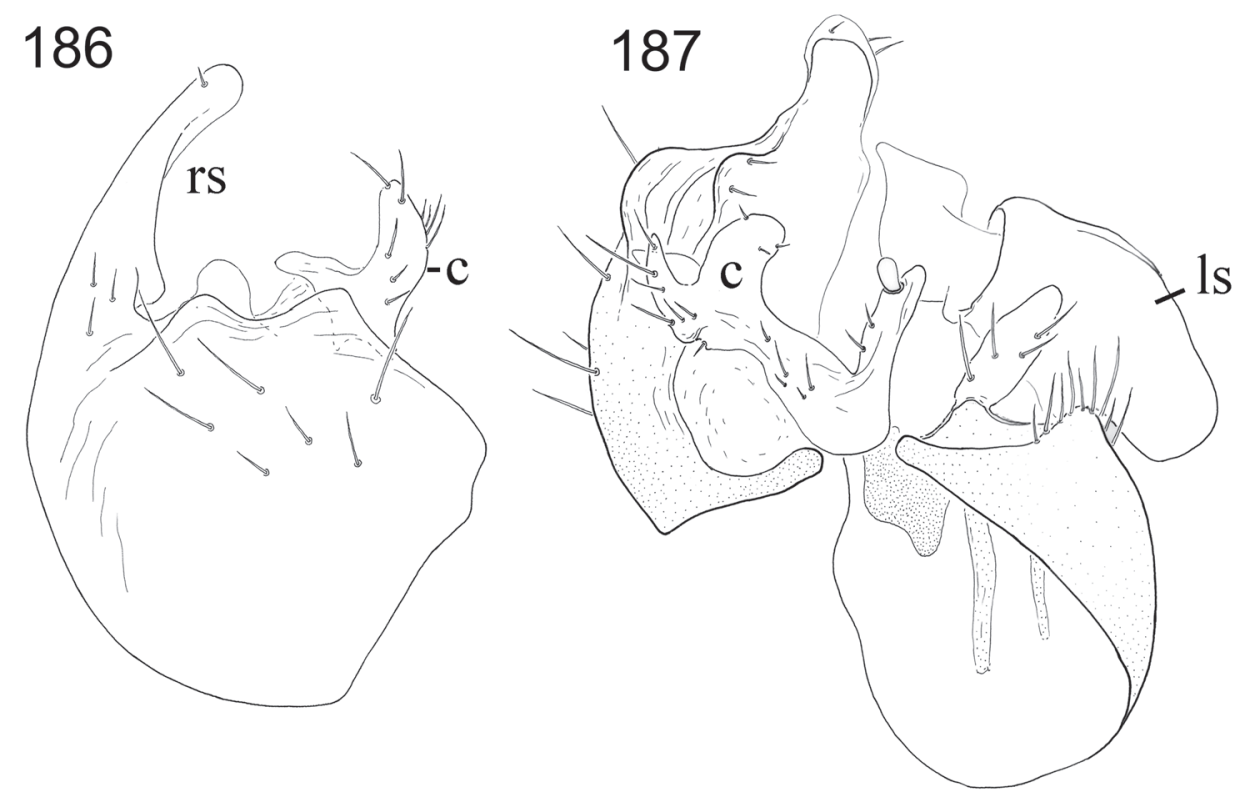

Figs 186-188. Nanodromia narmkroi Grootaert \& Shamshev, 2003, ô terminalia. 186. right epandrial lamella, lateral view. 187. epandrium with cerci, dorsal view. 188. left surstylus, lateral view. (after Grootaert \& Shamshev 2003). 
(Fig. 182) ventrally on apical third with curved flattened setae. Abdomen with gland-like structures (Fig. 177) between tergites 4 and 5 and 5 and 6 .

\section{Distribution}

Northeast Thailand (Loei Prov.).

\section{Habitat and seasonal occurrence}

This species occurs in dry mixed deciduous forest (about $500 \mathrm{~m}$ ), collected in April and May.

\section{Remarks}

Nanodromia phukhao is similar to N. hutan sp. nov., but the latter has no thickened anterior preapical bristle on mid femur. It is not unlikely that it could be present in Singapore as well. The epithet 'phukhao' means mountain in Thai. 'Ph' is pronounced as a strong 'p' (not ' $\mathrm{f}$ ) and 'kh' is a strong k. 'Khao' is pronounced as a rising tone.

\section{Nanodromia spinulosa sp. nov.}

Figs 172-173, 184, 193-195

\section{Diagnosis}

Acrostichal and dorsocentral bristles undifferentiated. Hind femur and tibia somewhat brownish on middle. Male: hind tibia slightly curved, anteriorly on apical half without squamiform setae, but with

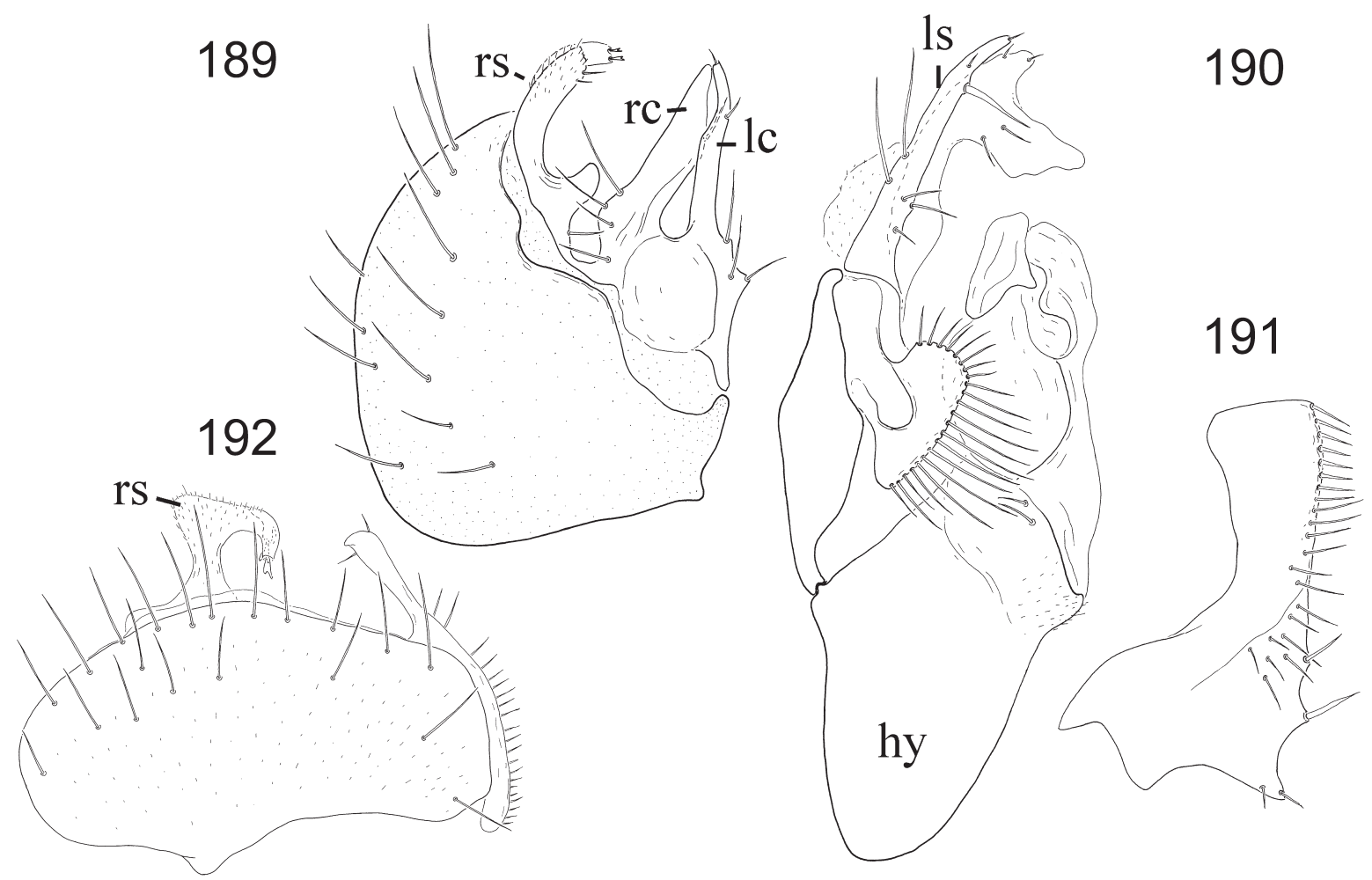

Figs 189-192. Nanodromia phukhao Grootaert \& Shamshev, 2003, ô terminalia. 189. right epandrial lamella with cerci, dorsal view. 190. left epandrial lamella with hypandrium, lateral view. 191. left surstylus, dorsal view. 192. right epandrial lamella, lateral view. (after Grootaert \& Shamshev 2003). 
a row of spinule-like setae. Abdomen with vessel-like glandular structure opening between tergites 4 and 5 .

\section{Description}

\section{Male}

LENGTH. Body $1.4 \mathrm{~mm}$, wing $0.98 \mathrm{~mm}$.

HEAD. Black, with brown to black setation. Ocellar tubercle with 2 proclinate anterior and 2 lateroclinate posterior bristles, both pairs about as long as postpedicel. Two inclinate verticals slightly longer than ocellars. Antenna with scape and pedicel yellow, postpedicel also yellowish, but paler on basal half; pedicel with moderately long ventral seta shorter than pedicel is wide; stylus brown, about 3.5 times as long as postpedicel. Palpus brown, with pale yellow subapical seta.

THorax. Black, subshining, with yellowish setation. Postpronotal bristle hardly prominent. Mesonotum with 1 notopleural, 1 supra-alar, 1 postalar and 4 scutellars (inner pair long); acrostichals and dorsocentrals undifferentiated, scutum uniformly covered with numerous short setae arranged in more or less regular rows.

LEGs. With faint brownish ring on hind femur and hind tibia, otherwise yellow. Fore femur thickened. Mid femur (Fig. 184) more slender than fore femur, but swollen in basal third bearing dense pubescence, 1 yellow ventral bristle near extreme base (shorter than femur is wide) and 1 yellow anterior subapical bristle as long as femur is wide. Mid tibia with unmodified setation. Hind femur only slightly wider than mid femur. Hind tibia slightly twisted and thickened on apical two-thirds; anteriorly on apical half with row of spinule-like setae.

WING. With brown pattern. Calypter brown, with pale setation. Halter white.

ABDOMEN. With tergite 1 pale, tergite 2 narrowly brown along posterior margin; remainding tergites brown; sternites 1-2 pale, remainding sternites pale brown. Tergites with scattered pale setulae dorsally

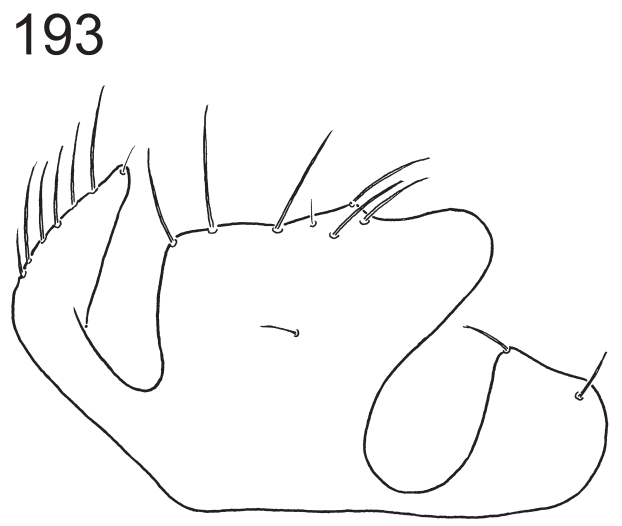

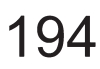

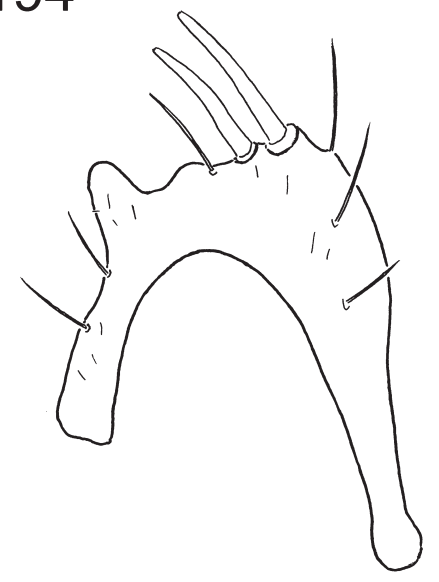

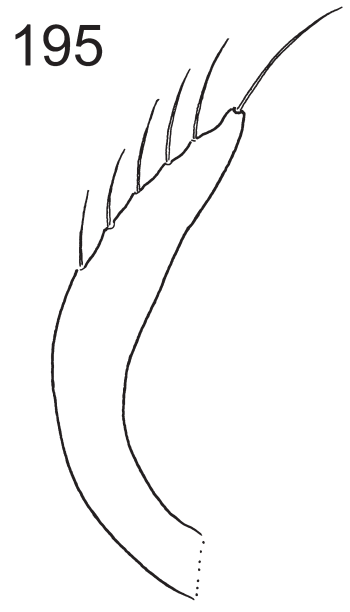

Figs 193-195. Nanodromia spinulosa sp. nov., ô terminalia. 193. right surstylus, dorsal view. 194. fused cerci bearing spines, dorsal view. 195. left surstylus, lateral view. 
and short lateral bristles becoming more numerous towards tergite 8. Intersegmental gland-like structures represented by 1 vessel-like internal structure opening between tergites 4 and 5 .

Terminalia. Brown. Cerci (Fig. 194) fused, with 2 subequally long apical spines and several unmodified setae of different lengths. Epandrium completely divided. Left epandrial lamella very narrow, separated from hypandrium. Left surstylus (Fig. 195) undivided, elongate, tapered, bearing row of setae in basal part and at apex. Right epandrial lamella large, with several unmodified setae of different lengths. Right surstylus (Fig. 193) divided into 3 lobes, with unmodified setae. Hypandrium with 1 short seta apically. Phallus short. Two rod-shaped apodemes present.

\section{Female}

Body Length: $1.05-1.12 \mathrm{~mm}$, wing length: $1.05-1.10 \mathrm{~mm}$. Hind tibia without modified bristles anteroventrally near middle. Tergite 1 white, tergite 2 only posteriorly brown, remaining tergites completely brown. Sternites 1 and 2 white, remaining sternites weakly brownish, pale brown. Ovipositor and cerci brown. No glands present.

\section{Material examined}

Holotype $\widehat{O}$

SINGAPORE: Seletar, 2 November 2005, swamp forest, sweeping (reg. 25410, leg. P.G.; in ZRC).

\section{Paratypes}

SINGAPORE: 1 , Nee Soon, 20 May 2005, swamp forest, Mal 1 (reg. 25144, leg. P.G.); 1 q, Sime

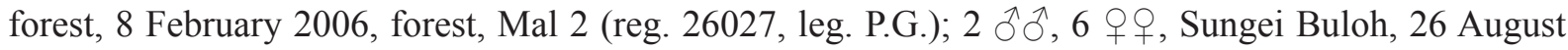
2005, mangrove, Mal 2 (reg. 25320, leg. P.G.).

\section{Etymology}

The epithet 'spinulosa' refers to the spine-like setae on the hind tibia.

\section{Distribution}

Singapore.

\section{Habitat and seasonal occurrence}

This species ocurrs in swamp forests and mangroves. The species apparently is present throughout the year.

\section{Remarks}

Nanodromia spinulosa sp. nov. is closely related to N. taksin Grootaert \& Shamshev but the latter has the hind tibia modified with rows of squamiform setae. In $N$. spinulosa sp. nov. the hind tibia is not so strongly curved and swollen and there is only an anterior row of spinule-like setae on the apical half instead of squamiform setae. Additionally, the new species resembles N. narmjeud Grootaert \& Shamshev that has also the basal third of mid femur swollen and pubescent. However, in N. narmjeud the mid tibia is curved, while it is straight in N. spinulosa sp. nov.

\section{Nanodromia taksin Grootaert \& Shamshev, 2003}

Figs 174, 196-198

Nanodromia taksin Grootaert \& Shamshev, 2003: 48, figs 14-18. 


\section{Diagnosis}

Species with undifferentiated acrostichal and dorsocentral bristles. Legs almost uniformly yellow, hind femur and tibia with brownish ring on middle. Male hind tibia somewhat curved, bearing short squamiform setae on apical half (Fig. 174). Bladder-like structure opening between tergites 4 and 5 (compare to N. narmjeud Fig. 175).

\section{Distribution}

South Thailand (Songkhla Prov.).

\section{Habitat and seasonal occurrence}

Rain forest, occasional records from October.

\section{Remarks}

Since this species was found at low altitude in rain forest in South Thailand it is not unlikely that it will be found in Singapore as well. It should be primarily compared with $N$. spinulosa sp. nov. that is its sister species.

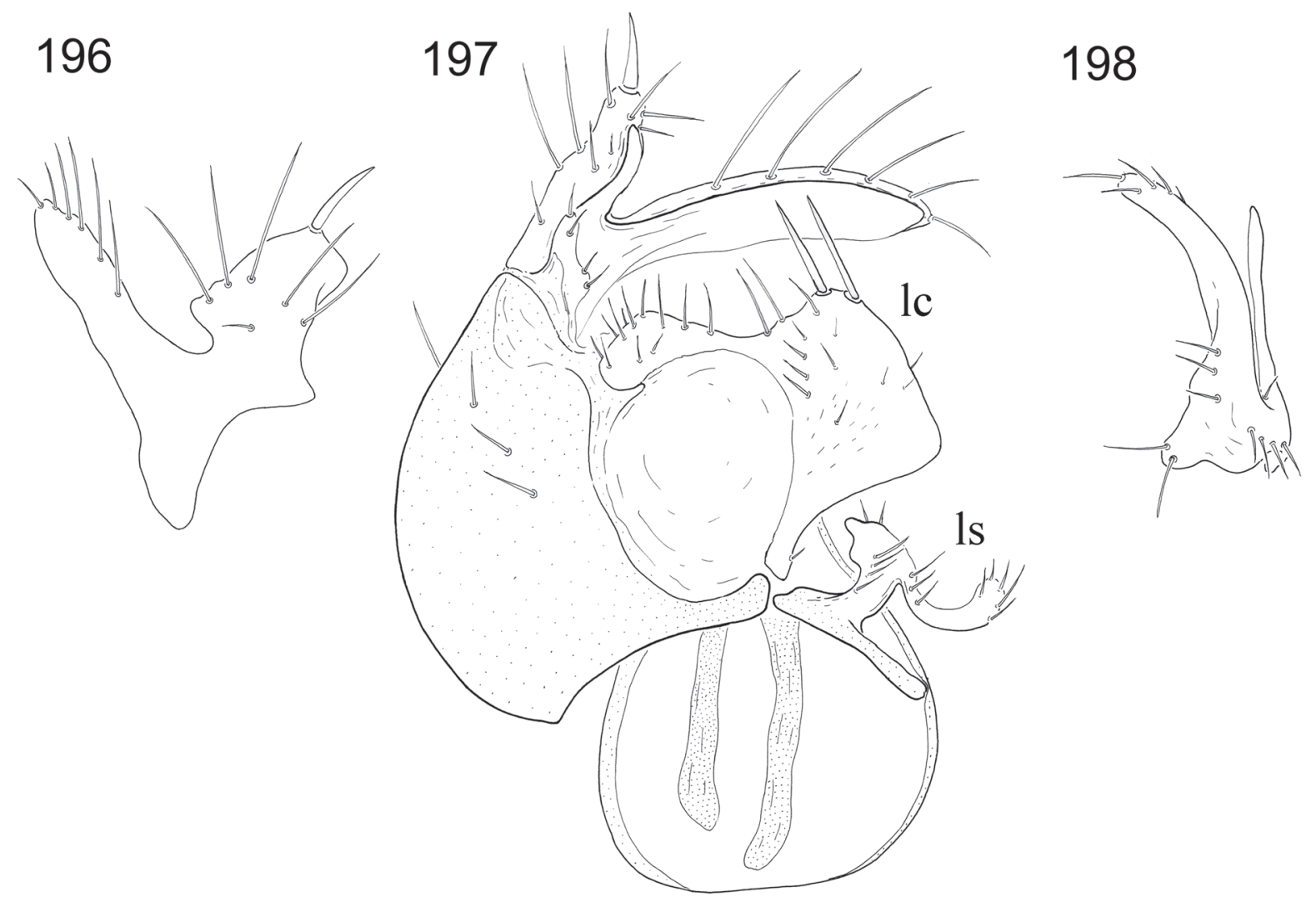

Figs 196-198. Nanodromia taksin Grootaert \& Shamshev, 2003, ô terminalia. 196. right surstylus, dorsal view. 197. epandrium with cerci, dorsal view. 198. left surstylus, lateral view. (after Grootaert \& Shamshev 2003). 
Genus Stilpon Loew, 1859

Agatachys Meigen, 1830: 343 (as MS name'Agatachysflavipes' of Winthem). Type-species: Tachydromia celeripes Meigen, 1830 ( $=T$. graminum Fallén, 1815) [designation by Coquillett, 1910: 504], by monotypy. Suppressed by the I.C.Z.N. (1997: 200 [Opinion 1881]), see Cumming \& Evenhuis (1996). Stilpon Loew, 1859: 34 (as subgenus of Drapetis Meigen). Type-species: Tachydromia graminum Fallén, 1815, by subsequent designation Loew, 1864: 5).

Tetraneurella Dahl, 1909: 362. Type-species: T. beckeri Dahl, 1909 [= Stilpon graminum (Fallén, 1915)], by monotypy.

Pseudostilpon Séguy, 1950: 83. Type-species: Tachydromia paludosa Perris, 1852, by original designation.

\section{Recognition}

Stilpon is recognized from other drapetine genera that occur in the Oriental Region by the following combination of features: eyes contiguous on face, frons with sides nearly parallel; antenna with dorsoapical arista-like stylus; wing with cell br much shorter than cell bm, $\mathrm{A}_{1}$ very weak or absent; abdominal tergites lacking squamiform setae; male terminalia with single rod-shaped ejaculatory apodeme.

\section{Diagnosis}

Very small flies, usually 1.0-1.5 mm (rarely $2.0-2.5 \mathrm{~mm}$ ). Eyes contiguous on face. Ommatidia slightly enlarged below antennae. Frons linear to sublinear, narrow to fairly wide. Face strongly convex. Gena barely extended below eye. Ocellar tubercle with 2 pairs of bristles. One pair of prominent inclinate vertical bristles. Antennae with pedicel large and globose, bearing long ventral preapical seta; postpedicel small, ovate, with very prominent dorsoapical extension; stylus dorsoapical, long. Palpus elongate-ovate, with distinct apical seta. Thorax blackish brown to yellow in ground-colour. Scutum shiney or tomentose; anepisternum largely shiney. Thoracic bristles mostly only slightly prominent. Metaepimeron large. Halter with knob yellow to black, rarely absent. Wing normally developed or sometimes shortened; nearly hyaline or with distinct pattern; Rs originating halfway along $\mathrm{R}_{1 ;}$ vein $\mathrm{R}_{2+3}$ complete or incomplete; cell br short, distinctly less than length of cell bm; crossvein bm-cu nearly transverse; $\mathrm{A}_{1}$ and crossvein $\mathrm{CuA}_{2}$ absent. Legs short, often with distinct colour pattern; fore femur thickened; mid femur slender to barely thickened, usually armed with bristles and spinules or spines arranged in specific patterns; fore tibia more or less spindle-like; mid tibia often armed with ventral spinules; hind tibia slender, lacking prominent bristles, rarely with modified posterior apical comb. Abdomen with segments 1-7 lightly sclerotised, rarely segments 1-2 modified; squamiform setae absent. Gland-like intersegmental structures present or absent. Male terminalia asymmetrical, rotated $90^{\circ}$ to right. Epandrium completely divided. Left epandrial lamella small and fused to hypandrium. Left surstylus divided into 3 (or 4 ) lobes; upper lobe with or without surstylar comb. Right epandrial lamella usually large, positioned ventrally. Right surstylus large to moderately large, undivided, sometimes with apical spines. Cerci, including subepandrial sclerite, fused together basally, rarely fused completely into one large lobe, sometimes greatly reduced and bearing apical spines. Phallus elongate, well sclerotised, hair-like or, rarely, straight or very short and rather weakly sclerotised; single rod-shaped ejaculatory apodeme present. Female similar to male except ordinary setation on mid legs and unmodified abdominal segments 1-2; abdomen always without gland-like structures; terminalia short to elongate; tergite 8 not fused laterally with sternite 8 ; sternite 8 entire, or with apex hinged and partly or completely separated from base. Cercus elongate-ovate or broadly ovate. 


\section{Remarks}

The species of the genus Stilpon are distributed in the Afrotropical (2 species), Nearctic (13 species), Oriental (26 species) and Palaearctic (12 species) regions, with 54 currently known species (including 5 new species recognised herein from Singapore).

Smith (1965) described the first Oriental species Stilpon divergens. Shamshev \& Grootaert (2004b) published 15 new species of Stilpon found in northeastern Thailand above $500 \mathrm{~m}$ altitude. Two short papers followed: first with two new species from Cambodia (Shamshev \& Grootaert 2006) and second with two new species from southern China (Shamshev et al. 2005). Cumming \& Cooper (1992) recognised three informal species groups of Stilpon (S. varipes group, S. graminum group, and S. divergens group), and Shamshev \& Grootaert (2004b) added the S. seeluang group.

Species of Stilpon are quite rare at low altitudes in the tropics as is demonstrated here too. On the other hand they are quite common at higher altitudes as is shown by the material collected during the TIGER project in Thailand. In the latter survey project, Stilpon is as common and diverse as Platypalpus and Elaphropeza and many new species await description.

Species of this genus inhabit different biotopes but usually occurring in the low-lying vegetation zones (Collin 1961; Chvála 1975; Cumming \& Cooper 1992; Przhiboro \& Shamshev 2007).

The key given below is limited to Stilpon from low altitudes including only S. laawae of the 15 species known from northern Thailand (Shamshev \& Grootaert 2004b).

\section{Key to species of Stilpon from Singapore}

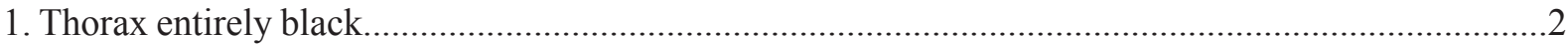

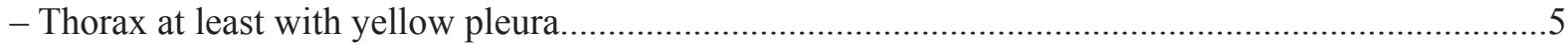

2. Wing lacking $\mathrm{R}_{2+3}$. Palpus brown............................................................ nigripennis sp. nov.

- Wing with $\mathrm{R}_{2+3}$. Palpus yellow. .3

3. $\mathrm{R}_{4+5}$ strongly curved toward costa in apical part; distance between apices of $\mathrm{R}_{2+3}$ and $\mathrm{R}_{4+5}$ about 1.5 times shorter than distance between apices of $R_{1}$ and $R_{2+3}$. Hind femur (except narrow basal portion) brownish. Male: abdominal tergite 1 produced laterally into small corner-like projection bearing 3 short bristles.

S. singaporensis sp. nov. $-\mathrm{R}_{4+5}$ evenly arcuate; distance between apices of $\mathrm{R}_{2+3}$ and $\mathrm{R}_{4+5}$ at least subequal to distance between apices of $\mathrm{R}_{1}$ and $\mathrm{R}_{2+3}$. Hind femur wholly yellow. Abdominal tergite 1 unmodified....................... 4

4. Only tarsomere 5 of all legs black. Male: mid femur with 3 moderately long, ventral, brownish bristles in basal 1/3 (Fig. 203). (Cambodia).

S. goesi Shamshev \& Grootaert, 2006

- Tarsomere 5 of all legs and tarsomere 1 of hind leg brownish. Male: mid femur with 1 black, posteroventral spine beyond middle and row of 7 spine-like bristles in basal part (Fig. 199). (Cambodia).

S. angkorensis Shamshev \& Grootaert, 2006

5. Hind tibia strongly curved. Halter yellow.

S. arcuatum sp. nov.

- Hind tibia unmodified. Halter brownish or black

6. Scutum entirely brown. Hind femur largely brownish......S. malayensis Shamshev \& Grootaert, 2004

- Scutum largely yellow, with brownish patch above wing base. Hind femur at most somewhat brownish in apical part. 
7. Wing finely infuscate; $\mathrm{R}_{4+5}$ slightly arcuate in apical part. Male: upper lobe of left surstylus lacking surstylar comb (Fig. 211). (Thailand; Singapore).

S. laawae Shamshev \& Grootaert, 2004

- Wing maculate or darker along some veins

8. Wing maculate; vein $\mathrm{R}_{4+5}$ strongly curved toward costa in apical part. Male: upper lobe of left surstylus with markedly developed surstylar comb (Fig. 223) (Singapore).

S. neesoonensis sp. nov.

- Wing broadly brownish infuscate along $\mathrm{R}_{2+3}$ and $\mathrm{CuA}_{1}$ (except subapical part). $\mathrm{R}_{4+5}$ evenly curved toward costa in apical part. Male: upper lobe of left surstylus lacking surstylar comb (Fig. 233) (Singapore).

S. weilingae sp. nov.

Stilpon angkorensis Shamshev \& Grootaert, 2006

Figs 199-202

Stilpon angkorensis Shamshev \& Grootaert, 2006: 39.
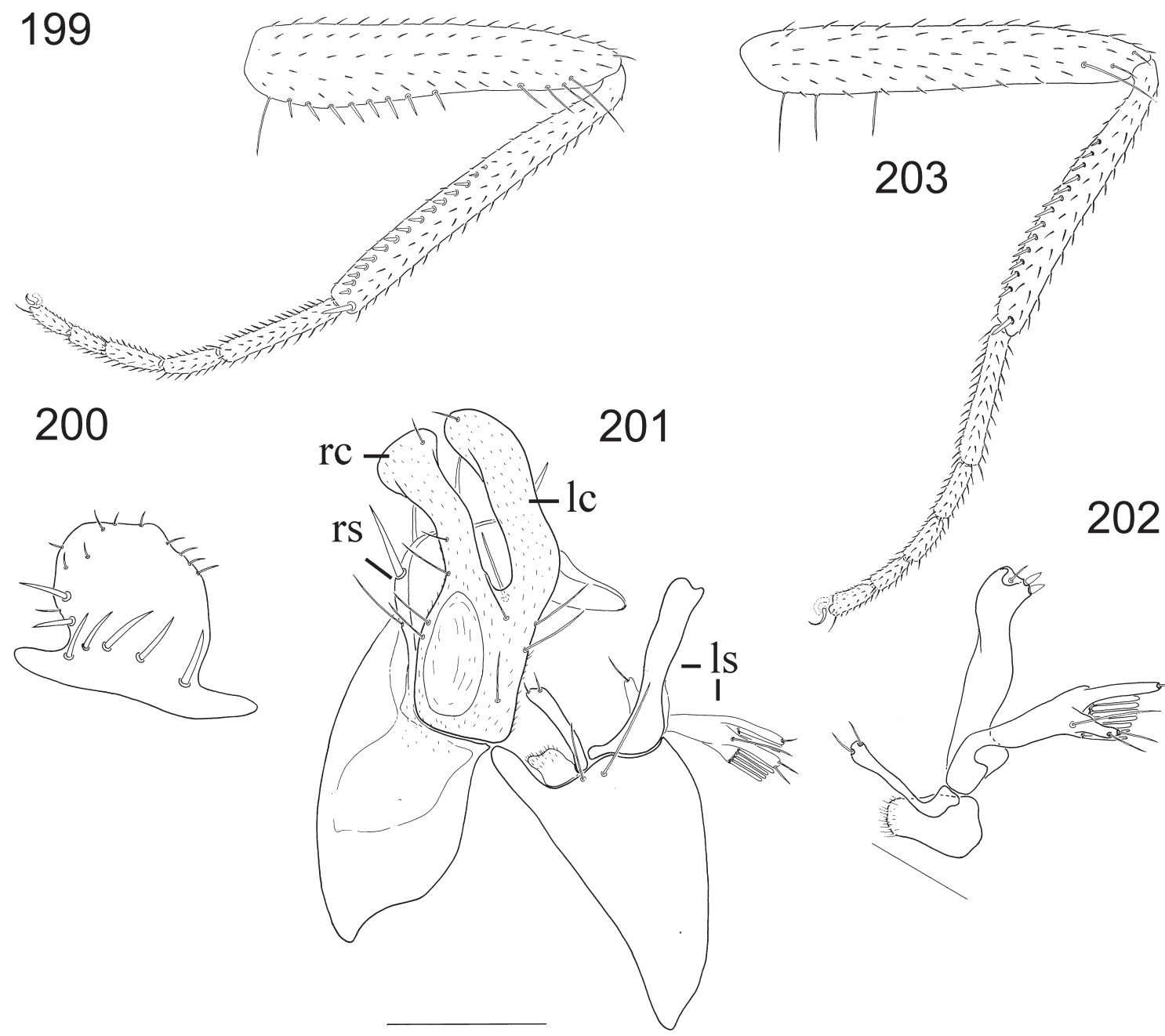

Figs 199-203. Stilpon, Oึ. 199-202. S. angkorensis Shamshev \& Grootaert, 2006. 199. mid leg, lateral view. 200. right surstylus, dorsal view. 201. epandrium with cerci, dorsal view. 202. left surstylus, lateral view. 203. S. goesi Shamshev \& Grootaert, 2006, mid leg, anterior view. (after Shamshev \& Grootaert 2006). 


\section{Diagnosis}

Body length $1.6 \mathrm{~mm}$, wing length $1.4 \mathrm{~mm}$. Palpus yellow. Thorax black. Acrostichal and dorsocentral bristles extending to base of scutellum. Legs almost wholly yellow, only tarsomere 5 of all legs and tarsomere 1 of hind leg brownish. Mid femur slender; with 1 black posteroventral spine beyond middle and row of 7 moderately long, spine-like bristles in basal part, 1 long, yellowish bristle near base. Mid tibia with row of black ventral spinules. Hind femur (viewed laterally) evenly thickened toward middle, with at least 5 moderately long anteroventral bristles in apical part. Wing normally developed, more or less evenly infuscate. $R_{2+3}$ present, about 2.5 times longer than Rs. Distance between apices of $R_{2+3}$ and $\mathrm{R}_{4+5}$ subequal to distance between apices of $\mathrm{R}_{1}$ and $\mathrm{R}_{2+3}$. $\mathrm{R}_{4+5}$ and $\mathrm{M}_{1+2}$ divergent and evenly arcuate in apical part. Abdominal gland-like structures present between tergites 2-3 and 3-4. Male terminalia with upper lobe of left surstylus bearing markedly developed surstylar comb. Female similar to male, except mid femur with 3 longer, yellow ventral bristles; mid tibia lacking black ventral spinules; abdominal gland-like structures absent.

\section{Distribution}

Cambodia.

\section{Habitat and seasonal occurrence}

No data on habitat, only known from January.

\section{Remarks}

Currently, S. angkorensis is known only from Cambodia. However, its occurrence in Singapore is quite possible. This species belongs to the $S$. divergens group and is comparable to $S$. goesi (also described from Cambodia), but can be distinguished as given in the key.

\section{Stilpon arcuatum sp. nov.}

Figs 204-206

\section{Diagnosis}

Species with entirely yellow thorax; legs largely brownish yellow, hind tibia modified, strongly curved and largely thickened towards apex; wing distinctly maculate, broadly brownish infuscate on middle leaving apical and basal parts hyaline, halter yellow.

\section{Description}

\section{Male}

Length. Body $1.2 \mathrm{~mm}$, wing $1.1 \mathrm{~mm}$.

HeAd. Black. Two moderately long, fine vertical bristles present. Frons linear with sides nearly parallel, broad, entirely tomentose. Ocellar tubercle with minute setulae. Antenna with scape and pedicel brownish yellow, postpedicel pale yellow. Palpus brownish yellow, with moderately long, brownish subapical bristle.

THORAx. Yellow in ground-colour with some brownish tinge (especially sutures); scutum entirely tomentose. Postpronotal bristle moderately long, inclinate. Dorsocentral and acrostichal bristles undifferentiated, scutum more or less evenly covered with uniform setulae.

LEGS. With fore and mid femora apically, hind femur entirely, fore and hind tibiae entirely, mid tibia basally, fore tarsus entirely, mid and hind tarsomere 5 brownish yellow, otherwise yellow. Coxae with unmodified setation; hind trochanter lacking spinules. Fore femur markedly thickened, with row of 
moderately long brown anteroventral and row of minute posteroventral bristles. Fore tibia spindle-like, with unmodified setation. Mid femur slender, with 4 moderately long ventral bristles basally and 1 long, subapical bristle anteriorly. Mid tibia lacking ventral spinules (ventral setulae slightly stronger apically) and prominent bristles. Hind femur (viewed laterally) evenly thickened towards middle, with 1 complete row of short anteroventral bristles, several similar setae on basal part anteriorly and several dorsal erect bristles near base. Hind tibia strongly curved and largely thickened towards apex, bearing longer than on other parts ventral setulae, with unmodified posterior apical comb. Fore and mid tarsi slender, hind tarsomere 1 slightly thickened.

WING. Normally developed, covered with uniform microtrichia; distinctly maculate, broadly brownish infuscate on middle leaving apical and basal parts hyaline. Costal vein with short setulae along anterior margin. $\mathrm{R}_{1}, \mathrm{R}_{2+3}$ (in less degree), $\mathrm{R}_{4+5}$ and $\mathrm{M}_{1+2}$ thickened. $\mathrm{R}_{2+3}$ long, nearly 2.0 times as long as $\mathrm{Rs}$, sinuate, meeting costa beyond middle of wing. Distance between apices of $R_{2+3}$ and $R_{4+5}$ subequal to distance between apices of $\mathrm{R}_{1}$ and $\mathrm{R}_{2+3}(22 / 18) . \mathrm{R}_{4+5}$ evenly curved towards costa in apical part. $\mathrm{R}_{4+5}$ and $\mathrm{M}_{1+2}$ slightly divergent before wing apex. Halter entirely yellow.
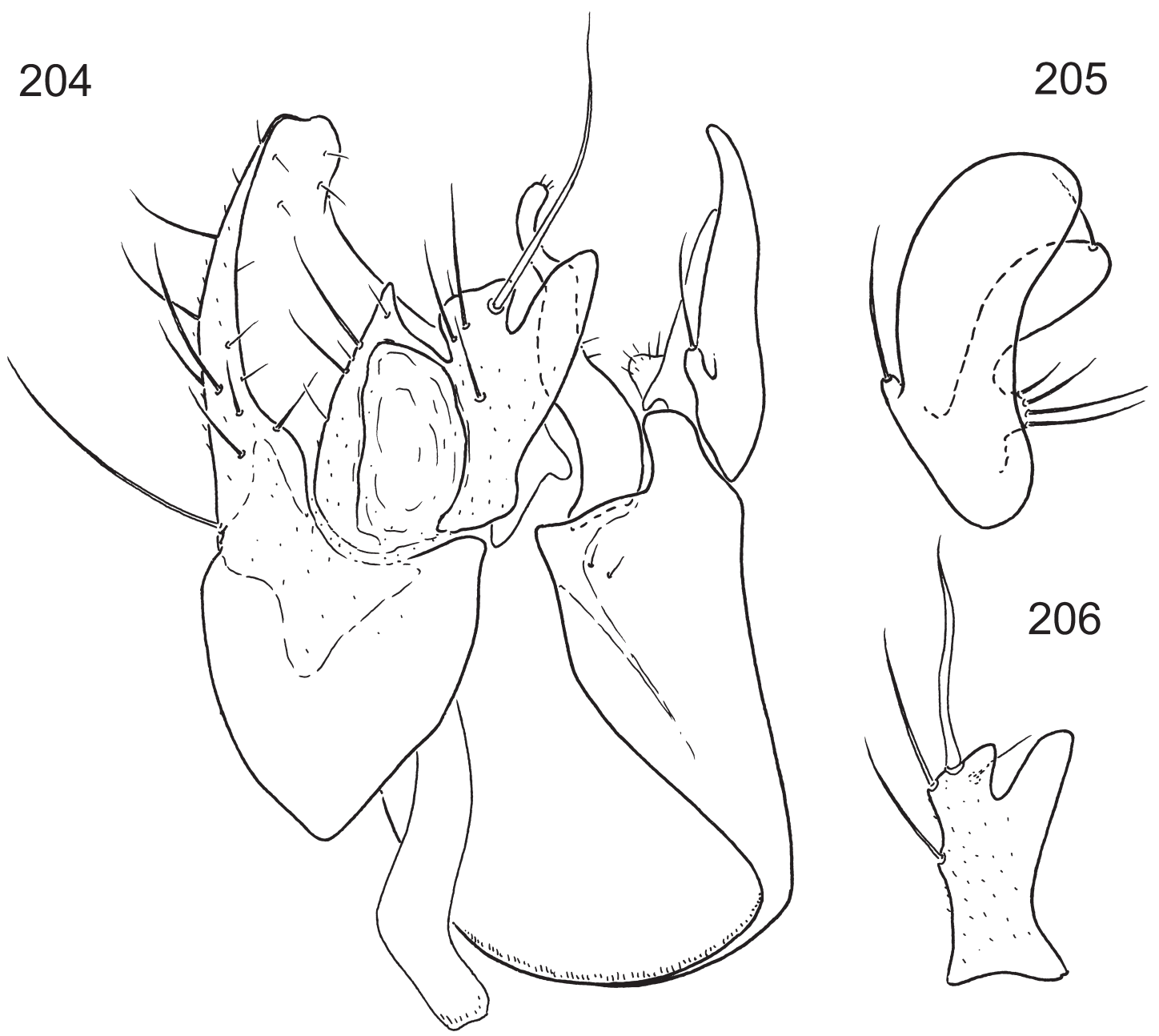

Figs 204-206. Stilpon arcuatum sp. nov., ô terminalia. 204. epandrium with cerci, dorsal view. 205. left surstylus, lateral view. 206. left cercus, lateral view. 
Aвdomen. Tergites 1 and 2 unmodified. Segment 8 with several unmodified setae of different lengths (2-3 long). Sternites brownish yellow, with scattered minute, brownish setulae. Gland-like structure present between tergites 2 and 3 and 3 and 4 .

Terminalia. Yellowish brown (Figs 204-206). Cerci narrowly fused, short, lacking spines; right cercus pointed, with several setae of different lengths; left cercus (Fig. 206) bilobed, with right lobe bearing 1 very long and several short setae. Epandrium completely divided. Right surstylus with several long submarginal setae dorsally, lacking spines. Left epandrial lamella fused to hypandrium, with 2 minute setulae in apical part. Left surstylus (Fig. 205) with upper lobe divided; lower part lacking surstylar comb, upper part elongate oval. Hypandrium with 2 long bristles in apical part. Phallus short.

\section{Female}

Unknown.

\section{Material examined}

Holotype $\widehat{O}$

SINGAPORE: Kranji (KNT01), 12 May 2009, mangrove, Mal. (reg. 29052, leg. P.G.; in ZRC).

\section{Etymology}

The name 'arcuatum' alludes to the bent hind femora and tibia of this new species.

\section{Distribution}

Singapore.

\section{Habitat and seasonal occurrence}

This species occurs in mangrove, with a single record from May.

\section{Remarks}

The new species can be readily distinguished from all other species of Stilpon described from the Oriental Region by a combination of characters that has been given in the diagnosis. It should be noted that in this species the structure of the hind tibia is unique within the genus.

Stilpon goesi Shamshev \& Grootaert, 2006

Figs 203, 207-209

Stilpon goesi Shamshev \& Grootaert, 2006: 37.

\section{Diagnosis}

Species with wholly black thorax. Palpus yellow. Thorax black. Legs almost wholly yellow, only tarsomere 5 of all legs black. Mid femur with 3 moderately long, brownish ventral bristles in basal 1/3. Wing deeper infuscate along $\mathrm{R}_{4+5}$ and $\mathrm{CuA}_{1} ; \mathrm{R}_{2+3}$ nearly 3.0 times longer than Rs. Distance between apices of $R_{2+3}$ and $R_{4+5}$ somewhat longer than distance between apices of $R_{1}$ and $R_{2+3}, R_{4+5}$ and $M_{1+2}$ divergent and evenly arcuate in apical part. Abdominal gland-like structures not prominent. Male terminalia lacking spines, upper lobe of left surstylus with markedly developed surstylar comb. Female similar to male except, mid femur with 3 longer, yellow ventral bristles and mid tibia lacking black ventral spinules.

\section{Distribution}

Cambodia. 


\section{Habitat and seasonal occurrence}

No data on habitat is know for this species, and it is only known from January.

\section{Remarks}

Currently, $S$. goesi is known only from Cambodia. However, its occurrence in Singapore is quite possible. This species belongs to the $S$. divergens group and could is comparable to $S$. angkorensis, but distinguishable as given in the key.

\section{Stilpon laawae Shamshev \& Grootaert, 2004}

Figs 210-213

Stilpon laawae Shamshev \& Grootaert, 2004b: 323.

\section{Diagnosis}

Body length about $1.5 \mathrm{~mm}$, wing length 0.9-1.2 $\mathrm{mm}$. Thorax almost wholly yellow, scutum with small brownish patch above wing base. Postpronotal bristle slightly prominent. Acrostichal and dorsocentral bristles extending to base of scutellum. Legs largely yellow, fore tibia (except base) and fore tarsomere 1 brown. Hind trochanter lacking spinules. Mid femur slender, with 4 long yellowish bristles in basal part. Mid tibia lacking prominent ventral spinules. Wing normally developed, finely infuscate. $\mathrm{R}_{2+3}$ present, nearly 2.0 times longer than Rs. Distance between apices of $R_{2+3}$ and $R_{4+5}$ about 2.0 times longer

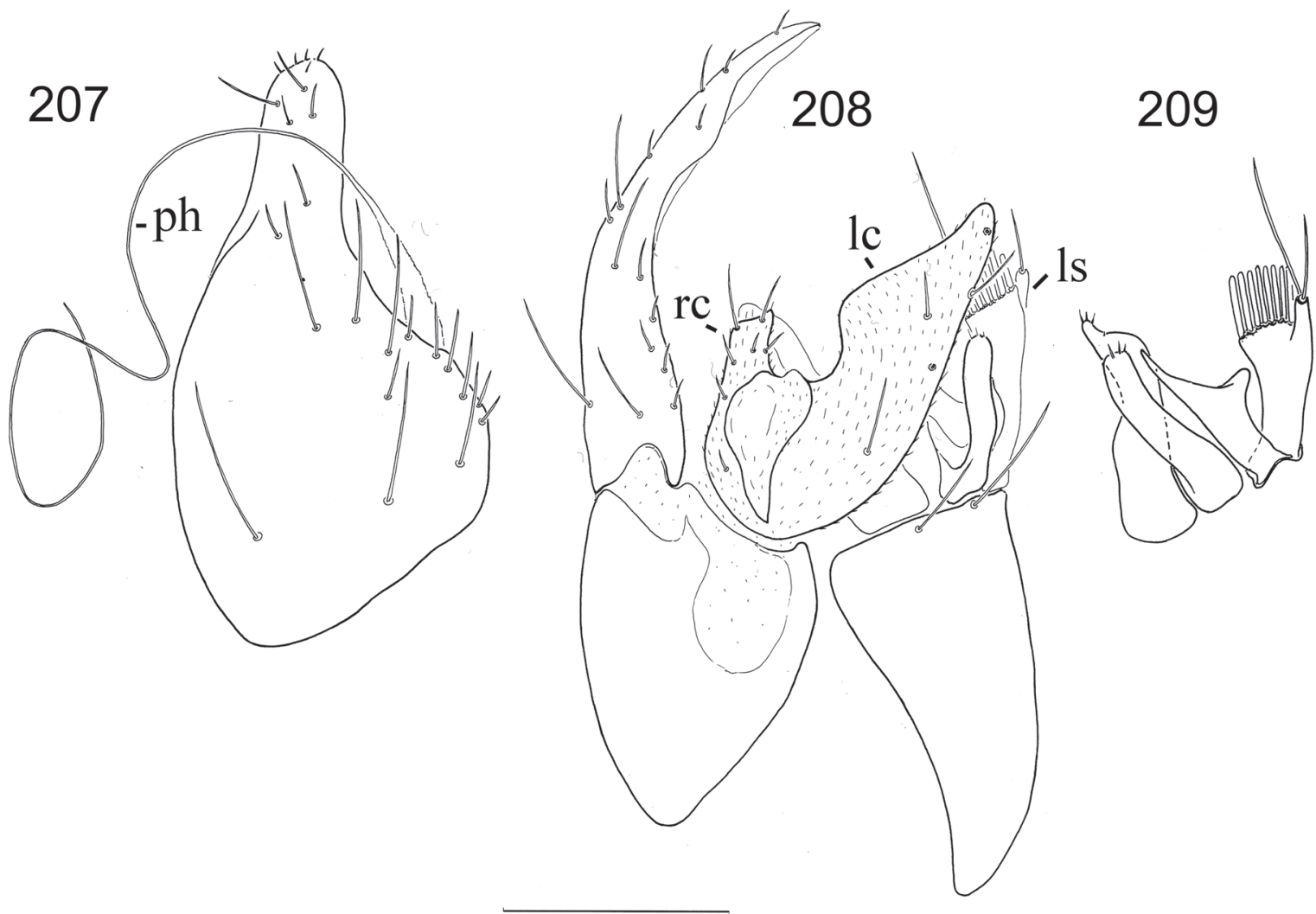

Figs 207-209. Stilpon goesi Shamshev \& Grootaert, 2006, ô terminalia. 207. right surstylus, lateral view. 208. epandrium with cerci, dorsal view. 209. left surstylus, lateral view. Scale bar $=0.1 \mathrm{~mm}$ (after Shamshev \& Grootaert 2006). 
than distance between apices of $\mathrm{R}_{1}$ and $\mathrm{R}_{2+3} \cdot \mathrm{R}_{4+5}$ and $\mathrm{M}$ slightly divergent and evenly arcuate in apical part. Halter with black, elongate knob, contrasting with pale yellow stem. Abdomen lacking gland-like structures. Male terminalia lacking spines; left surstylus without surstylar comb.

\section{Material examined}

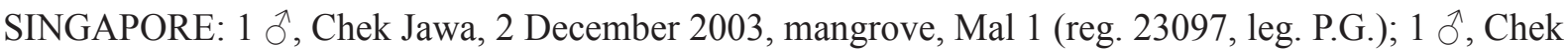
Jawa, 11 December 2003, mangrove, Mal 1 (reg. 23119, leg. P.G.); 1 Oे, Chek Jawa, 22 December 2005, mangrove, Mal 1 (reg. 25455, leg. P.G.).

MALAYSIA: 1 đ, 2 우, Pulau Tioman, Paya, 19 July 2005, secondary forest, sweeping (reg. 25238, leg. P.G.); 1 §, 4 우, Pulau Tioman, Paya, 19 July 2005, secondary forest, sweeping (reg. 25239, leg. P.G.).

\section{Distribution}

Malaysia, Singapore, Thailand.

\section{Habitat and seasonal occurrence}

In Thailand this species is known from two localities, respectively in central and northeastern Thailand, with records from the beginning of September to the beginning of October. In Singapore this species was taken from secondary forests and mangroves, with all records from only December, whereas in Malaysia this species was taken in July.
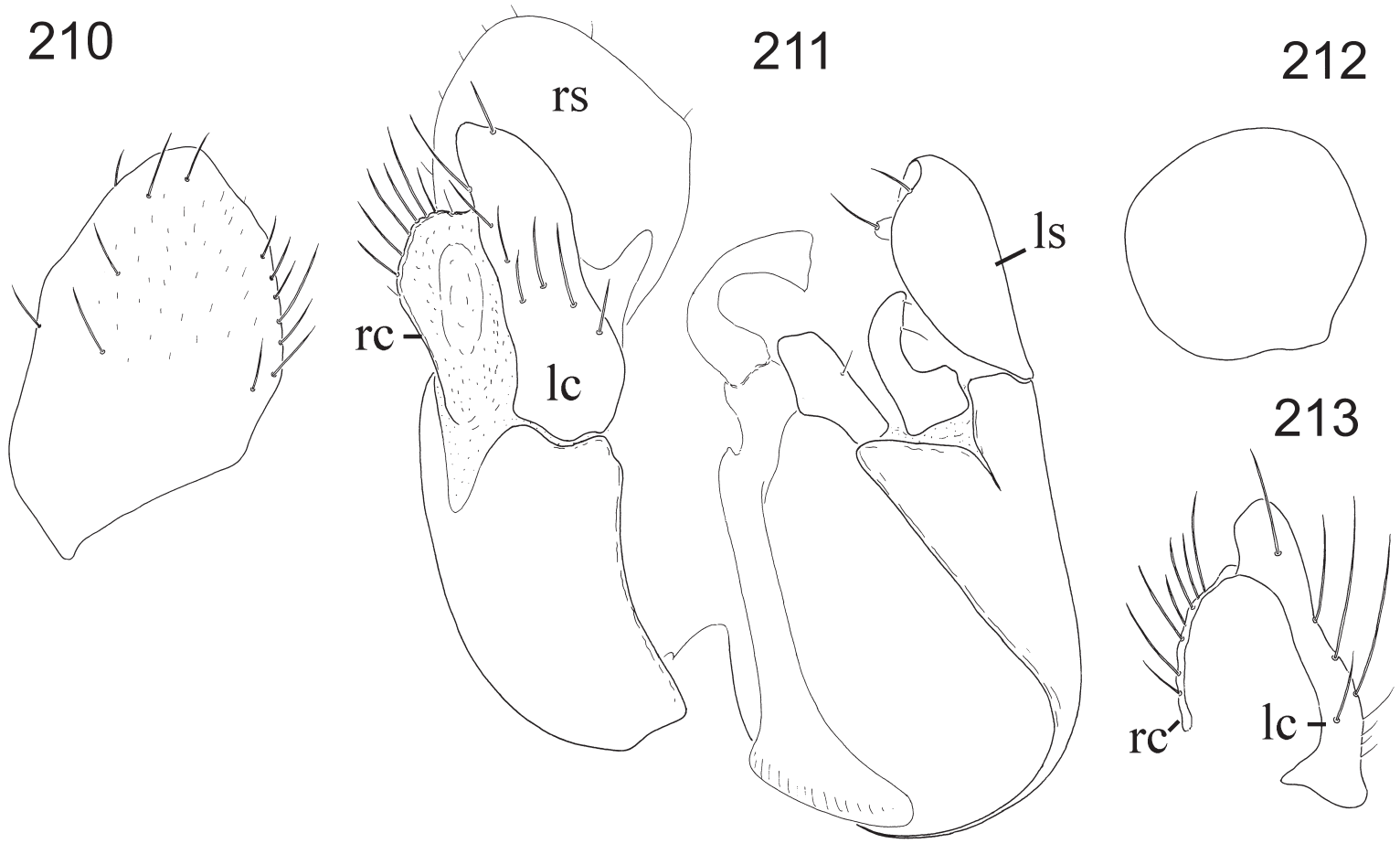

Figs 210-213. Stilpon laawae, Shamshev \& Grootaert, 2004, $\widehat{o}$ terminalia (Material Singapore). 210. right surstylus, dorsal view. 211. epandrium with cerci, dorsal view. 212. left surstylus, lateral view. 213. cerci, right lateral view. Scale bar $=0.1 \mathrm{~mm}$. 


\section{Remarks}

The species was only known previously from Thailand and is recorded here for the first time from Singapore and Malaysia. Stilpon laawae belongs to the $S$. seeluang species group and, currently it is the only member of this unit found in Singapore. Note that there are small differences in the structure of the male genitalia between the Singapore and Thailand populations, but we do not think it would be them as different species.

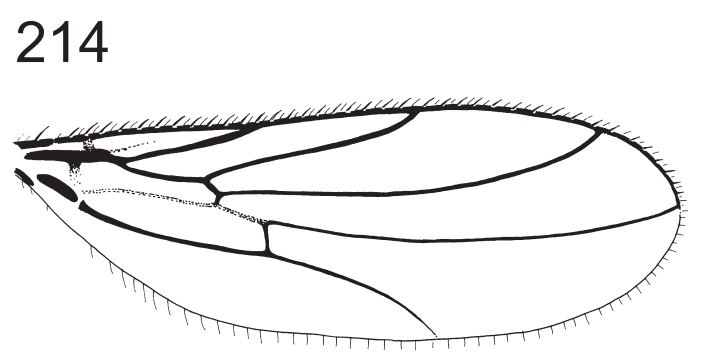

\section{5}
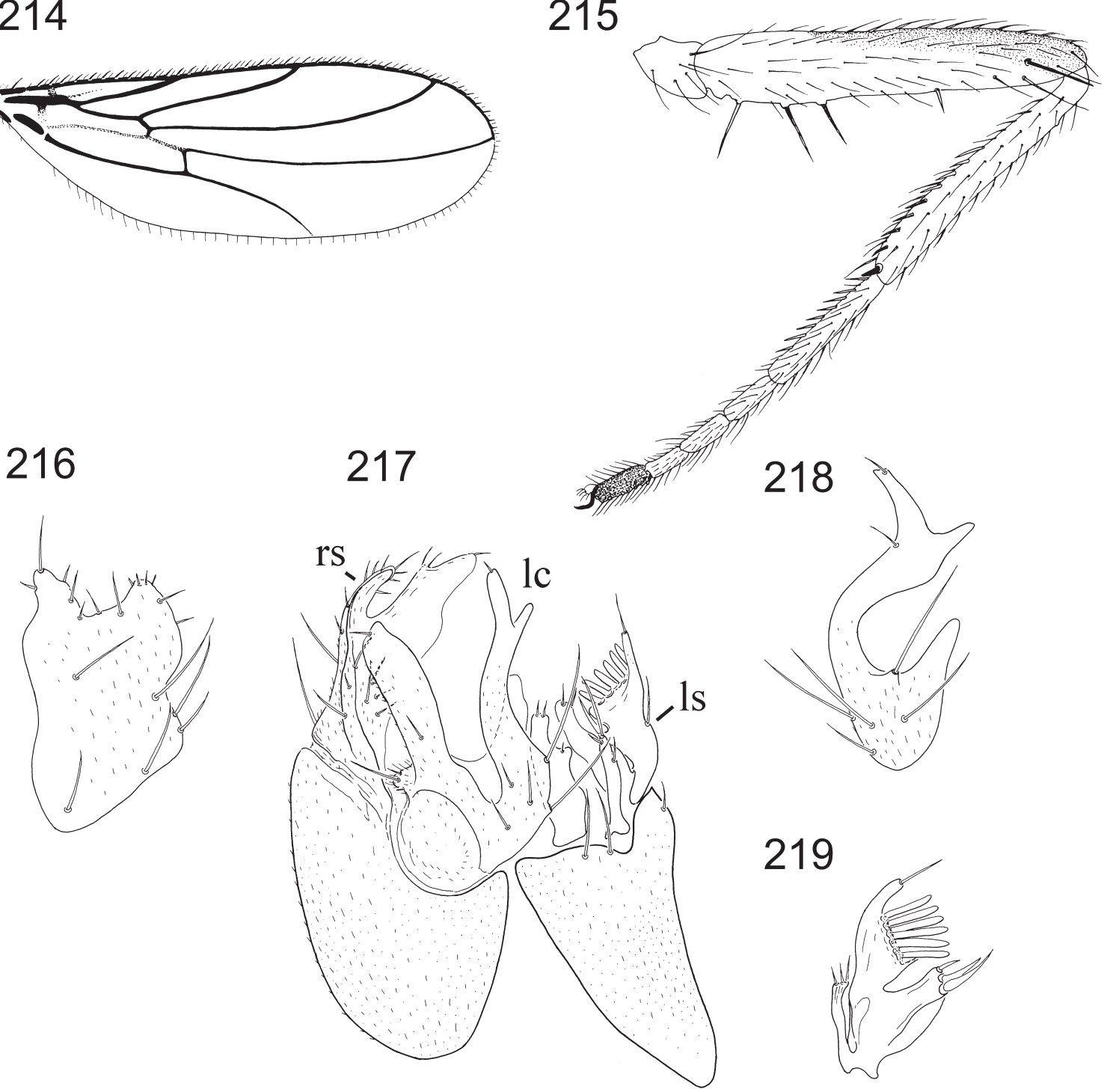

Figs 214-219. Stilpon malayensis Shamshev \& Grootaert, 2004, ð̊. 214. wing, dorsal view. 215. mid leg, anterior view. 216. right surstylus, dorsal view. 217. epandrium with cerci, dorsal view. 218. left cercus, lateral view. 219. left surstylus, lateral view. (after Shamshev \& Grootaert 2004). 
Stilpon malayensis Shamshev \& Grootaert, 2004

Figs 214-219

Stilpon malayensis Shamshev \& Grootaert, 2004b: 332.

\section{Diagnosis}

Body length $1.5 \mathrm{~mm}$, wing length $1.2 \mathrm{~mm}$. Palpus brownish yellow. Thorax with brown prothoracic sclerites and mesoscutum, otherwise yellow. Postpronotal bristle long. Legs with mid femur in apical $1 / 3$, hind femur in apical 3/4, mid and hind tarsomere 5 brownish, fore tarsomere 5 black, fore tibia and fore tarsomere 1 brownish yellow. Mid femur slender, with 2 short, dark posteroventral spines in basal $1 / 3,1$ similar anteroventral spine in apical $1 / 3$ and yellow bristle in extreme base. Mid tibia with rows of ventral spinules. Hind femur (viewed laterally) more or less evenly thickened. Hind tibia unmodified. Wing uniformly infuscate. $R_{2+3}$ present, about 2.5 times longer than Rs. Distance between apices of $R_{2+3}$ and $\mathrm{R}_{4+5} 1.2$ times longer than distance between apices of $\mathrm{R}_{1}$ and $\mathrm{R}_{2+3} \cdot \mathrm{R}_{4+5}$ and $\mathrm{M}$ slightly divergent and arcuate in apical part. Halter with elongate black knob constrasting with pale stem. Abdominal glandlike structures present between tergites 3 and 4 and 2 and 3. Terminalia lacking spines, with upper lobe of left surstylus bearing markedly developed surstylar comb. Female unknown.

\section{Distribution}

Singapore.

\section{Habitat and seasonal occurrence}

The single record of this species was found in a swamp, in December during the rainy season.

\section{Remarks}

In Singapore (and the Oriental Region on the whole) this species can be readily recognised by the combination of the uniformly brown scutum and yellow pleura of the thorax. However, the relationships of $S$. malayensis are unresolved beyond inclusion within the $S$. divergens group.

Stilpon neesoonensis sp. nov.

Figs 220-224

\section{Diagnosis}

Species with yellow thorax, scutum with brownish patch above wing base, katepisternum (= sternopleuron) and meron (= hypopleuron) brownish in lower part; metanotum broadly brownish in middle; hind femur brownish in apical part; wing distinctly maculate, $R_{2+3}$ and $R_{4+5}$ thickened, $R_{4+5}$ strongly curved in apical part.

\section{Description}

\section{Male}

LeNGTH. Body $1.2 \mathrm{~mm}$, wing $1.1 \mathrm{~mm}$.

HEAD. (Fig. 220) Black. Occiput subshining, finely greyish pollinose. Two moderately long vertical bristles present. Frons linear with sides nearly parallel, rather broad, entirely tomentose, subshiney. Ocellar tubercle with minute setulae. Antenna with scape and pedicel brownish yellow, postpedicel yellow. Palpus brownish in apical part, otherwise yellow, with moderately long, brownish subapical bristle. 
THORAX. Yellow in ground-colour. Scutum entirely tomentose, with large brownish patch above wing base; katepisternum and meron brownish in lower part; metanotum broadly brownish in middle. Postpronotal bristle long, inclinate. Dorsocentral bristles in multiple rows, complete posteriorly. Acrostichal bristles 2-serial, complete posteriorly.

LEGs. Almost wholly yellow, only hind femur somewhat brownish in apical part. Hind trochanter lacking spinules. Fore femur markedly thickened, with rows of moderately long anteroventral and posteroventral bristles. Fore tibia spindle-like, with ordinary setation. Mid femur (Fig. 221) slender, with 4 moderately long ventral bristles and 1 long subapical bristle anteriorly. Mid tibia lacking ventral spinules and prominent bristles. Hind femur (viewed laterally) evenly thickened towards middle, with 1 row of short anteroventral bristles and some dorsal erect bristles near base. Hind tibia with unmodified posterior apical comb, clothed in ordinary setulae. Fore and mid tarsi slender, hind tarsomere 1 thickened.

WING. Normally developed, covered with uniform microtrichia; distinctly maculate, cells $r_{1}$, basal part of $r_{2+3}$, whole $r_{4+5}$, br and wing apex hyaline, otherwise wing brownish (deeper on middle part). Costal vein with short setulae along anterior margin. $R_{2+3}$ and $R_{4+5}$ thickened. $R_{2+3}$ short, nearly as long as Rs. Distance between apices of $\mathrm{R}_{2+3}$ and $\mathrm{R}_{4+5}$ about 3.0 times longer than distance between apices of $\mathrm{R}_{1}$ and $\mathrm{R}_{2+3}$. $\mathrm{R}_{4+5}$ strongly curved toward costa in apical part. $\mathrm{R}_{4+5}$ and $\mathrm{M}_{1+2}$ strongly divergent before wing apex. Halter with brownish yellow knob and yellow stem.

AвDOMEN. Tergites 1 and 2 unmodified. Gland-like structure present between tergites 2 and 3, 3 and 4 and 4 and 5.

Terminalia. Brown (Figs 222-224). Cerci fused into one rather short and subrectangular lobe, with spines. Epandrium completely divided. Left epandrial lamella fused to hypandrium, with 2 long setae apically. Left surstylus (Fig. 224) with upper lobe divided; lower part with markedly developed surstylar comb and additional internal apophysis bearing 3 long setae, upper part short, digitiform, with 1 subapical seta. Right epandrial lamella (Fig. 223) subtriangular, covered with numerous unmodified setae of different lengths. Right surstylus not prominent. Hypandrium with 2 moderately long, strong setae sitting on tubercle in apical part. Phallus short.

\section{Female}

Unknown.

\section{Material examined}

Holotype $\hat{\sigma}$

SINGAPORE: Nee Soon, 3 December 2005, swamp forest, Mal 1 (reg. 25436, leg. P.G.; in ZRC).

\section{Etymology}

The specific name refers to the type locality, Nee Soon.

\section{Distribution}

\section{Singapore.}

\section{Habitat and seasonal occurrence}

This single known specimen was collected in a swamp forest, recorded from December.

\section{Remarks}

The new species belongs to the $S$. divergens group of species. Within this unit $S$. neesoonensis sp. nov. is closely related to $S$. malayensis. However, the latter can be readily distinguished from the new species 

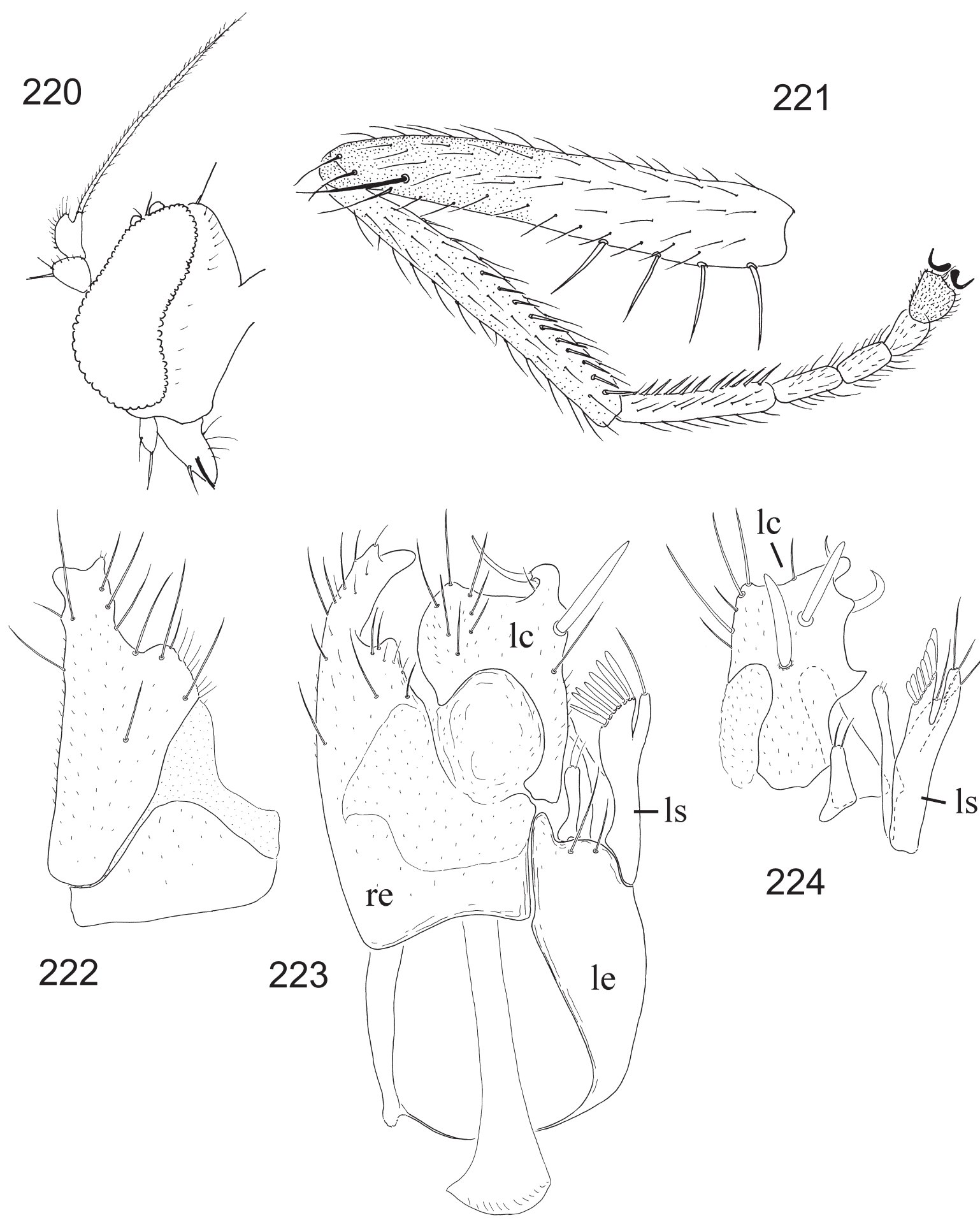

224

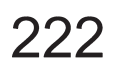

Figs 220-224. Stilpon neesoonensis sp. nov., đ̂. 220. head lateral, lateral view. 221. mid leg, anterior view. 222. right epandrial lamella, lateral view. 223. epandrium with cerci, dorsal view. 224. left surstylus and cercus, dorso-lateral view. 
in the wholly brown scutum (vs. largely yellow). It should be noted that within the $S$. divergens group only these two species have a partly yellow thorax.

Stilpon nigripennis sp. nov.

Figs 225-228

\section{Diagnosis}

Species with black thorax; palpus brown; wing lacking vein $\mathrm{R}_{2+3}$.

\section{Description}

\section{Male}

LENGTH. Wing $1.3 \mathrm{~mm}$.

HEAD. black. Occiput subshining, finely greyish pollinose. Two moderately long, black vertical bristles. Frons linear with sides nearly parallel, rather broad, entirely tomentose, subshiney. Ocellar tubercle with minute setulae. Antenna with scape and pedicel brown, postpedicel somewhat paler. Palpus brown, with moderately long, black subapical seta.

Thorax. Black in ground-colour. Scutum entirely tomentose. Postpronotal bristle long, inclinate. Dorsocentral bristles in multiple rows, complete posteriorly. Acrostichal bristles 2-serial, complete posteriorly.

Legs. With fore and mid tibiae and tarsi (less distinct on mid leg), hind femur (except extreme base) and hind tarsomere 5 brownish, otherwise legs yellow. Hind trochanter lacking spinules. Fore femur markedly thickened, with rows of moderately long antero- and posteroventral bristles. Fore tibia spindlelike, with ordinary setation. Mid femur slender, with 1 ventral bristle (as long as femur is deep) on about middle, 2 similar bristles closer to base and 1 long, subapical bristle anteriorly. Mid tibia with slightly prominent ventral spinules, lacking prominent bristles. Hind femur (viewed laterally) evenly thickened towards middle, with 1 row of anteroventral bristles (2-3 subapicals longer) and some dorsal erect bristles near base. Hind tibia with unmodified posterior apical comb, clothed in ordinary setulae. Fore and mid tarsi slender, hind tarsomere 1 thickened.

WING. Normally developed, covered with uniform microtrichia, uniformly brown infuscate. Costal vein with moderately long setulae along anterior margin. $\mathrm{R}_{2+3}$ absent. $\mathrm{R}_{4+5}$ and $\mathrm{M}_{1+2}$ slightly bowed, divergent before wing apex. Halter with brownish yellow stem and black knob.

ABdomen. Mostly with light brown tergites and sternites, with inconspicuous setation; segment 8 dark brown. Gland-like structures present between tergites 3-7 (Fig. 228).

Terminalia. Brown (Figs 225-227). Cerci broadly fused, with several long setae; left cercus digitiform, slender, bearing conidia-like apical sensilla. Epandrium completely divided. Left epandrial lamella fused to hypandrium, with 2 moderately long setae apically. Left surstylus (Fig. 226) with upper lobe divided; lower part with markedly developed surstylar comb and additional internal broad apophysis bearing 2 very long setae, upper part long, digitiform, with 1 subapical seta. Right epandrial lamella (Fig. 226) subtriangular. Right surstylus subtriangular (Fig. 225), divided at apex, with several long unmodified setae. Hypandrium with two processes at apex, lacking setae. Phallus short.

\section{Female}

Unknown. 


\section{Material examined}

Holotype $\widehat{\sigma}$

SINGAPORE: Chek Jawa, 22 December 2005, mangrove, Mal 1 (reg. 25455, leg. P.G.; in ZRC).

\section{Etymology}

The specific name refers to the brown infuscate wings.
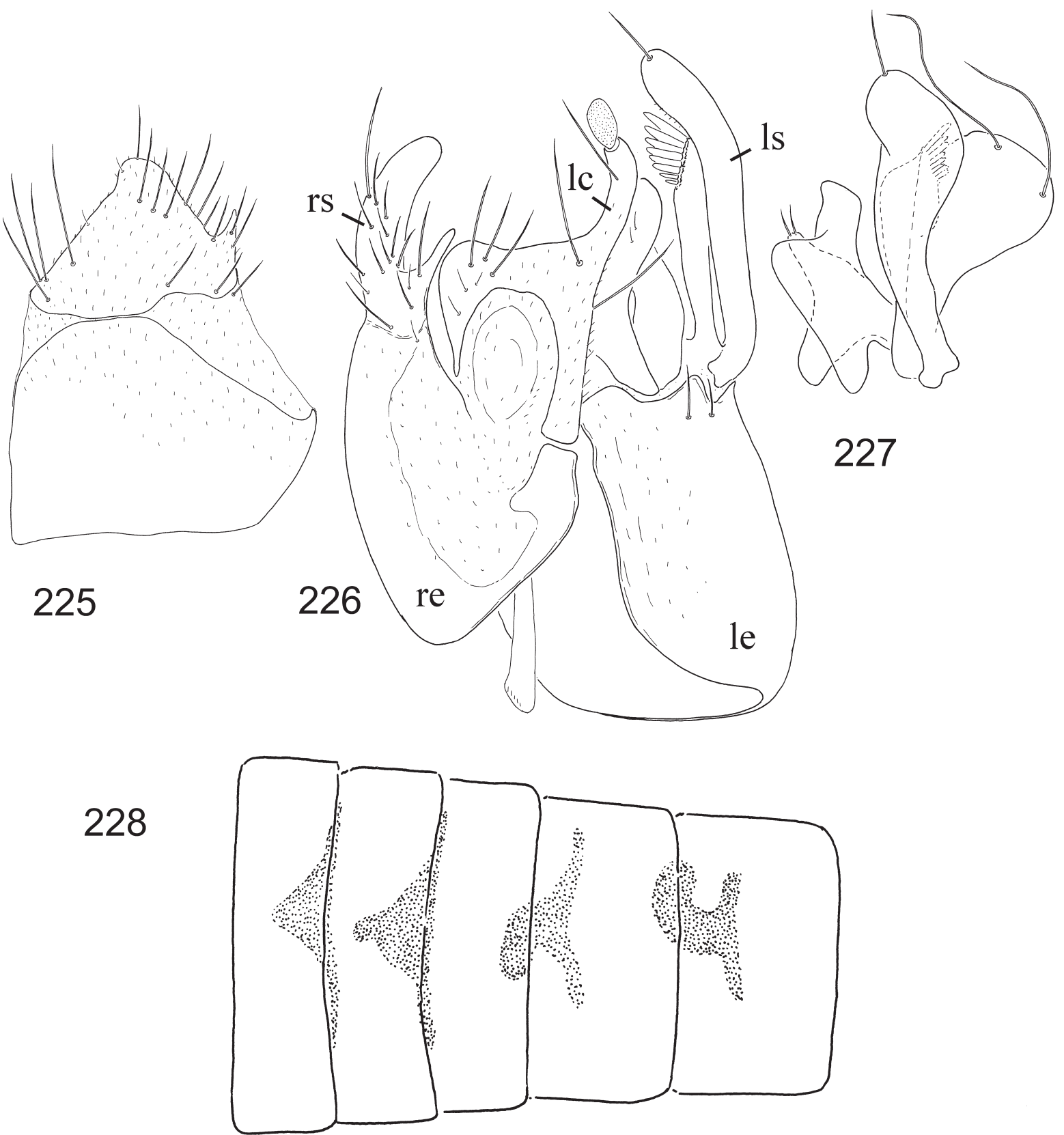

Figs 225-228. Stilpon nigripennis sp. nov., $ð$. 225. right epandrial lamella. 226. epandrium with cerci. 227. left surstylus. 228. gland-like structures (dark stiple) on abdomen, dorsal view. 


\section{Distribution}

Singapore.

\section{Habitat and seasonal occurrence}

Ths single known specimen was collected in mangrove, recorded in December.

\section{Remarks}

The new species can be readily distinguished from other species of Stilpon described from Singapore and from the Oriental Region because $S$. nigripennis sp. nov. is the only species lacking $\mathrm{R}_{2+3}$. In the Palaearctic Region an abbreviated vein $\mathrm{R}_{2+3}$ is present in $S$. paludosa (Perris, 1852) and S. delamarei (Séguy, 1950) both known from the Pyrenees and an unnamed species taken from Tajikistan (Shamshev \& Grootaert 2005d). The relationships of S. nigripennis sp. nov. are unresolved beyond inclusion within the $S$. divergens group.

\section{Stilpon singaporensis sp. nov.}

Figs 229-231

\section{Diagnosis}

Species with brown thorax; antenna brownish; wing distinctly brownish infuscate, $\mathrm{R}_{4+5}$ strongly curved towards costa in apical part; abdominal tergites 1 and 2 modified.

\section{Description}

Male

Length. Body $1.2 \mathrm{~mm}$, wing length $1.1 \mathrm{~mm}$.

HEAD. Black. Occiput subshining, finely greyish pollinose. Two moderately long vertical bristles present. Frons linear with sides nearly parallel, rather broad, entirely tomentose, subshining. Ocellar tubercle with minute setulae. Antenna brownish (in paler specimens postpedicel somewhat paler). Palpus yellow, with strong, black subapical bristle.

Thorax. Brown. Scutum entirely tomentose. Postpronotal bristle long, inclinate. Dorsocentral bristles in multiple rows, complete posteriorly. Acrostichal bristles 2-serial, complete posteriorly.

LEgs. With fore tibia and tarsus (tarsomere 5 darker), mid femur in apical part, hind femur (except narrow basal space), mid and hind tarsomeres 5 brownish, otherwise legs yellow. Hind trochanter lacking spinules. Fore femur markedly thickened, with rows of moderately long antero- and posteroventral bristles. Fore tibia spindle-like, with ordinary setation. Mid femur slender, with 2 strong, moderately long bristles near middle and 1 long, subapical bristle anteriorly. Mid tibia with black ventral spinules, lacking prominent bristles. Hind femur (viewed laterally) evenly thickened towards middle, with 1 row of short anteroventral bristles (4-5 subapicals longer) and some dorsal erect bristles near base. Hind tibia with unmodified posterior apical comb, clothed in ordinary setulae. Fore and mid tarsi slender, hind tarsomere 1 thickened.

WING. Normally developed, covered with uniform microtrichia; distinctly brownish infuscate. Costal vein with short setulae along anterior margin. $R_{2+3}$ long, meeting costa beyond middle of wing. Distance between apices of $R_{2+3}$ and $R_{4+5}$ about 1.5 times shorter than distance between apices of $R_{1}$ and $R_{2+3}$. $R_{4+5}$ strongly curved towards costa in apical part. $\mathrm{M}_{1+2}$ evenly bowed. Halter with black knob and pale stem. 
ABdomen. With tergites (except tergite 8) weakly sclerotised, brownish yellow. Tergite 1 produced laterally into projection bearing 3 short bristles and resting in shallow sclerotised excavation on tergite 2. Sternites 2-4 divided. Gland-like structure not prominent.

Terminalia. Brown (Figs 229-231). Cerci broadly fused, short, left cercus with 3 very long strong terminal bristles. Epandrium completely divided. Left epandrial lamella fused to hypandrium, with 1 long seta apically. Left surstylus (Fig. 231) with upper lobe divided; lower part with markedly developed surstylar comb and additional short internal apophysis bearing 3 short setae, upper part short, slender, digitiform, with 1 subapical seta. Right epandrial lamella (Fig.230) subtriangular, covered with numerous setae of different lengths. Right surstylus (Fig. 229) not prominent. Hypandrium with 2 very long, strong setae apically. Phallus short.

\section{Female}

Mid tibia lacking ventral spinules. Segment 8 elongate, with tergite and sternite separated; sternite 8 with apical part somewhat hinged. Cercus elongate oval, brownish. Otherwise as in male.

\section{Material examined}

Holotype $\widehat{\overbrace{}}$

SINGAPORE: Sime forest, 16 September 2005, forest, Mal 1 (reg. 25352, leg. P.G.; in ZRC).

\section{Paratypes}
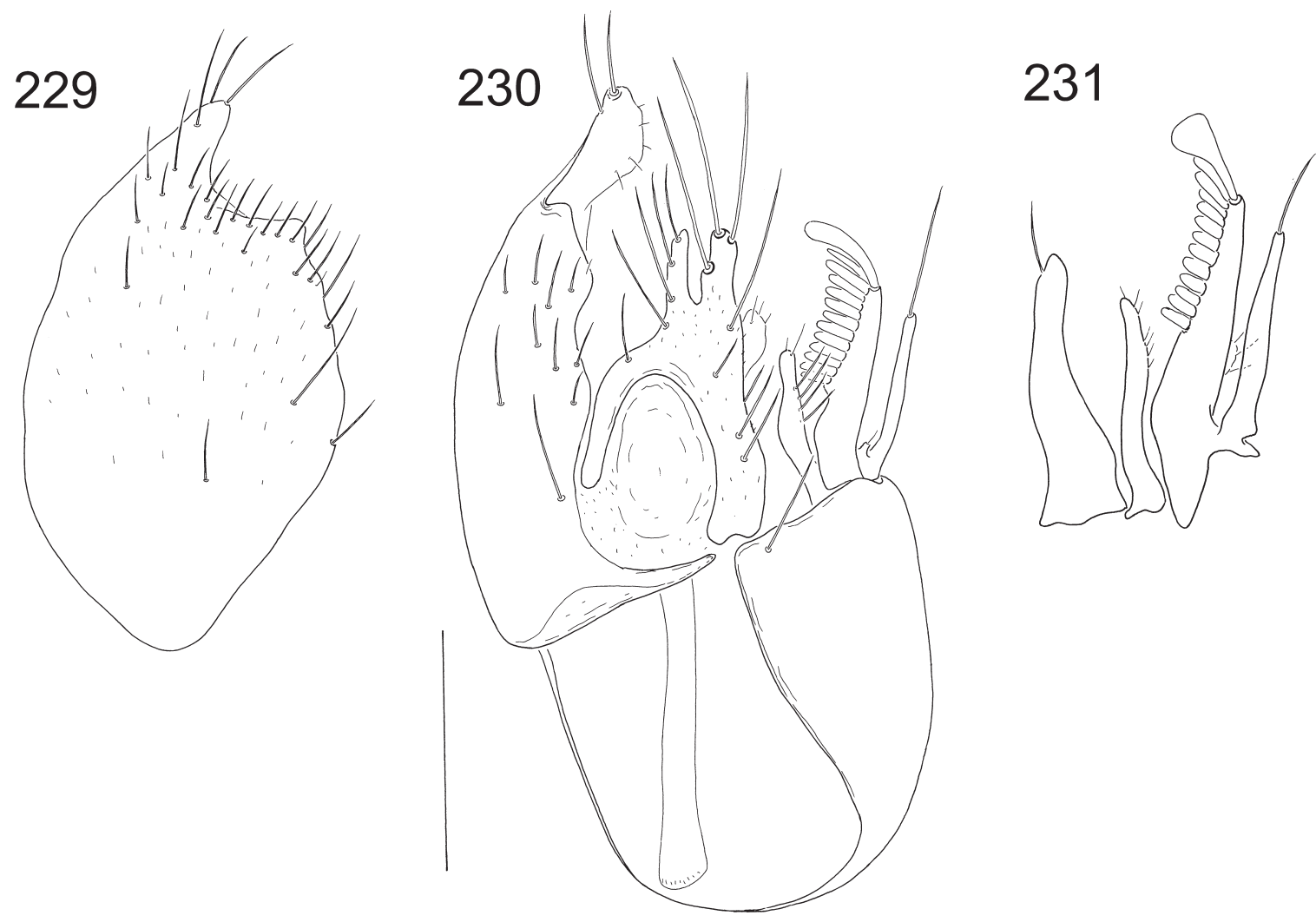

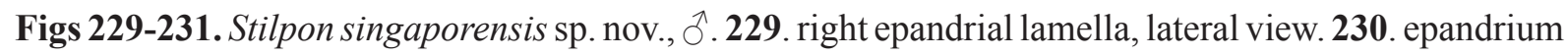
with cerci, dorsal view. 231. left surstylus, lateral view. Scale bar $=0.1 \mathrm{~mm}$. 
SINGAPORE: $3 \hat{\jmath} \widehat{\partial}, 1$ 中, Sime forest, 24 March 2005, forest, sweeping (reg. 25026, leg. P.G.); $3 \hat{\partial} \widehat{\partial}$, 1 , Sime forest, 15 April 2005, forest, sweeping (reg. 25061, leg. P.G.); 1 §, 2 q $ᄋ$, Sime forest, 1 July 2005, forest, sweeping (reg. 25191, leg. P.G.); 1 §, 2 우, Sime forest, 22 July 2005, forest, Mal 1 (reg. 25270, leg. P.G.); 1 ठ, Sime forest, 19 August 2005, forest, Mal 1 (reg. 25299, leg. P.G.); 1 ठ̃, Sime forest, 7 September 2005, forest, Mal 1 (reg. 25334, leg. P.G.); 1 J, 1 \&, Sime forest, 18 November 2005, forest, Mal 1 (reg. 25420, leg. P.G.); 1 q, Sime forest, 3 December 2005, forest, Mal 1 (reg. 25434, leg. P.G.).

\section{Etymology}

The new species is named after the country of origin, Singapore.

\section{Distribution}

Singapore.

\section{Habitat and seasonal occurrence}

This species was collected in forests, with records from March-April, July-September and NovemberDecember.

\section{Remarks}

In having modified male abdominal tergites 1 and 2, the new species is closely related to $S$. paradoxus Shamshev and Grootaert described from Thailand (Shamshev \& Grootaert 2004b). However, S. paradoxus can be readily distinguished from $S$. singaporensis $\mathrm{sp}$. nov. in the slightly arcuate $\mathrm{R}_{4+5}$ (vs. vein $\mathrm{R}_{4+5}$ strongly curved towards costa in the new species). Additionally, in the male of $S$. paradoxus the hind femur is constricted and bent near the middle and the hind tibia bears a long spur-like posterior apical comb. The relationships of both species with Stilpon are not clear.

\section{Stilpon weilingae sp. nov.}

Figs 232-235

\section{Diagnosis}

Species with yellow thorax, scutum with brownish yellow patch above wing base; legs entirely yellow; wing distinctly maculate, broadly brownish infuscate along $\mathrm{R}_{2+3}$ and $\mathrm{CuA}_{1}$ (except subapical part), halter with black knob.

\section{Description}

\section{Male}

Length. Body $1.2 \mathrm{~mm}$, wing $1.1 \mathrm{~mm}$.

HEAD. Black. Two short fine vertical bristles present. Frons linear with sides nearly parallel, broad, entirely tomentose. Ocellar tubercle with minute setulae. Antenna with scape and pedicel yellowish brown, postpedicel yellow. Palpus yellow, with moderately long, yellowish subapical bristle.

THORAX. Yellow in ground-colour; scutum with indistinct brownish yellow patch above wing base, metanotum brownish yellow medially, sutures brownish in various extents. Postpronotal bristle minute. Acrostichals arranged in 2 irregular rows, hardly separated from dorsocentrals, complete posteriorly; dorsocentrals multiserial, more numerous anteriorly, uniform, complete posteriorly.

Legs. Entirely yellow. Coxae with unmodified setation; hind trochanter lacking spinules. Fore femur markedly thickened, with row of moderately long yellowish anteroventral and row of minute 
posteroventral bristles. Fore tibia spindle-like, with unmodified setation. Mid femur slender, with 4 moderately long ventral bristles basally and 1 long, subapical bristle anteriorly. Mid tibia lacking ventral spinules and prominent bristles. Hind femur (viewed laterally) evenly thickened towards middle, with 1 complete row of short anteroventral bristles (longer subapically). Hind tibia unmodified, with unmodified posterior apical comb. Fore and mid tarsi slender, hind tarsomere 1 slightly thickened.

WING. Normally developed, covered with uniform microtrichia; distinctly maculate, broadly brownish infuscate along $\mathrm{R}_{2+3}$ and $\mathrm{CuA}_{1}$ (except subapical part). Costal vein with short setulae along anterior margin. $R_{1}$ (especially in meeting point with costa), $R_{2+3}$ and $M_{1+2}$ thickened. $R_{2+3}$ rather short, nearly 1.5 times as long as Rs, straight, meeting costa near wing midway. Distance between apices of $R_{2+3}$ and $R_{4+5}$ nearly 4.0 times longer than distance between apices of $\mathrm{R}_{1}$ and $\mathrm{R}_{2+3} . \mathrm{R}_{4+5}$ evenly curved toward costa in apical part. $\mathrm{R}_{4+5}$ and $\mathrm{M}_{1+2}$ slightly divergent before wing apex. Halter with deep black knob and yellow stem.

ABDOMEN. Tergite 1 pale yellow, remaining tergites brownish; tergites 1-2 unmodified. Segment 8 with 2 long and several short setae. Sternites brownish yellow, with scattered minute brownish setulae, sternites 2-5 divided along midline. Tergites 2-6 with darker lateral patches covered with microtrichia.

TERMinalia. Dark brown (Figs 232-235). Cerci narrowly fused, short, lacking spines; right cercus slightly prominent, with several setae of different lengths; left cercus unbranched, short, broadened apically, with several short setae. Epandrium completely divided. Right surstylus (Fig. 232), with several long

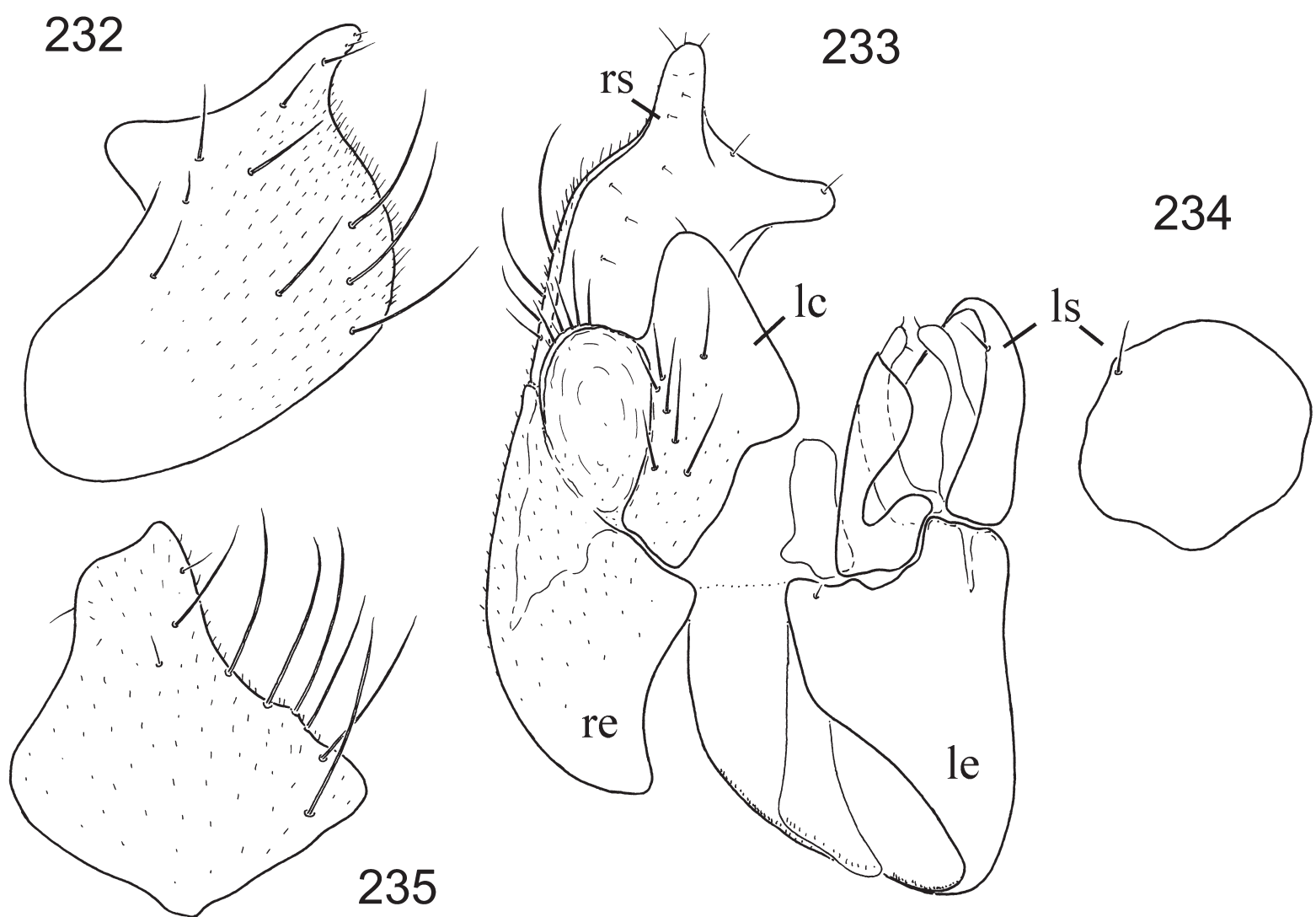

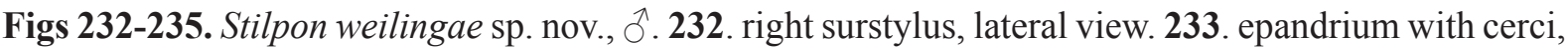
dorsal view. 234. left surstylus, lateral view. 235. right epandrial lamella. 
setae dorsally, lacking spines, prolonged into narrow lobe on each apical corner. Left epandrial lamella fused to hypandrium, with 1 minute setula in apical part. Left surstylus with upper lobe divided; lower part lacking surstylar comb, upper part subglobular (Fig. 234), with 1 minute setula. Hypandrium with 2 long setae apically. Phallus short.

\section{Female}

Unknown.

\section{Material examined}

Holotype $\widehat{\sigma}$

SINGAPORE: Mandai (MAN01), 12 May 2009, mangrove, Mal. (reg. 29056, leg. P.G.; in ZRC).

\section{Etymology}

The species is dedicated to Ms. Wei Ling Lim for her very enthusiastic help during the fieldwork.

\section{Distribution}

Singapore.

\section{Habitat and seasonal occurrence}

This species was collected in mangrove, with a single record from May.

\section{Remarks}

The new species is similar to $S$. laawae, which is known from Thailand and Singapore. The main differences between these species are listed in the key.

\section{Life History}

\section{General remarks}

The immatures of the Tachydromiinae still remain almost unknown. Cumming \& Cooper (1993) summarised scattered literature data that mostly regard to rearing records of adults of tachydromiines from different substrates. None of those records referred to the Oriental species of the subfamily. The rearing data indicate that the immatures of Tachydromiinae appear to occupy various terrestrial habitats. It is generally accepted that larvae of tachydromiines are predaceous. The adults of all Tachydromiinae are predaceous in both sexes attacking small invertebrates. Most of the Tachydromiinae groups are terrestrial inhabiting different biotopes, but the genera Chersodromia and Pontodromia mostly include coastal species. True marine or mangrove species are also found in Elaphropeza, Drapetis, Tachydromia and Nanodromia.

\section{Phenology}

The periods of activity of the adults (phenology) in Singapore show no clear relation with climatic conditions. When we look to the occurrence of the whole subfamily (Table 1) using all available data recorded by all techniques, we see that the highest diversity is found in December with 51 species or nearly $2 / 3$ of the total number of Tachydromiinae. This is partly due to the fact that four species of Chersodromia and four species of Stilpon are only found during that month. January and February are the months with the lowest diversity, with only 15 and 16 species recorded, respectively. This phenomenon is probably related to the fact that rainfall during the rainy season is the greatest hinderence to the activity and emergence of adult flies. The general activity is doubled in March, but fluctuating and reaching a peak in May followed by less activity in July and August. In September to December generally more than 30 species are present. These observations are important if one is interested in assessing diversity 
Table 1. Phenology of the Tachydromiinae in Singapore: figures represent the number of records (observation at a certain moment) not the number of specimens.

\begin{tabular}{|c|c|c|c|c|c|c|c|c|c|c|c|c|c|}
\hline Species & Jan. & Feb. & Mar. & Apr. & May. & Jun. & Jul. & Aug. & Sep. & Oct. & Nov. & Dec. & Tot. \\
\hline Chersodromia bulohensis sp. nov. & & & & & & & & & & & & 1 & 1 \\
\hline Chersodromia glandula sp. nov. & & & & & & & & & & & & 2 & 2 \\
\hline Chersodromia malaysiana sp. nov. & & & & & & & & & & & & 2 & 2 \\
\hline Chersodromia nigripennis & & & 2 & & 1 & & & & 1 & & 5 & 4 & 13 \\
\hline Chersodromia singaporensis & & & & & & & & & & & & 4 & 4 \\
\hline Chersodromia sylvicola sp. nov. & & & & & & & 1 & & & & & & 1 \\
\hline Crossopalpus temasek sp. nov. & & & 1 & 3 & 2 & & & & 1 & & 1 & & 8 \\
\hline Drapetis bakau sp. nov. & & & & & & & 1 & 1 & 1 & & 1 & 2 & 6 \\
\hline Drapetis hutan sp. nov. & & & 1 & & & & & & & & & & 1 \\
\hline Drapetis laut sp. nov. & & & & & & & & & 1 & & 1 & 1 & 3 \\
\hline Drapetis mandai sp. nov. & & & & & & & & & & 1 & & & 1 \\
\hline Drapetis pantai sp. nov. & & & & & & & & & & & 1 & 1 & 2 \\
\hline Elaphropeza acantha & 1 & & 2 & & & & 1 & & 1 & & 2 & 1 & 8 \\
\hline Elaphropeza asexa & 3 & 2 & & & 5 & 6 & 4 & 4 & 3 & 4 & 1 & 3 & 35 \\
\hline Elaphropeza asiophila & & & & & 11 & 1 & & & & & 1 & 3 & 16 \\
\hline Elaphropeza benitotani & 4 & 1 & 3 & & 1 & 3 & 4 & 1 & 3 & 3 & 3 & 4 & 30 \\
\hline Elaphropeza bezzii & & 1 & 1 & & & 1 & 3 & 6 & 3 & 1 & 2 & 1 & 19 \\
\hline Elaphropeza bicaudata & 8 & 6 & 8 & 2 & 9 & 9 & 9 & 15 & 16 & 9 & 5 & 6 & 102 \\
\hline Elaphropeza biuncinata & 2 & 5 & 9 & 1 & 6 & 2 & 7 & 12 & 10 & 8 & 4 & 7 & 73 \\
\hline Elaphropeza bulohensis & & & & & & & & & & & & 1 & 1 \\
\hline Elaphropeza chanae sp. nov. & & & & & 5 & 1 & & & & & & & 6 \\
\hline Elaphropeza chekjawa & & & & & & & & & & & & 1 & 1 \\
\hline Elaphropeza collini sp. nov. & & & & & & 1 & & & & & & & 1 \\
\hline Elaphropeza combinata & & 1 & 2 & & & & & & & 1 & 1 & 1 & 6 \\
\hline Elaphropeza crassicercus & 1 & 4 & 5 & 4 & 9 & 5 & 5 & 8 & 3 & 5 & 8 & 3 & 60 \\
\hline Elaphropeza darrenyeoi & & & & & & & & & & & & 1 & 1 \\
\hline Elaphropeza demeijerei & & & & & & & & & & 1 & & 1 & 2 \\
\hline Elaphropeza E-44 & & & & & & 1 & & & & & & & 1 \\
\hline Elaphropeza E-46 & & & & & & & & & & & 1 & & 1 \\
\hline Elaphropeza E-49 & & & & & & & & & & & & 1 & 1 \\
\hline Elaphropeza E-51 & & & & & & & & & 2 & & & & 2 \\
\hline Elaphropeza E-57 & & & & & & & & & 1 & & & & 1 \\
\hline Elaphropeza E-58 & & & & & & & & & & 1 & & & 1 \\
\hline Elaphropeza E59 & & & & & 1 & & & & & & & & 1 \\
\hline Elaphropeza equalis & & & & & & 1 & & & & & & 2 & 3 \\
\hline Elaphropeza feminata & & & & & 14 & 8 & 2 & & & 5 & 1 & 4 & 34 \\
\hline Elaphropeza flavicaput & 1 & 2 & 7 & & 1 & & 3 & 1 & 3 & 3 & 1 & 1 & 23 \\
\hline Elaphropeza furca & & & & & 8 & 4 & 2 & & 3 & & & & 17 \\
\hline Elaphropeza gohae sp. nov. & & & & & 4 & 2 & & & & & & & 6 \\
\hline Elaphropeza hirsutitibia & & 1 & 1 & 1 & & & & 2 & 4 & & 3 & 2 & 14 \\
\hline Elaphropeza kranjiensis sp. nov. & & & & & & 1 & & & & & & & 1 \\
\hline Elaphropeza limosa & & & 4 & 4 & 6 & 6 & 1 & 3 & 5 & 4 & 3 & 3 & 39 \\
\hline
\end{tabular}


Species

Elaphropeza lowi sp. nov.

Elaphropeza luanae

Elaphropeza luteoides

Elaphropeza malayensis

Elaphropeza meieri

Elaphropeza melanderi

Elaphropeza modesta

Elaphropeza monacantha

Elaphropeza monospina

Elaphropeza murphyi

Elaphropeza neesoonensis

Elaphropeza ngi

Elaphropeza palpata

Elaphropeza pauper

Elaphropeza pluriacantha

Elaphropeza riatanae

Elaphropeza semakau sp. nov.

Elaphropeza shufenae sp. nov.

Elaphropeza sime

Elaphropeza singaporensis

Elaphropeza singulata

Elaphropeza sivasothii

Elaphropeza spicata

Elaphropeza spiralis

Elaphropeza sylvicola

Elaphropeza temasek

Elaphropeza tiomanensis

Elaphropeza ubinensis

Elaphropeza yangi

Elaphropeza yeoi

Nanodromia hutan sp. nov.

Nanodromia narmkroi

Nanodromia spinulosa sp. nov.

Platypalpus singaporensis sp. nov.

Pontodromia pantai sp. nov.

Stilpon arcuatum sp. nov.

Stilpon laawae

Stilpon malayensis

Stilpon neesoonensis sp. nov.

Stilpon nigripennis sp. nov.

Stilpon singaporensis sp. nov.

Stilpon weilingae sp. nov.

Tachydromia luang

Total number of records

Number of species

Jan. Feb. Mar. Apr. May. Jun. Jul. Aug. Sep. Oct. Nov. Dec. Tot.

\begin{tabular}{|l|l|l|l|l|l|l|l|l|l|l|l|}
\hline & & & 5 & 2 & & & & & & & 7 \\
\hline
\end{tabular}

\begin{tabular}{|c|c|c|c|c|c|c|c|c|c|c|c|c|}
\hline & 1 & 1 & & & & & & 2 & & 1 & & 5 \\
\hline & & & & 1 & 2 & & & & 1 & 1 & & 5 \\
\hline 1 & & 1 & & 5 & 2 & 3 & 4 & 3 & 2 & 2 & 2 & 25 \\
\hline
\end{tabular}

\begin{tabular}{|c|c|c|c|c|c|c|c|c|c|c|c|c|}
\hline & 1 & 1 & & & & & & & 1 & 3 & 6 \\
\hline & & 4 & & 1 & & & 4 & 2 & 3 & 1 & 2 & 17 \\
\hline & 1 & & 1 & 2 & & & & & & 2 & 6 \\
\hline
\end{tabular}

\begin{tabular}{|c|c|c|c|c|c|c|c|c|c|c|c|c|} 
& 1 & 1 & 1 & & & & 1 & 1 & & & & 5 \\
\hline & & 4 & 3 & 11 & 4 & 3 & 3 & 3 & 1 & 4 & 4 & 40 \\
\hline 1 & & & & 1 & 2 & & & & 3 & 2 & 3 & 12
\end{tabular}

\begin{tabular}{|c|c|c|c|c|c|c|c|c|c|c|c|c|}
\hline 1 & & & & 1 & 2 & & & & 3 & 2 & 3 & 12 \\
\hline & & 2 & 1 & & & 2 & 1 & 1 & 2 & 2 & 4 & 15 \\
\hline & & 2 & & 1 & & & 1 & & & & 1 & 5 \\
\hline & & & & & & 1 & & & & & & 1 \\
\hline
\end{tabular}

\begin{tabular}{|c|c|c|c|c|c|c|c|c|c|c|c|c|} 
& & 1 & & & & & & 2 & & & 1 & 4 \\
\hline & & 1 & & 2 & 4 & & 1 & 1 & 2 & & & 11 \\
\hline & & & & 2 & 2 & & & & & & & 4 \\
\hline 1 & & & & & & & & & & & & 1 \\
\hline 2 & 2 & 2 & & 2 & 2 & 2 & 2 & 5 & 3 & & 1 & 23 \\
\hline
\end{tabular}

\begin{tabular}{|c|c|c|c|c|c|c|c|c|c|c|c|c|}
\hline & & & & & & & & & & & & \\
\hline & & 2 & & 1 & & 2 & 1 & & & 2 & & 8 \\
\hline & & 1 & & 3 & 1 & 1 & & 1 & & 1 & & 8 \\
\hline & & 1 & & 2 & 1 & 2 & & 2 & & & 1 & 9 \\
\hline 1 & 3 & 2 & 1 & 1 & 1 & 1 & 4 & 5 & 4 & & 2 & 25 \\
\hline
\end{tabular}


in sites and when the period for sampling is limited. September until the end of the year is the period guaranteeing a good (species diverse) sample.

Table 1 is based on all the samples that we studied, mixing sweep net and Malaise trap samples. Also the sampling effort is biased due to a high sampling effort in May and beginning of June 2009 which resulted in notable increases in diversity compared to earlier and later months. So this table shows only occurrence of species and no quantification. Figure 236 shows the activity of Elaphropeza based on a one year sampling with eight Malaise traps in four sites ( 3 terrestrial forests and 1 mangrove: 620 individuals belonging to 38 species). The highest diversity per month; i.e. more than 10 and up to 15 species per sample as well as the number of individuals, are found in March and from August till December. This confirms more or less the above observations that sampling is best during the last months of the year.

\section{Habitat preference}

Most species have a clear habitat preference and as such they can be used as indicators for a certain habitat type. Table 2 gives the occurrence of the Tachydromiinae per sampled habitat type. The first three columns are marine habitats: beach (sandy beach), beach forest (on sandy soil) and mangrove. Columns 5-7 represent terrestrial forest types: rain forest (secondary forest), primary rainforest (maybe somewhat disturbed by nearby human activity) and swamp forest (soil very wet and often inundated). The marshland is open, almost continuously flooded grassland in a rain forest. The drain habitat is open concrete ducts through the city to evacuate rainwater. They are often covered with mosses and short vegetation and may contain small permanent pools. Only three species are found here: two ubiquitous species: Crossopalpus temasek sp. nov. and Elaphropeza hirsutitibia. The third species Elaphropeza equalis is only known from drains and swamp forests.

Five species were observed in marshlands. None are really typical but Elaphropeza neesoonensis, E. meieri and E. yeoi are only found in other very wet conditions (mangrove, swamp forest). The others species are found in various forest types as well.

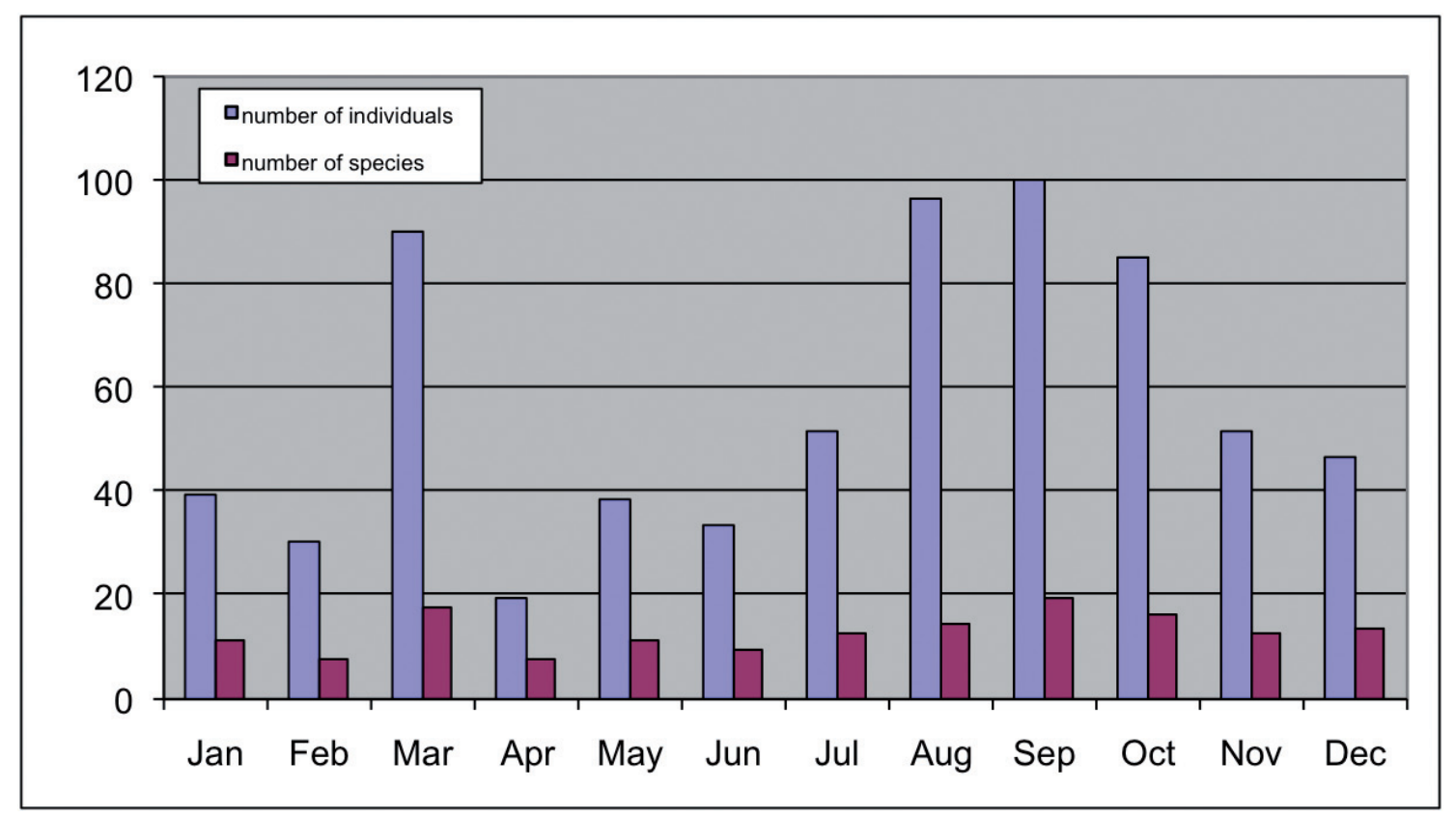

Fig. 236. Activity of Elaphropeza during a year cycle with Malaise traps (March 2005-March 2006) at four sites in Singapore ( 3 forest and 1 mangrove site). 
Sandy beach is of course characterised by species of Chersodromia. However it should be emphasised that Chersodromia sylvicola sp. nov. is only found in swamp forest. The other Chersodromia do occur also in mangroves, but then only on sandy patches inside mangroves that resemble normal open sandy beaches. The other Tachydromiinae that are often observed on sandy beaches disperse from other habitats such as the beach forest and mangrove.

Beach forest is in the supralitoral sone, with Pandanus and Casuarina trees. In this zone we recorded seven species of Tachydromiinae. Elaphropeza furca is thriving here although it is also observed in mangroves. A few specimens have been recorded also in primary rain forest, but this record requires verification. The other species observed in beach forests are mainly mangrove species such as Elaphropeza crassicercus, Elaphropeza sivasothii and Nanodromia narmkroi.

Mangroves have a very diverse Tachydromiinae fauna and presently 60 species have been recorded in this habitat in Singapore. This is a unique observation on a global scale and includes 36 species restricted to mangroves. Remarkably, four species of Drapetis (Drapetis bakau sp. nov., D. laut sp. nov., $D$. mandai sp. nov. and D. pantai sp. nov.) were found on the same sandy patch in the mangrove of Chek Jawa (Fig. 239) together with Chersodromia nigripennis, C. singaporensis and Crossopalpus temasek sp. nov. This part of the supralitoral zone was usually covered with wrack from green algae and beach dug of wild boar deposited probably while searching for ghost crabs. We hypothesized that this rich organic soil contains numerous larvae of other Diptera and mites that are possible prey for tachydromiine larvae. Other dominant species of mangrove are Elaphropeza asiophila, E. asexa, E. crassicercus, E.

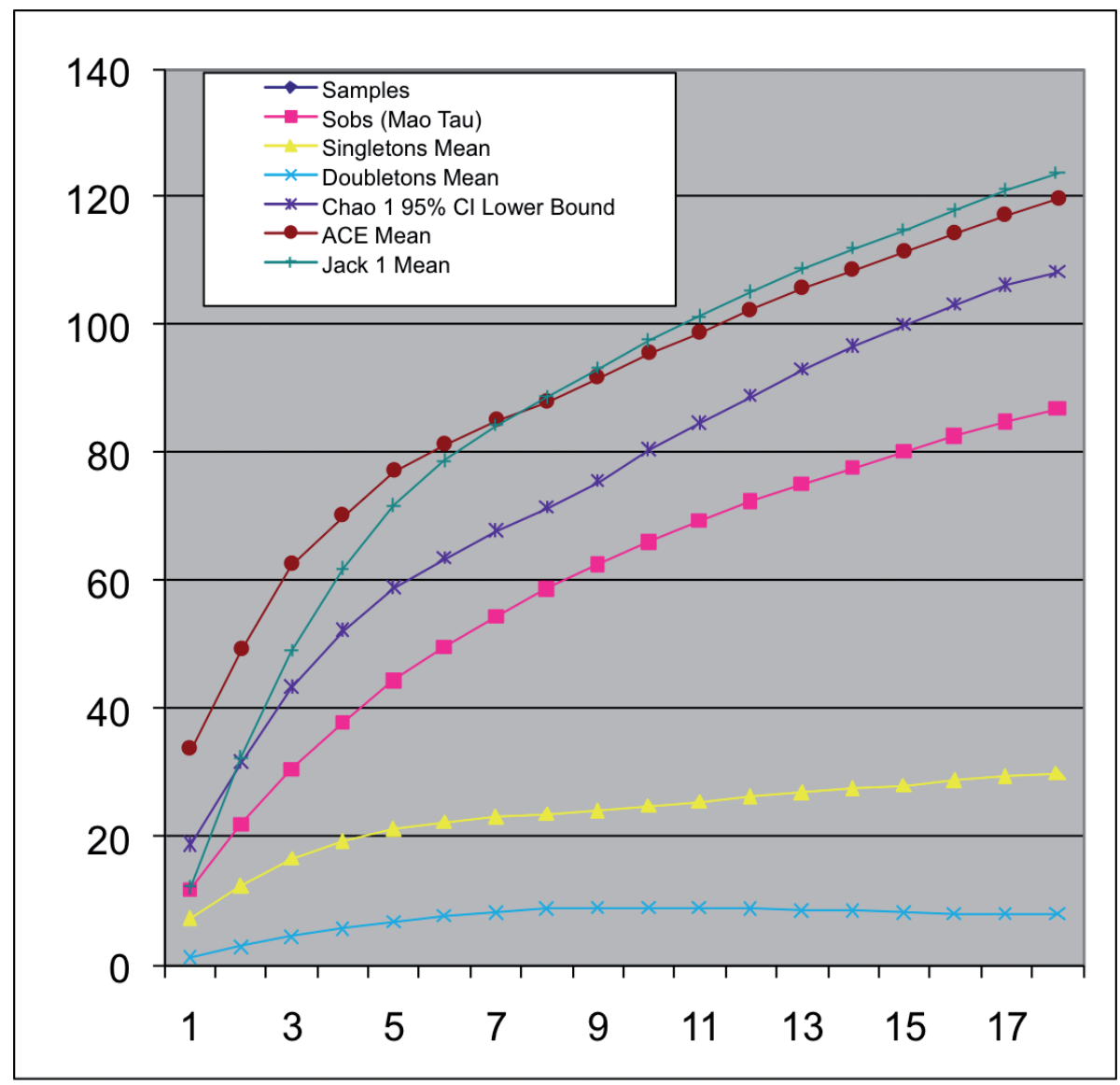

Fig. 237. Species accumulation curve: number of species in relation to the number of sampled habitats (x-axis). 
feminata, E. furca, E. gohae sp. nov., E. limosa, E. malayensis, E. monospina, E. murphyi, E. riatanae, E. shufenae sp. nov., E. sivasothii, E. temasek, Nanodromia narmkroi and Pontodromia pantai sp. nov.. The remaining 24 species found in mangrove do occur in wet habitats and/or have been observed in additional habitats. For these species there are often insufficient data to be conclusive about their true habitat restrictions or preferences.
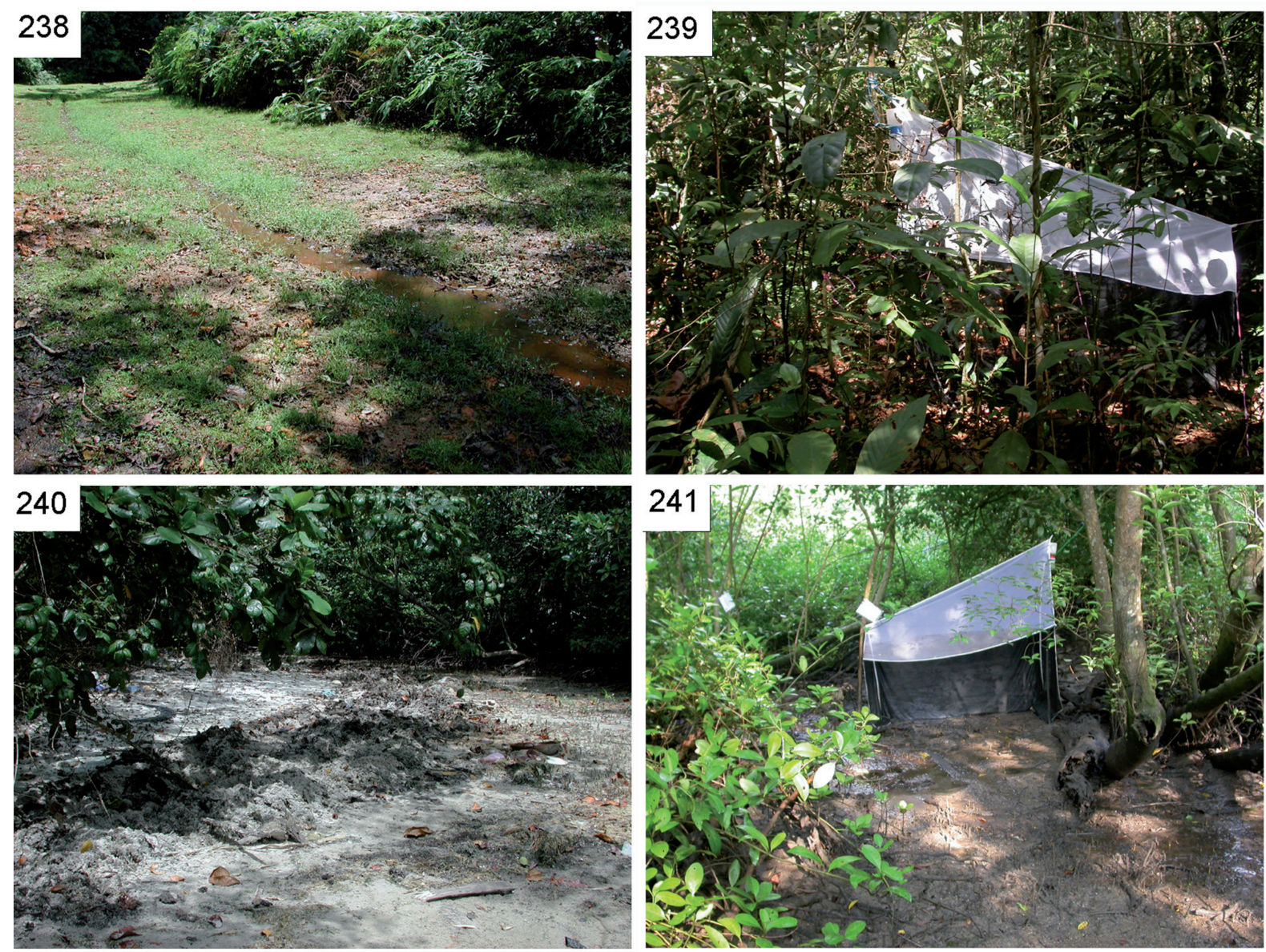

Figs 238-241. Photographs of Tachydromiinae habitats in Singapore. 238. Nee Soon (Upper Peirce Park reservoir), marsh land in swamp forest. The black Elaphropeza species E. neesoonensis Shamshev \& Grootaert, 2007 and E. meieri Shamshev \& Grootaert, 2007 occur here on the short grasses. 239. Nee Soon (Upper Peirce Park reservoir), Malaise trap in swamp forest. Mainly yellow-bodied Elaphropeza species do occur in this type of forest. 240. Pulau Ubin, Chek Jawa - partly shaded sand patch in the mangrove. Wrack on the supralittoral part of the beach is mainly composed of decaying green algae and is being disturbed by wild boar probably digging for ghost crabs. This is the only site where three Drapetis species (D. bakau sp. nov., D. laut sp. nov. and D. pantai sp. nov.) and four species of Chersodromia (C. glandula sp. nov., C. malaysiana sp. nov., C. nigripennis Shamshev \& Grootaert, 2005 and $C$. singaporensis Shamshev \& Grootaert, 2005) have been found. In addition it is type locality for Stilpon nigripennis sp. nov., Empis producta Daugeron \& Grootaert, 2005 and E. vitisalutatoris Daugeron \& Grootaert, 2005 are swarming above the wrack and in the undergrowth. 241. Kranji Nature trail (KNT02) on the border of Sungei Buloh Wetland Reserve. About 120 species of dance (Empididae, Hybotidae) and longlegged flies (Dolichopodidae) have now been recorded there and the site is type locality of 34 species. 
Three types of terrestrial forests were sampled in Singapore; rain forest (secondary forest), primary rainforest (somewhat disturbed by nearby human activity) and swamp forest (soil very wet and often inundated). The swamp forest (Nee Soon) with 41 species proved to be very rich in species though it must be emphasised that the sampling effort during this survey was much less intense in the other forest types. For example, the primary rain forest at Bukit timah was sampled with only one Malaise trap at a site where there might have been human activity in the past and nearby urbanisation. Much more sampling effort is needed to record all species from this rain forest habitat.

A number of species do occur or are observed in various habitats. We consider them as ubiquitous species. The dominant species, Elaphropeza bicaudata and E. biuncinata are such examples, and E. hirsutitibia and Crossopalpus temasek sp. nov. are not so common, but also occur in various habitats. Again more sampling will be needed in a greater variety of habitats to determine and identify the occurrence of widespread and adaptative species.

\section{Future research}

The 731 samples from Singapore contained 1,891 specimens of Tachydromiinae belonging to 85 species. Most of the nine genera of Tachydromiinae recorded from Singapore are almost worldwide in distribution. However, Platypalpus, Tachydromia, Chersodromia, Drapetis, and Crossopalpus are best represented in temperate zones whereas Stilpon and Elaphropeza are most diverse in tropics, especially in the Oriental Region. The genera Pontodromia and Nanodromia are only known from the Oriental and Australian (Papua New Guinea) Regions.

Twenty species (24\%) are represented by singletons, while five species (5\%) by doubletons. Thus, singletons and doubletons represent almost one third (29\%) of the fauna. This high number of singletons and doubletons suggest that the fauna of Singapore is still poorly known and that many new species
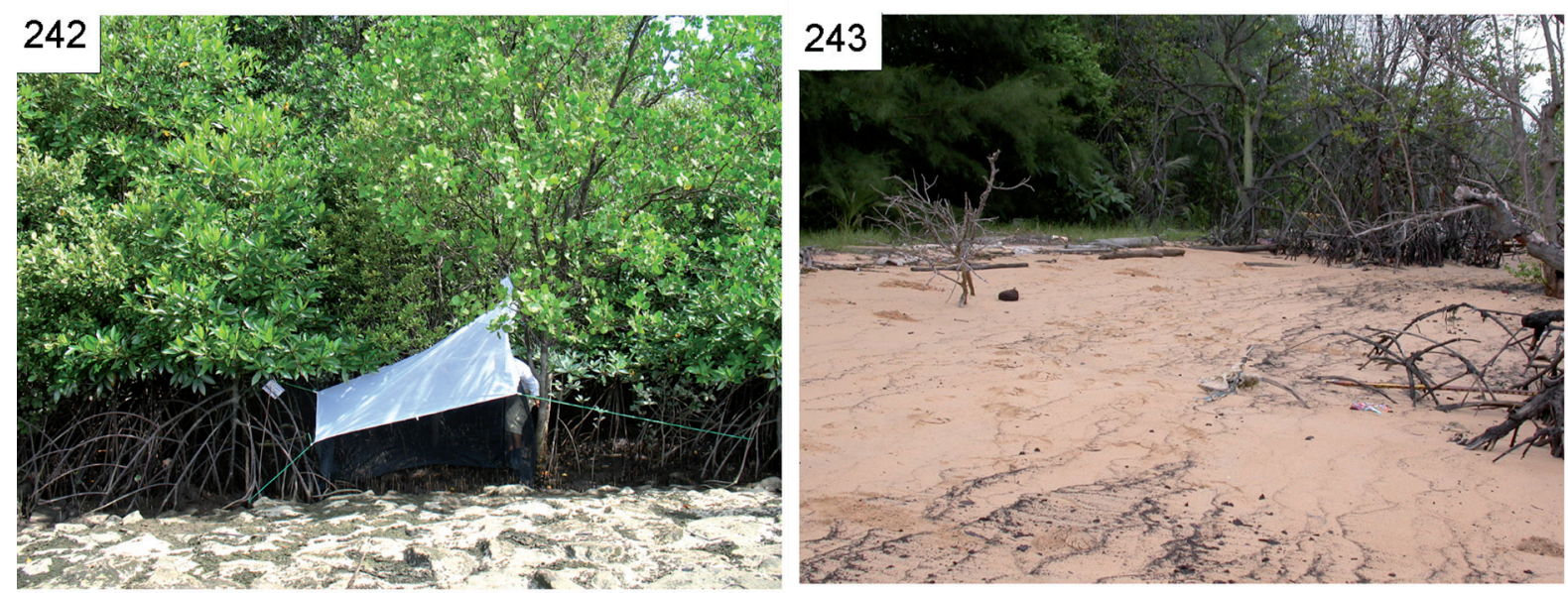

Figs 242-243. Photographs of Tachydromiinae habitats in Singapore. 242. Pulau Semakau, old mangrove (SMK05). Ten species of Elaphropeza were collected in the Malaise trap: E. asiophila Shamshev \& Grootaert, 2007, E. chanae sp. nov., E. feminata Shamshev \& Grootaert, 2007, E. gohae sp. nov., E. lowi sp. nov., E. malayensis Shamshev \& Grootaert, 2007, E. modesta Shamshev \& Grootaert, 2007, E. riatanae Shamshev \& Grootaert, 2007 and E. sivasothii Shamshev \& Grootaert, 2007. Nanodromia narmkroi Grootaert \& Shamshev, 2003 is also very abundant here. 243. Pulau Semakau (SMK01). Sandy beach with a few mangroves trees (right) and beach forest on the background (Casuarina tree in the left corner). Microphorella malaysiana Shamshev \& Grootaert, 2004 is found on the supralittoral while Elaphropeza furca Shamshev \& Grootaert, 2007 is dominant in the beach forest that transits in mangrove. 
await discovery. Only sixteen species (19\%) from Singapore were known from other countries before or have been found now in other countries: Chersodromia glandula sp. nov. (Malaysia), C. malaysiana sp. nov. (Malaysia), Drapetis bakau sp. nov. (Malaysia), D. laut sp. nov. (Malaysia), D. pantai sp. nov. (Malaysia), E. bicaudata (Malaysia, Phillippines), E. biuncinata (Philippines), hirsutitibia (Indonesia, Thailand, Malaysia), E. monospina (Malaysia), E. palpata (Indonesia), E. spicata (Malaysia), E. malayensis (Malaysia), Pontodromia pantai sp. nov. (Malaysia), Nanodromia narmkroi (Thailand, Malaysia), Stilpon laawae (Thailand, Malaysia), Tachydromia luang (Thailand). All other species are still known only from Singapore. All the above observations clearly indicate that there is a huge undersampling of Tachydromiinae in the Oriental Region and that many species await description.
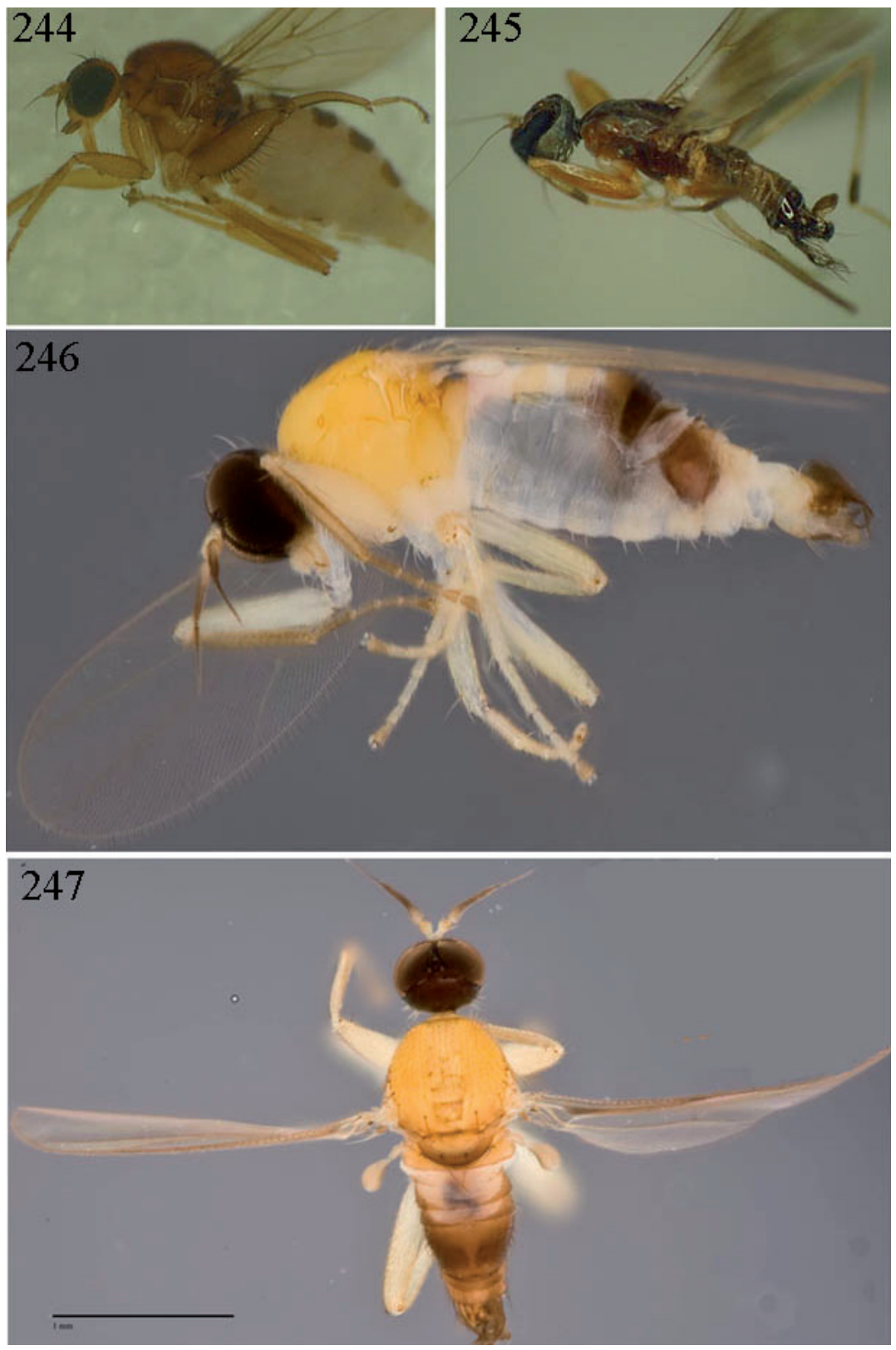

Figs 244-247. Habitus: 244. Platypalpus singaporensis sp. nov. + . 245. Tachydromia luang Shamshev \& Grootaert, 2005, Оิ. 246. Elaphropeza furca Shamshev \& Grootaert, 2007, Ô. 247. Elaphropeza ubinensis Shamshev \& Grootaert, 2007, ¿̊ dorsal. 
Table 2. Occurrence of the Tachydromiinae per habitat type in Singapore. The figures represent number of individuals observed per habitat.

\begin{tabular}{|c|c|c|c|c|c|c|c|c|c|}
\hline 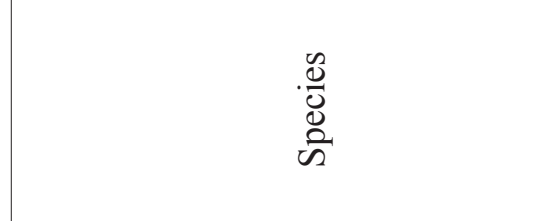 & $\begin{array}{l}\frac{\pi}{0} \\
\mathbb{\Xi} \\
0\end{array}$ & 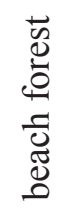 & 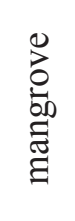 & 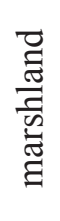 & 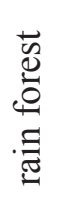 & 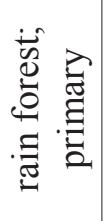 & 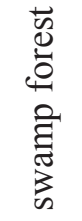 & . & 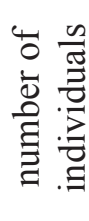 \\
\hline Chersodromia bulohensis sp. nov. & & & 1 & & & & & & 1 \\
\hline Chersodromia glandula sp. nov. & 1 & & 1 & & & & & & 2 \\
\hline Chersodromia malaysiana sp. nov. & 1 & & 1 & & & & & & 2 \\
\hline Chersodromia nigripennis & & & 7 & & & & & & 7 \\
\hline Chersodromia singaporensis & & & 4 & & & & & & 4 \\
\hline Chersodromia sylvicola sp. nov. & & & & & & & 1 & & 1 \\
\hline Crossopalpus temasek sp. nov. & & 3 & 15 & & 1 & & & 3 & 22 \\
\hline Drapetis bakau sp. nov. & & & 60 & & 1 & & 2 & & 63 \\
\hline Drapetis hutan sp. nov. & & & & & & & 1 & & 1 \\
\hline Drapetis laut sp. nov. & & & 32 & & & & & & 32 \\
\hline Drapetis mandai sp. nov. & & & 1 & & & & & & 1 \\
\hline Drapetis pantai sp. nov. & & & 10 & & & & & & 10 \\
\hline Elaphropeza acantha & & & & & 1 & 2 & 5 & & 8 \\
\hline Elaphropeza asexa & & & 33 & & 1 & 1 & 4 & & 39 \\
\hline Elaphropeza asiophila & & 6 & 83 & & & & & & 89 \\
\hline Elaphropeza benitotani & & & 2 & & 1 & 1 & 40 & & 44 \\
\hline Elaphropeza bezzii & & & 1 & & 5 & 10 & 11 & & 27 \\
\hline Elaphropeza bicaudata & & & 9 & & 18 & 19 & 205 & & 251 \\
\hline Elaphropeza biuncinata & & 2 & 5 & & 14 & 17 & 86 & & 124 \\
\hline Elaphropeza bulohensis & & & 1 & & & & & & 1 \\
\hline Elaphropeza chanae sp. nov. & & & 7 & & & & & & 7 \\
\hline Elaphropeza chekjawa & & & 1 & & & & & & 1 \\
\hline Elaphropeza collini sp. nov. & & & 1 & & & & & & 1 \\
\hline Elaphropeza combinata & & & & & & & 6 & & 6 \\
\hline Elaphropeza crassicercus & & 6 & 77 & & 5 & & 10 & & 98 \\
\hline Elaphropeza darrenyeoi & & & & & & & 1 & & 1 \\
\hline Elaphropeza demeijerei & & & 1 & & & & 1 & & 2 \\
\hline Elaphropeza E-44 & & & 1 & & & & & & 1 \\
\hline Elaphropeza E-46 & & & 1 & & & & & & 1 \\
\hline Elaphropeza E-49 & & & 1 & & & & & & 1 \\
\hline Elaphropeza E-51 & & & & & & & 2 & & 2 \\
\hline Elaphropeza E-57 & & & & & & 1 & & & 1 \\
\hline Elaphropeza E-58 & & & & & & & 1 & & 1 \\
\hline Elaphropeza E59 & & & 1 & & & & & & 1 \\
\hline Elaphropeza equalis & & & & & & & 2 & 2 & 4 \\
\hline Elaphropeza feminata & & & 71 & & & & & & 71 \\
\hline Elaphropeza flavicaput & & & & 1 & 5 & 2 & 29 & & 37 \\
\hline Elaphropeza furca & 1 & 40 & 26 & & & 2 & & & 69 \\
\hline
\end{tabular}


GROOTAERT P. \& SHAMSHEV I.V., Tachydromiinae of Singapore

\begin{tabular}{|c|c|c|c|c|c|c|c|c|c|}
\hline $\begin{array}{l}\frac{\tilde{U}}{0} \\
\frac{\tilde{D}}{n} \\
\tilde{n}\end{array}$ & 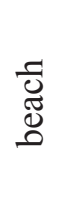 & 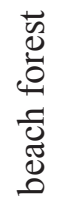 & 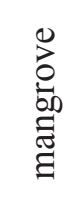 & 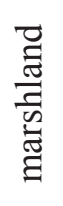 & 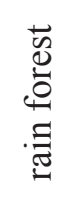 & 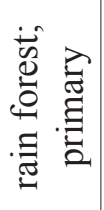 & 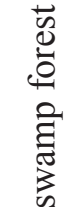 & 氕 & 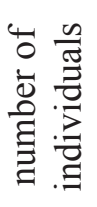 \\
\hline Elaphropeza gohae sp. nov. & & & 23 & & & & & & 23 \\
\hline Elaphropeza hirsutitibia & & & 6 & 1 & & 14 & 2 & 2 & 25 \\
\hline Elaphropeza kranjiensis sp. nov. & & & 1 & & & & & & 1 \\
\hline Elaphropeza limosa & & & 65 & & & & & & 65 \\
\hline Elaphropeza lowi sp. nov. & & & 41 & & & & & & 41 \\
\hline Elaphropeza luanae & & & 3 & & & & 3 & & 6 \\
\hline Elaphropeza luteoides & & & 2 & & & 1 & 2 & & 5 \\
\hline Elaphropeza malayensis & & & 28 & & & & 1 & & 29 \\
\hline Elaphropeza meieri & & & 1 & 2 & & & 7 & & 10 \\
\hline Elaphropeza melanderi & & & & & 3 & & 19 & & 22 \\
\hline Elaphropeza modesta & & & 8 & & & & & & 8 \\
\hline Elaphropeza monacantha & & & & & & & 6 & & 6 \\
\hline Elaphropeza monospina & & & 76 & & & & & & 76 \\
\hline Elaphropeza murphyi & & & 24 & & & 1 & & & 25 \\
\hline Elaphropeza neesoonensis & & & 26 & 10 & & & 122 & & 158 \\
\hline Elaphropeza ngi & & & & & & & 2 & & 2 \\
\hline Elaphropeza palpata & & & 1 & & 3 & & 1 & & 5 \\
\hline Elaphropeza pauper & & & & & & & 1 & & 1 \\
\hline Elaphropeza pluriacantha & & & & & & 1 & 3 & & 4 \\
\hline Elaphropeza riatanae & 1 & & 16 & & & & & & 17 \\
\hline Elaphropeza semakau sp. nov. & & & 1 & & & & & & 1 \\
\hline Elaphropeza shufenae sp. nov. & & & 11 & & & & & & 11 \\
\hline Elaphropeza sime & & & & & 1 & & & & 1 \\
\hline Elaphropeza singaporensis & & & & & 18 & 4 & 11 & & 33 \\
\hline Elaphropeza singulata & & & 1 & & 1 & 2 & 4 & & 8 \\
\hline Elaphropeza sivasothii & & 2 & 10 & & & & & & 12 \\
\hline Elaphropeza spicata & & & 5 & & & 1 & 3 & & 9 \\
\hline Elaphropeza spiralis & & & & & 4 & 1 & 21 & & 26 \\
\hline Elaphropeza sylvicola & & & & & 6 & 1 & 7 & & 14 \\
\hline Elaphropeza temasek & & & 10 & & & & & & 10 \\
\hline Elaphropeza tiomanensis & & & 1 & & & & & & 1 \\
\hline Elaphropeza ubinensis & & & 4 & & & & & & 4 \\
\hline Elaphropeza yangi & & & & & 2 & & 8 & & 10 \\
\hline Elaphropeza yeoi & & & 1 & 1 & & & 2 & & 4 \\
\hline Nanodromia hutan sp. nov. & & & & & 4 & & 1 & & 5 \\
\hline Nanodromia narmkroi & 2 & 1 & 104 & & & & & & 107 \\
\hline Nanodromia spinulosa sp. nov. & & & 8 & & 1 & & 2 & & 11 \\
\hline Platypalpus singaporensis sp. nov. & & & & & 3 & & & & 3 \\
\hline Pontodromia pantai sp. nov. & & & 13 & & & & & & 13 \\
\hline Stilpon arcuatum sp. nov. & & & 1 & & & & & & 1 \\
\hline
\end{tabular}




\begin{tabular}{|c|c|c|c|c|c|c|c|c|c|}
\hline $\begin{array}{l}\frac{\tilde{u}}{0} \\
\tilde{0} \\
\tilde{\omega}\end{array}$ & $\begin{array}{l}\tilde{D} \\
\mathbb{J} \\
0\end{array}$ & 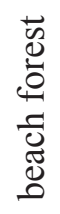 & 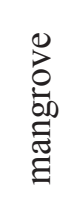 & 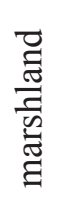 & 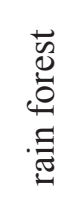 & 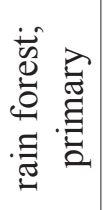 & 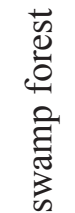 & 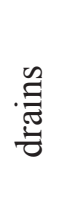 & 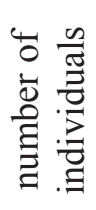 \\
\hline Stilpon laawae & & & 3 & & & & & & 3 \\
\hline Stilpon neesoonensis sp. nov. & & & & & & & 1 & & 1 \\
\hline Stilpon nigripennis sp. nov. & & & 1 & & & & & & 1 \\
\hline Stilpon singaporensis sp. nov. & & & & & 20 & & & & 20 \\
\hline Stilpon weilingae sp. nov. & & & 1 & & & & & & 1 \\
\hline Tachydromia luang & & & 3 & & 6 & & 8 & & 17 \\
\hline Stilpon malayensis & & & & & & & 1 & & 1 \\
\hline Number of individuals & 6 & 60 & 953 & 15 & 124 & 81 & 645 & 7 & 1891 \\
\hline Number of species & 5 & 7 & 60 & 5 & 23 & 18 & 41 & 3 & 85 \\
\hline
\end{tabular}

\section{ACKNOWLEDGEMENTS}

The first author thanks Prof. Dr. Peter Ng, director of the Raffles Museum for Biodiversity Research, and Prof. Dr. Rudolf Meier, head of the Evolutionary Biology Laboratory, for hosting him during his sabbatical stay at NUS. The authorities of the National Parks are thanked for issuing the Research permits to collect in the National Parks and granting the Singapore Mangrove Insect Programme (SMIP). Special thanks go to Dr. Lena Chan, Deputy Director of the National Biodiversity Centre at NParks and her staff who assisted P.G. with a lot of enthusiasm during field work: Linda Goh Mei Ee, Jeffrey Low Kim Yew, Tong Hor Yee (Collin), Lim Wei Ling and Shufen Yang. We received help in the field on Pulau Ubin from Jacky Soh Swee Meng, Mr. Justin Tan Chek Hwen and Alan Tan Yong Hong; at Sungei Buloh from Ramakrishnan s/o R Kolandavelu and Mohamad Azlin bin Sani. In 2005 Dr. Isabella Van de Velde helped weekly to retrieve the samples. The late Mr. K.L.Yeo (NUS) assisted P.G. in the field in 2005-2007. P.G. finally acknowledges a grant in the Action 4 programme of the Belgian Science Policy. The second author I. S. acknowledges a grant in the Action 1 programme of the Belgian Science Policy. Dr. Maurice Leponce (RBINS) helped with the statistics. Dr. Bradley Sinclair and Dr. Andreas Stark gave many useful comments on the manuscript.

\section{REFERENCES}

Becker T. 1902-1903. Aegyptische Dipteren. Mitteilungen aus dem Zoologischen Museum in Berlin 2: 1-195.

Bezzi M. 1904. Empididae Indo-australiani raccolti dal Signor L. Biro. Annales Historico-Naturales Musei Nationalis Hungarici 2: 320-361.

Bigot J.M.F. 1857. Essai d'une classification générale et synoptique de l'ordre des insectes diptères. $5^{\mathrm{e}}$ mémoire. Tribu des Asilidi (mihi). Annales de la Société Entomologique de France (3) 5: 517-564.

Brunetti E. 1913. New Indian Empididae. Records of the Indian Museum 9: 11-45.

Chvála M. 1970. Revision of Palaearctic species of the genus Tachydromia Meig. (= Tachista Loew) (Diptera, Empididae). Acta Entomologica Musei Nacionalis Pragae 38 (1969): 415-524. 
Chvála M. 1975. The Tachydromiinae (Dipt. Empididae) of Fennoscandia and Denmark. Fauna Entomologica Scandinavica 3: 1-336.

Chvála M. 1977. Revision of Palaearctic species of the genus Chersodromia Walk. (Diptera, Empididae). Acta Entomologica Musei Nationalis Pragae 39: 55-138.

Chvála M. 1989. Monograph of northern and central European species of Platypalpus Macq. (Diptera, Hybotidae), with data on the occurrence in Czechoslovakia. Acta Universitatis Carolinae Biologica 32 (1988): 209-376.

Chvála M. 1995. Two new species of mountain Tachydromia and Chersodromia (Diptera: Hybotidae), inhabiting a stony riverbed in the Julian Alps. Acta Universitatis Carolinae Biologica 38: 91-98.

Collin J.E. 1960. Some Empididae from Palestine. The Annals and Magazine of natural History 2 [1959] (13): 385-420. http://dx.doi.org/10.1080/00222935908650872

Collin J.E. 1961. Empididae. In: British Flies 6: 1-782. University Press, Cambridge.

Coquillett D.W. 1903. The genera of the dipterous family Empididae, with notes and new species. Proceedings of the Entomological Society of Washington 5: 245-272.

Coquillett D.W. 1910. New genera and species of North American Diptera. Proceedings of the Entomological Society of Washington 12: 124-131.

Corti E. 1907. Eine neue Art der Dipterengattung Tachydromia (Mg.) Lw. Wiener Entomologische Zeitung 26: 101-102.

Cumming J.M. 1992. Lactic acid as an agent for macerating Diptera specimens. Fly Times 8: 7.

Cumming J.M. \& Cooper B.E. 1992. A revision of the Nearctic species of the Tachydromiine fly genus Stilpon Loew (Diptera: Empidoidea). The Canadian Entomologist 124 (6): 951-998. http://dx.doi.org/10.4039/Ent124951-6

Cumming J.M. \& Cooper B.E. 1993. Techniques for obtaining adult-associated immature stages of predacious tachydromiine flies (Diptera: Empidoidea), with implications for rearing and biocontrol. Entomological News 104: 93-101.

Cumming J.M. \& Evenhuis N.L. 1996. Stilpon Loew, 1859 (Insecta, Diptera): proposed conservation. Bulletin of Zoological Nomenclature 53: 104-105.

Cumming J.M. \& Wood D.M. 2009. Adult morphology and terminology. In: Brown B.V., Borkent A., Cumming J.M., Wood D.M., Woodley N.E. \& Zumbado M.A. (eds.) Manual of Central American Diptera 1: 9-50. NRC Research Press, Ottawa, Ontario, Canada.

Curtis J. 1833. British entomology; being illustrations and descriptions of the genera of insects found in Great Britain and Ireland: containing coloured figures from nature of the most rare and beautiful species, and in many instances of the plants upon which they are found 10: plates 434-481. Privately published, London.

Dahl F. 1909. Die Gattung Limosina und die biocönotische Forschung. Sitzungsberichte der Gesellschaft naturforschender Freunde zu Berlin 1909: 360-377.

Daugeron C. \& Grootaert P. 2003. The Empis (Coptophlebia) hyalea-group from Thailand, with a discussion of the worldwide distribution of this species group (Diptera: Empididae: Empidinae). European Journal of Entomology 100 (1): 167-179.

Daugeron C. \& Grootaert P. 2005. Empidine dance flies from Singapore and Southern Malaysia (Diptera: Empididae: Empidinae). The Raffles Bulletin of Zoology 53 (2): 211-220.

Engel E.O. 1939. 28. Empididae. In: Lindner E. (ed.) Die Fliegen der palaearktischen Region 4: 41-104. 
Fállen C.F 1815. Empididae Sveciae. Lundae. 16 pp.

Freitas-Silva R.A.P. \& Ale-Rocha R. 2009. Revision of the species of Elaphropeza Macquart, 1827 (Diptera: Hybotidae, Tachydromiinae) from Amazon Basin and some remarks about E. ciliatocosta (Bezzi, 1904). Zootaxa 2245: 32-46.

Gistl J.N.F.X. 1848. Naturgeschichte des Thierreichs für höhere Schulen. R. Hoffmann, Stuttgart. xvi + $216+[4]$ pp., 32 pls

Grimaldi D. \& Cumming J. 1999. Brachyceran Diptera in Cretaceous ambers and Mesozoic diversification of the Eremoneura. Bulletin of the American Museum of Natural History 239: 1-124.

Grootaert P. 1992. New species of the genus Chersodromia Walker (Diptera Empidoidea Hybotidae) from the northern coast of Papua New Guinea. Bulletin et Annales de la Société Royale Belge d'Entomologie 128: $235-244$.

Grootaert P. 1994. Two new genera of empidoid flies (Diptera, Empidoidea, Hybotidae, Tachydromiinae) from Melanesia. Studia dipterologica 1 (2): 141-156.

Grootaert P. 2009. Oriental Diptera, a challenge in diversity and taxonomy. In: Pape T., Bickel D. \& Meier R. (eds) Diptera diversity: status, challenges and tools: 155-196. Koninklijke Brill NV.

Grootaert P. \& Chvála M. 1992. Monograph of the genus Platypalpus (Diptera: Empidoidea, Hybotidae) of the Mediterranean region and the Canary Islands. Acta Universitatis Carolinae Biologica 36: 3-226.

Grootaert P., Cumming J. \& Shamshev I. 2007. Non-marine Chersodromia Walker from Southeast Asia and Papua New Guinea (Diptera, Empidoidea, Hybotidae). Zootaxa 1661: 55-61.

Grootaert P. \& Shamshev I. 2003. New species of the genus Nanodromia Grootaert (Diptera: Empidoidea, Hybotidae) from Thailand and Singapore. The Natural History Journal of Chulalongkorn University 3 (2): 41-52.

Grootaert P. \& Shamshev I. 2006. The genus Platypalpus Macquart (Diptera: Hybotidae) from Northeast Thailand with comments on the species groups in the Oriental region. Journal of Natural History 39 (47): 4031-4065. http://dx.doi.org/10.1080/00222930500533781

Grootaert P. \& Shamshev I. 2008. Notes on the halobiont genus Chersodromia (Diptera: Hybotidae) from Tunisia with the description of a new brachypterous species and notes on brachyptery in empidoids. Bulletin de la Société royale belge d'Entomologie, S.R.B.E./K.B.V.E., 144: 57-63.

Grootaert P. \& Shamshev I. 2009a. First records of Tachydromia Meigen and Tachypeza Meigen (Diptera: Hybotidae) from Viet Nam, with descriptions of four new species. Zootaxa 2249: 33-43.

Grootaert P. \& Shamshev I. 2009b. New species of the genus Elaphropeza Macquart (Diptera: Hybotidae) with remarkable abdominal structures from Viet Nam. Studia dipterologica 15 (2008): 165-174.

Grootaert P. \& Shamshev I. 2011. The genus Tachydromia Meigen (Diptera: Hybotidae) from Australia. Records of the Australian Museum 63: 103-112. http://dx.doi.org/10.3853/j.0067-1975.63.2011.1552

Grootaert P. \& Yang D. 2009. A new Syndyas Loew, 1857 (Diptera, Hybotidae, Hybotinae) from mangroves in Singapore, with a review of the Oriental and Australasian species. Raffles Bulletin of Zoology 57 (1): 17-24.

International Commission on Zoological Nomenclature 1963. Opinion 678. The suppression under the plenary powers of the pamphlet published by Meigen, 1800. Bulletin of Zoological Nomenclature 20: 339-342.

International Commission on Zoological Nomenclature 1997. Opinion 1881. Stilpon Loew, 1859 (Insecta, Diptera): conserved. Bulletin of Zoological Nomenclature 54: 200. 
Kovalev V.G. 1972. Diptera of the genera Drapetis Mg. and Crossopalpus Bigot (Diptera, Empididae) from the European part of the USSR. Entologicheskoe Obozrenie 51: 173-196. [In Russian with English summary]

Latreille P.A. 1797. Précis des caractères génériques des insectes, disposés dans un ordre naturel. Prévôt, Paris; Bordeaux, Brive. xiv $+201+$ [7] pp.

Latreille P.A. 1810. Considérations générales sur l'ordre naturel des animaux composant les classes des crustacés, des arachnides, et des insectes; avec un tableau méthodique de leurs genres, disposés en familles. F. Schoell, Paris. 444 pp.

Lim G.S, Wei Song Hwang, Kutty S., Meier R. \& Grootaert P. 2009. Mitochondrial and nuclear markers of Oriental species support the monophyly of Dolichopodidae and suggest a rapid origin of the subfamilies (Diptera: Empidoidea). Systematic Entomology 35 (1): 59-70. http://dx.doi.org/10.1111/ j.1365-3113.2009.00481.x

Loew H. 1859. Neue Beiträge zur Kenntniss der Dipteren. Sechster Beitrag. Programm der Königlichen Realschule zu Meseritz 1859: 1-50.

Loew H. 1864. Ueber die schlesischen Arten der Gattungen Tachypeza Meig. (Tachypeza, Tachista, Dysaletria) und Microphorus Macq. (Trichina und Microphorus). Zeitschrift für Entomologie 14: 1-60.

Macquart J. 1827. Insectes diptères du nord de la France. Platypézines, dolichopodes, empides, hybotides. Lille.

Meigen J.W. 1800. Nouvelle classification des mouches à deux ailes (Diptera L.) d'après un plan tout nouveau. Perronneau, Paris.

Meigen J.W. 1803. Versuch einer neuen Gattungs Eintheilung der europäischen zweiflügeligen Insekten. Magazin für Insektenkunde 2: 259-281.

Meigen J.W. 1822. Systematische Beschreibung der bekannten europäischen zweiflügeligen Insekten. Dritter Theil. Schulz-Wundermann, Hamm.

Meigen J.W. 1830. Systematische Beschreibung der bekannten europäischen zweiflügeligen Insekten. Sechster Theil. Schulz, Hamm.

de Meijere J.C.H. 1911. Studien über Sudostasiatische Dipteren. VI. Tijdschrift voor Entomologie 54: 258-432.

de Meijere J.C.H. 1914. Studien über Sudostasiatische Dipteren. VIII. Tijdschrift voor Entomologie 56: $1-99$.

Melander A.L. 1902. Monograph of the American Empididae. Transactions of the American Entomological Society 28: 195-368.

Melander A.L. 1906. Some new or little-known genera of Empididae. Entomological News 17: 370-379.

Melander A.L. 1918. The dipterous genus Drapetis Meigen (Family Empididae). Annals of the Entomological Society of America 11: 183-221.

Melander A.L. 1928. Diptera, Fam. Empididae. In: Wytsman P. (ed.) Genera Insectorum 185 (1927): $1-434$.

Moulton J.K. \& Wiegmann B.M. 2007. The phylogenetic relationships of flies in the superfamily Empidoidea (Insecta: Diptera). Molecular Phlyogenetics and Evolution 43: 701-713. http://dx.doi.org/10.1016/j.ympev.2007.02.029

Osten-Sacken C.R. 1882. Diptera from the Philippine Islands, brought home by Carl Semper. Berliner Entomologische Zeitschrift 26: 83-120, 187-252. 
Patnaik N.C. \& Satpay J.M. 1984. Elaphropeza, a new pupal parasite of rice gall midge (GM) in India. International Rice Research Newsletter 9: 14.

Pont A.C. 1995. The type-material of Diptera (Insecta) described by G. H. Verrall and J. E. Collin. Clarendon Press, Oxford. $x+223$ pp

Przhiboro A. \& Shamshev I. 2007. Shore habitats of larval Stilpon graminum (Fallén, 1815) in Northwestern Russia (Diptera Hybotidae). Bulletin de la Société royale belge d'Entomologie 143: 110116.

Rafinesque C.S. 1815. Analyse de la nature ou tableau de l'univers et des corps organisés. Le nature est mon guide, et Linnéus mon maître. [privately published] Palermo. 224 pp.

Rondani C. 1856. Dipterologiae Italicae prodromus. Vol. 1. Genera Italica ordinis Dipterorum ordinatim disposita et distincta et in familias et stirpes aggregata. A. Storschi, Parmae. $226+$ [2] pp.

Séguy E. 1950. Un nouveau genre de Corynétine du Midi de la France (Dipt., Empididae). Vie et milieu 1: 83-87.

Shamshev I.V. \& Grootaert P. 2004a. Descriptions of four new species of the genus Microphorella Becker (Diptera: Empidoidea, Microphoridae, Parathalassiini) from Southeast Asia and New Guinea, with notes on the relationships within the genus. The Raffles Bulletin of Zoology 52 (1): 45-58.

Shamshev I.V. \& Grootaert P. 2004b. A review of the genus Stilpon Loew (Diptera, Empidoidea, Hybotidae) from the Oriental region. The Raffles Bulletin of Zoology 52: 315-346.

Shamshev I.V. \& Grootaert P. 2005a. Eothalassius, a new genus of parathalasiine flies (Diptera, Empidoidea, Dolichopodidae) from Southeast Asia and Papua New Guinea. European Journal of Entomology 102: 107-118.

Shamshev I. \& Grootaert P. 2005b. The genus Tachydromia Meigen (Diptera: Hybotidae) from Southeast Asia, with description of three new species. Studia dipterologica 12 (1): 109-117.

Shamshev I.V. \& Grootaert P. 2005c. Two new species of the genus Chersodromia Walker (Diptera: Hybotidae) from Southeast Asia. Zootaxa 942: 1-10.

Shamshev I.V. \& Grootaert P. 2005d. New data on the genus Stilpon Loew (Diptera: Hybotidae) from the Palaearctic region, with description of a new species from Tajikistan. Belgian Journal of Entomology 7: 81-86.

Shamshev I.V. \& Grootaert P. 2006. Description of new species of Stilpon Loew (Diptera: Hybotidae) from Cambodia. The Natural History Journal of Chulalongkorn University 6: 27-32.

Shamshev, I.V. \& Grootaert P. 2007. Revision of the genus Elaphropeza Macquart (Diptera: Hybotidae) from the Oriental Region, with a special attention to the fauna of Singapore. Zootaxa 1488: 1-164.

Shamshev I.V. \& Grootaert P. 2008. New and little-known species of the genus Tachydromia Meigen (Diptera, Hybotidae) from Thailand. Zootaxa 1830: 21-36.

Shamshev I.V. \& Grootaert P. 2009a. Two new species of the genus Tachydromia Meigen (Diptera: Hybotidae) from Malaysia. Raffles Bulletin of Zoology 57: 251-254.

Shamshev I.V. \& Grootaert P. 2009b. First data on the genus Elaphropeza Macquart (Diptera: Hybotidae) from Madagascar, with descriptions of two new species. Bulletin de la Société royale belge d'Entomologie 145: 136-140.

Shamshev I.V., Grootaert P. \& Stark A. 2006. Notes on a remarkable abdominal structure in Crossopalpus Bigot (Diptera: Hybotidae), with new records from Southeast Asia. Studia dipterologica 12 (1): 331336. 
Shamshev I.V., Grootaert P. \& Yang D. 2005. Two new species of the genus Stilpon from China (Diptera: Hybotidae). Genus 16: 299-305.

Sinclair B.J. 2000. Morphology and terminology of Diptera male terminalia. In: Papp L. \& Darvas B. (eds) Contributions to a Manual of Palaearctic Diptera, Volume 1. General and Applied Dipterology: 53-74. Science Herald, Budapest.

Sinclair B.J. \& Cumming J.M. 2006. The morphology, higher-level phylogeny and classification of the Empidoidea (Diptera). Zootaxa 1180: 1-172.

Smith K.G.V. 1965. Diptera from Nepal. Empididae. Bulletin of the British Museum (Natural History), Entomology 17: 63-112.

Smith K.G.V. 1967. Afrikanische Empididae (Dipt.). Stuttgarter Beiträge zur Naturkunde 179: 1-16

Solórzano Kraemer M.M., Sinclair B.J. \& Cumming J.M. 2005. Five new species of Tachydromiinae (Diptera: Empididae s.1.) from New World ambers. Zootaxa 1010: 37-52.

Tran A.T.T., Andersen A. \& Bui T.C. 2006. Predation by Crossopalpus hirsutipes Collin (Diptera: Empididae) on adult Liriomyza sativae Blanchard (Diptera: Agromyzidae). In: Suwa M. (ed.) Abstracts Volume. Sixth International Congress of Dipterology: 273. Fukuoka, Japan.

Ulrich H. 2004. Phylogenetic considerations about an early colonization of the sea coasts by Dolichopodidae (Diptera). Studia Dipterologica 11: 233-243.

Vimmer A. 1939. A new genus of the family Cypselidae (Borboridae-Dipt. Acalypr.). Acta Societatis Entomologicae Bohemiae 36: 64-65. [in Czech]

Walker F. 1849. List of the specimens of dipterous insects in the collection of the British Museum Part 4: 688-1172. British Museum, London.

Westwood J.O. 1840. Order XIII. Diptera Aristotle. (Antliata Fabricius. Halteriptera Clairv.). In: An introduction to the modern classification of insects; founded on the natural habits and corresponding organisation of the different families. Synopsis of the genera of British insects: 125-154. Longman, Orme, Brown, Green and Longmans, London.

Yang D., Gaimari S.D. \& Grootaert P. 2004a. Review of the species of the genus Crossopalpus Bigot (Diptera: Empididae) from China. Transactions of the American Entomological Society 130: 169-175.

Yang D., Gaimari S.D. \& Grootaert P. 2004b. A new genus of Tachydromiinae (Diptera: Empididae) from the Oriental Realm. Transactions of the American Entomological Society 130: 487-492.

Yang D. \& Grootaert P. 2006. Notes on Tachydromia from China (Diptera: Hybotidae). Transactions of the American Entomological Society 132: 133-135.

Yang D., Zhang K., Yao G. \& Zhang J. 2007. World Catalog of Empididae (Insecta: Diptera). China Agricultural University Press, Beijing.

Zhang L., Yang D. \& Grootaert P. 2007. Paraclius (Diptera: Dolichopodidae, Dolichopodinae) of Singapore, with new species from mangrove. The Raffles Bulletin of Zoology 55: 43-58.

Zhang L., Yang D. \& Grootaert P. 2008. Mangrove Hercostomus sensu lato (Diptera: Dolichopodidae) of Singapore. The Raffles Bulletin of Zoology 56: 17-28. 


\section{Check list of Tachydromiinae from Singapore}

\section{Tribe Tachydromiini}

\section{Platypalpus Macquart, 1827}

singaporensis sp. nov. (female) - Singapore.

Tachydromia Meigen, 1803

luang Shamshev \& Grootaert, 2005: 115 - Singapore, Thailand.

\section{Tribe Drapetini.}

\section{Chersodromia Walker, 1849}

bulohensis sp. nov. (male) - Singapore.

glandula sp. nov. (male) - Singapore, Malaysia.

malaysiana sp. nov. (male, female) - Singapore, Malaysia.

nigripennis Shamshev \& Grootaert, 2005: 3 (male, female), fig. 1 - Singapore.

singaporensis Shamshev \& Grootaert, 2005: 6 (male, female), fig. 2 - Singapore.

sylvicola sp. nov. (male) - Singapore.

\section{Crossopalpus Bigot, 1857}

temasek sp. nov. (male, female) - Singapore.

\section{Drapetis Meigen, 1822}

bakau sp. nov. (male, female) - Singapore, Malaysia.

hutan sp. nov. (male) - Singapore.

laut sp. nov. (male, female) - Singapore, Malaysia.

mandai sp. nov. (male) - Singapore.

pantai sp. nov. (male, female) - Singapore, Malaysia.

Elaphropeza Macquart, 1827

acantha Shamshev \& Grootaert, 2007: 52 (male, female), figs 75-79 - Singapore.

asexa Shamshev \& Grootaert, 2007: 128 (female), fig. 204 - Singapore.

asiophila Shamshev \& Grootaert, 2007: 85 (male, female), figs 135-138, 139-140 - Singapore, Malaysia. benitotani Shamshev \& Grootaert, 2007: 68 (male, female), figs 103-106 - Singapore.

bezzii Shamshev \& Grootaert, 2007: 96 (male, female), figs 157-161 - Singapore.

bicaudata (Melander), 1928: 313 (male and female, Drapetis (Elaphropeza)). Shamshev \& Grootaert, 2007: 119 (male, female), figs 192-195, 222, 225, 236, 257 - Philippines [Luzon], Malaysia, Singapore. biuncinata (Melander), 1928: 313 (male, Drapetis (Elaphropeza). Shamshev \& Grootaert, 2007: 14 (male, female), figs 1, 2-5, 6-9, 209, 211, 219-221, 239, 241, 251, 258 - Philippines [Luzon], Malaysia, Singapore.

bulohensis Shamshev \& Grootaert, 2007: 102 (male), figs 170-174 - Singapore.

chanae sp. nov. (male, female) - Singapore.

chekjawa Shamshev \& Grootaert, 2007: 72 (male), figs 111-114 - Singapore.

combinata Shamshev \& Grootaert, 2007: 23 (male, female), figs 18-22 - Singapore.

collini sp. nov. (male) - Singapore. 
crassicercus Shamshev \& Grootaert, 2007: 37 (male, female), figs 44-48- Singapore.

darrenyeoi Shamshev \& Grootaert, 2007: 48 (male), figs 67-70 - Singapore.

demeijerei Shamshev \& Grootaert, 2007: 124 (male, female), figs 200-203 - Singapore. = demeijeri Shamshev \& Grootaert, 2007, misprint.

equalis Shamshev \& Grootaert, 2007: 122 (male, female), figs 196-199 - Singapore.

feminata Shamshev \& Grootaert, 2007: 107 (female), fig. 180 - Singapore.

flavicaput Shamshev \& Grootaert, 2007: 35 (male, female), figs 40-43- Singapore.

furca Shamshev \& Grootaert, 2007: 90 (male, female), figs 145-148 - Singapore.

gohae sp. nov. (male, female) - Singapore.

hirsutitibia de Meijere, 1914: 75 (female, Elaphropeza). Shamshev \& Grootaert, 2007: 19 (male, female), figs 10-13, 259 - Indonesia (Java), Malaysia, Singapore, Thailand.

? = bihamata Bezzi, sensu de Meijere, 1911: 332.

kranjiensis sp. nov. (male) - Singapore.

limosa Shamshev \& Grootaert, 2007: 78 (male, female), figs 121-124 - Singapore.

lowi sp. nov. (male, female) - Singapore.

luanae Shamshev \& Grootaert, 2007: 42 (male, female), figs 53-56 - Singapore.

luteoides Shamshev \& Grootaert, 2007: 100 (male), figs 166-169 - Singapore.

malayensis Shamshev \& Grootaert, 2007: 94 (male, female), figs 153-156 - Singapore, Malaysia.

meieri Shamshev \& Grootaert, 2007: 76 (male, female), figs 117-120- Singapore.

melanderi Shamshev \& Grootaert, 2007: 29 (male, female), figs 31-34 - Singapore.

modesta Shamshev \& Grootaert, 2007: 105 (female), fig. 179 - Singapore.

monacantha Shamshev \& Grootaert, 2007: 39 (male), figs 49-52 - Singapore.

monospina Shamshev \& Grootaert, 2007: 81 (male, female), figs 125-130 - Singapore, Malaysia.

murphyi Shamshev \& Grootaert, 2007: 32 (male, female), figs 35-38 - Singapore.

neesoonensis Shamshev \& Grootaert, 2007: 61 (male, female), figs 89-94 - Singapore.

ngi Shamshev \& Grootaert, 2007: 98 (male), figs 162-165 - Singapore.

palpata de Meijere, 1911: 330 (male, Elaphropeza). Shamshev \& Grootaert, 2007: 129 (male, female), figs 205-208, 210, 260-261 - Indonesia (Java), Singapore, Cambodia.

pauper Shamshev \& Grootaert, 2007: 83 (male), figs 131-134 - Singapore.

pluriacantha Shamshev \& Grootaert, 2007: 47 (male, female), figs 63-66, 254 - Singapore.

riatanae Shamshev \& Grootaert, 2007: 88 (male, female), figs 141-144 - Singapore.

semakau sp. nov. (male) - Singapore.

shufenae sp. nov. (male, female) - Singapore.

sime Shamshev \& Grootaert, 2007: 26 (male), figs 23-26 - Singapore.

singaporensis Shamshev \& Grootaert, 2007: 44 (male, female), figs 58-62, 253 - Singapore.

singulata Shamshev \& Grootaert, 2007: 107 (female), fig. 181- Singapore.

sivasothii Shamshev \& Grootaert, 2007: 66 (male, female), figs 99-102 - Singapore.

spicata Shamshev \& Grootaert, 2007: 92 (male, female), figs 149-152 - Singapore, Malaysia.

spiralis Shamshev \& Grootaert, 2007: 21 (male, female), figs 14-17, 252, 256 - Singapore.

sp. 44 Shamshev \& Grootaert, 2007: 139 (female) - Singapore.

sp. 46 Shamshev \& Grootaert, 2007: 44 (female), fig. 57 - Singapore.

sp. 49 Shamshev \& Grootaert, 2007: 118 (female), fig. 191 - Singapore.

sp. 51 Shamshev \& Grootaert, 2007: 75 (female), fig. 115 - Singapore.

sp. 57 Shamshev \& Grootaert, 2007: 34 (female), fig. 39 - Singapore.

sp. 58 Shamshev \& Grootaert, 2007: 76 (female), fig. 116 - Singapore.

sp. 59 (female) - Singapore.

sylvicola Shamshev \& Grootaert, 2007: 54 (male, female), figs 80-83 - Singapore.

temasek Shamshev \& Grootaert, 2007: 59 (male), figs 85-88- Singapore.

tiomanensis Shamshev \& Grootaert, 2007: 50 (male, female), figs 71-74 - Singapore, Malaysia.

ubinensis Shamshev \& Grootaert, 2007: 104 (male), figs 175-178 - Singapore. 
yangi Shamshev \& Grootaert, 2007: 27 (male, female), figs 27-30, 255 - Singapore. yeoi Shamshev \& Grootaert, 2007: 64 (male, female), figs 95-98 - Singapore.

Nanodromia Grootaert, 1994

hutan sp. nov. (male, female) - Singapore.

narmkroi Grootaert \& Shamshev, 2003: 49 (male, female), figs 19-24 - Singapore, Malaysia, Thailand. spinulosa sp. nov. (male, female) - Singapore.

Pontodromia Grootaert, 1994

pantai sp. nov. (male, female) - Singapore.

Stilpon Loew, 1859

arcuatum sp. nov. (male) - Singapore.

laawae Shamshev \& Grootaert, 2004: 323 (male, female), figs 20-24 - Singapore, Thailand. malayensis Shamshev \& Grootaert, 2004: 332 (male), figs 54-59 - Singapore.

neesoonensis sp. nov. (male) - Singapore.

nigripennis sp. nov. (male) - Singapore.

singaporensis sp. nov. (male, female) - Singapore.

weilingae sp. nov. (male) - Singapore. 


\section{Index}

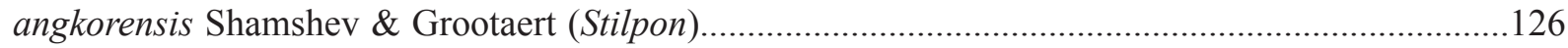

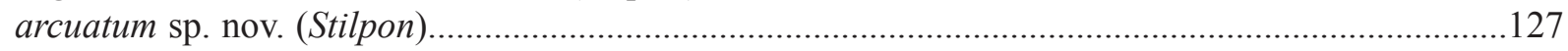

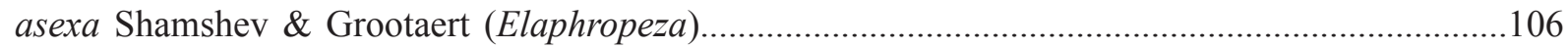

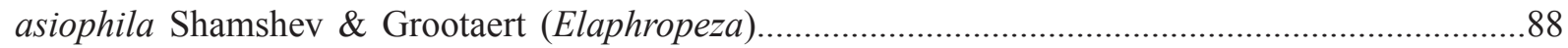

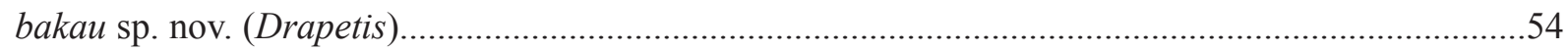

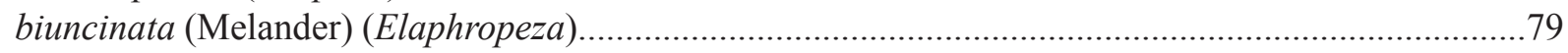

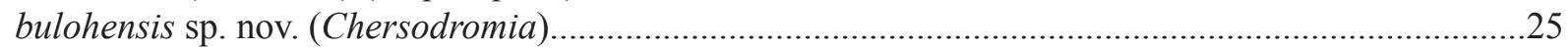

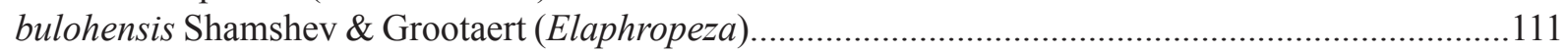

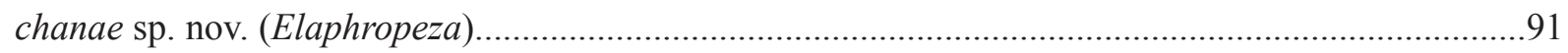

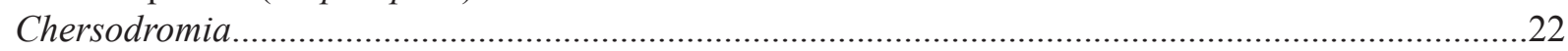

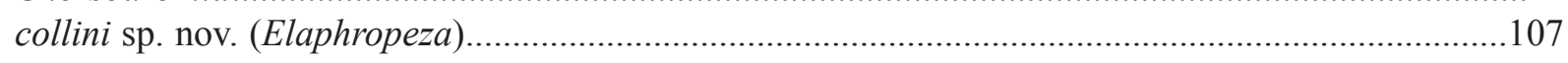

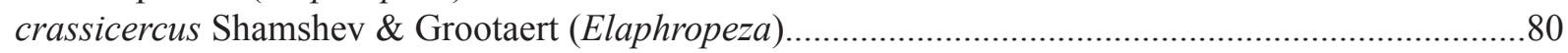

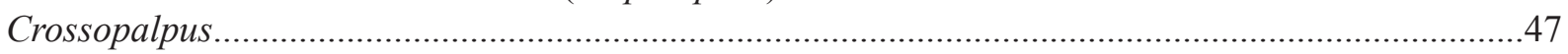

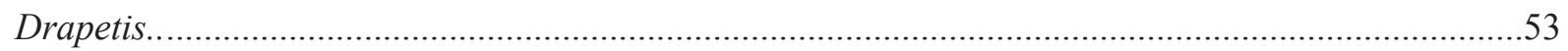

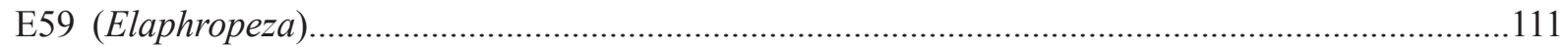

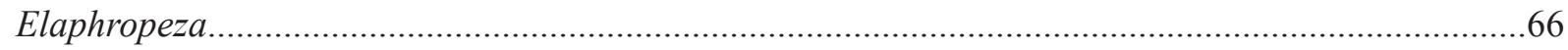

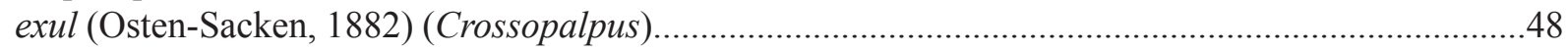

flavicaput Grootaert, Cumming \& Shamshev (Chersodromia)...........................................................28

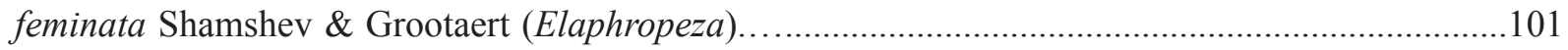

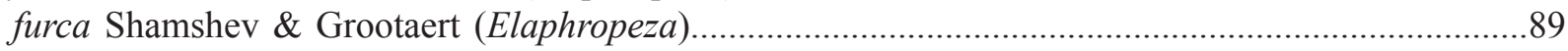

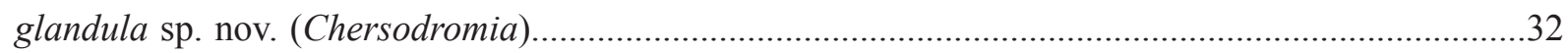

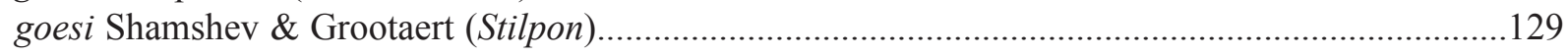

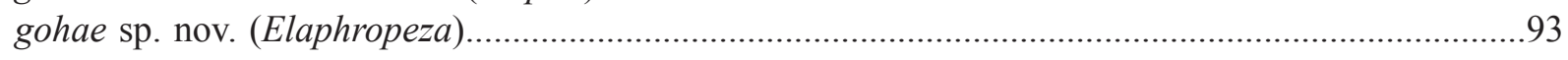

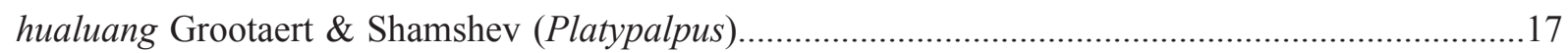

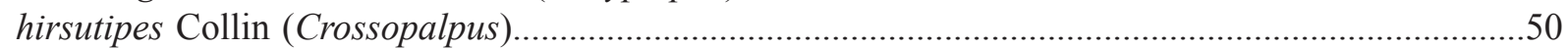

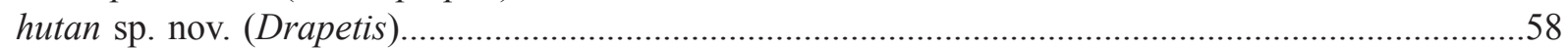

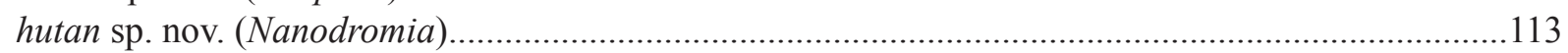

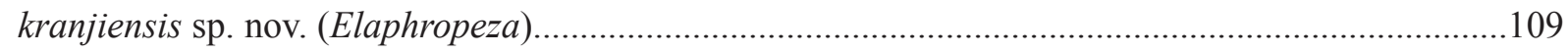

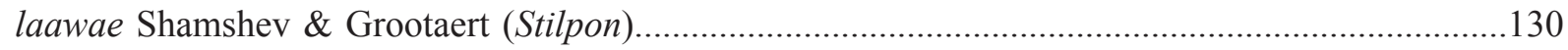

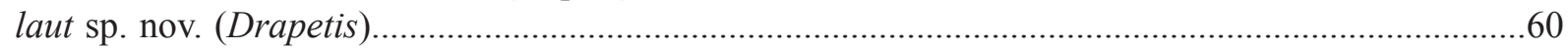

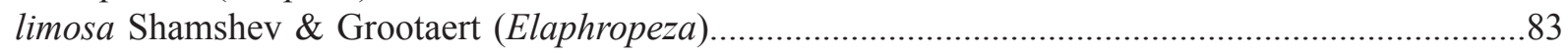

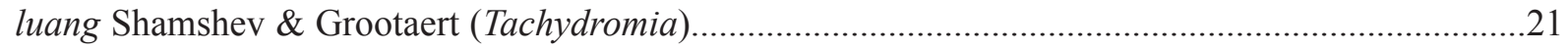

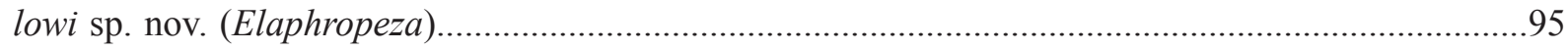

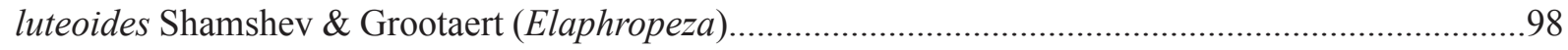

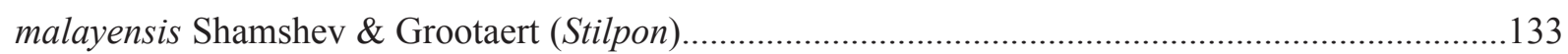

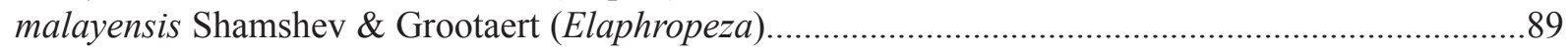

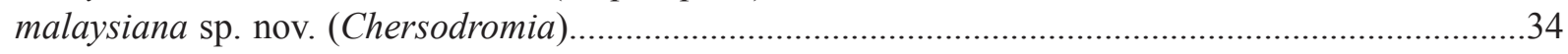

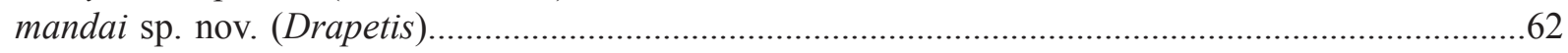

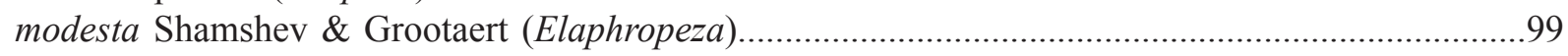

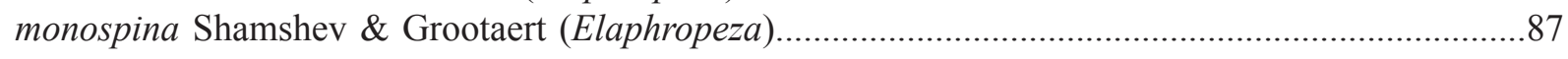




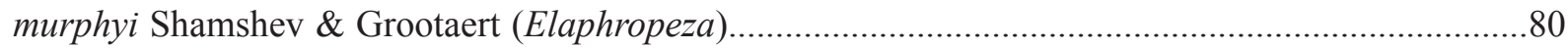

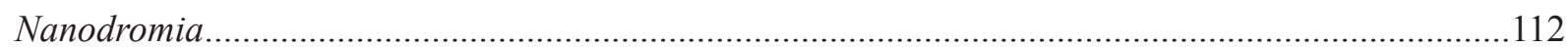

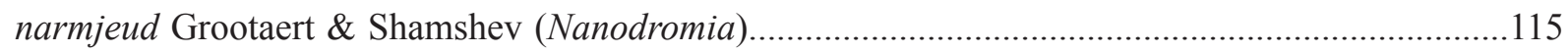

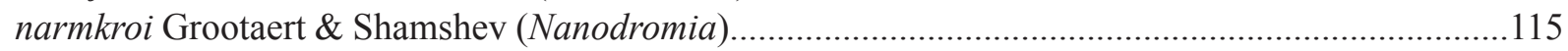

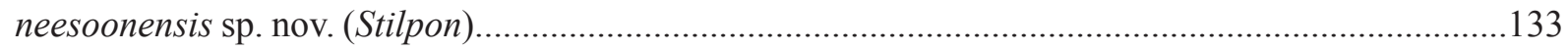

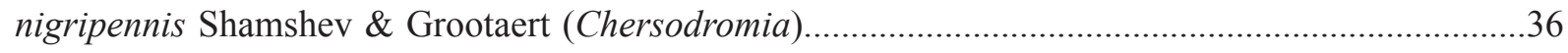

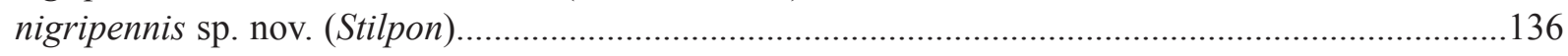

obscura Grootaert, Cumming \& Shamshev (Chersodromia)

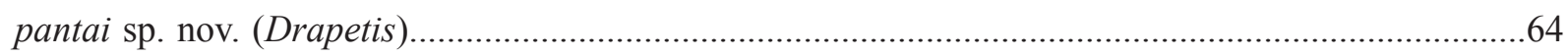

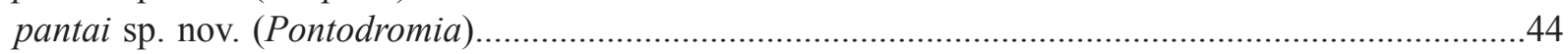

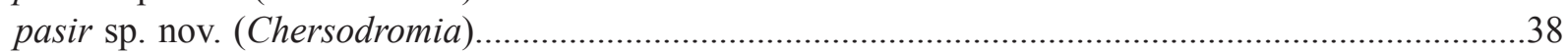

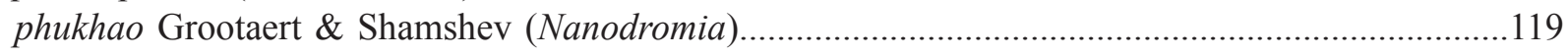

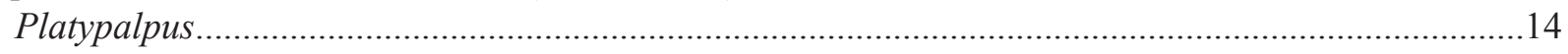

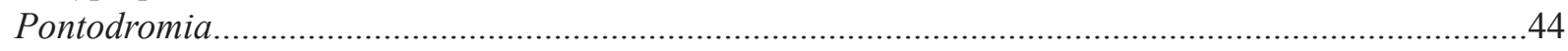

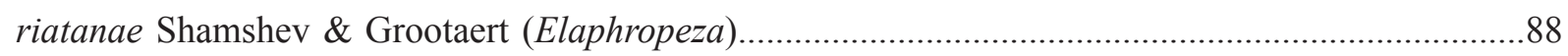

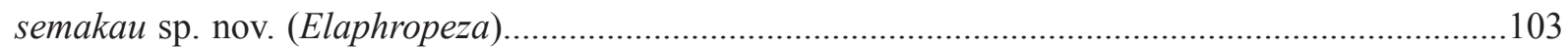

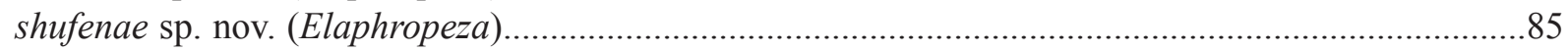

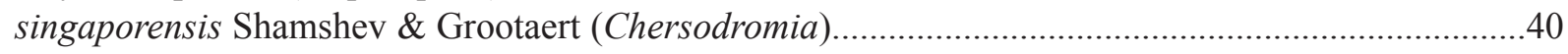

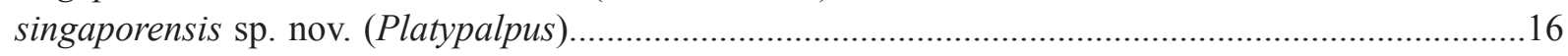

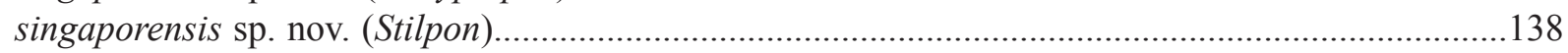

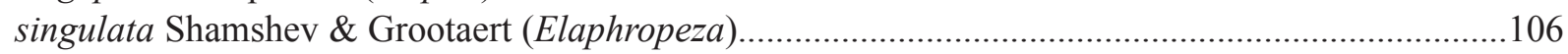

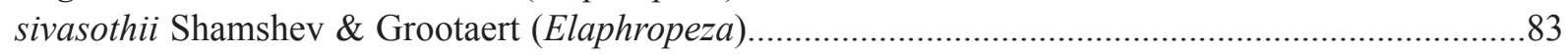

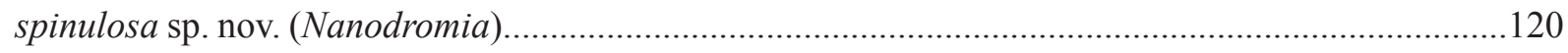

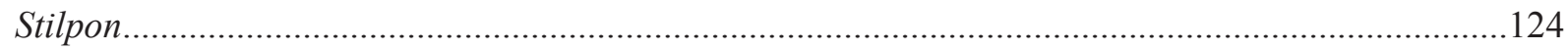

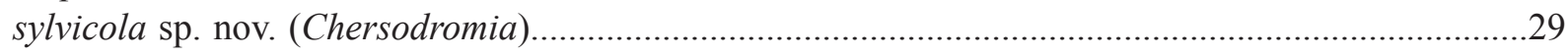

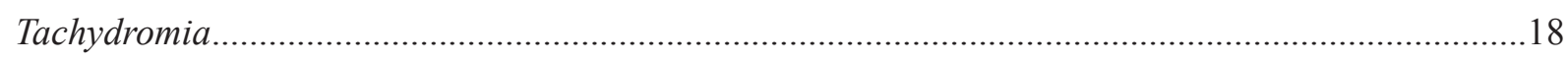

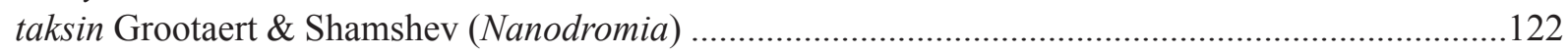

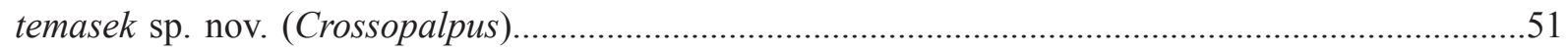

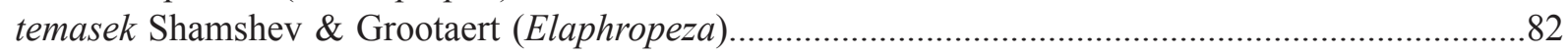

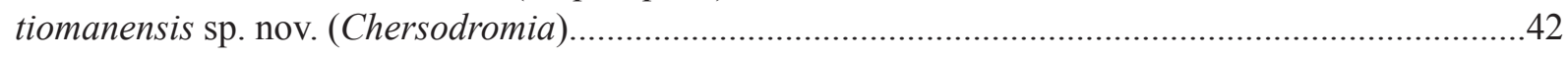

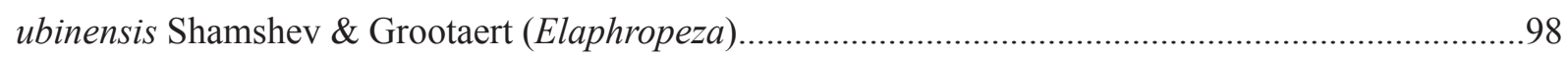

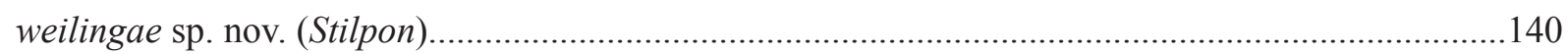

Manuscript received: 29 June 2011

Manuscript accepted on: 21 November 2011

Published on: 6 January 2012

Topic editor: Malcom Scoble

In compliance with Article 8.6 of the ICZN, printed versions of all papers are deposited in the libraries of the institutes that are members of the EJT consortium. 